
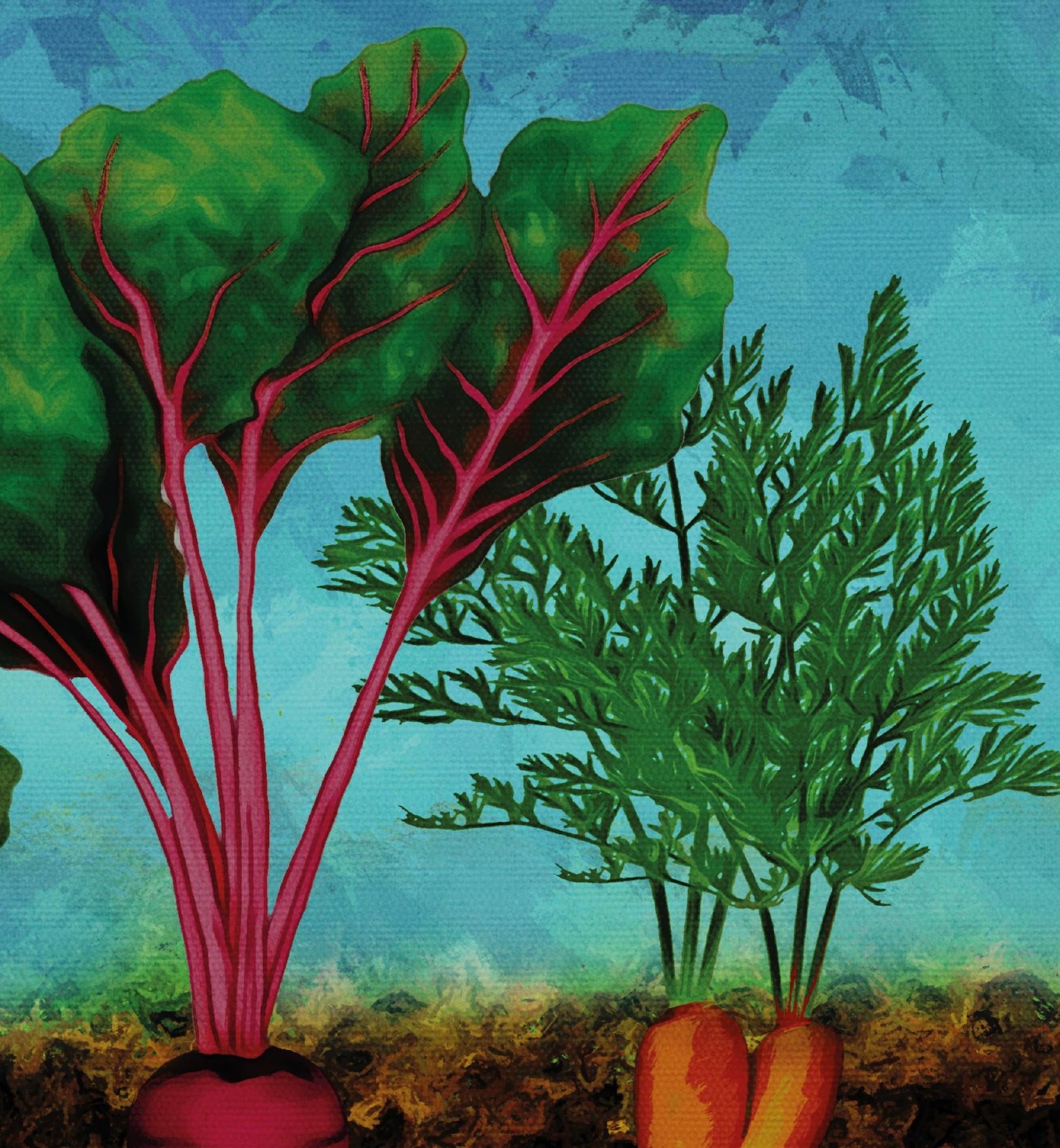

$$
\text { GROW. SHARE OR BUY? }
$$

Understanding the diverse food economies of urban gardeners 


\section{Propositions}

1. Gardeners interested in gardening produce more food than gardeners interested in food.

(this thesis)

2. Logistic skills are just as important for self-sufficiency as gardening and cooking skills.

(this thesis)

3. Consumer research will get a more accurate understanding of people's food provisioning strategies by acknowledging that people are not only consumers.

4. The main perk of being an anthropologist is that you can see every life situation as fieldwork.

5. There's a geography to every research because all researchers come from somewhere.

6. Diced pumpkin sold in supermarkets symbolizes social norms around work and social reproduction in the Netherlands.

7. The Czech ability to identify all possible obstacles and the Dutch 'can do' attitude are best served mixed.

Propositions belonging to the thesis, entitled

Grow, share or buy?

Understanding the diverse food economies of urban gardeners

Lucie Sovová

Wageningen, 13 October 2020 


\section{Grow, share or buy? \\ Understanding the diverse food economies \\ of urban gardeners}

Lucie Sovová 


\section{Thesis committee}

\section{Promotor}

Prof. Dr J. S. C. Wiskerke

Professor of Rural Sociology

Wageningen University \& Research

\section{Co-promotors}

Dr P. Jehlička

Senior Lecturer in Environmental Geography

Faculty of Arts \& Social Sciences, The Open University, Milton Keynes, UK

Dr E. J. Veen

Assistant Professor, Rural Sociology Group

Wageningen University \& Research

\section{Other members}

Prof. Dr E. S. van Leeuwen, Wageningen University \& Research

Dr M. Grivins, Baltic Studies Centre, Riga, Latvia

Prof. Dr S. Wahlen, Justus Liebig University Giessen, Germany

Dr S. C. O. Wertheim-Heck, Aeres University of Applied Sciences, Almere

This research was conducted under the auspices of the Wageningen Graduate School of Social Sciences. 


\title{
Grow, share or buy? \\ Understanding the diverse food economies of urban gardeners
}

\author{
Lucie Sovová
}

Thesis

submitted in fulfilment of the requirements for the degree of doctor at Wageningen University by the authority of the Rector Magnificus,

Prof. Dr A. P. J. Mol,

in the presence of the

Thesis Committee appointed by the Academic Board

to be defended in public

on Tuesday 13 October 2020

at 1.30 p.m. in the Aula. 
Lucie Sovová

Grow, share or buy? Understanding the diverse economies of urban gardeners, 210 pages.

PhD thesis, Wageningen University, Wageningen, the Netherlands (2020)

With references, with summary in English, Dutch and Czech

ISBN: 978-94-6395-382-5

DOI: https://doi.org/10.18174/519934 
Only two things money can't buy

That's true love and homegrown tomatoes

- Guy Clark, an American country singer-songwriter ${ }^{1}$

1 Clark G (1983) Homegrown tomatoes. Nashville: Warner Bros. 



\section{Contents}

Introduction: Locating alternative food and gaps in the 1 literature

1.1 The search for a 'different' food system 4

1.1.1 AFNs as a response to the problems of the conventional food system 4

1.1.2 What is mainstream, alternative and ethical? The problem of 5 reflexivity and normativity

$\begin{array}{lll}1.1 .3 & \text { The problem of the conscious consumer } & 7\end{array}$

1.1.4 Urban agriculture and its overlaps with AFNs: Different 9 conceptualizations of urban gardens in the Global North and South

1.1.5 Summary and concluding thoughts 12

1.2 Food self-provisioning in post-socialist Central and Eastern Europe 13

1.2.1 Post-socialism, transition economies and the shortage economy 14

1.2.2 Informal food economies as a coping strategy 16

1.2.3 Domesticating otherness, catching up with the West 18

$\begin{array}{ll}\text { 1.2.4 Rethinking food self-provisioning } & 21\end{array}$

1.2.5 The transforming food systems of CEE 24

1.2.6 Summary and concluding thoughts $\quad 25$

1.3 Problem statement 26

2 Conceptualizing FSP as an economic activity: 29 Understanding invisibility and reading for difference

2.1 Economic invisibilities: The everyday, domestic, gendered and informal 29

2.2 Diverse economies: Making visible and overcoming othering 32

2.3 Towards a non-capitalocentric reading of FSP: Research goals 36

Methodology 39

3.1 Operationalizing diverse economies as practices 39

3.1.1 Food economies as practices and materialities 41

3.1.2 The household as a system and a bundle of practices 43

3.2 Theory building through generative causality 44

3.3 Study design and methods $\quad 46$

3.3.1 Quantitative description $\quad 47$

3.3.2 Qualitative explanation and gradual theory building 52

3.3.3 Respondent sample $\quad 54$

3.4 Concluding thoughts and reflections $\quad 57$ 
4.1 Winter (mid-February-mid-March) 64

4.2 Spring (mid-May-mid-June) 65

4.3 Summer (mid-August-mid-September) 67

4.4 Autumn (mid-November-mid-December) 70

4.5 Summary of seasonal patterns $\quad 72$

Diverse food sources $\quad 75$

5.1 An overview of diverse food economies $\quad 75$

5.2 Convenience, identity and responsibility 79

5.2.1 Convenient supermarkets $\quad 80$

5.2.2 Routinized and socially embedded alternative market sources 81

5.2.3 Obtaining food as a gift $\quad 85$

5.2.4 Pragmatic and personal food growing 90

5.3 Summary: Diverse economies, diverse considerations 94

Understanding good food 97

6.1 Hierarchy of sources 97

6.1.1 Good food sources and seasonal eating 100

6.2 Responsibility: Towards the world and the household 103

6.2.1 Environmental ethics and conscious consumption 103

$\begin{array}{ll}\text { 6.2.2 Caring about healthy eating } & 107\end{array}$

6.2.3 Healthy eating throughout the seasons $\quad 110$

6.3 Summary: Negotiating quality, responsibility and seasonality 111

The garden-kitchen interaction $\quad 115$

7.1 Gardening and food provisioning: Integrated or separate? 116

7.2 Four ideal types of garden-kitchen interaction 118

$\begin{array}{ll}\text { 7.2.1 Love to grow, not to eat } & 121\end{array}$

$\begin{array}{ll}\text { 7.2.2 Fun at the garden } & 123\end{array}$

$\begin{array}{ll}7.2 .3 \text { Eating well, growing a bit } & 124\end{array}$

$\begin{array}{ll}7.2 .4 \text { Serious self-provisioning } & 127\end{array}$

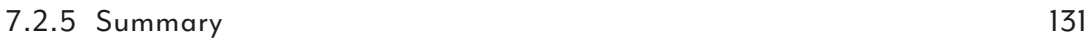

7.3 Practising food self-provisioning 132

7.3.1 Gardening, food provisioning, and competing practices 133

$\begin{array}{ll}\text { 7.3.2 Storing and preserving } & 135\end{array}$

7.3.3 Coordinating the garden-kitchen interaction 138

7.4 Summary: Gardens as food sources 141 
(O) Discussion of research results 145

8.1 The role of FSP within broader food provisioning practices 145

8.2 Diverse food economies in CEE and beyond 147

8.3 Ethical food provisioning: Rethinking reflexivity 149

8.4 Turning the garden into a food source: How does FSP work? 152

8.5 Seasonality 155

$\begin{array}{ll}\text { 8.6 Reflections on practice theory } & 157\end{array}$

8.7 Reflections on the diverse economies framework 160

Conclusion: Ordinary practices, extraordinary economies 165

$\begin{array}{lr}\text { References } & 169\end{array}$

$\begin{array}{ll}\text { Summary } & 179\end{array}$

$\begin{array}{ll}\text { Shrnutí } & 183\end{array}$

$\begin{array}{ll}\text { Samenvatting } & 187\end{array}$

$\begin{array}{ll}\text { Appendix 1: Interview guide used for the first round of interviews } & 191\end{array}$

$\begin{array}{ll}\text { Acknowledgements } & 193\end{array}$

$\begin{array}{ll}\text { About the author } & 196\end{array}$ 



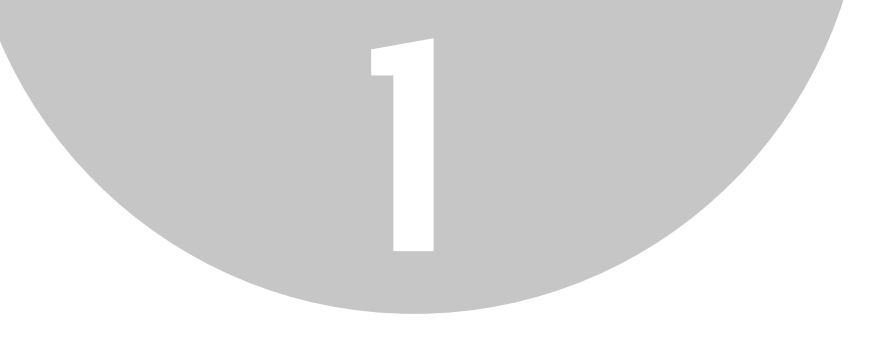

\section{Introduction:}

\section{Locating alternative food and gaps in the literature}

There is already so much research on urban gardening! That was, in a nutshell, the main critique I received when I first pitched the idea for my PhD project at Masaryk University's Department of Environmental Studies in Brno, Czechia. Scholars at this department have indeed seen countless studies of urban gardens, ${ }^{2}$ and gardening has also been researched at other Czech academic institutions. Some of the reasons for the popularity of studying urban gardens are laid out by Gibas in an edited volume on allotment gardens in Prague (Gibas et al., 2013). Gardens, particularly in their more institutionalized form of allotments or community gardens, ${ }^{3}$ constitute a well-defined ethnographic field. Their distinctiveness and at the same time precariousness in the urban fabric lay the foundation for a 'typical anthropological research situation of preserving awareness of a distant and disappearing environment' (Gibas et al., 2013: 48). The activities facilitated by urban gardens, their materialities and social norms, and even the aesthetics of these spaces are peculiar enough to be an interesting research subject but at the same time ordinary enough to be accessible to researchers.

The commonplace nature of gardening is partly specific to the region. According to a representative survey (Jehlička and Daněk, 2017), 40 per cent of the Czech population has access to cultivable land, and most of these people (38 per cent of the population) use it to grow food. ${ }^{4}$ Even those who do not engage in gardening are connected to extensive networks of gardens and home-grown food, and thus have indirect experience with this practice.

Urban gardens have also been studied thoroughly in other contexts. Located at the intersections of nature and culture, these spaces represent society and the world in miniature because they provide 'small', local cases for discussing a number of 'big' issues: food security and nutrition, income generation (de Zeeuw and Dubbeling, 2009), the greening of urban environments (van

2 My own MSc thesis dealt with urban allotments as spaces of alternative food production (Sovová, 2015). Other master's theses were written on community gardens (Malá, 2015), the importance of gardens in the life of elderly women (Plošková, 2015), a conflict over the elimination of urban allotments in Brno (Hošková, 2011), and the use of agrochemicals in hobby gardens (Hrazdírová, 2010), to name just a few.

3 I understand an allotment garden as a piece of land divided into plots which are tended by individual gardeners. In comparison, a community garden is a plot cultivated jointly by a group of people. Both allotment gardens and community gardens can be categorized as types of urban gardening, together with home gardens in the city, guerrilla gardening and other forms of non-commercial food growing in urban settlements. Urban agriculture is a broader term that covers both private and commercial food production practised in cities.

4 Professional farmers were excluded from the sample. 
Veenhuizen, 2006), community cohesion (Veen et al., 2016), environmental education (Bhatti and Church, 2001), civic participation and activism (McClintock, 2014), community resilience (Okvat and Zautra, 2011), place-making (Koopmans et al., 2017), land use and its politics (Eizenberg, 2012), and so forth.

Somewhat paradoxically, though, this extensive body of literature offers few data on one of the basic functions of gardening: food production. In order to address this knowledge gap identified for instance by Tornaghi (2014) and Taylor and Lovell (2014) - my research deals with urban gardens as sources of food. My interest in this topic evolved from the emerging trend of alternative food networks (AFNs), which reached Czechia in the 2010s (Fendrychová and Jehlička, 2018; Spilková, 2016). I deliberately use the word reached, as many of the newly emerging initiatives, such as farmers' markets (Fendrychová and Jehlička, 2018), community supported agriculture (CSA; Frélichová, 2013), and community gardens (Richtr, 2013), were openly inspired by similar initiatives in other countries - typically in Western Europe ${ }^{5}$.

The provenance of these attractive initiatives offering local, fresh, healthy and tasty food which is produced under socially just conditions and with respect for nature did not come as a surprise. Growing up in Central and Eastern Europe (CEE) after the end of state socialism, my generation internalized the assumption that good examples come from the West. Western standards - related to issues such as wages, environmental protection and food quality - have been something to aspire to. The domestic situation, on the other hand, has seemed invariably deficient. ${ }^{6}$

Such feelings of inferiority are experienced, in different shades and intensities, by the majority of the world's population living outside the centres of power (Comaroff and Comaroff, 2012). Like many such people, I set out to Western Europe to learn from its examples and experiences, in my case to discover more about sustainable and equitable food systems. This journey brought me to Wageningen, the 'City of Life Sciences', and arguably a hub of knowledge on this topic. It was here where I learned about urban agriculture, permaculture, agroecology, agroforestry, food forests, rooftop and vertical farms, mushroom and algae plantations, organic and biodynamic agriculture, and hydro- and aquaponics. I also became a member of two CSA projects, a buying group and a community garden.

One of the most valuable lessons, however, was gaining a fresh perspective on my own background. Learning about urban agriculture and visiting initiatives in densely populated Dutch cities made me aware of the wealth of urban gardens that I recalled from Czechia. From there it was just a small step ${ }^{7}$ to wondering why these gardens have not been described in the literature on urban

5 The division between Central and Eastern Europe and Western Europe mentioned here and used throughout the thesis neglects other geographical differences, for instance, between Northern and Southern Europe (Sonnino and Marsden, 2006). It also obscures the internal diversity of both East and West, treating them as internally homogenous and mutually opposite. Nonetheless, such simplified notions of East and West have played an important role in both the theorization and practice of different food networks in Czechia.

6 See Kuus (2004) or Müller (2018) for a theorization of these dynamics.

7 This step was made possible by Henk Renting, who supervised my internship at the RUAF Foundation (Resource Centre on Urban Agriculture and Food Systems) and who introduced me to the work of my future supervisor, Petr Jehlička. 
agriculture and AFNs and why they do not make for inspiring examples that could be followed in other contexts.

This $\mathrm{PhD}$ thesis is a continuation of this personal geographical and mental journey. It starts from the search for a more sustainable food system, and it draws from the literature on AFNs and the gaps, tensions and inconsistencies identified in this academic debate. A second stream of literature that inspired me - and which is mostly separate from the literature on AFNs - deals with food self-provisioning (FSP) in CEE. The literature review thus places my research in debates on AFNs and urban agriculture, while it also traces and uncovers geopolitical biases in knowledge production. This thesis responds to these issues by studying urban gardens in Czechia as spaces which are relevant for the current debates on more sustainable urban food systems, but which have until recently been under-represented in the literature.

Exploring the 'invisibility' of Czech gardeners brought me to a broader theoretical reflection on what practices and types of knowledge are marginalized or unseen. A conceptual framework inspired by feminist and ecological economics links the knowledge gaps identified in the literature review to a narrow understanding of the economy as a system of monetary transactions facilitated by a capitalist market (Gibson-Graham, 2006). This narrative tends to overlook nonmarket and informal practices which do not generate monetary value. Such practices are often concerned with basic human needs, and they are carried out in and around households as part of everyday routines (Donath, 2000). In the case of Czech gardeners, these characteristics are reinforced by the association of FSP with a failed non-capitalist economic system and the othering of CEE (Jehlička and Daněk, 2017).

To counter the discursive dominance of capitalist modernity, the diverse economies framework (Gibson-Graham, 2008) proposes to decentre the market as the site of the economy. In this view, multiple and diverse economies are understood as arrangements through which people satisfy their needs. Furthermore, the diverse economies research agenda specifically calls for more attention to informal and alternative economic practices. Conceptualizing FSP as such, I set out to investigate its functioning. The main research question this thesis addresses is, How is food self-provisioning involved in the food provisioning practices of urban households? In other words, how do urban gardens function as sources of food?

To summarize, this thesis aims to bring attention to FSP and other informal food economies in CEE and challenge the way they are usually depicted in the literature. In doing so, it contributes to knowledge on the productive function of non-commercial urban agriculture. This detailed study presents FSP as an economic practice in the broader sense of the word - a practice which satisfies human needs. It explores the meanings and functioning of FSP and the factors which influence this practice. In this way it reveals and celebrates the diversity of food provisioning practices, creating inspiration and hope for more sustainable food systems. This study is thus not only about Czech gardeners or Eastern realities and Western concepts; instead it is about good things that are as of yet unseen and how to make them visible. 


\subsection{The search for a 'different' food system}

This section outlines the debates that informed the starting point of my research. It can be read as a record of (parts of) the discussion on sustainable food systems at the start of my research project in 2015. The concept of AFNs, which I introduce in more detail in Section 1.1.1, has been a key entry point to the topic. In recent years, the scholarly understanding of AFNs has been refined in response to critiques outlined in Sections 1.1.2 and 1.1.3. As a result, this concept is currently used with more caution and nuance. My own research moves beyond AFNs and the urban gardening literature in Section 1.2, in which I reflect on similar practices in CEE and their specific representation in the academic discourse. The gaps I identify in the literature eventually bring me to formulate a more promising conceptual framework and introduce the goals of my research in Chapter 2.

\subsubsection{AFNs as a response to the problems of the conventional food system}

In recent decades, academics and practitioners, particularly in the Global North, have been searching for different ways of producing, distributing and consuming food. The reason for this is that the conventional system - which, in this part of the world, means industrial agriculture, distribution through corporate chains and a focus on food volume, availability and hygiene standards - is proving to be unsustainable. Some of its problems include dependency on external inputs based on fossil fuels, through which conventional agriculture contributes to climate change (Carolan, 2016), and environmental damage caused by intensive production and agrochemical use, for example, loss of biodiversity, soil depletion, and water and air pollution (Bruinsma, 2003). The world's (commercial) food supply is controlled by a handful of international corporations, and distribution channels are lengthy and non-transparent. Access to affordable and appropriate food is riddled with social and economic inequalities on both local and global scales (Carolan, 2016). Food is subject to price fluctuations linked to oil prices and the increasing financialization of agricultural commodities (Carolan, 2016). Small farmers can hardly compete with large agribusinesses in terms of supply flexibility and standardized quality of products for a minimal price (Carolan, 2016; Norberg-Hodge et al., 2002). Consumers rely on suppliers as they are disconnected from the sources of their food. General knowledge on how food is produced and agricultural and culinary skills are getting lost (McClintock, 2010).

Practices and initiatives that attempt to create a more sustainable, just and transparent food system are often described as alternative food networks ${ }^{8}$. This concept includes a broad spectrum of endeavours that share some features. In general, AFNs try to (re)empower and (re)connect producers and consumers while reducing the role of intermediates, that is to say, retailers and distributors. In Maye and Kirwan's (2010: 1) words, AFNs 'connect people who are concerned with the morals of their consumption practices in some way with those who want a better price for their food, or who want to produce food in ways counter to the dominant (or conventional) market logic'.

8 The word network emphasizes the participants involved in food production, distribution and consumption, and their mutual relationships. A similar denomination, alternative food systems, focuses more on the actual processes. For the purpose of this thesis, I use both terms interchangeably. 
The origins of AFNs can be traced back to both these groups - producers and consumers. On the production side, AFNs can be linked to a turn in the European Union's Common Agricultural Policy (CAP). From the 1980s onwards, CAP reforms aimed to mitigate the negative impacts of mainstream agriculture. Financial support was gradually decoupled from the amount of food produced, and new policy tools were developed to support animal welfare, nature and landscape conservation, and rural development (Renting et al., 2012). However, scholars more commonly link the origins of AFNs to the so-called quality turn on the consumer side (Maye and Kirwan, 2010), which was caused by food scares such as mad cow disease as well as by growing public awareness about environmental issues and animal welfare, which in turn led to demands for reforming the food system (see also Section 1.1.3).

Eliminating intermediaries, and therein shortening food-supply chains, has several effects. Food becomes more tightly linked to place (i.e. relocalization), both in agronomic terms (varieties appropriate for local conditions) and in connection to local traditions and culture (Dansero and Puttilli, 2014; Feagan, 2007). Reducing the physical distance that food travels lowers the environmental impact of the transportation itself 9 as well as that of related measures (cooling, packaging, processing). Food can reach the consumer 'at the right moment' - fresh and ripe. From the consumer's perspective, shorter supply chains offer more transparency. The risk of food contamination is reduced or at least more traceable, and information on the origin of food is more accessible. For producers, a shorter supply chain offers fairer pay, as the money paid by the customer is shared with fewer (if any) intermediaries (Norberg-Hodge et al., 2002). In short, AFNs strive for greater ecological, social and economic sustainability and fairness in the production, distribution and consumption of food (Fendrychová and Jehlička, 2018).

\subsubsection{What is mainstream, alternative and ethical? The problem of reflexivity and normativity}

At the dawn of the alternative food debate in the 2000s, the attribute alternative served to contrast AFNs with the conventional agro-food system. As the concept developed, however, it became subject to criticism (Dansero and Puttilli, 2014). As Renting et al. (2012: 291) put it, 'the main shortcoming of the AFN concept is that it has no clear normative content of its own, since it is ultimately defined in terms of its distinction from "mainstream" food networks.' The AFN concept is defined more in terms of what it is not, rather than what it is (Tregear, 2011: 424).

The notion of an alternative is based on an assumption of an existing (single and homogenous) mainstream (Cameron and Wright, 2014). But what is mainstream in food production? The industrial, corporatized agro-food system, against which AFNs often define themselves, has only existed for about half a century, and although this system might be the new norm in Europe and

9 The concept of food miles has been developed to point out the unnecessarily long distances between food producers and consumers in conventional agriculture. The clarity of this concept proved useful for campaigns such as the '50-mile diet', which urged consumers to only purchase food coming from within this distance. However, critics point out that food miles overestimate the contribution of transport to the overall environmental impact of food products. In some cases, food coming from farther away can actually be more environmentally friendly due to production methods or scale (Shimizu and Desrochers, 2008). 
North America, this cannot be assumed about the rest of the world. Smallholders and family farms are the most important sources of food in many countries (IFAD and UNEP, 2013). A report by the ETC Group (2009: 1) points out that 'eighty-five percent of the world's food is grown and consumed - if not within the "100 mile diet" - within national borders and/or the same ecoregional zone'. This type of 'local food' is nonetheless hardly seen as 'alternative' because of the context in which it occurs - mostly the Global South. As stated in the same report, 'ninety-six percent of all recorded food and agricultural research takes place in industrialized countries' (ETC Group, 2009: 1). The understanding of 'alternatives' is thus defined by the 'mainstream' of the Global North and not easily applicable in other contexts.

Moreover, and contrarily to the above quote from Renting et al. (2012), 'alternative' does not mean simply 'different', but it carries a number of inherent value connotations. It follows from the origins of AFNs (see above) that alternative ought to be better, overcoming the pitfalls of the conventional. This normative assumption remains present in AFN scholarship, although it is often implicit and in many cases also unfounded (Tregear, 2011).

Understandings of 'alternatives' can vary even among AFN participants, as shown by Holloway et al. (2010). Some participants perceived the denomination as elitist. Others even found it disdainful, marginalizing the food systems in question as a peculiar rarity - whereas the participants considered their way of acquiring food as 'the original mainstream', that is, the norm upon which a food system should be based. ${ }^{10}$

Tregear (2011: 419) describes AFNs as 'different from, perhaps counteractive to' the mainstream food system. This touches upon another sore point in the theorization of AFNs. Whereas 'different' ways of food production, distribution and consumption can be ascertained (organic agriculture uses different practices than conventional farming, self-harvesting is a different way of distribution than shopping in a supermarket), the question of 'oppositeness' is more complex, as it relates to the issue of reflexivity and construction of meaning: Who decides what is alternative? To what extent do alternative food initiatives consider themselves to be opposing the mainstream?

Here, the meaning of alternative converges with terms such as ethical, conscious, political and radical. The question is not only whether people produce, distribute, acquire and consume food in the 'right' (i.e. environmentally and socially just) way, but also whether they are driven by the 'right' motivations and values (i.e. consciously trying to accomplish those goals) - two aspects that are not necessarily in accord. Veen et al. (2012) point out that AFNs are often implicitly linked to a certain higher morality, regardless of whether it is indeed intrinsic to their members. According to Tregear (2011), the romanticized condition of reflexivity puts overly high demands on existing AFNs and can lead to overlooking functional systems whose goals and motivations are not virtuous enough.

Subsequently, authors tried to move beyond the polarized and normative dichotomy of 'good alternatives' and the 'evil mainstream'. Tregear (2011) notes that in many cases alternative and conventional food systems are not strictly separated and that both can offer desirable qualities.

10 This is related to the capitalocentrism of social science, an issue discussed in Section 2.2. 
McClintock (2014) argues that urban agriculture initiatives can relate to the conventional food system in diverse and sometimes contradictory ways, being simultaneously radical and oppositional, cooperative and complementing. These contradictions constitute an intrinsic dynamic of the search for a better food system. Similarly, numerous empirical studies (e.g. Farges, 2015; Fendrychová, 2015; Smith and Jehlička, 2013; Veen et al., 2012) have demonstrated that members of AFNs (be they producers, consumers or other actors) possess a broad spectrum of motivations which cannot be categorized within the constructed dichotomies and often do not differ from the motivations and values linked to conventional food systems (Tregear, 2011).

In sum, the concept of AFNs can be understood as shorthand for discontent with the conventional system and the search for 'better' ways of producing, distributing and consuming food. However, the actual environmental, social and economic impacts of concrete practices and initiatives, as well as their motivations and normative grounding, need to be studied instead of assumed.

\subsubsection{The problem of the conscious consumer}

Consumers play an important role in the search for a better food system, as mentioned in Section 1.1.1. The origins of conscious or ethical consumption ${ }^{11}$ date to the 1980 , when national governments stepped back from regulating the corporate activities dominating the developing global free market (Humphery, 2011). Conscious consumers have taken over this watchdog role by actively searching for information on the origins of their food and using it as a basis for consumer choices (Veen et al., 2012). By making these choices, consumers can grant support to or withdraw it from different types of food networks - hence the overlap between the literatures on ethical consumption and AFNs. ${ }^{12}$

Consumption thus becomes a reflexive political act of expressing one's opinion and advocating for change. The role of consumer merges with that of citizen (Pottinger, 2015). Consumption seems to be an attractive and convenient means for political participation, since it is (at least in theory) open to everyone who consumes food (Clarke et al., 2008), as promised by the popular slogan 'Vote with your fork'. Ethical consumption falls under Micheletti's (2002) definition of 'individualized collective action', where personal interests expressed through everyday behaviours support collective causes.

The very idea of individual and independent consumer choice, however, is problematic. Veen et al. (2012) note that the conscious consumer can be led astray by marketing or status consumption. Reflecting on the origins of one's food does not guarantee that the final choice is indeed the best one. Their study also demonstrates that consumer choices are situational and are influenced by many, often irrational or unconscious, factors. Consumers' proclaimed attitudes may differ

11 I use both terms interchangeably.

12 Apart from participating in AFNs, ethical consumption can also mean boycotting or 'buycotting' (deliberately purchasing ethical products). According to some authors (e.g. Pottinger, 2015), ethical consumption also includes voluntary simplicity aimed at the overall reduction of consumption, whereas others (e.g. Humphery, 2011) define it solely as the consumption of ethical goods. 
from their actual practices, a mechanism described in psychological literature as the attitudebehaviour gap (Terlau and Hirsch, 2015).

Competing consumer considerations are reflected in Belasco's (2008) triangle of consumer choice (Figure 1). According to Belasco (2008: 8), consumer choices result from 'a rough negotiation - a pushing and tugging - between the dictates of identity and convenience'. Identity, put simply, refers to personal preferences and foods that people consider appropriate for who they are. Convenience encompasses practical considerations such as price, availability, and the time and energy required to acquire and prepare food (p. 9). Conscious consumerism, that is, the awareness of the impact of one's food choices on the world, falls under the triangle's third apex: responsibility. However, as Belasco states, this factor tends to be less prominent than the other two. In other words, consumer choices are more strongly guided by identity and convenience than by ethical considerations.

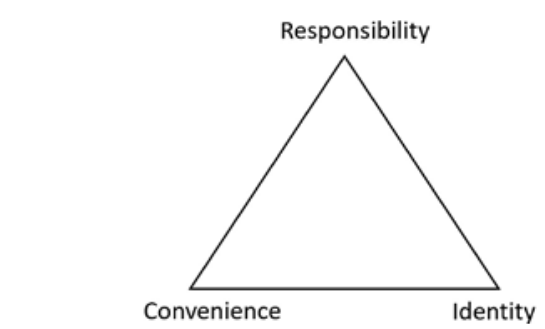

Figure 1: Triangle of consumer choice (Source: Belasco, 2008: 7)

In addition, consumer choice is not limited to the moment of acquiring food, but it includes other dimensions such as preparing and sharing food. Particularly in these situations, personal ethics meet social relationships and care for others (Pottinger, 2015). Consumption is thus driven not only by personal choices but also by social and cultural norms (Mylan and Southerton, 2018) as well as the social, economic and spatial constraints of real-life food provisioning options (McIntyre and Rondeau, 2011). In sum, consumer choice is neither individual nor independent.

Moreover, the notion of consumption as a political act has been subject to critique for commodifying the nature of ethical behaviour and civic participation. The paradox of ethical consumption is that the market is both the target and the means of critique: 'The materialistic ideology of Western consumption is thoroughly contested, but how we act as consumers is retained as a principal medium of opposition' (Humphery, 2011: 47). This is problematic for a number of reasons. Firstly, the market as a 'medium of opposition' is not universally accessible. Ethical consumption can be socially exclusive and elitist, suggesting that political participation is a privilege possessed by well-educated and informed people with sufficient purchasing power and opportunities. ${ }^{13}$ Secondly, when taken to the extreme, 'voting with your fork' obscures other

13 It should however be acknowledged that the problem of elitism is not limited to market-based AFNs. Exclusion can also occur on the basis of place affiliation or social structures. As Schupp et al. (2015) note for the US context, even initiatives that aim to find an alternative approach to market exchange most commonly attract white middle-class participants 
ways of civic engagement, creating the impression that one can only express one's worldviews as a consumer; lowering one's consumption thus limits means of political expression (Kosnik, 2018; Shaw, 2007).

Both these points relate to the implicit link of consumption to the market. Conscious consumerism does not necessarily question the conventional divide between producers and consumers and the power relations it entails (Tregear, 2011). It also overlooks other roles people can assume in different types of economies (see Chapter 2). In this narrow form, AFNs limit themselves to offering differentiated products within the market economy, perpetuating the economic logic of the mainstream food system rather than creating an alternative. This criticism is addressed by initiatives which adopt different economic models. By decentring the market as the site of AFNs, they open possibilities for more economically inclusive food systems and diverse relationships between producers and consumers. As I detail in the next section, urban agriculture can be seen as an example of such an initiative.

\subsubsection{Urbanagriculture and its overlaps with AFNs: Differentconceptualizations of urban gardens in the Global North and South}

In connection to the search for 'different' food systems, in recent years more attention has been devoted to growing food in cities. Several factors have made urban agriculture ${ }^{14}$ increasingly relevant. Among the most important is changing global demographics: in 2008, more people lived in cities than in the countryside for the first time in human history (UNFPA, 2007: 6). Furthermore, the dependency of urban settlements on external supplies makes them vulnerable. Striving for higher self-sufficiency, therefore, is a response to the risk of supply disruptions due to extreme weather, security threats or price fluctuations linked to fossil fuel dependency (Simms, 2008).

Urban agriculture overlaps in several ways with the concept of AFNs. It represents a localized food system because production and consumption are typically close in space and time. This fact, in combination with well-developed urban infrastructure, facilitates shorter supply chains. Market-based urban agriculture benefits from the proximity of urban purchasing power and the ability to deliver perishable produce. From the consumer perspective, urban agriculture promises higher transparency and the reconnection of urban dwellers with their food sources. These features legitimize it as part of the search for a better food system. Urban farms and gardens are indeed often framed as AFNs (McClintock, 2014; Renting et al., 2012; Veen, 2015). However, they surpass this category by offering services which are not food related but instead hold specific relevance for urban environmental issues. As green spaces, urban agriculture sites are praised for improving the urban environment by absorbing carbon dioxide; retaining rainwater; reducing noise, dust and heat; creating refuges for animals and plants; and protecting biodiversity (de Zeeuw and Dubbeling, 2009).

14 I understand urban agriculture in keeping with Mougeot's (2000) and van Veenhuizen's (2006) definitions as food production which is located in and around cities and which is intrinsically linked with urban ecological and economic systems. 
Urban agriculture can take the form of commercial enterprises, but it can also operate outside the market, supplying food for producers' own needs. My interest lies in the latter, non-market type of urban agriculture, that is, urban food self-provisioning (FSP). ${ }^{15}$ FSP has the potential to resolve some of the issues associated with market-based AFNs mentioned in Section 1.1.3. Its added value lies in overcoming the problematic producer-consumer gap and the reliance of AFNs on conscious consumers. By growing their own food, urban dwellers are truly reconnected with their food, their biophysical environment, and physical labour (McClintock, 2014). While FSP is obviously not confined to the urban environment, these benefits seem particularly relevant for cities, which are on one hand seen as the foci of AFNs in terms of lifestyle trends and purchasing power, but on the other hand largely divorced from food production as such. ${ }^{16}$

While there seems to be a general consensus on the benefits of urban FSP (McClintock, 2014; Okvat and Zautra, 2011; Taylor and Lovell, 2014; van Veenhuizen, 2006), scholars tend to emphasize different features of this practice based on its geopolitical context. The literatures on urban FSP in the Global North and South have developed diverging understandings and to some extent also separate terminology for what seems to be the same practice: growing food for one's own consumption in an urban setting. The rest of this section elaborates on these different framings.

In the context of the Global North, the term urban agriculture carries an inherent contradiction resulting from the modernist opposition between the city and the countryside, in which food production is inseparably linked with the latter (Djokić et al., 2018; Tornaghi, 2014). In addition, the term agriculture is reserved for professionalized - and by extension also market-based - food production (Taylor and Lovell, 2014; Tornaghi, 2014). Urban FSP in the Global North is thus typically described with the term urban gardening. Furthermore, urban gardens seem to distance themselves from the straightforward focus on efficient food production inherent in 'rural' agriculture. Scholars and policymakers often praise urban agriculture for its multifunctionality, and they emphasize that 'it is not just about food production' (e.g. van den Berg and van Veenhuizen, 2005).

Within the multifunctionality discourse, particular attention is devoted to the social aspects of urban gardening. Community gardens, which are the most frequently described type of urban FSP in the Global North (Taylor and Lovell, 2014), are praised for enhancing social cohesion (Veen et al., 2016), intergenerational encounters, the informal integration of minorities and civic participation (Koopmans et al., 2017). Other commonly highlighted benefits of urban gardens include education and awareness rising; through them urban inhabitants become acquainted with the principles of food production and broader environmental issues (Okvat and Zautra, 2011). In the civic or political sphere, urban food production presents an opportunity to challenge and transform the usual ways of inhabiting urban space (Eizenberg, 2012), as well as conventional ideas about land use and ownership (Tornaghi, 2014). Urban gardens are thus often depicted as alternative or political not only in relation to the conventional food system (Taylor and Lovell, 2014).

15 The use of this term is further explained at the start of Section 1.2.2

16 I am aware that the association of food production with the countryside is based on the modernist conceptualization of the city and the countryside, which does not necessarily capture current realities in many places of the world. In other words, one should be careful in assuming that rural dwellers are by default more connected with their food system (see Sovová and Krylová, 2019, for a discussion of this issue) 
Urban gardening may thus appear to be a panacea for many urban issues. However, caution is in order since empirical evidence of its proclaimed benefits is relatively scarce (Tornaghi, 2014). Furthermore, the exploration of the multiple uses of urban gardens has led to a major knowledge gap regarding one of their core purposes: food production. It is commonly assumed that urban gardeners grow some food, which potentially contributes to their food security, self-sufficiency and improved diets (Okvat and Zautra, 2011). However, data to support these claims are scarce and often rely on the potentially inaccurate estimates and self-reports of respondents. ${ }^{17}$ Economic aspects of FSP are seldom mentioned, whether in terms of gardeners' motivations to grow food or in terms of the effects of FSP on household budgets. In sum, scholars mostly portray urban gardening in the Global North as a hobby with social and environmental benefits and potential political meanings, while actual food production is neglected.

The literature on urban FSP in the Global South offers a nearly inverse perspective: scholars emphasize benefits such as mitigating poverty and hunger; ensuring food security and selfsufficiency; and even providing potential income (de Zeeuw and Dubbeling, 2009; van Veenhuizen, 2006). It is therefore an economically motivated activity whose main goal is to produce food. This might also be the reason why urban FSP in the Global South is more commonly referred to as urban agriculture, even though the areas in question may be closer to gardens in terms of size.

The focus on food self-sufficiency and the overall improvement of the economic situation of gardeners obscures the social functions of urban FSP, which are highlighted in the context of the Global North. ${ }^{18}$ It is also worth noting that in the Global South urban food growing is not depicted as an alternative to the conventional food system; contrarily, it is described as 'common practice' (Taylor and Lovell, 2014; Tornaghi, 2014: 551). Furthermore, gardeners are not expected to have political motivations. Rather than being an innovative activity practised by conscious city dwellers, urban agriculture in the Global South is framed as a traditional practice brought to the cities by rural migrants that has not undergone any significant change of meaning.

Urban gardening in the Global North and urban agriculture in the Global South represent two ends of the spectrum of possible perspectives on urban FSP depending on the emphasis on the productive function and the (presumed) economic motivations of food growers. Admittedly, this dichotomy is rather simplistic. Even in the countries of the Global North, urban gardening has been documented to serve economic needs in times of scarcity. One such commonly cited case is that of victory gardens, which significantly contributed to food provisioning in many cities in Western Europe, the USA and Canada during the Second World War (Simms, 2008). More recently, food justice and the fair distribution of food have become relevant topics in the USA, where community gardens have emerged in reaction to the problem of food deserts, that is, neighbourhoods with insufficient access to fresh fruits and vegetables which are often inhabited by socially excluded groups (Dutko et al., 2012). Another example is the renewed interest in FSP in Southern Europe after the 2008 economic crisis (Delgado, 2017).

17 Honourable exceptions include the Farming Concrete initiative in New York City, Capital Growth in London and the recent British project MYHarvest, all of which devised their own methods for measuring harvests as well as other benefits of gardens.

18 There is however a significant amount of research on the contribution of urban agriculture to climate change adaptation and mitigation, waste (water) use and similar environmental functions (e.g. van Veenhuizen, 2006). 
It is thus more precise to say that the literature emphasizes the productive function of urban FSP in connection to marginalized groups and peripheral spaces (be they global or local) and/ or situations of economic distress (be they temporary or long term). Contrarily, if we talk about urban FSP as a politically engaged activity contributing to social cohesion, food production receives little attention. Linking these dichotomous framings to the literature on AFNs reveals a paradox: urban gardens in the Global North are seen as part of the search for a better food system, while their contribution to food production is largely unknown; on the other hand, urban agriculture in the Global South is documented to bolster food supply, but it is rarely seen as an alternative in the sense of a deliberate improvement of the dominant system.

Apart from perpetuating stereotypes, this habitual conceptualization makes research less perceptive of practices that do not fall into either category. For instance, Taylor and Lovell (2014: 286) make a compelling case about the lack of research on home gardens in the Global North, which, in their opinion, can offer similar benefits as often supported and scrutinized community gardens: 'The lack of interest in urban home food gardens is perplexing, particularly because the social, economic, and health benefits of home food gardens are well documented in the Global South.'

Furthermore, the North-South dichotomy overlooks other geopolitical spaces: Taylor and Lovell's (2013) thorough review of household food production fails to mention cases from CEE. As I elaborate in Section 1.2, CEE has a long and widespread tradition of FSP, which can offer relevant contributions to broader discussions on urban agriculture and AFNs (e.g. Gabriel, 2005; Jehlička and Daněk, 2017; Smith, 2003; Smith and Jehlička, 2013). These insights are only slowly penetrating the academic discourse due to its persistent geopolitical bias. As I also discuss in Section 1.2, knowledge generated in CEE is often neglected, as this region falls through the cracks between the Global North and South and is rarely seen as relevant for global debates (Müller, 2018).

\subsubsection{Summary and concluding thoughts}

This section introduced AFNs as an umbrella concept employed in the debate on more sustainable food systems. I proceeded by deconstructing the concept and showing some of its shortcomings. In the academic literature, the understanding of what is alternative is highly context dependent, which leads to blurred and, eventually, exclusive definitions of AFNs. Specifically, the scholarly depiction of AFNs seems to favour practices which originated in the Global North as a reaction to the flaws of the conventional food system there and which rely on conscious consumerism. On the one hand, the concept of AFNs lacks definitional clarity and is overly broad. On the other hand, its practical usage narrows the common understanding of AFNs to a specific type of initiative. ${ }^{19}$ This perspective obscures a number of practices that can contribute - or are in fact already contributing - to a more sustainable food system.

19 In this thesis, I understand AFNs in the narrow sense which prevails in the literature - as practices and initiatives originating mostly in the Global North or Western Europe which strive to create alternatives to the conventional food system. I talk about 'the search for a more sustainable food system' to refer to the broader discussion from which AFNs originated. 
The practice of FSP can be seen as an alternative to the dominant food system in that it involves a short, localized supply chain. Furthermore, it overcomes some of the pitfalls of market-based AFNs, namely the persisting producer-consumer divide and the risk of elitism and exclusivity. FSP is therefore highly relevant for the search for a better food system. However, its depiction can also fall in the false alternative-mainstream dichotomy, which furthermore seems to be geographically conditioned. Table 1 summarizes some of the characteristics attributed to urban FSP in different contexts.

Table 1: Stereotypical framings of urban FSP in different geopolitical contexts

\begin{tabular}{|l|l|}
\hline Global North/centre & $\quad \begin{array}{l}\text { Global South/periphery } \\
\text { Urban gardening } \\
\text { Hobby, conscious motivations } \\
\text { Ecological, educational and social functions } \\
\text { Data on food production relatively scarce } \\
\text { Urban lifestyle } \\
\text { Innovative, trendy }\end{array} \quad \begin{array}{l}\text { Subsistence, unreflective necessity } \\
\text { Food security and economic benefits } \\
\text { Other benefits neglected } \\
\text { Rural lifestyle transferred to urban environment } \\
\text { Traditional, backwards }\end{array}$ \\
\hline
\end{tabular}

These stereotypes lead to a lack of knowledge about the contribution of urban gardens to food production in the Global North, since scholars tend to focus on other benefits of urban gardens in this context. Furthermore, geopolitical regions that could provide relevant insights into FSP are under-represented in AFN literature because of the contextually dependent understanding of 'alternativeness'. Insights into FSP practices in the Global South thus rarely enter the debates on alternatives to the conventional food system. The aim of this thesis is to question these stereotypical understandings of urban FSP and to enrich the literature on AFNs with findings from overlooked practices and geopolitical regions. The following section will zoom in on the practice of FSP in the context of Central and Eastern Europe.

\subsection{Food self-provisioning in post-socialist Central and Eastern Europe}

This section elaborates on urban FSP and its potential contribution to the search for a better food system, and it focuses on the post-socialist countries of CEE, a region which offers relevant insights into this practice. FSP has a long tradition in CEE, and it remains widespread, especially in comparison with Western Europe (Alber and Kohler, 2008). However, Central and Eastern European FSP is underexplored in the literature on AFNs and urban agriculture, presumably due to the region's geopolitical position - a variant of the conceptual bias introduced in Section 1.1.4. Specifically, informal (food) economies ${ }^{20}$ in CEE are framed in relation to the region's socialist past, and therefore seen as outdated and backwards (Pungas, 2019; Smith and Jehlička, 2013).

20 I use the term informal food economies for food practices that take place outside the market and do not involve monetary transactions. Apart from FSP, these include food sharing and gifting, foraging, gleaning and so forth. The position of such informal practices within the economy and the use of this term are further discussed in Chapter 2. 
In what follows, I first outline prevalent narratives of the post-socialist transition, and I illustrate how they influence the study of informal food economies as well as the development of traditional and new food practices on the ground. After deconstructing and challenging some of the assumptions of this framing, I present a more nuanced and positive reading of FSP. This allows me to bring together insights from literatures on Western European urban gardening and Central and Eastern European FSP. In the final section of this chapter, I return to the local context, and I briefly discuss some of the trends in the foodscapes ${ }^{21}$ of CEE.

\subsubsection{Post-socialism, transition economies and the shortage economy}

The collapse of the Eastern Bloc and the end of socialist regimes were perceived by Western intellectuals as confirmation of the position of capitalism as the correct and unavoidable path to development (Gibson-Graham, 2008; Williams et al., 2013). The transition discourse of the 1990 s framed economic systems as inseparable from political ideologies: the market economy appeared to be a precondition for democracy. It was for ideological reasons that the centrally planned socialist economies hastily adopted deregulated market mechanisms (Pavlovskaya, 2004; Williams et al., 2013). Geopolitics and social science alike were dominated by neoliberalism and modernization theory (Thelen, 2011), according to which post-socialist countries were underdeveloped and needed to catch up with the West. This transformation was perceived as linear and homogenous, and the differences between (post-)socialist economies were disregarded as was the fact that there was never a single model for Western democracy and capitalism. The transition was framed as the inevitable result of 'evolution', although in reality it was supported by significant interventions from international institutions (Williams et al., 2013).

One of the incarnations of modernization theory that significantly influenced research on postsocialist countries is Kornai's concept of shortage economy, here summarized according to Thelen (2011). Kornai subscribes to the neo-institutionalist approach, which postulates that institutions are not external to the economy but they form as an aggregation of individuals trying to maximize their benefits. One of the key institutions that influences a society's economic development is property. According to Kornai, property should be defined as clearly as possible. He considers private property to be the most efficient form for using resources and improving welfare. He therefore concludes that socialist economies are inferior to capitalist ones because state property belongs to all and to none. This causes the free-rider problem, which eventually leads to scarcity at all levels of the economy. Thus, in Kornai's view, centrally planned socialist economies are inherently economies of shortage (Thelen, 2011).

Kornai's notion of the shortage economy, as Thelen (2011) notes, is normative and essentialist since it implies that shortages cannot emerge in other (capitalist) economies. Nevertheless, Kornai's view was widely accepted even outside the field of economics. According to Thelen, the normative perception of post-socialist countries as underdeveloped has coloured even more recent anthropological research, despite the fact that anthropologists rarely adopt economic theories.

21 Foodscape is defined as 'the contextual milieu in which food consumption takes place, including social, cultural, economic, political, and geographic spaces' (Trenouth and Tisenkopfs, 2015). 
Although neo-institutionalism opposes mainstream economics, it retains some of its assumptions, above all, the assumption that resources are scarce and individuals try to maximize their benefits, that is, they act as the rational and independent homo economicus. ${ }^{22}$ Furthermore, the (unexplained and unquestioned) emphasis placed on private property links neo-institutionalism to neoliberalism (Thelen, 2011). Based on these convictions, the shortage economy discourse is particularly dismissive of the informal economies widespread in socialist countries - whether they involve bartering, self-provisioning and do-it-yourself practices, or the black economy and bribery. All these activities are framed as reactions to malfunctioning market mechanisms (resulting from the absence of private property), means to overcome shortage and thus essentially symptoms of underdevelopment.

Sharing the geopolitical bias of its time, this perspective disregards the fact that informal economic practices can be found in capitalist economies as well. Thelen (2011: 48) criticizes this dichotomy, presenting the use of social networks to obtain services or goods as an example: 'Personal relations [in socialist countries] are described as the outcome of necessity, as instrumental to overcoming shortages in consumer goods, and are hence different from the supposedly interest-free friendships possible in Western democracies'. She further notes that most jobs in Western countries are gained through personal networks and that the scholars who criticize Eastern European kin networks have similarly intertwined professional and personal relations. Analogically, FSP is framed as a reaction to food shortages (and not as an alternative food system), and self-help manual and craft jobs are seen to arise from a lack of trust in paid workers (not from do-it-yourself culture).

The narrative of the natural and desirable development towards capitalism, which will eventually replace informal economies, is based on two propositions of mainstream economics. The formalization thesis assumes a gradual transformation from the informal (civic) to the formal (private and public) sphere. Instead of individuals, families or communities fulfilling their own needs, this task is delegated to the state or the market. Secondly, the marketization (commercialization, commodification) thesis predicts a transition from the non-market (civic and public) sphere to the market sphere (Williams et al., 2013).

As already mentioned, this evolutionary perspective has normative undertones. The established dichotomy entails a hierarchy which almost infallibly links the informal and non-market to underdevelopment, whereas formalization and marketization are signs of progress (see also Chapter 2). Indeed, the level of commodification and privatization was used to measure the development of post-socialist countries in the 1990s (Williams et al., 2013). The formalization and marketization theses were not fulfilled in CEE. Now, 30 years after the end of socialism, informal economic practices are still widespread in CEE despite the vigorous adaptation of the market economy (Williams et al., 2013). ${ }^{23}$ The modernization perspective and the discourse of the shortage economy have however influenced the perception of traditional informal economies, as I show in the following section.

22 Homo economicus is an ideal type of economic actor assumed in mainstream economics.

23 Informal economies also persist in Western European countries with longer histories of the market economy, as mentioned by Thelen (2011) or White and Williams (2016); see Chapter 2. 


\subsubsection{Informal food economies as a coping strategy}

In CEE, FSP and related informal economies (such as food sharing, discussed in this section) are often considered to be remnants of the socialist era and are viewed through the lens of the shortage economy (Smith and Jehlička, 2013; Thelen, 2011). In this section, I present and deconstruct this narrative, which still appears in the writings of both Western and Eastern European authors. I use the term food self-provisioning (FSP), which prevails in much of the literature discussed here. ${ }^{24}$ While this activity, that is, growing food for one's own consumption, could also be described with the terms gardening and agriculture introduced in Section 1.1.4, the term food self-provisioning indicates a focus on food production and subsistence: it lacks the connotations of fun, voluntary leisure, social innovation and political potential that gardening has in the Global North, and at the same time it is not as professionalized as agriculture.

FSP in post-socialist countries is noteworthy for its prevalence alone. According to Trenouth (2013), FSP is one of the most widespread food alternatives in CEE. Data published by Alber and Kohler (2008) indicate that 50 per cent of the population of CEE grows some of their food, compared to 10 per cent in Western Europe. ${ }^{25}$ Considering these numbers, the literature on urban gardening in Western Europe actually describes a fairly marginal practice. By contrast, Central and Eastern European FSP has only appeared in the literature on urban agriculture and AFNs in recent years. Formerly, this practice was described by anthropologists and theorized through the aforementioned lens of the shortage economy (Smith and Jehlička, 2013; Thelen, 2011).

FSP and other informal economies in CEE are typically viewed in the context of post-socialism and therefore interpreted in relation to the socialist past. This resonates with Müller's (2018: 8) point that contemporary CEE seems to be 'stuck in time', constantly being described through its past - as post-socialist, the former Second World, the old Eastern Bloc and so forth. In academic practice, this path dependence has been maintained by chronological jumps in argumentation, which effectively conflate the socialist era with the 'transition period' of the 1990 s and beyond. It is not uncommon for studies written 15 or more years after the fall of the Soviet Union (Acheson, 2007; Alber and Kohler, 2008) to refer unproblematically to literature written immediately after the end of socialism (e.g. Kornai, 1992; Rose and Tikhomirov, 1993). This creates a paradox: on one hand, scholars describe the massive changes CEE went through and the difficulties of this transformation, while on the other hand they assume that knowledge produced at the start of this turbulent period is still applicable without revisions.

The persistent influence of the concept of the shortage economy is one example of such anachronism. Whereas Kornai (1992) claims that shortage was caused by the centrally planned economy, according to many authors, it still persists even after the introduction of a market economy. See Alber and Kohler's (2008: 113) explanation of the prevalence of FSP in CEE:

24 Although my interest is in urban FSP, this section also draws on sources which do not distinguish between rural and urban settings.

25 According to Church et al. (2015), 15 per cent of the inhabitants of EU15 countries engaged in FSP in 2007, increasing from 9.6 per cent in 2003. Countries in CEE were not included in the data set. Vávra, Megyesi et al. (2018: 450) found that in 2010, 48 per cent of the population was involved in FSP in Hungary, 40 per cent in Czechia, 38 per cent in Cermany, 34 per cent in Scotland and 14 per cent in the Netherlands. 
In these countries the market never became the predominant source of production or exchange to a similar degree as in western countries. Having experienced how the command economy frequently translated into a 'shortage economy', where even the supply of food remained problematic (Kornai 1992), the citizens of these countries learned to cope with economic stress by relying on barter, informal assistance by family or friends, exchange in the shadow economy and also on the production of food.

Similarly, Acheson (2007) frames the system of family exchange networks in Slovakia as a reaction to uncertain livelihoods. Under socialism, these networks compensated for the dysfunctional economy. After the transition to the market economy, they substituted the failing social sector and compensated for the persistent scarcity of certain goods. The persistence of informal economies is thus explained by the incompleteness of the economic transition: 'Markets in Slovakia were very inefficient under socialism and they are still inefficient today' (Acheson, 2007: 412). ${ }^{26}$

The reading of FSP as a reaction to the shortage economy is based on several problematic assumptions. Firstly, FSP and other informal economies are regarded purely in economic terms, and their other dimensions are neglected, much like in the case of urban agriculture in the Global South (Section 1.1.4). Although Acheson (2007:408) mentions the sociocultural aspect of exchange networks, she sees it as a means to an economic end: 'What may be seen to the untrained eye to be simple acts of generosity is actually part of an intricate weaving of social interaction. Individuals are very strategic with their gifts'.

Here, the author touches upon the question of calculated reciprocity, which is an intricate part of the anthropology of gift and exchange. Indeed, the close bond between economic and social (or even cultural) elements, which is typical of informal economies, presents a challenge for understanding these practices. Interpretations vary from author to author. For instance, whereas Belk (2010) considers being part of an exchange network as a sign of social inclusion, Acheson (2007) demonstrates the threat of social exclusion for those unwilling to participate in mutual exchange. Concerns that non-market economies can be just as exploitative and unequal as the capitalist market (Smith and Stenning, 2006) are legitimate, but they seem to be overemphasized in the post-socialist context and reflect a pre-existing bias (see also Section 2.2). Recent research from Czechia (Jehlička and Daněk, 2017) and Slovakia (Zvončeková, 2019) suggests that participation in informal sharing networks is motivated by the joy of gifting and the wish to efficiently use resources rather than by social obligations or expectations of reciprocity.

The second problematic claim of the shortage economy discourse is the supposed dependence of people's livelihoods on informal economies, which is deduced from the prevalence of these practices. Whereas Acheson (2007:405) states that 'in Slovakia, families obtain a large percentage of consumption goods - especially food - by exchanges with other family members,' this fact alone does not prove that Slovak families are 'highly dependent' on these networks, as the author claims without further evidence. While FSP and informal exchange have economic benefits, they are not necessarily practised with a utilitarian goal. In fact, recent research on FSP in CEE

26 Also in this case the author conflates socialism with post-socialism, as is apparent already in the introduction of the paper - 'Under socialism and during the current period of post-socialist transition [...]' (Acheson, 2007: 405) - and further in its methodology, where the author mixes data obtained separately in 1993 and 2005 without much reflection. 
(discussed in Section 1.2.4) demonstrates the opposite: FSP is driven by a number of motivations, but economic need is among the least important (Mehić et al., 2015; Pungas, 2019; Smith and Jehlička, 2013; Smith and Stenning, 2006).

Thirdly and perhaps most importantly, even if informal economies are indeed a response to market shortages or the flaws of a political-economic system, this does not make them inferior, as both Acheson (2007) and Alber and Kohler (2008) imply. FSP initiatives which (more or less explicitly) address the pitfalls of the current market economy - such as food deserts, poverty, social inequality or neoliberalizing cities - are mostly depicted optimistically in the literature through concepts such as food sovereignty, environmental justice, local resilience, social integration and so forth (e.g. Kortright and Wakefield, 2011; Okvat and Zautra, 2011; Schupp et al., 2015). Practices which question the status quo are perceived as inspiring ${ }^{27}$ 'counter-hegemonic spaces' (Eizenberg, 2012), whereas the much less empowering term coping strategy (Alber and Kohler, 2008) prevails in the post-socialist context.

To conclude, the perspective of the shortage economy is an incarnation of geopolitically biased modernization theory, as it assumes that once post-socialist countries 'catch up' and develop a market economy, backward informal economic practices will vanish:

There is consensus among anthropologists that extended kin relationships play a key role in tribal and peasant societies. Ostensibly, such networks become far less important in modern industrial societies where people are dependent on wage labour and obtain most goods and services in markets. (Acheson, 2007: 405)

Although the decline of some traditional food economies in post-socialist countries seems to confirm this proposition (see Section 1.2.5), an opposite trend can be observed as well: in the Global North, interest in FSP is growing, and this practice is especially appreciated for its nonmarket character (see also Section 2.2). ${ }^{28}$

\subsubsection{Domesticating otherness, catching up with the West}

The construct of CEE as an underdeveloped 'other' (Müller, 2018) presented in the previous sections is not only the domain of Western researchers influenced by their own cultural backgrounds, but it has also been adopted within post-socialist countries, where it has arguably become the most powerful. In this section I outline how this perspective shapes public opinion and policy interventions.

Duží et al. (2014) were among the first authors to use the term urban agriculture in the context of

27 In recent years, some authors have approached the relationship between urban agriculture and the neoliberal system more critically (McClintock, 2014; Tornaghi, 2014). The basic argument is that if gardening initiatives substitute the role of the state in providing food security or social security in general, they are in fact contributing to legitimizing neoliberalization and the rolling back of the state. However, these voices do not define the discourse of urban agriculture in the West - they are critical of capitalism, not gardens.

What is more, some Western authors (e.g. Schupp et al., 2015) frame FSP as a luxurious activity for the well-off, since it requires resources that are hardly available to everyone (most importantly land). This view strongly contrasts with the understanding of this practice as a coping strategy of the poor. 
Czechia and Slovakia and to contribute to the English-written literature on the topic. Their paper, however, perpetuates the geopolitical distinction of CEE as essentially different and troubled:

[The] role [of home gardens] is emphasized especially in developing countries as an instrument on how to avoid malnutrition or the food insecurity of urban inhabitants. But they play a serious role in developed, and an even more important role in post-communist, countries where they help inhabitants to overcome economic transitions and difficulties. (Duží et al., 2014: 95)

The authors admit that food production is (no longer) the primary function of Czech and Slovak gardens, and the motivation to grow food has decreased with the transition to the market economy. They therefore suggest providing new incentives for gardeners, which should be in accord with 'contemporary approaches' such as agritourism or organic production for local markets (Duží et al., 2014: 97). This can be read as an attempt to wed the traditional practice of FSP with the current AFNs discourse. These 'contemporary approaches' (implicitly: Western models) involve the commodification of originally non-market practices, which should reframe and re-legitimize them in line with the neoliberal transformation (see also the examples from the Baltic countries below).

Why is the image of the East as underdeveloped and the West as modern harmful? In addition to contributing to a collective inferiority complex that affects about half of Europe, this discourse is performative in that it can discredit practices which are (rightfully or not) associated with the socialist era. All non-capitalist (non-market, informal) practices that existed before the end of socialism can in turn be dismissed as outdated and obsolete. This discourse serves as a self-fulfilling prophecy when used as a base for policymaking: existing practices are rendered non-legitimate, non-credible and in turn non-existing (Santos, 2004).

Urban allotments in Czechia are an example of such a performative process. In their aforementioned account of urban agriculture, Duží et al. (2014: 83) claim that 'post-communist cities [are] delayed approximately thirty years compared with democratic states'. The very same phrasing was used by the director of the Environmental Protection Department of Prague City Hall as an argument to abolish urban allotment gardens: 'Prague has a certain disadvantage, which is the industrial development that has been absent here for those 35 years. So obviously we change the city masterplan, we still have the opportunity to keep building' (Teislerová, 2006, 13:00). Spaces for urban FSP are thus reduced in the name of modernization and 'catching up' with the West. Describing FSP as related to the past prevents it from becoming a part of the future.

Urban gardening also offers good examples of different perceptions of food practices linked to the socialist tradition as opposed to ones that are inspired by Western Europe. On one hand, the aforementioned allotment gardens are commonly viewed as non-modern and obsolete (Gibas et al., 2013). On the other hand, community gardens, which could be seen as a different form of the same practice $^{29}$ (i.e. collectively organized FSP in a semi-public urban environment), have acquired strikingly different framing in both the academic and the public discourse. ${ }^{30}$

29 There is an ongoing debate on the differences between community gardens and allotments. While some authors conflate the two terms or include allotments under the heading of community gardens (e.g. Okvat and Zautra, 2011; Veen, 2015), others (e.g. Rasper, 2014) see allotments as fundamentally different. I understand community gardens as places where a community cultivates a shared piece of land, whereas in allotments gardeners take care of their own plots. 
Research on the first community gardens in Prague (Richtr, 2013) discovered that these were without exception started by young educated people who found inspiration while travelling in Western Europe. This is reflected in the self-presentation of these initiatives, which emphasizes 'improving the quality of urban space', 'bottom-up community management' and similar qualities (Jechová, 2015). Much like their Western models, many Czech community gardens distance themselves from the pure productive function (see Section 1.1.4), as implied by statements such as 'the word "community" is more important than the word "garden" (Jechová, 2015), and 'grow vegetables and neighbourly relationships' (Vítková, 2012). The similarities between Czech community gardens and their Western counterparts are attractive for the media, which present them with certain pride: 'Community gardens have started to appear in the [Czech] capital, following the example of London or New York' (Řimanová, 2014). Any link to the Czech tradition of FSP is omitted.

A broader look at the development of 'Western-style' AFNs in CEE reveals various ways in which these initiatives 'travel' and are adopted in the local context. ${ }^{31}$ Similarly to community gardens, farmers' markets and CSA in Czechia were explicitly inspired by the West. In both cases the introduction of these AFNs can be seen as successful. At the same time, the Czech 'adaptations' developed some locally specific characteristics. For instance, the first Czech CSA projects were initiated by the civic sector, whereas in Western Europe such initiatives are commonly established by farmers or consumers (Frélichová, 2013). In the case of farmers' markets in Prague, Fendrychová (2015) has documented a shift of focus compared to Western models. Farmers' markets were presented through a narrative of food quality and consumer satisfaction, framed in relation to criticism of imported low quality food. Environmentally sound production methods, which are part of the rationale of farmers' markets in Western countries, were omitted. Fendrychová and Jehlička (2018) see two factors that explain this development: the situation of the Czech agricultural sector in which small-scale farmers are scarce and political support which made farmers' markets economically profitable and contributed to their early conventionalization.

Apart from developing local particularities in the process of 'translation', 'imported' food alternatives are at risk of reproducing the pitfalls of their models. In the case of farmers' markets, these could be exclusivity and a focus on more affluent consumers (Fendrychová and Jehlička, 2018). CSA in Czechia, as in Western Europe, runs the risk of commodification, which replaces actual community participation with consumerism (Frélichová, 2013; Pole and Gray, 2013).

In other cases, Western AFNs might even struggle to succeed in the Eastern context. For instance, the development of collective farmers' marketing initiatives (COFAMIs) was hindered by farmers' memories of forced socialist collectivization (Tisenkopfs et al., 2011), and cooperatives are only slowly regaining their reputation (Johanisová, 2012). On the consumer side, certified organic produce is frequently viewed with suspicion. This could be caused by the traditional association of 'natural' foods with non-market channels such as FSP (Trenouth, 2013; see further), lower willingness to pay or lack of trust in institutional guarantees of quality (Fendrychová, 2015).

31 See Fendrychová and Jehlička's (2018) application of the 'travelling concept' theory. 
Finally, in some instances Western models and already existing Eastern practices collide. Examples from the Baltic countries show that EU hygiene standards (or their local interpretations) endanger traditional short supply chains, which otherwise fulfil all characteristics of AFNs. Mincyte (2012) states that while the delivery of milk directly to consumers by peri-urban farmers was outlawed after Lithuania joined the European Union, the new farmers' markets mushrooming in Vilnius offer similar produce - except it is certified and therefore more expensive. The situation is similar in neighbouring Latvia, where, according to Aistara (2015), EU regulations have forced small-scale producers to the grey economy of informal sales, just like the planned economy did in Soviet times. Whereas some consumers perceive this informality as a feature of ethical consumption, for others it symbolizes a lack of modernity. In both cases, however, existing practices are marginalized in an attempt to emulate Western models through marketization and formalization.

To summarize, local food practices in CEE interact with AFNs imported from the West in many different ways. I have shown that under the influence of the modernization discourse of 'catching up with the West' practices with a long tradition in the region have become marginalized while similar initiatives of Western provenience are promoted as novelties. Furthermore, there is a variety of ways in which 'Western' AFNs are adopted in CEE. As Fendrychová and Jehlička (2018: 8) highlight, the spread of AFNs from the Western core to the CEE periphery cannot be seen as an uncomplicated process of the spatial diffusion of an innovation. Instead, imported ideas interact with local understandings and conditions to create hybrid variations. In other words, while post-socialism can, in some cases, create specific conditions for the development of AFNs, these particularities cannot be reduced to the aforementioned modernization perspective. With that in mind, in the next section I return to FSP, offering a more nuanced reading of this practice.

\subsubsection{Rethinking food self-provisioning}

Numerous authors challenge the perception of FSP and other informal economies in CEE as motivated by economic necessity. Smith and Stenning (2006: 196), who are otherwise fairly critical of post-socialist informal economies, review literature on household food production to conclude that ' $[\mathrm{d}]$ omestic food production does not occur in this sense as the result of economic necessity but for other, more complex reasons.' Smith and Jehlička (2013) enumerate the diverse but mostly non-economic motivations of Polish and Czech gardeners. Both studies considered demographic variables among people involved in FSP, proving that people from all social strata grow their own food, with lower income groups actually being slightly under-represented. Financial savings do play a role in the motivations of Czech gardeners (Jehlička and Daněk, 2017), but they are less important than acquiring fresh, healthy food. For Slovenian gardeners, neither financial savings nor market shortages play a role (Mehić et al., 2015). Smith's (2003: 179) essay on házi, the Hungarian term for home-grown or homemade food, gives a clear summary:

Házi is different than what poor people do for survival growing vegetables in the garden and raising pigs and the like because the family can not [sic] afford to buy things at the market or in stores - this is a kind of low level subsistence agriculture. ${ }^{32}$

32 Notice the judgmental undertone related to 'poor people's subsistence agriculture', which reproduces the inferiority of practices performed for economic reasons, assuming they cannot have other values. 
What, then, are the motivations for FSP? Studies from across CEE typically point to a combination of enjoyment - that is, people grow their own food as a hobby because they like the activity - and the desire to have fresh, healthy food. In what follows I elaborate on the nuances of these factors. One of the most important values across CEE is the quality attributed to home-grown food, which is perceived as fresh, healthy and generally better than food from different (especially commercial) sources (Aistara, 2015; Mehić et al., 2015; Smith, 2003; Smith and Jehlička, 2013). In this sense, the characteristics that Eastern Europeans associate with FSP seem compatible with the quality turn which gave grounds to the emergence of AFNs in Western Europe or North America. It appears, however, that notions of quality, health and freshness are linked to the care invested in growing and preparing food rather than to strict compliance with the principles of ecological food production.

Taking the Czech example, Jehlička and Smith (2011) assert that most household food production is compatible with the principles of organic food production. However, their results might be coloured by the fact that gardeners sometimes fail to recognize commonly used fertilizers or pesticides as 'chemicals' and that they tend to perceive their own produce as healthy and natural regardless of the treatments used (Sovová, 2015). In other words, fruit from grandma's garden can subjectively be of higher quality than certified organic food. ${ }^{33}$ Gabriel's (2005: 194) observation from Russia confirms this:

In short, whereas North Americans emphasize the physical, environmental impact of food production when they question the ecological cleanliness of their food, Russians tend to emphasize the human relationships that went into food production and distribution. When Russians say that a food is 'good for you,' they mean in more ways than purely nutritional value.

In their analysis of Latvian foodscapes, Trenouth and Tisenkopfs (2015:367) capture the blending of characteristics such as tasty, ecological, natural, clean, fresh, traditional and local, with the last two revealing a connection between the quality of food and the construction of identity (Belasco, 2008). The desire for proper food is often linked to family or national traditions, and it features a touch of nostalgia for flavours remembered from childhood (Trenouth and Tisenkopfs, 2015). FSP is taken for granted by many because it has been a family tradition for generations (Aistara, 2015) or it is perceived as a national custom (Mehić et al., 2015). A quasi-nationalist undertone can slip into these discourses, especially when domestic foods are promoted over imported ones (Fendrychová, 2015; Smith, 2003; Trenouth and Tisenkopfs, 2015).

Although FSP does support national identity, it seems to take a rather critical position towards the state. The desire to escape state control is considered one of the causes of the popularity of gardening in the socialist era (Duffková, 2002; Jehlička and Daněk, 2017), being possibly even more important than the potential economic benefits of FSP (Trenouth and Tisenkopfs, 2015). What is more, Aistara (2015) frames informal economies in the socialist era as indirect political resistance, where bypassing official channels also meant criticizing the dysfunctional state.

33 De Hoop and Jehlička (2017) offer an interesting nuance to this debate. They observe that members of environmental organizations and media tend to be more sceptical about the ecological cleanliness of home-grown food and contrarily more supportive of certified market goods. 
Smith (2003: 180) understands FSP as an expression of desire for dignified meaningful work, which stands in opposition to both the socialist state and the capitalist market:

The communist state claimed to provide everything needed in life and therefore házi was an insult to the state. Similarly in capitalism everything is in theory available on the market for consumption, and because capitalism is said to be more efficient [...], to do it yourself seems stupid and a waste of time. But házi is about dignity, creativity, self-reliance, individuality, and self worth; it symbolizes the power [...] to be a human being not a robot-worker, backward peasant, or mindless consumer.

By perceiving working in the garden as a source of self-fulfilment, meaning, personal autonomy and the re-appropriation of work (Trenouth, 2013), Eastern European gardeners are no different from their counterparts elsewhere (e.g. Bhatti et al., 2009; McClintock, 2010). One of the changes brought about by the transition to the market economy concerns the time available for this informal work. Longer working hours and loss of free time are perceived as a threat to FSP by Slovenian gardeners (Mehić et al., 2015). Mincyte (2012) explains that those who are not involved in the paid economy (the elderly, the unemployed or part-time workers) compensate for lower incomes by dedicating their time to participation in informal food economies. In contrast, the economically active population can only access foods with the desired qualities through official distribution channels, which is more time efficient (Mincyte, 2012; Smollett, 1989; Trenouth, 2013) but more costly. Different values of time and money are also captured by Smith (2003) in his account of Hungary, where homemade food is perceived as better but the time investment in its preparation makes it a luxury which many cannot afford. If the socialist economy was characterized by scarcity of goods, capitalism has brought scarcity of time and energy, he concludes.

In line with the intrinsic social dimension of informal economies, many authors link the loss of time available for these practices to the loss of interpersonal relationships that they foster. Trenouth and Tisenkopfs (2015) found that the food choices of 'urban professionals' were influenced by time constraints. With less cooking and more convenience food, the social function of eating together has also diminished. This change is also reflected in Gabriel's (2005: 206) study of Russians, some of whom 'don't even have time to drink tea together'. (Homemade) food and drinks not only give grounds for social interaction, but they are also a direct expression of social relationships: 'Házi means making food for example, because one loves one's friends, family, or neighbors. A person engaged in házimunka does so with them and for them' (Smith, 2003: 180).

Sharing with family and broader networks is an integral part of FSP and is grounded in social norms and moral values such as the stigmatization of food waste and selfishness (Acheson, 2007; Smith and Jehlička, 2013; Sosna et al., 2019). Food is shared without expectations of reciprocation (Jehlička and Daněk, 2017; Smollett, 1989; Zvončeková, 2019). This practice is both based on and fosters social relationships (Jehlička et al., 2019; Zvončeková, 2019). Informal food economies thus offer a multitude of values which surpass their economic utility (Pungas, 2019). According to Gabriel (2005: 186), the social aspect of home-grown food reinforces, and is in fact a part of, its 'cleanness' and healthiness: 'Food that helps cement desirable social relationships is healthy; food that disrupts these relationships is not.' In other words, the social embeddedness of a food network is not an additional benefit but a condition of food quality. 


\subsubsection{The transforming food systems of CEE}

I will conclude this chapter by addressing the assumption that informal food economies will disappear with the transition of post-socialist countries to the market economy, as implied by Acheson (2007) or Alber and Kohler (2008; see Section 1.2.2). I will do so by summarizing the changes in food provisioning that have occurred since the end of socialism, as observed by Smith and Jehlička (2007) in Czechia and Poland and Trenouth and Tisenkopfs (2015) in Latvia.

Both works identify three main tendencies. Firstly, and mostly importantly, Central and Eastern European foodscapes follow Western consumer trends. In the 1990 s and 2000 s supermarkets quickly became the most common shopping venues, and exotic foods and fast food chains became popular. Nevertheless, enthusiasm for new consumer options was soon replaced by more ambivalent reactions. Complaints about the low quality of imported foods, high prices and the devastating impacts of competition on local producers and distributors (Fendrychová, 2015; Smith, 2003; Trenouth and Tisenkopfs, 2015) were complemented by (partly also Westerninspired) growing health awareness and interest in food quality and origin. Despite the specific nature of the region, this trend is not dissimilar from the quality turn which marked the beginning of AFNs in Western Europe (Spilková, 2016).

The second trend, which is still more important than 'Western' AFNs, consists of persisting traditions from (pre-)socialist times (Smith and Jehlička, 2007) or their contemporary incarnations. Smollet (1989: 132) explains the transformation and continuation of traditions on the example of mutual help and kin networks:

If we imagine that social life at a particular stage is composed of sets of traits or traditions, we will assume that these evaporate somehow at a later stage, and are replaced by others. But society is not made of traits and traditions. Society is a process, involving the action, interaction, and thought of conscious human beings - people, who actively transform the patterns of social behavior they inherit from the past, including kinship relationships. So that they will serve their needs in a new type of society. (emphasis in the original)

The meanings and functions of FSP have indeed changed. Czech allotments have seen an increase in recreational (as opposed to productive) features after the regime change (Gibas et al., 2013; Keyzlarová, 2012). This type of organized urban gardening has been declining since 1989, both in terms of land area and the number of allotment members (Sovová, 2015; Spilková and Vágner, 2016). During my field research conducted in allotments in Brno, several gardeners expressed the opinion that social cohesion was stronger during socialist times, whereas nowadays gardens are used in a more individualized manner, and common activities are less frequent (Sovová and Krylová, 2019). A representative survey from 2015 (unpublished) revealed that some Czechs currently feel less involved in informal food economies compared to 10 years ago (questions focused on topics such as FSP, self-help repairs and housework and receiving and giving help). However, most respondents stated that their involvement in these practices has remained constant.

Moreover, the lessons that can be drawn from the history of FSP in Western Europe reveal fluctuation rather than linearity. Arguably, the declining interest in gardening after the end of socialism in CEE resembles what Western countries experienced after the Second World War 
(Gibas et al., 2013). This parallel is at risk of reproducing the framing of gardening as a coping strategy in times of crisis and the idea of a linear 'evolution' where CEE 'catches up', but it also offers hopeful predictions for the future: a renaissance of gardening is taking place in Western Europe, in connection to higher consumer awareness and AFNs. The first signs of such a renaissance can also be observed in CEE, where the gap between tradition and its rediscovery is much smaller. Growing interest in food is also marked by the emergence of 'Western-style alternatives', the third trend described by both Smith and Jehlička (2007) and Trenouth and Tisenkopfs (2015), examples of which I mentioned in Section 1.2.3.

Here, in connection with traditional and newly emerging food practices, a note on reflexivity is called for, as this is an important topic within the discussion on AFNs (see Section 1.1.2). As mentioned in Section 1.2.3, AFNs inspired by Western initiatives also often adopt Western discourses. Topics such as solidarity with small farmers (as mentioned in the case of Czech CSA), building social relationships (in the case of community gardens) and food quality and transparent origin (for most AFNs) can be identified in the self-presentation of these initiatives, although they can take on different meanings or run into paradoxes (as shown by Fendrychová and Jehlička, 2018, on the case of Prague farmers' markets). In comparison, traditional practices such as FSP can partly share similar values (i.e. food quality and origin or even social embeddedness, as discussed in Section 1.2.4). However, these values are proclaimed less explicitly and intertwined with other norms and motivations. Smith and Jehlička (2013:155) have termed such 'unconscious' practices quiet sustainability:

Quiet sustainability is defined by practices that result in beneficial environmental or social outcomes, that do not relate directly or indirectly to market transactions, and that are not represented by the practitioners as relating directly to environmental or sustainability goals.

These 'quiet' or 'traditional food networks' (Tisenkopfs, 2017) are rarely motivated by political convictions or activist endeavours. However, as should be clear from this chapter, like Western AFNs, they are not devoid of critical perspectives on the mainstream food system (Pungas, 2019), and they might even 'surpass' Western networks in terms of prevalence, level of integration in everyday routines and independence from the market. At the same time, the absence of reflexivity is not specific to the post-socialist context but rather a topic to be discussed within AFN scholarship as a whole. The understanding of Eastern European 'quiet alternatives' offers a relevant perspective for this debate. ${ }^{34}$

\subsubsection{Summary and concluding thoughts}

This section has explored the phenomenon of FSP in CEE in the context of the search for a more sustainable food system and the characteristics of the region. Until recently, literature on FSP in CEE has mostly adapted an economically focused perspective informed by Kornai's (1992) notion of the shortage economy. This discourse can be seen as a variation of the diverging and geopolitically biased conceptualizations of similar practices which I introduced in Section 1.1.5.

34 Veen (2015) uses the term actually existing alternatives, which is inspired by the here-mentioned concept of Smith and Jehlička, for Dutch gardeners who do not display 'higher morality' but are, in their activities, enacting an alternative to the industrial food system, often more successfully than actors with 'conscious' motivations. 
The perception of FSP in CEE is, to some extent, similar to the framing of urban agriculture in the Global South. In both cases, scholars highlight food production as a means of supporting livelihoods, which is reflected in the terms used, that is, food self-provisioning or household food production in contrast to urban gardening.

However, while the potential of FSP to enhance food security is praised as a tool for empowerment, social justice and food sovereignty in the context of the Global South (or peripheral spaces within the Global North), it is frowned upon as an obsolete coping strategy in CEE. This reflects the different positions of these two regions in the world hierarchy. The transformation of the 'Third World' into the 'Global South' arguably brought about certain empowerment in terms of knowledge production (represented for instance by post-development or postcolonial scholarship), ${ }^{35}$ recognition of locally developed concepts (e.g. buen vivir, ubuntu) and indigenous practices such as peasant and subsistence farming.

This has not been the case for the so-called Second World. After the collapse of state socialist regimes, post-socialist Europe became what Domazet and Marinović Jerolimov (2014: 20) term 'semi-periphery': countries which are positioned between the 'core' (that is, in simplified terms, Western Europe and the Global North in general) and the 'periphery' (by and large corresponding to the Global South). While the semi-periphery includes features of both the core and the periphery, it also tends to get lost between the two: it is not as affluent as the Global North but is also not as poor as the Global South; inferior, but not inferior enough; similar, but different (Müller, 2018). CEE, no longer socialist but not quite Western, thus vanishes from the radar. Local practices such as FSP do not fit conceptual frameworks informed by the context of both the Global North and South. As Tuvikene (2016) puts it, they are not part of the mainstream nor of the critique.

In an attempt to overcome this gap, in this chapter I have introduced novel readings of FSP as well as other food practices in CEE, which bring them into dialogue with similar food alternatives elsewhere in the world. I have shown that while CEE maintains some peculiarities related to the region's history, some of the developments parallel discussions held in Western Europe and offer relevant insights.

\subsection{Problem statement}

This chapter brought together literatures on AFNs, urban agriculture, FSP and informal food economies in CEE. I have identified several knowledge gaps and inconsistencies, which can be summarized into the points contained in the following problem statement:

1. While AFNs are promising for the search for a better food system, they often fail to overcome the producer-consumer divide and they remain embedded in mainstream market mechanisms, reproducing their power dynamics and leading to exclusivity and elitism (Sections 1.1.1-1.1.3).

2. Urban FSP can potentially address some of these pitfalls, as it merges the producer and consumer roles, and it operates to a large extent outside market mechanisms. However, the

35 See e.g. Comaroff and Comaroff (2012) or Müller (2018) for a more nuanced discussion. 
productive function of urban gardens in the Global North is under-researched (Section 1.1.4). 3. If urban gardens are viewed as sites of food production, it is often in relation to economic hardship or disadvantaged people or areas. This literature is to a large extent separate from the discussion on AFNs. Different framings of urban FSP are geopolitically conditioned (Section 1.1.4).

4. FSP and other informal food practices in CEE are an example of such geopolitical bias, as they are often theorized as backward practices driven by economic need. Knowledge about these practices rarely contributes to the debates on more sustainable food systems (Section 1.2).

This thesis reacts to these issues by studying urban gardens in Czechia as spaces which can offer insights relevant for the current debates on AFNs and urban agriculture but which have been until recently neglected in these literatures and subject to geopolitical biases. In the following chapter I elaborate on some theoretical considerations that underpin the current knowledge gaps as well as my attempts to address them. After introducing my conceptual lens, I formulate my research question in Section 2.3. 



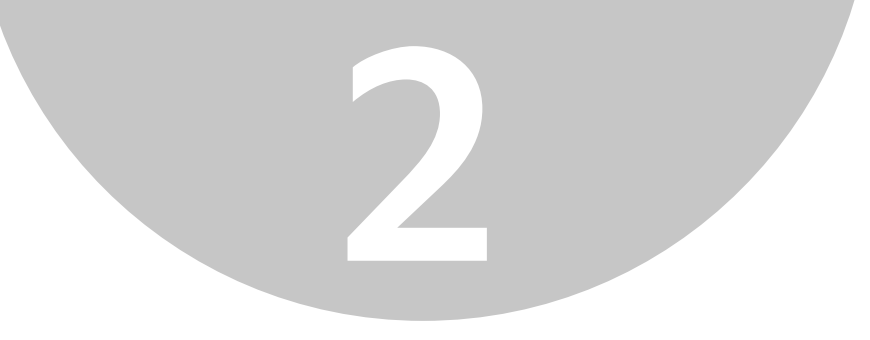

\section{Conceptualizing FSP as an economic activity: Understanding invisibility and reading for difference}

This chapter explores some of the issues related to the search for better food systems by linking them to different understandings of the economy. The first section uses insights from ecofeminist political economy to understand the tensions surrounding the productive function of urban gardens. It demonstrates that the 'invisibility' of some practices and spaces is a result of implicit and normative understandings of the economy. The second section then introduces diverse economies as a conceptual framework which is promising for the reframing of urban gardens as alternative sources of food, viewing FSP as an economic activity without associating it with economic hardship. The third section summarizes how these perspectives are applied in my research on FSP in Czechia.

\subsection{Economic invisibilities: The everyday, domestic, gendered and informal}

Reflecting on the knowledge gaps and practices that are under-represented in the literature reveals several patterns. Firstly, several authors have pointed out that the literature on AFNs tends to focus on novelties rather than on traditional practices, excluding practices such as home gardening (Taylor and Lovell, 2014), allotment gardening (Exner and Schützenberger, 2018; Veen et al., 2014) or (food) sharing (Belk, 2010; Jehlička and Daněk, 2017), which are seemingly trivial and taken for granted. Such practices are often related to the domestic realm. In practical terms, this can make them less visible than projects realized in (semi-)public spaces. Penetrating the realm of everyday private life, to which households and gardens belong, can be a difficult task for researchers (Taylor and Lovell, 2014).

More importantly, the domestic realm operates - by definition - outside the market and its logic. ${ }^{36}$ The segmentation of society into the state (the public), the market (the private) and community

36 I understand the market as a virtual or physical space where different actors exchange goods and services. Mainstream economists assume that actors enter into these interactions in different roles (sellers, buyers, labourers) but that all behave in line with the archetype of homo economicus - an independent, rational individual who strives to maximize profits and utility and minimize costs. Most commonly, market exchange involves money; the same logic, however, can be applied to other means of exchange. Under market logic, 'everything has a price', which does not necessarily (and not exclusively) depend on the use value of the object of exchange. 
(the informal, civic or third sector), each with its own processes of redistribution, market exchange and (unconditional) reciprocity, ${ }^{37}$ is one of the cornerstones of social science (Williams et al., 2013). With advancing neoliberalization, ${ }^{38}$ however, market logic has become privileged to the point that it is almost assumed to be the all-encompassing logic of human behaviour. Belk (2010) notes that this preconception contributes to the ignorance of other principles (e.g. sharing) which might be just as, or even more, integral to human nature. Furthermore, the capitalist market is seen as a privileged site where 'the economy' - which is understood as a guiding force of society - happens (Gibson-Graham, 2006).

According to mainstream economists, households ${ }^{39}$ are sites of consumption. Household members partake in the economy as consumers and labourers. What happens inside the household (reproduction, redistribution, division of labour) is uninteresting for economic models, and the other potential roles of people (e.g. producer, citizen, carer) are ignored. This perspective explains the emphasis on conscious consumer behaviour in some AFNs (Section 1.1.3).

In contrast, urban gardeners engage in food systems also as producers, (or, as I explain later, provisioners). In doing so, they 'step outside' the role they are assigned in the mainstream economic view. In academic literature influenced by mainstream economic thought this incoherence is resolved by framing household food production either as economically insignificant (i.e. a hobby) or as a 'workaround', that is, a (temporary) replacement for a (presumably more appropriate) market-based food system - the two conceptualizations of urban FSP introduced in Section 1.1.5.

Reframing the productive function of urban gardens and exploring their potential for food provisioning without normative assumptions thus require a different understanding of the economy. Ecological and feminist economists have long criticized the mainstream view of the economy and its focus on the market and rationality. Instead, they propose a broader understanding of the economy as a range of activities that satisfy human wants and needs. Dash (2014: 11), for instance, understands the economy as 'the ways people organise themselves collectively to make a living, and the ways a society organises itself to (re)produce its material life and well-being.

Mellor (2006) uses the term provisioning to emphasize the orientation on human needs as opposed to the maximization of (financial) profit characteristic of the current neoliberal economy. A similar distinction is included in Mies and Bennholdt-Thomsen's (1999: 20) use of the term subsistence to mean securing both material and non-material conditions for a happy life:

Subsistence production or production of life includes all work that is expended in the creation, re-creation and maintenance of immediate life and which has no other purpose. Subsistence

37 The term reciprocity has multiple and even contradictory meanings. Whereas in some contexts, it can be synonymous with the market logic of value for price (as is the case in Acheson's 2007 paper discussed in Section 1.2.2), other authors (e.g. Sahlins, 1972, quoted in Belk, 2010) talk about reciprocity as being free of this rational calculus and based on social bounds rather than economic considerations.

38 I use the term neoliberalization to describe the process by which parts of society are increasingly organized according to the principles of the market, as opposed to the reign of the state. This 'rolling back' of the state also entails 'rolling out' new social and economic institutions to take over what were previously public services (McClintock 2014). 
production therefore stands in contrast to commodity and surplus value production. For subsistence production the aim is 'life', for commodity production it is 'money' which 'produces' ever more money [...]. For this mode of production life is, so to speak, only a coincidental side-effect.

These approaches build on the (neo-)Marxist concept of reproduction. In the Marxist economic model, reproduction is understood as the reproduction of labour (i.e. workers' performances improve when they are fed, well rested and content). Contemporary authors (BennholdtThomsen, 2012; Pérez Orozco, 2014) offer a broader understanding of the reproduction of life, which is close in meaning to care(work). In general, (eco)feminist economics shifts the focus to 'ends', that is, reproduction, care, sustenance or livelihoods, instead of 'means', which can be based on diverse mechanisms, including but explicitly not limited to the market economy (Gibson-Graham, 2006). As Murton et al. (2016: 5) put it, 'if we start by asking not about the economy, or work, or commodities, or other abstractions but about how people feed themselves, things look different'.

The feminist perspective further discusses the gendered nature of informal, non-market economies, which goes hand in hand with their marginalization in mainstream economic models. Mellor (2006) uses the concept of the dualist economy to summarize the characteristics of the valued and the invisible or marginalized. The 'valued economy' is represented by the economic 'man', who impersonates market value, personal wealth, labour and intellect, tradeable skills and knowledge, physical fitness, mobility and exploitable resources. The 'other economy' (Donath, 2000) includes women's work; subsistence; social reciprocity; the body; feelings; emotions; untradeable wisdom; the sick, needy, old and young; embeddedness in place; ecosystems; and wild nature. Although feminist scholars often refer to men and women as representatives of the two economic spheres (and this distinction is well justified), the dichotomy surpasses gender. As Mellor (2006) acknowledges, the pattern of exclusion and marginalization that affects women also applies to non-Western, ${ }^{40}$ non-market and non-white economies and people.

FSP clearly has features of the 'other economy'. It is concerned with human needs (food), which are satisfied through interaction with the biophysical environment using physical labour (McClintock, 2014). The activity of growing your own is both embodied and embedded in natural and social systems (Pottinger, 2018); these characteristics are associated with women's (reproductive) work (Mellor, 2006). Indeed, food provisioning, as well as sharing, is traditionally attributed to women (Belk, 2010; Taylor and Lovell, 2014). These characteristics add to the aforementioned non-market nature of FSP and the invisibility of this practice from mainstream economic positions.

Integrating these insights with the othering of post-socialist countries that I laid out in Section 1.2.1 unravels the 'double invisibility' of FSP and the related informal food economies in CEE. Firstly, these practices are marginalized because they take place outside the market. Secondly, their non-market nature is seen as resulting from and intrinsically linked to a failed non-capitalist system. This historicizing perspective is important, as it presents informal food economies as

40 A point relevant for the theorization of the 'invisibility' of CEE. 
remnants of the past, and it frames them as different from similar activities performed in the context of Western capitalist economies (as discussed in Sections 1.2.1 and 1.2.2). The economic and geopolitical dispositions for exclusion enhance each other in the case of informal food economies in CEE, as the current search for sustainable food provisioning remains embedded to a large extent in a Western, market-based context (Tornaghi, 2014).

The broader understanding of the economy offered by ecofeminist approaches allows me to rehabilitate the productive function of FSP and other informal food economies as indeed different from, but not necessarily inferior to, market systems. In fact, the same characteristics which contribute to the marginalization of FSP can be seen as relevant in overcoming some of the pitfalls of AFNs (discussed in Section 1.1.3), such as bridging the producer-consumer gap and escaping the inequities of market-based food systems.

\subsection{Diverse economies: Making visible and overcoming othering}

The diverse economies framework (and research agenda) was introduced by feminist geographers Julie Gibson and Katherine Graham $^{41}$ as a reaction to the capitalocentric bias of geography and social science in general. The authors point out that scholars tend to implicitly reproduce the notion that capitalism ${ }^{42}$ is the main operating principle of economic activities and by extension society in general. Capitalocentric views describe other forms of economies in relation to capitalism - as being the same, modelled upon or evolving towards capitalism, or as being oppositional to it. Even scholarship which is critical of capitalism can thus reproduce its dominance (Gibson-Graham, 2006).

The critique of capitalocentrism relates to the more general issue of the performativity of science: Gibson-Graham (2008) point out that the way scholars think about a topic not only determines the results of scientific inquiry, but it also influences the reality of the researched phenomena. Put simply, describing a practice as marginal contributes to its marginalization, while describing a practice as emerging can facilitate its emergence (see the example of allotment and community gardens in Section 1.2.3). Capitalocentric perspectives thus produce other economic practices as non-existent (Santos, 2004).

Gibson-Graham (2014) thus suggest that research should primarily consist of observation of existing practices and should avoid presumptions which can distort our perception of reality (the methodological implications of this position are discussed in Chapter 3). In addition, being aware of the performativity of research and in an attempt to counter the capitalocentrism of scientific knowledge, Gibson-Graham call for more attention to non-capitalist economies, which can represent, legitimize and support these practices, 'make them more real and more credible' (Gibson-Graham, 2008: 1), and 'transform impossible into possible objects' (Santos, 2004: 238).

41 Writing jointly under the pen name ]. K. Gibson-Graham

42 Gibson-Graham (2008) define capitalism as an economic system in which exchange takes place according to market principles and with the use of money, and individuals are paid for their labour. The term capitalist thus corresponds to 'formalized and market-based', following the formalization and marketization theses (Section 1.2.1) 
Building on the ecofeminist approach to the economy, Gibson-Graham (2006) use the metaphor of an iceberg in which the market economy represents the visible but relatively small tip, which is supported by the huge yet hidden body of care and reproductive work, solidarity, the 'work' of nature and non-human others and so forth. In order to capture the entire spectrum of economies (i.e. the different ways in which people satisfy their needs), the authors propose three categories: capitalist economies based on market relations and wage labour; non-capitalist economies based on non-reciprocal transactions and unpaid labour; and alternative capitalist economies, which are to some extent based on markets and capitalist logic, but in which the negotiation of prices and rewards follows different logic and involves wider criteria (Gibson-Graham, 2006; see Table 2).

Table 2: A diverse economy matrix based on capitalist, alternative capitalist and non-capitalist arrangements of transactions, labour and enterprise. Adapted from Gibson-Graham (2006; 2008).

\begin{tabular}{lcc}
\hline Transactions & Labour & Enterprise \\
\hline Market & Wage & Capitalist \\
\hline Alternative market & Alternative paid & Alternative capitalist \\
Sale of public goods & Self-employed & State enterprise \\
Fair trade & Cooperative & Green capitalist \\
Alternative currencies & Reciprocal labour & Social enterprise \\
Underground market & Workforwelfare & Non-profit \\
Cooperative & In-kind & \\
Barter & & Non-capitalist \\
\hline Non-market & Unpaid & Communal \\
Household flows & Housework & Independent \\
Gifting & Carework & Feudal \\
State allocations & Community work & Slave \\
State appropriations & Volunteering & \\
Gleaning & Self-provisioning & \\
Foraging & Slavelabour & \\
Theft & & \\
\hline
\end{tabular}

By introducing the notion of multiple and diverse economies, Gibson-Graham's framework overcomes the problem of alterity discussed in Section 1.1.2. The understanding of all economic practices as coexisting, interacting and inherently equal, enables moving beyond the problematic dichotomy of 'the bad mainstream' and 'the good alternatives' ${ }^{43}$ While alterity and oppositionality are part of the discussions about diverse economies, they are not necessarily the starting point, as Fickey and Hanrahan (2014:395) observe: some scholars prefer to focus on capturing the diversity of economic practices instead of exploring the extent to which they disrupt the status quo. Compared to the 'alternativeness' of AFNs, talking about diverse or even informal, non-market or non-capitalist economies avoids the implicit assumption of oppositionality and reflexivity.

White and Williams (2016) add another critical point to the issue of alterity from a diverse economies perspective. They assert that the word alternative might connote that the practices in question are either marginal or less desirable options. As they demonstrate with the example

43 Although the authors use the term alternative market economies, they are defined rather clearly, as explained above. 
of housework in the UK, the opposite is often true: their respondents typically preferred noncapitalist practices (i.e. housework was carried out by household members), while capitalist practices (outsourcing the work using paid labour in the private sector) were explicitly seen as a 'last resort'. White and Williams (2016) thus argue that describing non-capitalist practices as 'alternatives' reinforces the capitalocentric discourse and can seem disrespectful to practitioners who choose them as their first option in everyday life. ${ }^{44}$

That being said, the agenda of the diverse economies project extends beyond a mere inventory of diverse economic practices: 'Research which seeks to document diversity and alterity is often motivated by the negative effects of capitalist systems [...] and the presence of other kinds of economic practices which may provide an expansion of social possibilities' (Fickey and Hanrahan, 2014: 396). This research therefore tends to describe non-capitalist practices in supportive and hopeful terms, rather than in overly critical ones (Fickey and Hanrahan, 2014; Gibson-Graham, 2008), framing them as spaces of hope and possibility (Gritzas and Kavoulakos, 2016) and seeing their imperfections as signs of struggle and transformative processes (Schmid, 2018). This embracement of performativity is inspiring, but it runs the risk of reproducing (albeit implicitly) the mainstream-alternative dichotomy with similar perceptions of capitalist versus noncapitalist practices, thus replacing one set of assumptions and prejudices with another one. As Gibson-Graham (2008) note using the examples of slavery and feudalism, not all non-capitalist practices are 'better', and a critical (yet still hopeful) perspective is needed to understand the living conditions produced by diverse economic relations (Fickey and Hanrahan, 2014).

The geopolitical context, which is one of the recurring themes of this thesis, needs to be considered here as well. The diverse economies approach aligns with the critique of the notion of development as linear, evolutionary progress towards capitalist modernity. Santos (2004: 239) argues that by enforcing narrow Eurocentric and capitalocentric understandings (in his words, 'monocultures') of knowledge, time, classification, scale, productivity and efficiency, the development discourse produces 'the other' as 'the ignorant, the residual, the inferior, the local and the non-productive'. This resembles the narratives of post-socialist transformation in CEE discussed in Sections 1.2.1-1.2.3, in which practices and institutions are marginalized due to their association with a failed political system and lack of compliance with the new world order. To counter this hegemonic 'production of non-existence', Santos (2004: 239) proposes, it is necessary to expose and make credible the diversity and multiplicity of social practices, and replace epistemological 'monocultures' with more inclusive 'ecologies' which can accommodate non-Western contributions.

The diverse economies approach therefore seems promising for conceptualizing post-socialist economies in CEE. Pavlovskaya (2004), for instance, uses the diverse economies lens to theorize the transition in post-Soviet Russia as a transformation of multiple heterogeneous economies taking place at different scales and in different spaces. Contrary to the predominant understanding of the transition as a simple shift from state socialism to capitalism, this perspective accounts for the multiplicity of economic practices and subjectivities and therefore allows for a much more nuanced understanding of development and change.

44 The latter point was discussed in relation to AFNs by Holloway et al. (2010); see Section 1.1.2. 
Several other authors have used the diverse economies framework to conceptualize the informal economies of post-socialist Europe. Contrarily to the aforementioned values inherent to diverse economies, however, these accounts do not always 'focus on possibility' (Santos, 2004: 241). Firstly, scholars struggle to relate post-socialist economies to other economic alternatives which are seemingly universal but implicitly located in a Western European context (Jehlička and Daněk, 2017). For instance, Gritzas and Kavoulakos's (2016) review paper suggests the following three categories of diverse economies: diverse economies of post-socialist countries, alternative food networks and alternative exchange networks. Here, the authors present post-socialist informal economies as essentially different and defined by their context, whereas the other two categories are supposedly acontextual and defined by their content. Similarly, in their inventory of alternative market economies in post-socialist countries, Smith and Stenning (2006) focus on the grey and black economy, surprisingly omitting not only new 'West-inspired' alternative enterprises, but even ones with long traditions in CEE, such as cooperatives (Johanisová, 2012). Despite challenging the dominance of capitalism, these authors perpetuate the West-East dichotomy, implying that alternative monetary or food systems are an exclusively Western domain, while the black economy is typical of the former Eastern Bloc.

Secondly, depictions of post-socialist informal economies appear gloomy in comparison with 'hopeful' images of Western alternatives. Researchers use case studies from CEE to 'illustrat[e] the danger of underestimating the role of power relations' (Gritzas and Kavoulakos, 2016: 8) and point out that even non-capitalist economies can reproduce social inequalities, especially those related to age and gender. Through this lens, for instance, Smith and Stenning (2006) view helping with work at ageing parents' gardens as an example of the appropriation of family members' labour. While this might be true in strictly political-economic terms, the very same reality might be theorized as family tradition, intergenerational learning and care (Belk, 2010), or the positive integration of children into domestic work (White and Williams, 2016). ${ }^{45}$ Pavlovskaya (2004: 291) nuances this debate by recognizing the household as

a contradictory space that, on the one hand, can become a site of heightened exploitation (e.g. increased labour inputs into domestic work and demanding cash generating jobs coupled with traditional gender, ethnic, and age hierarchies) and, on the other hand, a site of possibility where ethical economic practices prioritize cooperation, collective well-being, and mutual support.

It appears, though, that research dealing with post-socialist countries focuses disproportionally on the issue of exploitation, while Western diverse economies scholarship emphasizes 'possibility' to an extent bordering on romanticization (Fickey and Hanrahan, 2014). While both the possibilities and drawbacks of diverse economies should be acknowledged, it seems that a hopeful reading is still more difficult to believe in a post-socialist context than in a (post-) capitalist one. Although Gibson-Graham (2014) advise scholars to avoid 'strong theories' that colour their perception of reality, the narrative of the backward 'Second World' seems to be rooted particularly deeply. My application of the diverse economies lens to the practice of FSP in

45 According to Jehlička et al. (2013), only 6 per cent of Czech gardeners mentioned fulfilment of family obligations as their motivation for FSP. 
CEE, which is presented in the next section, seeks to broaden diverse economies scholarship in the post-socialist context while overcoming some of the persisting biases related to the region.

\subsection{Towards a non-capitalocentric reading of FSP: Research goals}

In the preceding sections I linked the lack of knowledge about the productive function of urban gardens to the capitalocentric understanding of the economy. I argued that capitalist societies tend to overlook practices which are related to subsistence, reproduction and the home; which are often performed by women; which are seemingly ordinary and thus taken for granted; and which, perhaps most importantly, take place outside the market. In the case of FSP in CEE, these characteristics are further reinforced by the geopolitical biases discussed in Sections 1.1.4 and 1.2.1-1.2.3.

Furthermore, I introduced the diverse economies framework as an alternative, more 'hopeful' reading of the economy which can contribute to the re-legitimization of FSP as an economic activity. This theoretical lens invites scholars to look at diverse economic practices as inherently coexisting and mutually interacting, while at the same time it suggests that more attention needs to be paid specifically to non-market economies. My research accepts this invitation by focusing on FSP, which I see as an informal economic practice - a way in which people obtain food. ${ }^{46}$ I explore the relationship between FSP and other types of food provisioning, starting from the assumption that diverse food economies interact and mutually influence each other, but that none of them is by default seen as dominant, or as 'the norm'. The diverse economies framework thus allows me to move beyond capitalocentric stereotypes, which either present FSP as a backward 'pre-capitalist' practice which will be replaced by market-based food networks (Section 1.2.2) or, by assuming the reflexivity of urban gardeners, constitute FSP as a reflexive 'anti-capitalist' alternative (Sections 1.1.2 and 1.1.4). Through this 'reading for difference rather than dominance' (Gibson-Graham, 2008: 11), I hope to advance the existing understandings of FSP and other informal food economies in CEE presented in Section 1.2.4, which frame these practices as not driven by economic need, but as relevant for potentially producing a different type of economic relations and contributing to a more sustainable food system.

White and Williams (2016) identify three ways in which diverse economies scholarship counters capitalocentrism. Firstly, it articulates the diversity of economic practices and makes commonly overlooked informal economies visible. Gibson-Graham's metaphor of the economy as an iceberg (Section 2.2) is an example of such action, as is putting FSP in the centre of attention in this research. Secondly, White and Williams argue that it is crucial to demonstrate that non-capitalist practices not only exist but that they are widely used in people's everyday lives. Thirdly, diverse economies scholars should improve the understanding of the nature of non-capitalist economic practices and their functioning.

46 While FSP also fulfils other functions and brings multiple benefits to people's lives (such as self-fulfilment, physical exercise, interaction with nature, social interaction, place- and identity-making), these are not the focus of this research. 
In the case of FSP in CEE, the first two points seem to be adequately addressed by the existing literature: it is established that growing food for one's own consumption is a widespread practice in the region (Section 1.2.2). This practice has been commonly described as part of the economy, while its understandings range from a 'substitute' for the market economy (the coping strategy discourse presented in Section 1.2.2) to recent re-framings as a different form of economy (Section 1.2.4). The aim of this thesis is to advance this scholarship by addressing the third point raised by White and Williams (2016) and exploring how diverse economies related to FSP function and how FSP relates to other food economies. This translates into an exploration of how urban gardens operate as sources of food and how they interact with other food sources. The overarching research question is: How is food self-provisioning involved in the food provisioning practices of urban households?

As I elaborate in Section 3.3, this question is explored on quantitative and qualitative levels, captured by two sub-questions:

Research sub-question 1: How much food do gardeners acquire through food self-provisioning in absolute terms $(\mathrm{kg})$ and in relation to the total food throughput (\%)?

Research sub-question 2: How is the position of food self-provisioning within broader food provisioning practices constituted?

By answering these questions, my research contributes to the literature on urban agriculture as an alternative food provisioning practice. Specifically, it fills the knowledge gap on the contribution of urban gardens to food provisioning in the context of the Global North. Using the diverse economies approach, this thesis enriches AFN scholarship with insights into practices that take place outside the market, while moving beyond capitalocentric stereotypes which present informal economies as either pre- or anti-capitalist. In a broader sense, it therefore advances the reframing and 'taking back' (Gibson-Graham et al., 2013) of the economy as a set of diverse practices centred around human needs. Last but not least, by situating my research in Czechia, a country in CEE, I hope to contribute to the emancipation of this region in terms of knowledge production and to challenge persistent stereotypes about informal (food) economies in CEE. In the next chapter, I present the analytical tools and research methods used to answer my research question. 



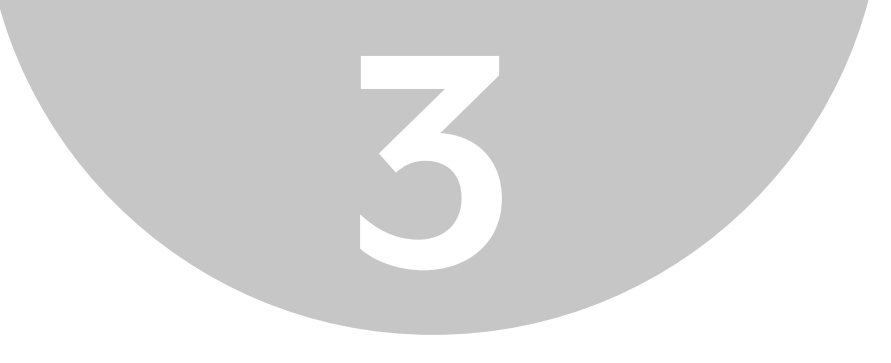

\section{Methodology}

In this chapter I describe the methodological approach of my dissertation. The diverse economies framework, introduced in Section 2.2, provides a starting point for my understanding of FSP as an economic practice. This framework thus serves as an umbrella concept for my research, and it also offers some analytical tools. My operationalization of diverse economies is further refined with the use of other concepts and theoretical anchorings, inspired by social practice theory, social metabolism and generative causation. In the first and second sections of this chapter I elaborate on the theoretical approach which resulted from combining these concepts and which informs my research design and data analysis. In the third section of the chapter, I lay out the research design, present the methods used and introduce the research participants.

\subsection{Operationalizing diverse economies as practices}

To understand how FSP 'works' and how it relates to other ways of food provisioning, I investigate the diverse food economies in which my respondents are involved. These economies are operationalized as bundles of social practices. (Social) practice theory is not a single theory but rather a family of conceptual approaches which share some common features. This thesis adds to the plethora of eclectic variations on practice theory by adapting some of its features and combining them with other conceptual inspirations.

Central to practice theory is a focus on 'actions, processes, relationships, and contexts through which and where the ordinary, real, and everyday world is constituted' (Jones and Murphy, 2010: 308), or, in other words, 'on how social action is carried out, and on the constituting and conditioning of such microprocesses of acting in social life' (Halkier and Jensen, 2011: 103). Put simply, practice theory takes interest in what people do, how they do it and why, in relation to their social context.

This social context constitutes what many authors term the meso-level: 'an interaction between micro-level phenomena (e.g. the personal, situational, performative) and macro-level processes (e.g. related to institutions, social relations, political economy)' (Mylan and Southerton, 2018: 1136). Practice theory thus offers a middle ground between structuralist approaches, which understand human actions as a result of larger cultural structures beyond individual reach, and methodological individualism, which sees humans as independent and rational actors (Jones and Murphy, 2010). It moves beyond the limitations of over-individualized concepts such as homo economicus (see Footnote 22), while at the same time acknowledging personal agency: people both shape and are shaped by their social contexts (Warde, 2005). Despite Mylan and Southerton's 
(2018) use of the word levels, practice theory is based on flat ontology, where social contexts or larger social phenomena are not higher-order entities existing 'out there', but rather extensive alignments of horizontally positioned social practices (Schmid, 2018).

Social actions are understood as practices, that is, routinized patterns of behaviour (Reckwitz, 2002), configurations of recognizable, intelligible and describable elements (Mylan and Southerton, 2018). Scholars have proposed various ways of categorizing these elements. In Reckwitz's (2002: 249) detailed enumeration, practices are constituted by 'forms of bodily activities, forms of mental activities, "things" and their use, a background knowledge in the form of understanding, know-how, states of emotion and motivational knowledge'. Shove et al. (2012) cluster these elements into equipment (material things), images (their meanings) and competences (skills and know-how needed to perform the practice). Other authors build on Warde's (2005) understanding of practice as 'a nexus of practical activity and its representations (doings and sayings) which become coordinated by understandings, procedures and engagements' (Halkier and Jensen, 2011: 104), where understandings, procedures and engagements denote both cognitive and emotional linkages.

While this thesis does not strictly follow any of the variations on practice theory, it uses several of its elements in combination with other conceptual inspirations. Firstly, in their focus on 'what people do', practice theories often result in descriptive, (quasi-)ethnographic accounts of reality. This aligns with Gibson-Graham's (2014) proposition of 'weak theory and thick description'. As mentioned in Section 2.2, diverse economies scholarship should avoid presumptions based on 'strong theories' (such as modernization, development or capitalocentrism) and instead focus on accurately and truthfully understanding existing phenomena. This approach seems relevant for the debates on more sustainable ways of food provisioning, since it avoids the gap between proclaimed attitudes and actual behaviours (Terlau and Hirsch, 2015) - one of the sources of criticism of conscious consumerism and AFNs in general (Section 1.1.3). Research based on practice theory complements actors' 'sayings' by investigating their 'doings', providing a more complete picture of what is actually happening (Veen, 2015).

Secondly, the diverse economies framework and practice theory share an appreciation of the routine, the ordinary and the everyday. For diverse economies scholarship, this domain offers opportunities to explore the invisible, informal economies which sustain life (Section 2.1). Practice theorists see the everyday as a site of negotiations, contestations and accomplishments which facilitate both social reproduction and social change (Halkier and Jensen, 2011; Mylan and Southerton, 2018). Put simply, practices as patterns of behaviour only exist if they keep being performed by individuals ('carriers' of practice), and they evolve by being performed differently (Warde, 2005). Ordinary actions and everyday negotiations of practices competing for practitioners' limited time thus determine, in a collective, cumulative way, which practices (and therefore also which economies) persist in society.

Thirdly and more practically, the notion of practice, along with its constitutive elements, serves to further operationalize the diverse food economies this research explores. Diverse food economies can be seen as an array of food provisioning practices, which include shopping for food, growing food, meal planning, cooking, eating, and sharing food, among many others 
(McIntyre and Rondeau, 2011). Each of these practices can be further deconstructed into its constitutive elements. In sum, diverse food economies can be understood as configurations of, for instance, materials, meanings, and competences. Being able to discern these elements can be useful for understanding how diverse food economies operate, how they interact with each other and why. The next subsections elaborate on how the diverse economies perspective and practice theory are brought together.

\subsubsection{Food economies as practices and materialities}

In practice theory, materiality is one of the elements that constitute a practice. In my research, the material receives particular attention. Following the implications of the term food selfprovisioning, I choose to frame urban gardening as a way of obtaining food (see Section 1.2.2). Despite the multiple meanings, competences and other aspects related to food, it can be argued that food provisioning practices are centred around materiality - the foodstuffs themselves.

My focus on materiality is in line with existing diverse economies scholarship which puts the material at the centre of inquiry. Schmid (2018) and Holmes (2018) use practice theory approaches to emphasize the materiality of diverse economies, the former pointing out that a 'discourse of economic difference should not be divorced from its materialities' (Schmid, 2018: 5). A study of how diverse economies are 'made material' offers an insight into how different ways of provisioning operate while at the same time appreciating how they are facilitated or constrained by the materials they involve (Holmes, 2018).

My understanding of material flows as elements of food provisioning practices and representations of diverse food economies is further inspired by the social metabolism framework, a theoretical and methodological approach which studies the relations between society and nature from a material perspective, through analysis of the flows of energy and material between the two (González de Molina and Toledo, 2014). The emphasis on the biophysical conditions of human practices sets a firm base for debates on different modes of production and consumption, complementing the fuzzy discussions on discourses and motivations common in AFN scholarship (Section 1.1.2), and providing an opportunity to fill the knowledge gaps on the actual contribution of urban gardens to food production (Section 1.1.4).

I was particularly inspired by the work of Burger Chakraborty et al. (2016), who adapt a simplified version of social metabolism to study household flows of food to analyse consumer behaviour. ${ }^{47}$ Similarly, I use the social metabolic notion of the household as a system with inputs and outputs (see Section 3.1.2 for my definition of household). The household is the most appropriate unit for analysing food provisioning because it is the place where food enters (after being produced, bought or otherwise acquired), is processed (cooked, eaten, preserved) and eventually leaves from (in the form of a gift, exchange or other distribution mode, or as waste).

47 Social metabolism is more commonly used in the study of production units and supply chains (see e.g. Fraňková et al., 2018) to account for all material and energy flows, including human labour, sources of fuel, etc. By examining only flows of food, Burger Chakraborty et al. (2016) simplify the complexity of the framework, while they innovatively put consumers at the centre of attention. Some of the limitations of their approach are discussed below. 
Linking the metabolic perspective back to practice theory, I see the material flows of incoming and outgoing food as manifestations of food provisioning practices. Furthermore, these practices facilitate economies which can be categorized, following Gibson-Graham (2006), as capitalist, alternative capitalist and non-capitalist (see Table 2 in Section 2.2). All kinds of food flows (and the food provisioning practices they represent) can thus be placed in one of these three categories, or rather somewhere on the continuum between them. In terms of food inputs, nonmarket economies include practices such as FSP, foraging or receiving food as a gift. Practices linked to 'Western' AFNs as well as 'traditional food networks' (Section 1.2.5), such as buying food directly from a farmer, constitute alternative market economies. Lastly, buying food through conventional channels is categorized as part of the market economy. These economies can also be observed in terms of household outputs, specifically in the practices of selling, bartering or non-reciprocally sharing household produce.

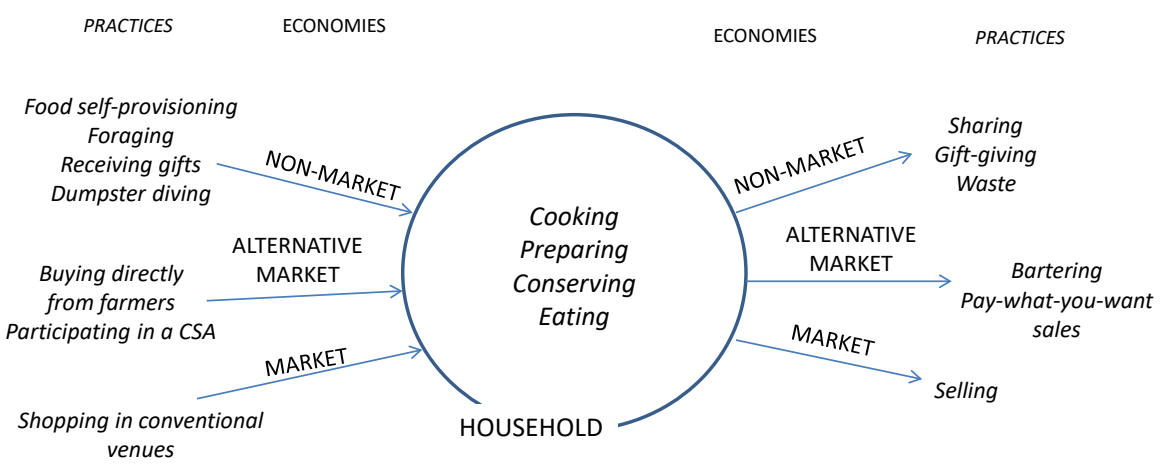

Figure 2: Household food provisioning practices constituting diverse food economies

Figure 2 summarizes my operationalization of diverse economies constituted by food provisioning practices performed by households. ${ }^{48}$ As mentioned above, the three types of economies should not be seen as absolute categories but rather as forming a spectrum between the market and the non-market, or the formal and the informal (I use both sets of terms interchangeably). Furthermore, the boundaries of the household as a system are flexible, as detailed in the next section. Lastly, the examples of practices depicted in the figure are illustrative and do not have clear definitions and borders. ${ }^{49}$

48 This thesis focuses on household practices and therefore ignores practices performed by farmers, retailers and other actors, which also constitute diverse food economies

49 At this point in my research I do not take a stance on whether each type of economy has its own practices, or whether one practice can lead to different types of economies. For instance, it is not clear whether the practice of 'shopping' can lead to different economies depending on where it is executed, or whether 'shopping in a supermarket' and 'shopping at a farmers' market' are two different practices, as presented in the figure. I return to this question in Sections 5.3 and 8.7 (see also Halkier, 2009, for a discussion of a similar issue). 


\subsubsection{The household as a system and a bundle of practices}

Reid et al. (2010) refer to the household as the meso-level, located between the (individual) microlevel and the (city, regional, state) macro-level. It is on the household level where personal values and attitudes meet social norms and institutional demands (Collins, 2015). This pairs well with the 'middle ground' in which practice theorists situate agency and social reproduction (Section 3.1). Consumer studies as well as practice theory agree that the meso-level is an important locus of pro-environmental behaviour (Mylan and Southerton, 2018; Wahlen, 2011).

The literature on reproductive work and informal economies suggests that the household is an appropriate site for studying non-market practices which integrate economic and non-economic dimensions (Mellor, 2006). As explained in Section 2.1, the inner economies of households as well as their potential productive functions are often obscured by the non-market nature of these spaces. The mainstream economic notion of households as sites of consumption is a capitalocentric one. This is evident in the aforementioned study by Burger Chakraborty et al. (2016), which uses household expenditures as proxy for consumption. In doing so, the authors disregard possible informal flows and privilege market economies. In comparison, the concept of eaters used in Wegerif's (2014:3749) research on Tanzania facilitates a more inclusive perspective:

In Dar es Salaam, concepts such as 'consumer' and 'household' run into definitional and practical challenges. Many research subjects live and eat within complex and fast-changing sets of social and familial relations. Further, many are not 'consumers' in the sense that they are eating food they did not buy - they have many other means of acquiring food, and they often lack the sense of choice implied in the concept of a consumer.

The author replaces the problematic concepts of households and consumers with a very functional focus on 'people who eat'. My research - while situated in a different context - also aims to overcome the notion of households as consumers which indeed implies that food is acquired via market mechanisms (see Section 2.1). Instead, the term food provisioning includes diverse ways of dealing with food and allows for more diversity of economic roles. ${ }^{50}$

What is a household though? Defining this unit faces the challenge of incorporating its multiple functions. Intuitively, the household is linked to the house, that is, a physical space, and to family, that is, the people who shape and co-create this space, creating the experience of 'home' (Collins, 2015). The household is thus seen as a physical space, social group or organizational structure, as well as an emotional experience. In other words, the household manifests and constitutes itself on the level of materiality, social organization and meaning, and it can thus be seen as a bundle of social practices of its own. ${ }^{51}$

This multifaceted nature of the household system complicates the application of the social metabolic accounting of inputs and outputs. Burger Chakraborty et al. (2016:2) define households in terms of physical houses and interpersonal relations, as 'groups of people living together and

50 In practice, I will refer to my research participants as 'gardeners', since growing food in a garden was the first selection criterion and thus their shared characterizing feature; see Section 3.2

51 Diverse reproductive practices such as caring, eating, cleaning and many others can be seen as constitutive of the household. 
taking food from a common kitchen'. However, they relied mostly on the spatial definition of the household during their data collection, as they followed the flows of food that enter the physical space of the house. Two limitations of this approach influenced the results of their study. Firstly, it is the assumption that all food that enters the household is consumed by its members, which disregards waste but also donations of food or sharing food with visitors. As the authors admit, in some cases these significantly increased the amount of food acquired by the households. Secondly, their quantitative research did not account for eating out, which also turned out to be significant.

The emphasis on the house as a physical location is also questioned by Smith and Stenning (2006: 202), who point out that household economies often involve family members living in different places as well as multiple locations where people establish socio-economic relations: 'the workplace, the apartment block, the allotment, and the "home" village', and possibly others. Smith and Stenning therefore use the term nested geographies, which captures the household economy as a network connecting different nodes or nests. Similar reflections can be encountered in the literature on urban gardening. Bhatti and Church (2001) note that gardeners often perceive the space of their gardens as part of the home. Mougeot's (2000: 10) definition of urban agriculture emphasizes that it is not physical location but rather integration in the urban ecological and economic system which distinguishes urban agriculture from its rural counterpart. In both cases, gardens are effectively seen as part of nested household systems, regardless of their location.

Following these observations, my research principally understands the household as the main residence of the user(s) of the gardens and the people with whom they live and share food provisioning practices. This definition is customized based on respondents' specific situations and the identification of other 'nests' involved in their household economies, such as gardens located at different places as well as the households of other family members (see Section 3.3.1).

\subsection{Theory building through generative causality}

Practice theories and perhaps ethnographic accounts in general have been criticized for focusing too much on describing the individual and particular, with a limited ability to produce generalizable theories (Jones and Murphy, 2010). These concerns are in part addressed by investigating patterns of practices, instead of the individual performances of their carriers (Mylan and Southerton, 2018). In this way, individual practitioners are not privileged as actors, but they are seen as places where a plurality of practices intersect (Halkier and Jensen, 2011). General patterns of practices are identified through empirical observations and abductive reasoning (Schmid, 2018).

My approach to theory building and translating observations into general explanations is further based on a generativist approach to causality. Pawson (2008) explains the difference between the successionist, configurationist and generativist approaches to causality as follows: The first two establish causality via statistical evidence of correlation between cause and effect (the successionist approach works with individual variables, and the configurationist one 
searches for a combination of factors). The generative understanding of causality dives deeper into how causality is established. It does not stop at identifying factors that influence certain behaviours, but it seeks to explain how the underlying mechanisms generate outcome patterns. In other words, the explanatory power does not lie in the independent variables alone but in the relationships that relate them to the changes in the dependent variables.

Pawson (2008: 15) notes that "[c]ausal powers are therefore understood as "potentials" or "processes" inherent in the system studied'. In human behaviour, these processes manifest themselves as decisions. However, in line with practice theory approaches, the relationship between intention and the result of a human action is far from linear (Bourdieu, 1998). As Pawson (2008: 15) states, 'it is capacitated, constrained, collective, contested choices that constitute the basic mechanisms of social explanation' (emphasis in original). In other words, and returning to the critique of conscious consumerism (Section 1.1.3), I propose that researchers should not assume that social actions are propelled by the straight-forward choices of rational individuals. Instead, they need to understand them as the results of negotiation between various, often competing factors related not only to individuals but also to their social contexts (Belasco, 2008; Mylan and Southerton, 2018).

In this thesis, I explore the processes of negotiating, coordinating and choosing between diverse food provisioning practices - shopping, growing, preserving, donating, cooking and so forth. Apart from viewing gardeners' choices as conscious and premeditated, I am also aware of the unconscious, irrational and external factors which shape these choices. The aim of this thesis is, to rephrase my research question, to understand the position of FSP within people's food provisioning practices and to illuminate how this position comes about. It is in the latter point where generative causality is used.

I will use Kamiyama et al.'s (2016) study on FSP in Japan to illustrate the limitations of a successionist approach to causality and to highlight the added value of the generativist approach. The authors investigated factors which influence FSP and non-market food practices. One of their hypotheses was that rural households acquire greater varieties and quantities of food through non-market transactions than semi-urban households do (p. 186). Their data confirmed this hypothesis, but it provided no explanation of the links between causes (living in the countryside) and effects (acquiring greater varieties and quantities of food from non-market sources). The authors thus resort to what Pawson (2008) describes as the 'hidden generative genie', that is, an assumption which leads to the formulation of a hypothesis but remains unpronounced, or a post-hoc interpretation of the statistical results. In this example, Kamiyama et al. (2016) argue that rural residents consume more home-grown food because their traditional lifestyle is closer to nature. This explanation, however plausible, cannot be directly inferred from the statistical evidence the authors present. The same phenomenon could also be explained in other ways - for instance, rural households could be more active in FSP because they have better access to land than semi-urban households.

According to Pawson (2008), preliminary 'hunches' and follow-up interpretations of data are useful tools for research, as long as they are explicitly stated and, most importantly, tested. Not only does this make the conclusions more solid, but it also allows for generalizations beyond 
the case in question. In sum, research that wishes to produce theory beyond case-based interpretations should not stop at establishing causality, but it needs to unpack its underlying mechanisms, that is, how does a particular cause lead to a given outcome. With that in mind, this thesis applies generative causation as a methodological position: it informs my approach to developing and testing a generalizable theory based on qualitative data. Specific implications of this approach for the research design are detailed in the following section.

\subsection{Study design and methods}

The goal of my research is to scrutinize the role of FSP in the urban context of CEE. It aims to understand how this practice contributes to the food provisioning of urban households and what determines its position among other food provisioning practices. The study population consists of Czech urban dwellers who grow some of their food in a garden, hereinafter referred to as gardeners. ${ }^{52}$

My inquiry takes place on two levels: one that is descriptive, quantitative and focused on the research sample, and one that is explanatory, qualitative and aimed at theory development. These can be seen as sub-questions as well as chronological (yet reiterative) steps:

Research sub-question 1: How much food do gardeners acquire through food self-provisioning in absolute terms (kg) and in relation to the total food throughput (\%)?

Research sub-question 2: How is the position of food self-provisioning within broader food provisioning practices constituted?

Both steps are complementary: in the first one, I focus on the material flows of food which are captured using a model of the household as a social metabolic system with diverse economic sources (see Figure 2 in Section 3.1.1). In the second one, I complement the material elements of food provisioning practices with their social context, investigating meanings related to diverse food practices.

FSP is naturally a seasonal practice (Wahlen, 2011). In order to fully understand the role of gardens as food sources, the research design needs to consider their temporality. Furthermore, the generative causation approach suggests that theory should be developed through multiple iterations between empirical observation and hypothesizing (Pawson, 2008). For both these reasons, the research design features four rounds of data collection spread over a period of one year (one month in each season). Data obtained in four seasons serve to monitor seasonal variations in food provisioning practices. At the same time, repeated interactions with research participants serve the purpose of formulating and testing hypotheses in a gradual and participatory fashion. The chronology of data collection and analysis is depicted in Table 3. In what follows I present the methods used in both the qualitative and quantitative parts of the research, and I elaborate on the iterations between data collection and theory building. 
Table 3: Timeline of data collection and analysis

\begin{tabular}{|c|c|c|}
\hline & Data collection & Data analysis \\
\hline January & & formulation of primary candidate mechanisms $\mathrm{s}^{53}$, \\
\hline 2017 & selection of respondents & construction of interview guide 1 \\
\hline \multirow{2}{*}{ February } & interviews 1 & \\
\hline & food logs 1 ('winter') & \\
\hline \multirow{2}{*}{ March } & & analysis of interviews 1 \\
\hline & & analysis of food logs 1 \\
\hline April & & $\begin{array}{l}\text { refinement and reformulation of candidate mechanisms, } \\
\text { construction of interview guide } 2\end{array}$ \\
\hline \multirow{2}{*}{ May } & interviews 2 & \\
\hline & food logs 2 ('spring') & \\
\hline \multirow{2}{*}{ June } & & analysis of interviews 2 \\
\hline & & analysis of food logs 2 \\
\hline July & & refinement and reformulation of candidate mechanisms \\
\hline \multirow{2}{*}{ August } & interviews 3, where new hypotheses arose & \\
\hline & food logs 3 ('summer') & \\
\hline \multirow{2}{*}{ September } & & analysis of interviews 3 \\
\hline & & analysis of food logs 3 \\
\hline October & & refinement and reformulation of candidate mechanisms \\
\hline \multirow{2}{*}{ November } & interviews 4, where new hypotheses arose & \\
\hline & food logs 4 ('autumn') & \\
\hline \multirow{2}{*}{ December } & & analysis of interviews 4 \\
\hline & & analysis of food logs 4 \\
\hline January & & general analysis of data per respondent, preparing data \\
\hline 2018 & & sheets for respondents \\
\hline February & $\begin{array}{l}\text { final interviews with respondents covering } \\
\text { results throughout the year }\end{array}$ & \\
\hline March & & general analysis of aggregate data \\
\hline April & seminar to discuss general (preliminary) co & onclusions with respondents \\
\hline
\end{tabular}

\subsubsection{Quantitative description}

Research sub-question 1: How much food do gardeners acquire through food self-provisioning in absolute terms (kg) and in relation to the total food throughput (\%)?

This part of the research measures the amount of food related to FSP and other food provisioning practices of gardeners' households. Following the conceptualization of social metabolic systems, I observe both food inputs (acquiring food) and outputs (distributing food). To collect data I used food logs: notebooks in which respondents recorded the foods that entered their households, their sources and usage. The format of the food logs, with examples of observed foods, is shown in Table 4 .

53 See Section 3.3.2. 
Table 4: Food log template with examples of recorded food flows in different seasons

\begin{tabular}{lllll}
\hline Date & Food & Source & Amount & Usage \\
\hline 1 March & potatoes & supermarket & $2 \mathrm{~kg}$ & own consumption \\
\hline 8 June & strawberries & garden & $200 \mathrm{~g}$ & gift for neighbour \\
\hline 20 July & zucchini & gift from sister & $1 \mathrm{~kg}$ & pickled \\
\hline 3 Sept. & apples & bought from a farmer & $20 \mathrm{~kg}$ & stored \\
\hline$\ldots$ & $\ldots$ & $\ldots$ & $\ldots$ & $\ldots$ \\
\hline
\end{tabular}

The method of food logs was developed and tested during my previous research on allotment gardens (Sovová, 2015). This tool serves to obtain very accurate data on households' food provisioning practices, and it is presumably more precise than respondents' recollections, which are commonly used in this type of research. ${ }^{54}$ Its main disadvantage is that it requires persistence and dedication not only from the researcher but particularly from the participants, whose active involvement in data collection is essential. ${ }^{55}$ Furthermore, it inherits two methodological challenges from the social metabolism perspective, namely determining which inputs and outputs should be accounted for and how system boundaries should be defined. Some notes on these issues follow.

Since my primary research interest lies in FSP, food logs are used only for foods that the gardeners (can) produce themselves, namely fruits, vegetables, herbs and potatoes (hereinafter also referred to as observed foods). ${ }^{56}$ To determine the share of the gardens in the total flows of observed foods through the households, the respondents needed to record fruits, vegetables and potatoes from all sources.

In addition, I asked the respondents about other foods they acquire from informal economies. These include eggs, honey, mushrooms, nuts, meat and dairy products. For the sake of feasibility, however, the respondents only recorded these foods from non-market sources. The data thus give an insight into the extent of informal economies used to acquire these foods, but they do not allow for a comparison with market sources.

In terms of defining the system's boundaries, my default conceptualization of the household was each gardener's main residence and the people with whom the gardener lives (following Burger Chakraborty et al., 2016). However, in reality, the situation was sometimes more complex (see Section 3.1.2), and the boundaries of respondent households therefore needed to be ascertained during introductory interviews. One expected issue revolved around the distinction between respondents' own consumption and the informal distribution of food in the case of interconnected households. Some of my respondents organized their food provisioning

54 But see Footnote 17 for exceptions.

55 In this sense, food logs can be seen as an example of citizen science.

56 Some Czech households also produce other foods, as discussed in the next paragraph. However, most research on FSP focuses on fruits, vegetables and potatoes (Smith and Jehlička, 2013; Vávra, Daněk, et al., 2018), as the self-provisioning of other foods is less common and not always possible in all types of gardens (e.g. most allotments do not allow livestock). 
practices in close connection with other households, typically those of family members (e.g. adult children who live alone but still maintain a 'second home' in their parents' household). In such cases, food was shared rather than gifted. Following Belk (2010), I understand food as shared when it is freely available and perceived as common property. In comparison, gifting involves a moment of handing over, when ownership is transferred from the giver to the receiver. In terms of data collection, this implies that the amount of gifted food can be recorded, whereas shared food can become conflated with internal household consumption. This happened in the case of respondent 24: although her household only included two people living together, two other households (those of her children and their families) regularly obtained food from her kitchen by sharing: the respondent perceived this as part of her household consumption. This was important to consider when establishing the food consumption per person. ${ }^{57}$

Another issue which arose unexpectedly during data collection relates to the shared usage of garden plots. Several respondents with second-home gardens were in fact using plots adjacent to the permanent residences of other family members (see Section 3.3.3), who also worked in these gardens to varying extents. It therefore had to be ascertained whether the harvest should be seen as the respondents' own produce, or as a gift they received. Similar to the gifting/sharing logic explained above, I based this decision on how the ownership of the food was perceived: when respondents harvested food as they pleased, I understood it as their own self-provisioning practice. If acquiring food involved a distinct moment of ownership transfer, I categorized it as a gift. Empirical examples of these cases are presented in Section 5.2.3.

In each round of data collection (see Table 3) respondents kept food logs for one month. Food logs thus captured food provisioning practices from mid-February till mid-March (winter), from mid-May till mid-June (spring), from mid-August till mid-September (summer) and from mid-November till mid-December (autumn)..$^{58}$ The resulting picture is thus not complete, ${ }^{59}$ but it gives a fairly accurate idea of food provisioning practices throughout the year. The length of each round - one month - seems sufficient to record regular food provisioning patterns while remaining feasible in terms of respondent engagement.

The purpose of the quantitative level of the research is twofold: firstly, it contributes to the current knowledge on AFNs and urban agriculture, where quantitative data on household food production are scarce. Secondly, and more importantly, it provides a basis for qualitative data collection and analysis.

57 In this case, I estimated the consumption of the children's families as equivalent to two more people. In my quantitative analysis, I thus treated the household as having four inhabitants.

58 The exact start and end dates of the food log rounds were adjusted to fit the respondents' needs. All respondents started collecting data in the same week (e.g. some on the $12^{\text {th }}$, some on the $15^{\text {th }}$ ). If respondents kept food logs for a longer time on their own, I used these data to gain a deeper understanding of their individual practices, but I excluded them from quantitative comparisons, which only included four times four weeks of data per respondent. In the results sections, I refer to the periods of data collection by the name of the season - i.e. I talk about 'winter food provisioning' based on data collected from mid-February till mid-March.

59 As many respondents remarked, foods that have a short harvest season outside the observed period were not accounted for. These data could give an even more precise indication of the importance of gardens in terms of quantity of produce, but they are unlikely to reveal new explanatory mechanisms. 


\section{Data analysis}

The data were entered into an Excel spreadsheet ${ }^{60}$ and categorized to facilitate the analysis. I developed several categories for types of food, ${ }^{61}$ sources of food, ${ }^{62}$ and uses of food..$^{63}$ During data entry, I estimated the weight of the food when needed ${ }^{64}$ and performed other necessary corrections, ${ }^{65}$ which I always marked in the data sheets. After this processing, I first analysed respondents' individual results. I used contingency tables to get an overview of what food they acquired from which sources. I wrote notes about the observed dietary patterns and the ratio of different food sources, focusing specifically on FSP (see Figure 3 for an example). These notes formed the basis for the next interview, during which we also discussed new questions or hypothesis that arose from both quantitative and qualitative data analysis, and clarified any unclear log entries.

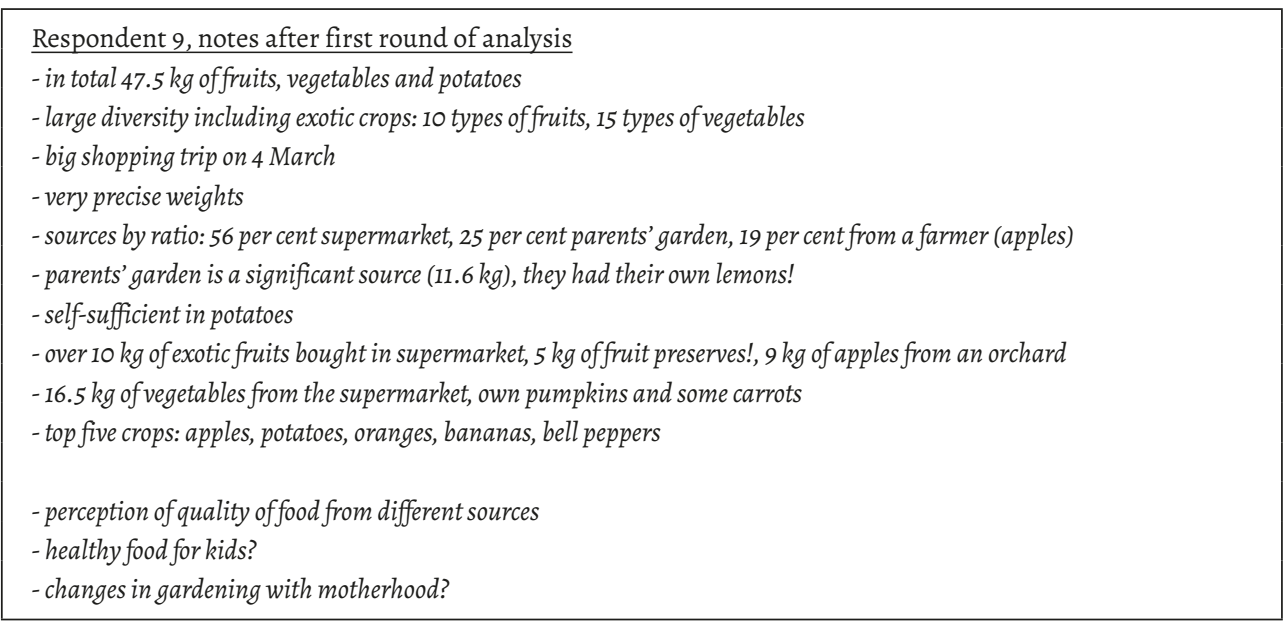

Figure 3: Example of notes from the first round of analysis (winter food log). Apart from quantitative results, the last three lines record ideas for further exploration.

60 Most respondents kept their food logs on paper.

61 The main observed categories were fruits, vegetables, exotic crops and potatoes. Additional categories included herbs, meat, dairy, nuts, mushrooms, eggs, honey and 'other'. Furthermore, foods were categorized as either fresh or preserved.

62 The main categories were supermarkets, food shops, organic food shops, farmers' markets, farmers' shops, direct sales, gifts and exchanges, FSP and foraging. The sources are further introduced in Chapter 5

63 Household consumption, gift, sale, storing and preserving. Some respondents also recorded food used as animal feed.

64 I encouraged respondents to record the foods in units of weight, even if only estimated. However, some logs also included units such as pieces, bunches, jars, etc. During data processing, I corrected these using a list of the average weights of different types of fruits and vegetables that I constructed based on several online sources. When necessary, I consulted the respondents during our next encounter (e.g. what size jars do they refer to).

65 For instance, respondents sometimes recorded multiple types of use for a single entry (' $6 \mathrm{~kg}$ of potatoes - own consumption, storage, gift to neighbour'), in which case I would divide the quantity into separate entries ('2 kg potatoes for own consumption, $2 \mathrm{~kg}$ for storage, 2 kg gift'). 
Furthermore, I created a table that summarizes individual respondents' food log data for each round (see the example in Table 5). This table was also brought to the next interview and used as a basis for the conversation; it was a way of involving respondents in data analysis and somehow reciprocating for the effort they invested in data collection (see further).

Table 5: Summary of a respondent's food log data from the winter round of data collection. The rows show different types offood, and the columns, the amounts from different sources. Numbers are in grams.

\begin{tabular}{|c|c|c|c|c|c|}
\hline Respondent 9, food $\log 1$ & Gift & Direct sales & Supermarket & Garden & Total \\
\hline potatoes & 5000 & & & & 5000 \\
\hline exotic crops & & & 10275 & 200 & 10475 \\
\hline bananas & & & 3525 & & 3525 \\
\hline lemons & & & 500 & 200 & 700 \\
\hline mango & & & 350 & & 350 \\
\hline oranges & & & 3840 & & 3840 \\
\hline tangerines & & & 2060 & & 2060 \\
\hline fruits & 5000 & 8700 & & & 13700 \\
\hline preserved & 5000 & & & & 5000 \\
\hline cherry compote & 1500 & & & & 1500 \\
\hline pear compote & 1500 & & & & 1500 \\
\hline plums, dried & 100 & & & & 100 \\
\hline strawberry compote & 1800 & & & & 1800 \\
\hline strawberry jam & 100 & & & & 100 \\
\hline fresh & & 8700 & & & 8700 \\
\hline apples & & 8700 & & & 8700 \\
\hline vegetables & 1600 & & 16626 & & 18226 \\
\hline preserved & & & 1500 & & 1500 \\
\hline sauerkraut & & & 1500 & & 1500 \\
\hline fresh & 1600 & & 15126 & & 16726 \\
\hline bell peppers & & & 3236 & & 3236 \\
\hline broccoli & & & 1000 & & 1000 \\
\hline carrots & 600 & & 1500 & & 2100 \\
\hline celery & & & 975 & & 975 \\
\hline cucumbers & & & 300 & & 300 \\
\hline garlic & & & 250 & & 250 \\
\hline Hokkaido pumpkins & 1000 & & & & 1000 \\
\hline iceberg lettuce & & & 900 & & 900 \\
\hline leeks & & & 820 & & 820 \\
\hline onions & & & 700 & & 700 \\
\hline parsley root & & & 125 & & 125 \\
\hline radishes & & & 2000 & & 2000 \\
\hline spring onions & & & 570 & & 570 \\
\hline white cabbage & & & 2050 & & 2050 \\
\hline white radishes & & & 700 & & 700 \\
\hline Total & 11600 & 8700 & 26981 & 205 & 47486 \\
\hline
\end{tabular}


From the second round of data collection onwards, my analysis also followed seasonal variations: I observed quantitative changes in respondents' consumption of all fruits, vegetables and potatoes; variations in different kinds of fruits and vegetables; and changes in sources and usage. ${ }^{66}$ At this point I also started analysing the combined data of all respondents. This large data set ${ }^{67}$ was useful particularly for observing seasonal changes (see Chapter 4), as the patterns shared by the respondents became apparent.

\subsubsection{Qualitative explanation and gradual theory building}

Research sub-question 2: How is the position of food self-provisioning within broader food provisioning practices constituted?

The qualitative and explanatory level of my research aims to explore underlying mechanisms that shape gardeners' food provisioning practices. After having illuminated the position of informal food economies within broader food provisioning practices in quantitative terms, I approach my second sub-question with the goal of unravelling how this position comes about. The extent of FSP in Czechia as well as its correlation with other variables has been previously captured by representative surveys (Smith and Jehlička, 2013; Vávra, Daněk, et al., 2018). However, these surveys cannot explain the mechanisms by which correlation is established (see Section 3.2). My research thus aims to complement them with an in-depth inquiry which uses food log data as a base for investigating the nuanced interactions between gardeners' choices, motivations, external influences and so forth.

The generative causation approach (Section 3.2) starts with a thorough observation and description of the studied phenomenon (Blom and Morén, 2011). After the identification of relevant topics, abductive inference is used to theorize on the candidate mechanisms (de facto hypotheses), which are subsequently explored and tested (Pawson, 2008). In my case, I used my previous research (Sovová, 2015), observations, secondary data and literature review as a base for identifying influencing factors. I formulated candidate mechanisms across the three stages of provisioning activities shown in Figure 2 (household inputs or acquiring, internal processing, and outputs or distributing) and the three spheres of materiality, competences and meanings (Section 3.1). These preliminary hypotheses informed the questions for semi-structured introductory interviews during my first encounter with the respondents, although some of them required longer observation to be tested..$^{68}$ Examples of how hypotheses were developed are presented in Figure 4.

66 This made my notes from later rounds of data collection significantly longer than those from the first round.

67 In total, more than 6,000 entries were recorded in the four rounds of food logs.

68 Some hypotheses were in fact already considered during research design: I chose to collect data in four seasonal rounds because I assumed that seasonality is an influencing factor in FSP; I chose to involve respondents with different types of gardens because I suspected that ownership and location might play a role. 


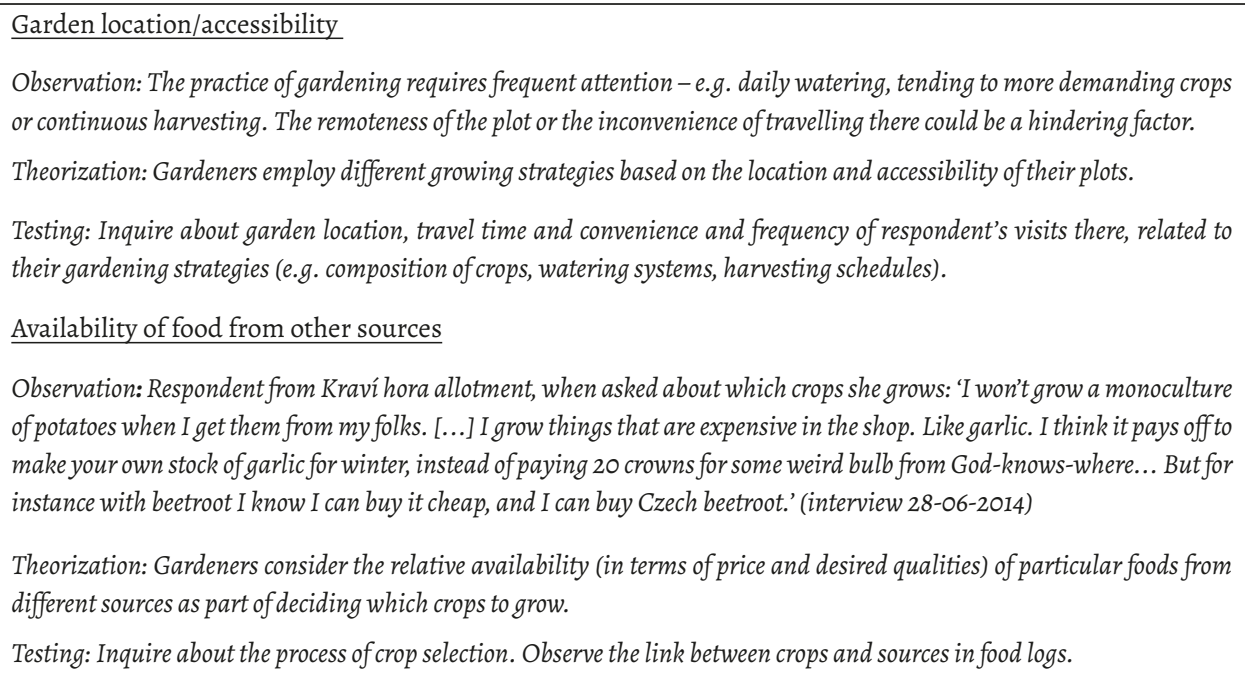
of potatoes when I get them from my folks. [...] I grow things that are expensive in the shop. Like garlic. I think it pays off to make your own stock of garlic for winter, instead of paying 20 crowns for some weird bulb from God-knows-where... But for instance with beetroot I know I can buy it cheap, and I can buy Czech beetroot.' (interview 28-06-2014)

Theorization: Gardeners consider the relative availability (in terms of price and desired qualities) of particular foods from different sources as part of deciding which crops to grow.

Testing: Inquire about the process of crop selection. Observe the link between crops and sources in food logs.

Figure 4: Examples of hypothesis development for introductory interviews. The topics mentioned here are explored in result sections 5.2.4 and 7.2.

\section{Introductory interviews}

Candidate mechanisms served to develop an interview guide for the semi-structured introductory interviews (see the interview guide in the Appendix). I asked respondents about their garden (size, location) and its use (frequency of visits, other users), focusing particularly on FSP (crop selection, growing methods). Questions about their households aimed to establish the boundaries of these systems. I also asked about eating habits (eating at home or out, cooking, general dietary preferences) and storing and preserving food. I further inquired about diverse food sources - how respondents acquire food and how they choose particular food sources.

Several questions focused on gifting and sharing, in which respondents could take on both giving and receiving roles. Lastly, I asked about changes in food provisioning and diets in recent years, and about respondents' wishes for the future (i.e. would they like to change something about their food provisioning). Although I was not directly interested in this temporal dimension, it promised to provide insights into factors that might facilitate or hinder food provisioning practices.

The interviews were transcribed and coded in Atlas.ti. I used a combination of inductive and deductive coding, in which some codes followed from the interview questions, while others were created as new topics emerged during the analysis. The software allowed me to explore code cooccurrences and map out relationships between different topics. This was used in advancing my initial hypotheses and formulating new ones.

\section{Follow-up interviews}

During the second round of interviews (May 2017), I asked additional questions, and I invited respondents to reflect on the quantitative results from the first round of food logs and my preliminary interpretations. This way of verifying my understandings contributed to more 
solid conclusions. At the same time, bringing back processed quantitative data (Table 5) as well as tentative conclusions was a way of symbolically remunerating respondents for their work during data collection and inviting them to participate in the research not only as 'subjects' but also as knowledgeable partners. In sum, discussing preliminary results with respondents served as a theory-building method, while it also constituted an attempt at doing research in a more participatory way. Last but not least, inviting respondents to 'think along' worked as an incentive to maintain their engagement throughout the long period of time that the data collection required.

In total, I conducted four to five interviews with each respondent, depending on their availability and the need for additional questions. In general, the third and fourth rounds of interviews (September and December 2017) were shorter and focused mostly on food log data, as the need to explore new hypotheses became saturated. This also lowered the need for verbatim transcriptions and exhaustive coding; instead, I used notes from recordings in the analysis. The fifth round of interviews held in February 2018 served to discuss preliminary conclusions from all four rounds of data collection, ${ }^{69}$ which sometimes resulted in longer conversations. In total, I conducted 114 interviews with a total length of 55 hours.

During data analysis, I kept track of preliminary results and preliminary understandings. Many candidate mechanisms were dropped as they proved to be analytically uninteresting or tangential to the research goals. Others were explored in several iterations before I reached the conclusions presented in the empirical chapters. Although I analysed data and built hypotheses gradually throughout the data collection period, an extra round of result analysis was required once the four rounds of data collection were completed. I presented the general preliminary conclusions to research participants during a meeting in April 2018. This encounter also served the double purpose of 'giving back' to the respondents while verifying my conclusions.

\subsubsection{Respondent sample}

Despite using quantitative data and aiming for generalizable theories, the presented research is qualitative in nature: its main goal lies in developing an in-depth reliable understanding rather than an extensive overview. This, together with the chosen methods (which are rigorous but also time consuming), justifies a relatively small research sample. Considering the resources available for this study, I established the optimal size of the respondent sample to be $20-30$ respondents, which still allowed for observation of similarities and patterns. Respondent drop-out was expected due to the relatively high demands put on the participants; the initial sample size therefore needed to be closer to 30 respondents. In order to prevent drop-out and to increase the accuracy of the obtained data, participants received financial compensation for the time dedicated to the study. ${ }^{70}$ I recruited 28 respondents at the start of data collection. Two of them stopped participating after the first round, but another respondent joined from the second round of data collection. The final

69 In addition to the tables of food and sources (Table 5), I also prepared figures summarizing respondents' food consumption, sources and usage. Some of these figures are used in the empirical chapters.

70 At the end of the fourth round of data collection, each respondent received 1,000 CZK in compensation (approx. 40 EUR). 
sample thus includes 27 respondent households, presented in Table $6 .{ }^{71}$ To preserve gardeners' anonymity, I refer to them by respondent numbers in the empirical chapters (respondent $1-28$, or r. $1-28$ for short).

The operational population consisted of the inhabitants of $\mathrm{Brno}^{72}$ who are not professional farmers but produce some food for their own consumption. The population of Czechia is generally homogeneous with low internal diversity. In terms of the prevalence of gardening, national surveys reveal slight differences between cities with more than 100,000 inhabitants and rural settlements but little differences between regions (unpublished data). It can therefore be assumed that the results from Brno are comparable to those from other Czech cities of a similar size. Brno also has a high density of gardens, which facilitated fieldwork.

In selecting respondents I aimed for diversity in order to observe a wide range of influencing factors. As the first criterion, I included respondents with different types of gardens, since physical circumstances and garden ownership might influence the practice of FSP. Originally, I aimed for equal (and therefore non-proportional) representation of the three most common kinds of gardens in Czechia (unpublished data): home gardens (a private plot in the vicinity of one's house), allotment gardens (a rented plot in the city, in the vicinity of other plots) and second-home gardens (a private plot outside the city). This proved to be a challenge in respondent recruitment, primarily because many gardeners did not fit into such clear-cut categories. It was not uncommon for respondents to tend multiple gardens, some of which hardly fit the aforementioned garden types. Secondly, it was difficult to find respondents with second-home gardens. This can be explained by the relatively lower incidence of second homes in Brno (this type of garden is slightly more common in other cities; unpublished data), as well as by the practicalities of approaching the respondents: allotment gardeners are organized and generally easy to contact, and home gardens are at least physically visible, whereas there is no way of identifying people with a garden outside the city. Second-home gardens are thus slightly under-represented in the sample (see further).

Apart from setting a garden type quota, I also aimed for diversity of respondents in terms of age, place of residence, socio-economic status and lifestyle in general. Although FSP is a widespread practice, no sampling frame (i.e. a list of all gardeners) is available. I therefore used contacts from my previous research (allotment gardeners) and other personal networks to identify potential respondents. Furthermore, I published an invitation to participate in the study in the local newsletter of a neighbourhood at the edge of Brno with a village-like character where family houses with gardens prevail. As a follow-up to the advertisement, a colleague living in the neighbourhood introduced me to local gardeners..$^{73}$ Lastly, I used snowball sampling and asked respondents to recommend other participants for the study.

71 Respondents are numbered from 1 to 28 ; number 21 is omitted. The data from the two respondents who withdrew from the study were not used in the analysis. Respondent 18 joined from the second round of data collection.

72 The second biggest city in Czechia with a population of 380,000 .

73 The neighbourhood is a former village which was annexed by the city as it spread. Most of the houses are old, with plots of land traditionally used for small-scale agriculture (including livestock breeding). This differentiates the neighbourhood from newly built areas with a more suburban character. In addition, the local community is tightly knit: most inhabitants know each other and their families have lived in the village for generations (this also results in suspiciousness towards outsiders - I was only able to recruit research participants thanks to my gatekeeper's credentials). 
Table 6: Respondent sample.

\begin{tabular}{|c|c|c|c|c|}
\hline $\begin{array}{l}\text { Respondent } \\
\text { no. }\end{array}$ & Garden type & Gender, age ${ }^{74}$ & $\begin{array}{l}\text { Education, } \\
\text { employment status }\end{array}$ & $\begin{array}{l}\text { Household } \\
\text { size }^{75}\end{array}$ \\
\hline 1 & home garden & F, young & tertiary, employed & 2 \\
\hline 2 & home garden and allotment & M, young & tertiary, employed & 1 \\
\hline 3 & home garden & F, middle-aged & secondary, employed & 3 \\
\hline 4 & home garden & F, elderly & unknown, retired & 2 \\
\hline 5 & home garden & M, elderly & unknown, retired & 2 \\
\hline 6 & home garden & F, elderly & primary, retired & 2 \\
\hline 7 & home garden & $\begin{array}{l}\text { F, young in } \\
\text { two-generation } \\
\text { household }\end{array}$ & tertiary, employed & 3 \\
\hline$\underline{8}$ & home garden & F, middle-aged & secondary, employed & 2 \\
\hline 9 & $\begin{array}{l}\text { home garden, city garden }{ }^{76}, \\
\text { second-home garden (shared) }\end{array}$ & F, middle-aged & tertiary, employed & 5 \\
\hline 10 & home garden & F, young & secondary, employed & 2 \\
\hline 11 & second-home garden (shared) & F, young & tertiary, employed / maternity leave & 2 \\
\hline 12 & $\begin{array}{l}\text { second-home garden (shared) } \\
\text { and allotment }\end{array}$ & M, elderly & tertiary, employed & 2 \\
\hline 13 & $\begin{array}{l}\text { second-home garden } \\
\text { and home garden }\end{array}$ & F, young & tertiary, maternity leave & 3 \\
\hline 14 & second-home garden & F, young & secondary, employed & 2 \\
\hline 15 & $\begin{array}{l}\text { second-home garden } \\
\text { and allotment }\end{array}$ & $\mathrm{M}$, middle-aged & tertiary, employed & 2 \\
\hline 16 & second-home garden & M, elderly & $\begin{array}{l}\text { tertiary, retired and employed part- } \\
\text { time }\end{array}$ & 2 \\
\hline 17 & second-home garden & $\mathrm{M}$, middle-aged & tertiary, employed & 4 \\
\hline 18 & second-home garden & F, elderly & tertiary, retired & 2 \\
\hline 19 & allotment & F, middle-aged & tertiary, employed & 1 \\
\hline 20 & allotment & F, elderly & tertiary, self-employed & 2 \\
\hline 22 & allotment & F, elderly & tertiary, retired & 1 \\
\hline 23 & allotment & F, elderly & tertiary, employed & 1 \\
\hline 24 & allotment & F, elderly & primary, retired & 2 \\
\hline 25 & allotment, city garden & F, elderly & unknown, retired & 2 \\
\hline 26 & allotment & F, elderly & unknown, retired & 1 \\
\hline 27 & allotment & F, young & tertiary, maternity leave & 5 \\
\hline 28 & community garden & M, young & tertiary, employed & 1 \\
\hline
\end{tabular}

74 'Young' $>40$ years, 'middle-aged' $=40-60$, 'elderly' $>60$

75 Here understood as people living together.

76 A privately owned plot in the city not belonging to any organization. 
The final sample composition in terms of garden type was as follows: 11 gardens adjacent to respondents' houses in Brno; 14 gardens located somewhere else within the city (of which 11 gardens were in an allotment, 1 was a plot in a community garden and 2 were privately owned plots not belonging to any organization, referred to as 'city gardens' in Table 6); and 9 secondhome gardens located outside Brno ( 3 of these gardens were adjacent to a permanent home of the respondents' relatives). Note that the number of gardens (34) is higher than the number of respondents (27), as some households use multiple plots.

I was aware that my personal networks were likely to lead to young, educated respondents with environmentally conscious lifestyles, and I attempted to avoid this bias. My contacts from allotment gardens and the village-like neighbourhood were particularly useful in recruiting older gardeners with diverse social backgrounds and lifestyles. The resulting respondent sample was nonetheless biased in that most respondents were highly educated. A representative survey revealed that on the national level people with only a primary or secondary education are typically more active gardeners (Vávra, Daněk, et al., 2018). However, the city of Brno has one of the highest proportions of inhabitants with a tertiary education in Czechia (Czech Statistical Office, 2011).

Furthermore, most of the respondents (20) were female. This was caused mainly by the fact that I intended to interview, using McIntyre and Rondeau's (2011) term, primary food providers, that is, people who have control over, or at least a good overview of, food provisioning in their household. ${ }^{77}$ In most cases, women were the most active food providers, confirming the gendered nature of food provisioning as reproductive work (Section 2.1). Nonetheless, a closer investigation revealed that food provisioning and gardening tasks were shared and divided in many different ways, as I discuss in result sections 5.2.3 and 7.1.

Lastly, the sample seems to perpetuate the association of allotment gardening with the older population. According to national surveys, older people are generally slightly more involved in FSP in Czechia (Jehlička et al., 2013; Vávra, Daněk, et al., 2018). In my case, however, this resulted mostly from the use of snowball sampling, in which older respondents from allotments recommended other gardeners from the same age group.

\subsection{Concluding thoughts and reflections}

This chapter has presented the methodological approach of my research. Starting from the theoretical lens of diverse economies, I operationalized the food economies my respondents are involved in as bundles of food provisioning practices such as growing food, shopping, preparing food, sharing food and so forth. Insights from social practice theory and the social metabolism approach are instrumental for grasping diverse food provisioning practices and the economies they constitute. This framework is further accompanied by the generative

77 In this sense, I did not only interview respondents as individuals but also as representatives of their households. My accounts of household practices are thus based on the information provided by one person. Only in two cases ( $r$. 11 and 16) other household members joined some of the interviews. 
approach to causality which explores the mechanisms by which causal relations are established and thus allows for building a theory applicable beyond the studied households.

My theoretical and methodological standpoints shaped the research design. The diverse economies lens led me to regard FSP as an informal economic practice, and the inspiration from social metabolism focused my attention on flows of food. The method of food logs is valuable for documenting the extent of the diverse food practices of respondent households, and it contributes to knowledge on food production in urban gardens. My research, however, aims to go beyond a mere accounting of garden produce. The quantitative data serve as a starting point for exploring the functioning of diverse food provisioning practices. While the research participants diligently recorded all fruits, vegetables and potatoes that they obtained, they never forgot to remind me that for them, gardening was far more than a way of getting food. Indeed, my research consciously focuses on a single aspect of the multifunctional practice of urban gardening, and it should be read as such.

While attempting to bring quantitative data into the debates on FSP, the methodological chapter has also revealed that measuring food flows can be a delicate matter, particularly once one starts reflecting on which foods to measure, where the borders of the household are, and what constitutes 'consumption', 'gifting' or 'sharing'. While the food log data add to current knowledge on urban FSP, and they document the extent of diverse food economies, the numbers presented in the following chapters are not self-explanatory and always remain subject to interpretation. The methodological challenges I ran into during the analysis of the quantitative data often present interesting insights into the nature of the phenomenon. For instance, the difficulty of distinguishing between one's own consumption and sharing with family members points to the interconnectedness of food economies beyond a single household and the taken-for-granted nature of sharing.

The iterative and staggered design of data collection, shaped by the generative approach to causality as well as the seasonality of FSP, was instrumental for interpreting food log data. I benefited greatly from the opportunity to consult my understandings with the research participants, and I would recommend this practice to other researchers. I also chose this approach as a way of at least partly equalizing the inherently hierarchical relationship between myself as a researcher and the gardeners as informants. In the remainder of this chapter I want to reflect on several elements which shaped this relationship.

My position in the field was, in many ways, one of an insider-outsider (Dwyer and Buckle, 2009). Considering the question of geopolitical contexts, I benefited from my insider position as a Czech person who grew up routinely engaged in FSP and other informal food economies. This gave me an intuitive understanding of these practices in the local context. Demonstrating basic knowledge about FSP helped me build rapport with my research participants; it shifted the dynamics of our conversations from 'interviewing', which can be experienced as somewhat formal, to an exchange of insights between aficionados, which felt genuine. 
Moreover, my own practice made me more attuned to the practices of my respondents. During the data collection period, I was involved in FSP in several gardens, ${ }^{78}$ which made me aware of seasonal struggles such as droughts, pests and sudden produce surpluses. Experiencing these dynamics as an insider not only enhanced my practical understanding of what it means to grow food, but it also made me more sensitive to the meanings of the practice and the competences it requires. Although autoethnography was not formally a part of my research, my own involvement in gardening definitely provided me with some hunches and realizations that I later tested in my theory building.

At the same time, I entered the field as an outsider due not only to my academic perspectives on FSP but also to my experience of living abroad. As Fendrychová (2015: 36) aptly remarks, researchers who have moved from CEE to Western countries have the benefit of combining their personal experience from CEE with theoretical debates held largely in the West. As mentioned in this thesis's introduction, I only became theoretically interested in FSP during my internship at RUAF, a global network dedicated to urban agriculture based in the Netherlands. My attempt to fit Czech urban gardeners into the mould of AFNs (Sovová, 2015) was not satisfying, as their motivations and the meanings they attributed to FSP differed from those of the conscious citizen-consumers presented in Western literature. This realization raised bigger questions about reflexivity, alterity and geopolitical biases in knowledge production. Nonetheless, the view 'from the outside' also made me realize that food practices in CEE were worthy of investigation. The appreciation of FSP as a significant phenomenon was also something I introduced to my respondents, who mostly considered their practices to be ordinary and unremarkable, and performed them in a routine fashion without much reflection. My research thus indeed worked to make informal economies visible (Gibson-Graham, 2008) - even to the practitioners.

Throughout the data collection process, respondents became more conscious of their food provisioning practices. Keeping track of their own harvest was particularly exciting for many of them, since they take pride in growing their own food. Conversely, participants were frustrated and sometimes nearly apologetic in seasons when they recorded little or no home-grown food. Although I was worried that the respondents might colour their food log data in favour of more 'desirable' results (i.e. more home-grown food), I believe that the routine character of data collection helped prevent this. I also tried to clarify to respondents that my intention was not to 'evaluate' their practices but simply to understand and document them. In my opinion, the more

78 The different contexts of these gardens gave me great insights into different facets of FSP. One garden was located in the inner courtyard of an apartment building in Brno where each of the tenants, including my flatmates and I, had one big vegetable bed. Food growing here was practised as an ordinary, matter-of-fact activity, which facilitated occasional small talk with neighbours. The second garden, shared by the block of houses where I live in Wageningen, produces more flowers than food, but the shared community effort allowed me to experience gardening as a means of cultural integration first-hand. Thirdly, the Creative community garden in Wageningen gave me insight into the diversity of knowledges (from academic plant science to traditional techniques from different cultures) and interests (from experimenting with growing techniques to building sheds or celebrating food festivities) associated with gardening. Lastly, my parents' second-home garden embodies family roots, and it provides an example of integrating the workweek lifestyle of urban professionals with weekend subsistence farming. 
equal relationship between me and the research participants, as well as the trust we developed throughout the multi-staged and long data collection period, was useful for overcoming these biases. In the following chapters, I will first present the data collected via food logs, which also reveal seasonal patterns in respondents' food provisioning practices (Chapter 4). After that, I will unpack these patterns using insights from interviews and gradual theory building. 


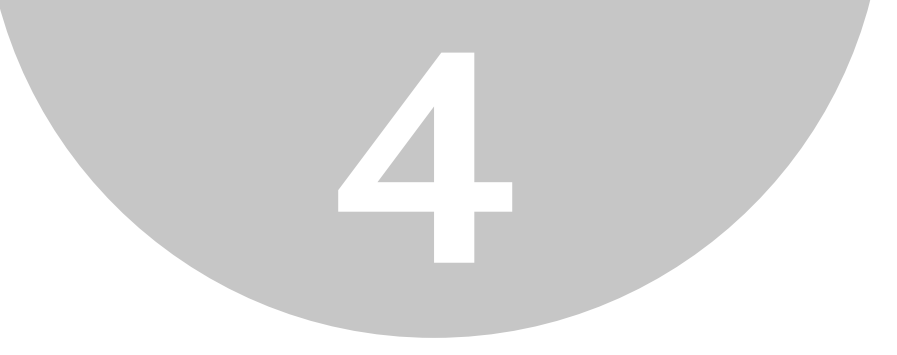

\section{Seasonality: A quantitative overview}

This chapter summarizes findings from food logs, that is, the quantitative layer of the research. Four times a year, 27 gardeners from Brno spent one month recording all fruits, vegetables and potatoes that entered their households, taking note of their sources, amounts and uses (see Section 3.3.1 for details). Summarizing the quantitative data on respondents' diets and food sources answers the first research sub-question. Furthermore, the quantitative, descriptive analysis covered in this chapter forms the basis for the more qualitative, explanatory analysis in the following chapters.

The organization of this chapter according to the four rounds of data collection - representing the four seasons - is the first step in this analysis. The idea that gardeners' diets and food provisioning strategies can change seasonally was one of my starting hypotheses, and it informed the research design. The seasonal patterns laid out in this chapter are instrumental to understanding the general role of gardens as sources of food and the interactions between FSP and other food provisioning strategies.

Each of the sections is structured as follows. I first discuss seasonal changes in respondents' diets, observing the categories of vegetables, fruits of the temperate zone, exotic fruits and potatoes. I look at the amounts consumed, the most prominent crops and the ratio between preserved and fresh foods. I then proceed to discuss sources of food with special attention paid to gardens, where I look at respondents' self-sufficiency. Lastly, I summarize different ways of using foods, such as preserving, gifting and selling. These trends are also summarized in bullet points at the start of each section. The average amounts of the foods that respondents consumed and the sources they used are summarized in the Tables 7-10. After presenting the four seasons, I conclude the chapter with general findings and comparative figures. Throughout the chapter, I use footnotes to explain the methodological choices I made during data analysis, to give exact figures and to refer to chapters which explain the food provisioning patterns presented here. 
Table 7: Average consumption of observed foods per household ( $\mathrm{kg}$ ) by source in the winter round of data collection

\begin{tabular}{|c|c|c|c|c|c|c|c|c|c|c|}
\hline $\begin{array}{l}\text { sources / } \\
\text { foods }\end{array}$ & supermarket & shop & $\begin{array}{r}\text { organic } \\
\text { shop }\end{array}$ & $\begin{array}{c}\text { farmers' } \\
\text { market }\end{array}$ & $\begin{array}{r}\text { farmer's } \\
\text { shop }\end{array}$ & $\begin{array}{r}\text { direct } \\
\text { sales }\end{array}$ & garden & gift & foraging & total \\
\hline potatoes & 1.8 & 0.3 & 0.0 & 0.0 & 0.0 & 3.6 & 0.9 & 0.3 & 0.0 & 6.9 \\
\hline exotic fruits & 5.3 & 0.4 & 0.0 & 0.0 & 0.0 & 0.0 & 0.0 & 0.2 & 0.0 & 5.9 \\
\hline fruits & 2.7 & 0.1 & 0.0 & 0.1 & 0.0 & 2.8 & 1.7 & 0.8 & 0.1 & 8.2 \\
\hline preserved & 0.1 & 0.0 & 0.0 & 0.0 & 0.0 & 0.1 & 0.9 & 0.2 & 0.1 & 1.5 \\
\hline fresh & 2.6 & 0.1 & 0.0 & 0.0 & 0.0 & 2.7 & 0.7 & 0.5 & 0.0 & 6.7 \\
\hline vegetables & 9.7 & 0.5 & 0.0 & 0.0 & 0.1 & 0.4 & 2.0 & 1.1 & 0.1 & 13.9 \\
\hline preserved & 1.4 & 0.1 & 0.0 & 0.0 & 0.0 & 0.0 & 1.1 & 0.8 & 0.1 & 3.5 \\
\hline fresh & 8.3 & 0.4 & 0.0 & 0.0 & 0.1 & 0.4 & 0.9 & 0.3 & 0.0 & 10.4 \\
\hline total & 19.5 & 1.2 & 0.0 & 0.1 & 0.1 & 6.9 & 4.6 & 2.4 & 0.2 & 34.9 \\
\hline
\end{tabular}

Table 8: Average consumption of observed foods per household $(\mathrm{kg})$ by source in the spring round of data collection

\begin{tabular}{|c|c|c|c|c|c|c|c|c|c|c|}
\hline $\begin{array}{l}\text { sources / } \\
\text { foods }\end{array}$ & supermarket & shop & $\begin{array}{r}\text { organic } \\
\text { shop }\end{array}$ & $\begin{array}{c}\text { farmers' } \\
\text { market }\end{array}$ & $\begin{array}{r}\text { farmer's } \\
\text { shop }\end{array}$ & $\begin{array}{r}\text { direct } \\
\text { sales }\end{array}$ & garden & gift & foraging & total \\
\hline potatoes & 1.6 & 0.1 & 0.0 & 0.6 & 0.0 & 1.2 & 0.4 & 0.2 & 0.0 & 4.3 \\
\hline exotic fruits & 2.6 & 0.4 & 0.0 & 0.3 & 0.0 & 0.0 & 0.0 & 0.1 & 0.0 & 3.3 \\
\hline fruits & 3.8 & 0.3 & 0.0 & 0.8 & 0.0 & 0.8 & 3.3 & 1.1 & 0.2 & 10.3 \\
\hline preserved & 0.1 & 0.0 & 0.0 & 0.0 & 0.0 & 0.0 & 0.3 & 0.1 & 0.0 & 0.6 \\
\hline fresh & 3.7 & 0.3 & 0.0 & 0.8 & 0.0 & 0.8 & 3.0 & 1.0 & 0.2 & 9.7 \\
\hline vegetables & 8.0 & 0.8 & 0.0 & 1.0 & 0.0 & 0.4 & 5.4 & 0.9 & 0.0 & 16.6 \\
\hline preserved & 0.6 & 0.0 & 0.0 & 0.0 & 0.0 & 0.0 & 0.4 & 0.4 & 0.0 & 1.3 \\
\hline fresh & 7.5 & 0.8 & 0.0 & 1.0 & 0.0 & 0.4 & 5.0 & 0.5 & 0.0 & 15.3 \\
\hline total & 16.0 & 1.6 & 0.0 & 2.7 & 0.0 & 2.5 & 9.1 & 2.3 & 0.2 & 34.4 \\
\hline
\end{tabular}


Table 9: Average consumption of observed foods per household $(\mathrm{kg})$ by source in the summer round of data collection

\begin{tabular}{|c|c|c|c|c|c|c|c|c|c|c|}
\hline $\begin{array}{l}\text { sources / } \\
\text { foods }\end{array}$ & supermarket & shop & $\begin{array}{r}\text { organic } \\
\text { shop }\end{array}$ & $\begin{array}{c}\text { farmers' } \\
\text { market }\end{array}$ & $\begin{array}{r}\text { farmers' } \\
\text { shop }\end{array}$ & $\begin{array}{r}\text { direct } \\
\text { sales }\end{array}$ & garden & gift & foraging & total \\
\hline potatoes & 1.8 & 0.0 & 0.0 & 0.5 & 0.0 & 1.1 & 2.8 & 0.5 & 0.0 & 6.6 \\
\hline exotic fruits & 2.6 & 0.0 & 0.0 & 0.3 & 0.0 & 0.0 & 0.1 & 0.1 & 0.0 & 3.6 \\
\hline fruits & 3.7 & 0.0 & 0.0 & 1.0 & 0.0 & 0.1 & 6.6 & 1.7 & 0.1 & 12.8 \\
\hline preserved & 0.0 & 0.0 & 0.0 & 0.0 & 0.0 & 0.0 & 0.1 & 0.2 & 0.0 & 0.4 \\
\hline fresh & 3.6 & 0.0 & 0.0 & 1.0 & 0.0 & 0.1 & 6.5 & 1.5 & 0.1 & 12.5 \\
\hline vegetables & 4.6 & 0.4 & 0.0 & 1.3 & 0.1 & 1.0 & 25.0 & 3.0 & 0.0 & 35.4 \\
\hline preserved & 0.2 & 0.0 & 0.0 & 0.0 & 0.0 & 0.0 & 0.1 & 0.5 & 0.0 & 0.7 \\
\hline fresh & 4.4 & 0.4 & 0.0 & 1.3 & 0.1 & 1.0 & 25.0 & 2.5 & 0.0 & 34.7 \\
\hline total & 12.6 & 0.4 & 0.0 & 3.2 & 0.1 & 2.2 & 34.5 & 5.3 & 0.1 & 58.4 \\
\hline
\end{tabular}

Table 10: Average consumption of observed foods per household $(\mathrm{kg})$ by source in the autumn round of data collection

\begin{tabular}{|c|c|c|c|c|c|c|c|c|c|c|}
\hline $\begin{array}{l}\text { sources / } \\
\text { foods }\end{array}$ & supermarket & shop & $\begin{array}{r}\text { organic } \\
\text { shop }\end{array}$ & $\begin{array}{c}\text { farmers' } \\
\text { market }\end{array}$ & $\begin{array}{r}\text { farmers' } \\
\text { shop }\end{array}$ & $\begin{array}{r}\text { direct } \\
\text { sales }\end{array}$ & garden & gift & foraging & total \\
\hline potatoes & 1.8 & 0.1 & 0.0 & 0.0 & 0.0 & 3.5 & 2.0 & 1.8 & 0.0 & 9.3 \\
\hline exotic fruits & 8.1 & 1.0 & 0.0 & 0.0 & 0.0 & 0.0 & 0.0 & 0.6 & 0.0 & 9.8 \\
\hline fruits & 3.2 & 0.0 & 0.0 & 0.4 & 0.2 & 2.6 & 1.5 & 1.5 & 0.0 & 9.5 \\
\hline preserved & 0.4 & 0.0 & 0.0 & 0.0 & 0.0 & 0.1 & 0.7 & 0.3 & 0.0 & 1.5 \\
\hline fresh & 2.8 & 0.0 & 0.0 & 0.4 & 0.2 & 2.4 & 0.9 & 1.2 & 0.0 & 8.0 \\
\hline vegetables & 9.7 & 0.4 & 0.0 & 0.1 & 0.3 & 0.4 & 5.1 & 0.8 & 0.0 & 16.9 \\
\hline preserved & 0.8 & 0.0 & 0.0 & 0.0 & 0.0 & 0.0 & 1.8 & 0.2 & 0.0 & 2.9 \\
\hline fresh & 8.9 & 0.4 & 0.0 & 0.1 & 0.3 & 0.4 & 3.2 & 0.6 & 0.0 & 14.0 \\
\hline total & 22.8 & 1.5 & 0.0 & 0.5 & 0.6 & 6.5 & 8.6 & 4.7 & 0.0 & 45.4 \\
\hline
\end{tabular}




\subsection{Winter (mid-February-mid-March)}

- lowest consumption of fruits and vegetables

- fruit and vegetable preserves

- exotic fruits

- stocks purchased in bulk directly from a farmer

- stocks of home-grown food

In the winter season, respondents had the lowest average consumption of vegetables and fruits of the temperate zone of the four seasons, ${ }^{79}$ as shown in Figure 6 (Section 4.5). The most prominent ${ }^{80}$ fruits by far were apples, followed by the exotic fruits of oranges and bananas. The most prominent vegetables were carrots, onions, cucumbers and cabbage, the last two consumed both fresh and pickled.

In winter, respondents consumed the most preserved (dried, frozen, canned, etc.) fruits and vegetables (see Table 7). All but two respondents reported consuming some preserves in the winter round of data collection. Preserved vegetables were more common than preserved fruits (24 respondents consumed preserved vegetables, and 16, preserved fruits). Preserved vegetables also made up a more significant part of respondents' diets: on average, they covered a quarter of respondents' vegetable consumption. ${ }^{81}$ Fruit preserves accounted for 18 per cent of consumed fruits.

Twenty-two different kinds of vegetables appeared in the form of preserves, the most common being cucumbers, cabbage and tomatoes, followed by various mixes. Fruit preserves included about 19 types of fruits processed in many ways - jams; compotes; juices; and dried, canned and frozen fruits. No particular type of fruit or preservation method was dominant. The majority of fruit preserves were homemade, either by respondents themselves or by gift givers. This suggests that fruit preserves often result from particular recipes and personal tastes. ${ }^{82}$ While these customized ways of preserving can also be observed with vegetables, respondents were more likely to buy vegetable preserves in supermarkets, resulting in less variety.

In terms of food sources, ${ }^{83}$ respondents relied mostly on conventional market venues. Fifty-one per cent of the overall food throughput ${ }^{84}$ originated in supermarkets (see Figure 7 ). The second

79 When talking about respondents' consumption, I refer to the consumption of their entire household, unless specified otherwise.

80 When comparing most common fruits and vegetables, I firstly look at the overall weight of crops consumed by all respondents. Furthermore, I consider the number of respondents who consumed these crops. In spring, for instance, cherries were among the most common fruits in terms of weight, but this was mostly due to a single respondent's large harvest (29 kg out of the total $46 \mathrm{~kg}$ ). Considering this, I do not mention cherries among the most common spring fruits; they are very significant for one respondent but hardly representative of the diet of the whole sample.

81 The portion of winter vegetable consumption consisting of homemade preserves is indicative of respondents' selfsufficiency, as discussed in Chapter 7 .

82 For more on preserves, see Section 7.3.2.

83 The diverse sources used by my respondents are introduced in Chapter 5.

84 'Overall food throughput', presented in Figure 7, refers to all food recorded in the food logs. Apart from respondents' consumption captured in Table 7, it also includes food they gave away, preserved or used in other ways. 
most important source, which seems to be specific for the winter season, was direct purchases from farmers ( 24 per cent of the total throughput). Direct sales were used by 13 respondents. Apart from two respondents who subscribed to vegetable box schemes, ${ }^{85}$ the purchases were collected directly on farms or at related distribution centres and stored at home. ${ }^{86}$ The majority of these purchases (both in terms of aggregate weight and the number of respondents involved) comprised apples and potatoes. Considering the generally lower diversity of fruits and vegetables during the winter season, these bulk purchases often covered a great part of overall household consumption. For instance, the apples that six respondents bought from a local orchard constituted the majority, if not all, of the fresh fruits they consumed in the observed period. This suggests a strong link between choice of food source and dietary preferences. ${ }^{87}$

The level of self-sufficiency (i.e. the share of total food consumed by households from garden produce) in winter was the lowest from all rounds of data collection - 13 per cent on average. Only four respondents enjoyed a fairly high level of self-sufficiency. ${ }^{88}$ Garden production was mostly an important source for preserved fruits and vegetables, as mentioned before. In addition, several respondents still had fresh pumpkins, garlic, apples and potatoes from their own harvest. Comparing these results with those from the autumn round of data collection demonstrates the thinning of stocks throughout the winter. Four respondents reported that they consumed no food from their gardens in the winter round of data collection.

On average, respondents gave away nearly $6 \mathrm{~kg}$ of food in the winter round of data collection, which corresponds to 14 per cent of the total throughput (see Figure 8). Most of this gifted food comprised potatoes and apples purchased in bulk from farmers together with other family members who live in separate households. ${ }^{89}$ Home-grown potatoes and apples were also given away, and homemade preserves featured frequently among gifts. One-fifth of all gifts were purchased in shops, comprising mostly exotic and other fruits.

\subsection{Spring (mid-May-mid-June)}

- 'spring vegetable effect'

- less preserves and more fresh fruits and vegetables

- exotic fruits largely replaced by fruits of the temperate zone

- thinning of stocks - 'potato mystery'

- more food from the garden

- farmers' markets

Spring brought an increase in consumption of vegetables and fruits of the temperate zone (see Figure 6). Two mechanisms can be inferred from the most prevalent types of vegetables. Firstly, the first garden harvests, featuring crops such as lettuce (the most consumed vegetable in this

85 Delivery systems similar to CSA schemes.

86 For more on storing arrangements, see Section 7.3.2.

87 This pattern is explored in Section 6.1.1.

88 They produced 39, 40, 42 and 68 per cent of their own food.

89 See Section 5.2.2 on direct sales. 
round), radishes, green peas and spinach, influenced the composition of respondents' diets. Secondly, respondents bought different vegetables in the shops than they did in winter - for instance, the consumption of (mostly store-bought) tomatoes was more than double in the spring round of data collection. As respondents explained, this 'spring vegetable effect' was driven by the better quality and price of vegetables in shops, combined with the wish to eat more fresh fruits and vegetables in the spring..$^{90}$ In addition, the most common vegetables included staples such as cucumbers, carrots and onions, mostly purchased in supermarkets.

Apples remained the most common fruit, although their main source shifted from direct purchases to supermarkets (see further). The spring round of data collection corresponded with the strawberry harvest: not only did strawberries become the second most common fruit in this round, but nearly half of the total amount of this fruit was home grown. There was a significant decrease in the consumption of exotic fruits compared to the winter round (see Figure 6). For most respondents, though, the overall consumption of fruits did not change much, as exotic fruits were replaced by temperate-zone fruits.

A decline in the consumption of preserved fruits and vegetables was observed in the food logs of 21 respondents. Average consumption decreased from $5 \mathrm{~kg}$ per respondent in the winter round of data collection to below $2 \mathrm{~kg}$ in spring (see Table 8). Although some preserves seem to be consumed regardless the season, the interviews confirmed that respondents mostly associate preserves with winter. While some gardeners explained this change by the fact that they had used up all the preserves they had made, others just preferred to eat fresh fruits and vegetables in the spring, although they still had preserves. Several respondents mentioned intentionally trying to use up preserves from the previous year in order to make space (e.g. in the freezer) for new ones (see Section 7.3.2). Preserves were mostly replaced with fresh foods in terms of amounts, and in some cases, the same kinds of fresh foods were consumed instead of the preserves.

The fewest potatoes were consumed in spring (see Figure 6). This 'potato mystery' can be explained through the mechanism of winter stocks. As mentioned, the most important source for potatoes in winter was bulk purchases from farms. Come spring, these stocks - or in other cases, stocks of home-grown potatoes - run dry or at least get thinner, and the quality of stored potatoes also decreases. In turn, most spring potatoes were purchased in supermarkets, but at the same time the consumption decreased. ${ }^{91}$ The same pattern can be observed for apples. ${ }^{92}$

This 'thinning of stocks' can be observed in the mix of food sources (see Figure 7). The total amount of food purchased directly from farmers by all respondents decreased from $252 \mathrm{~kg}$ in winter to $72 \mathrm{~kg}$ in spring. Similarly to the winter round, most direct purchases comprised potatoes and apples. In addition, strawberries from self-harvest farms appeared in the spring. Farmers' markets ${ }^{93}$ emerged as a new food source in the spring, used by 15 respondents. For most

90 These seasonal patterns are further explored in Sections 6.1.1 and 6.2.3.

91 The link between seasonality, food sources and diets is further unpacked in Chapter 6.

92 Several respondents mentioned that they deliberately lowered their consumption of apples and potatoes because they preferred to wait for the new harvest. However, other respondents had different reasons for changing their dietary patterns - e.g. they associated potatoes more with heavy winter dishes, or they replaced apples with other types of fruits that were in season. 
of them, markets constituted a less significant source of food..$^{94}$

Supermarkets and grocery stores were used less in the spring round of data collection than in winter, both in terms of the amount of food purchased and in terms of share of the total throughput. Nonetheless, they were still the most important source for most respondents, and they accounted for 40 per cent of all food recorded in food logs. Eight respondents purchased more food in the spring round than in the winter, which they explained by the 'spring vegetable effect' mentioned above.

The food logs confirmed the common sense expectation that gardeners would have more homegrown food in the spring. This was the case for all but four respondents. ${ }^{95}$ The level of self-sufficiency rose from 10 to 27 per cent on average. The most productive garden (r. 6), nonetheless, yielded nearly $52 \mathrm{~kg}$ of food, ${ }^{96}$ and the most self-sufficient household (r. 4) covered 72 per cent of its consumption of the observed foods with its own resources. The most prominent home-grown crops were lettuce, strawberries and green peas.

As shown in Figure 8, the average household consumption did not change significantly between the winter and spring rounds of data collection. Similarly, the amount of food respondents gave away remained on a comparable level: on average $5.7 \mathrm{~kg}$ in winter and $6.3 \mathrm{~kg}$ in spring. Spring gifts were clearly shaped by the first garden harvest; the majority were home-grown seasonal crops that were also prevalent in respondents' own diets: strawberries, lettuce, cherries and green peas. At the same time, strawberries and lettuce were also the foods respondents most commonly received from other people. ${ }^{97} \mathrm{~A}$ new use of food that appears in the spring round of data collection is preserving. ${ }^{98}$ Ten respondents preserved a total of $30 \mathrm{~kg}$ of food, mostly strawberries, spinach, rhubarb, elder blossom and various herbs. Other uses of food, such as sales and exchanges, remained marginal.

\subsection{Summer (mid-August-mid-September)}

- garden vegetables

- high production, high self-sufficiency, high consumption

- lower diversity of crops

- preserving, gifting and sharing

- poor fruit harvest

In the summer round of data collection, respondents' food provisioning strategies and diets were strongly shaped by the harvest from their gardens, despite the fact that some crops were

94 Although six respondents covered over 20 per cent of their consumption there; see Section 5.2.2.

95 These four respondents had a significant amount of stocks from their own production in the winter round of data collection and/or their spring harvest was low because the crops they produce were not in season yet.

96 The majority of which were cherries, as mentioned earlier.

97 Although the same crops appear among the most commonly received gifts and the most commonly shared foods, receiving and giving usually did not concern the same respondents. For example, in spring people who gave away lettuce and strawberries from their own harvest did not receive these crops from others. Instead, gardeners typically received crops that they did not have from their own harvest or that they only had in small amounts.

98 This includes all forms of conservation: freezing, drying, canning, pickling and making jams, liquors and other products. 
harvested entirely outside this data collection period. ${ }^{99}$ On average, over $73 \mathrm{~kg}$ of produce was harvested per garden during the summer round of data collection, with the most productive garden yielding $254 \mathrm{~kg}$ of produce during the month. The average household consumption increased, as shown in Figure 8.

Summer food logs reveal a remarkable increase in vegetable consumption, and the data link this increase to the respondents' harvests (see Table 9). Gardens were by far the most important source of vegetables in the summer. The most common vegetable was the tomato, which was grown by all respondents. From the total $357 \mathrm{~kg}$ of tomatoes consumed in the summer, $332 \mathrm{~kg}$ came from respondents' gardens and another $13 \mathrm{~kg}$ were obtained as gifts, making market sources completely marginal. ${ }^{100}$ The same pattern can be observed for cucumbers, pumpkins and zucchinis - crops strongly linked to gardens. ${ }^{101}$ All these vegetables were also given away and preserved. Onions, which were also among the most common vegetables, were mostly purchased in supermarkets. Respondents consumed more onions in the summer than in other seasons, which they explained by a change of diet (mixed salads, lecsón ${ }^{102}$ and other dishes that use abundant tomatoes, cucumbers and zucchinis and also require onions), while they also agreed that onions are not easy to grow (see Section 6.1.1).

The summer diet of most respondents was strongly influenced by the garden harvest. Interestingly, this also resulted in lower diversity, especially in the consumption of vegetables. In summer many respondents consumed fewer types of vegetables than in other seasons, while some types became dominant. The vegetable consumption of respondent 23 shown in Figure 5 exemplifies this pattern. Home-grown tomatoes, produced by all respondents and praised by many, were dominant in the diets of most. ${ }^{103}$ This is a result of the tight link between harvests and diets in the summer and the specific nature of the garden as a source of food (explored further in Section 6.1). At any given moment in time, gardens tend to yield an abundance of several crops, and gardeners feel compelled to consume these. In contrast, in commercial venues the offer is consistently diverse and not so strictly dictated by the seasonality of the harvest. In seasons when respondents rely more on commercial sources of food, their diets are hence more diverse and balanced.

Regarding fruits, it should be noted that the year in which data were collected was bad for fruit trees. Many respondents complained that their harvest was destroyed by spring frosts and droughts, as was also discussed in the media in relation to commercial food production. The exceptionally poor fruit harvest is confirmed by the food logs: whereas in the winter round of data collection some respondents still had fruit stocks or preserves from the previous year (2016), the 2017 harvest was small and rarely lasted till autumn. The consumption of fruits also peaked in the summer, but the difference from other seasons was more subtle than with vegetables.

99 According to respondents' verbal accounts, the most abundant crops that were harvested outside the data collection period included apricots and currants (both harvested in late June and July).

100 In total, $635 \mathrm{~kg}$ of tomatoes were produced in respondents' gardens during the summer round of data collection. More than one-half of this harvest was preserved or given away as gifts.

101 See Figure 12 in Section 5.2.4.

102 An originally Hungarian dish consisting of bell peppers and tomatoes.

103 For several respondents, the same happened with cucumbers. Only a minority of respondents had a more balanced diet comparable to other seasons. 
Respondents' gardens were the most significant source of fruits. Arguably, though, the fruit harvest and therefore also the degree of self-sufficiency and consumption could be even higher in more favourable years.
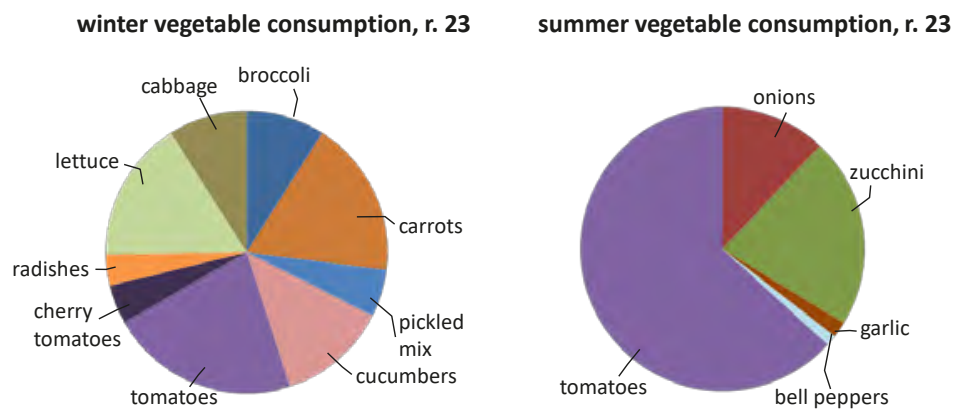

Figure 5: Seasonal variation in diversity of vegetable consumption (r. 23)

Apples remained the most common fruit, originating mostly from respondents' own gardens. Grapes and peaches were other prevalent fruits, also originating mostly from gardens. ${ }^{104}$ Melons ranked fourth in terms of total weight, although they were only consumed by nine respondents. ${ }^{105}$ In summer the consumption of exotic fruits stayed low overall, and the consumption of preserves was the lowest of all seasons.

The consumption of potatoes increased again after the spring drop (see Figure 6). Ten respondents had their own potatoes, and gardens were also the most prominent source of this crop in the summer.

The mix of food sources, shown in Figure 7, confirms the importance of gardens: 69 per cent of all foods recorded in the food logs originated from them. Another 11 per cent of foods were received as gifts. Four respondents reported foraging for mushrooms and fruits. ${ }^{106}$ Commercial venues became far less significant in terms of total throughput, ${ }^{107}$ but they were still used to supplement food for respondents' own consumption. The difference is caused by the aforementioned limited diversity of crops from the gardens: while respondents had more than they were able to consume of some crops, they still decided to buy others. Specifically, commercial venues were mostly used to supply exotic and other fruits (which was probably also influenced by the poor fruit harvest), potatoes and staple vegetables gardeners did not grow - onions, bell peppers and carrots.

\footnotetext{
104 In the case of peaches, only five respondents grew their own, although this still outweighed other sources in terms of total volume. Most respondents (12 out of 18 who consumed peaches in summer) bought them in the supermarket.

105 Three of them produced melons in their own gardens. In these cases, melons were categorized as fruits of the temperate zone instead of exotic fruits.

106 This amount was certainly higher, as several other respondents mentioned mushroom picking during interviews. They failed to record this food in their logs even though they were instructed to do so - possibly because both the type of food (mushrooms) and the source (foraging) are quite distinctive, and respondents did not associate them with provisioning fruits and vegetables, which was the main focus of the research.

107 Thirteen per cent of food came from supermarkets, 4 per cent from farmers' markets and 2 per cent from direct sales
} 
The summer round of data collection recorded not only the highest consumption of the observed foods, but also the highest volume of gifts, preserves and storing. A look at the total throughput of food (Figure 8) reveals that only 55 per cent was consumed by respondents. Twenty-five per cent of all food was stored or preserved, and 20 per cent was given away as gifts.

Nineteen respondents gave some food away in the summer round of data collection. ${ }^{108}$ On average, each of them distributed nearly $30 \mathrm{~kg}$ of food, although this figure is skewed by several respondents who gave away great amounts (in one case, over $100 \mathrm{~kg}$ ). ${ }^{109}$ As in the spring round, most gifts comprised home-grown foods: tomatoes, cucumbers and zucchinis. Twenty-three respondents received food gifts, ${ }^{110}$ some of them in fairly significant amounts. Cucumbers, apples and potatoes were the crops that respondents most commonly received as gifts.

Twenty respondents preserved some fruits or vegetables: over $26 \mathrm{~kg}$ of them on average, although this number hides a wide spectrum again, from less than $2 \mathrm{~kg}$ to over $100 \mathrm{~kg}$. The most common crops to preserve were tomatoes and cucumbers. Most preserved fruits and vegetables originated from non-market sources: the majority (76 per cent) were from respondents' gardens, and 15 per cent were gifts. Some were also purchased, mostly onions and bell peppers. Nine respondents reported storing ${ }^{111}$ durable crops such as potatoes and garlic $-24 \mathrm{~kg}$ of them on average. These stocks were entirely from non-market sources; only in one case was garlic purchased directly from a farmer. Other uses of food such as sales and exchanges remained marginal.

\subsection{Autumn (mid-November-mid-December)}

- stored crops, preserves and the last harvest from gardens

- potatoes

- exotic fruits for St. Nicholas Day

- direct purchases from farmers

Autumn is the season in which respondents consumed the most potatoes (see Figure 6). This is explained through the same mechanisms as the decrease of potato consumption in spring - their sources and seasonal harvesting. In autumn, potatoes, whether purchased from farmers (in the case of eight respondents), grown in gardens (eight respondents) or obtained as gifts (four respondents) are fresh and abundant, leading to increased consumption. This mechanism does not apply to respondents who provision their potatoes in shops (see Section 6.1.1).

Autumn is also marked by the highest consumption of exotic fruits. Tangerines, bananas and oranges are the most common. As several respondents confirmed, their increased consumption can be explained by the tradition of giving and eating these fruits on St. Nicholas Day (5 December) and during Advent.

108 Compared to 21 in spring, 12 in winter and 16 in autumn.

109 See Figure 11 in Section 5.2.3 for an overview of gifts and sharing.

110 Compared to 17 in winter and 19 in both spring and autumn.

111 Storing refers to keeping crops for later use in their original fresh state, although sometimes in specific ways (e.g. in sand) or places (e.g. in a cellar). 
The most prevalent fruits in total, though, remained apples. Only a negligible amount originated from respondents' gardens due to the poor harvest, and many respondents remarked that this situation was unusual for them. The most significant source of apples (in terms of volume) was direct sales, used by eight respondents. Twelve people bought their apples in supermarkets, and seven received them as gifts. The consumption of preserved fruits increased, returning to the winter pattern (see Table 10). ${ }^{112}$ Some preserved fruits were consumed by 17 respondents, and most of them came from their own harvest. Apricots, currants and plums were the most consumed preserved fruits.

Autumn vegetable consumption also resembles winter dietary patterns, with the most common crops being onions, carrots, cabbage (fresh and preserved) and pumpkins. Whereas the first three vegetables were mostly purchased in supermarkets, home-grown pumpkins were vestiges of the summer harvest - they originate mostly from gardens or gifts, sources which become less important in winter. The use of preserves follows the same logic described for fruits. ${ }^{113}$ Vegetable preserves were consumed by 22 respondents in autumn. Pickled cabbage and cucumbers were the most common types. Most preserves were homemade in autumn, whereas in winter, slightly more preserves are purchased in supermarkets, also due to the thinning of stocks.

The composition of respondents' food sources in autumn reflects the end of the harvest season. Market sources become the most important again, accounting for 44 per cent of the total throughput. Compared to the winter round of data collection, though, home-grown foods are more significant (22 per cent). These include a large variety of preserves as mentioned, but also potatoes, apples, pears and a significant variety of fresh vegetables: pumpkins and beets as well as tomatoes that many gardeners left to ripen after the harvest. Some frost-resistant vegetables were still being harvested, such as leeks and chard.

Autumn also marks the return of direct sales, which were less significant in spring and summer (see Figure 7). Fourteen respondents reported buying food directly from farmers. ${ }^{114}$ As in the winter period, they mostly bought potatoes and apples, and part of these purchases was shared with other households.

The gifts that respondents received and gave away were largely the vestiges of the summer harvest; they most commonly included potatoes, apples and pumpkins, although (store-bought) exotic fruits were also quite common due to the holidays. Sixteen respondents gave food gifts of nearly 8 $\mathrm{kg}$ on average, which amounted to 14 per cent of the total autumn throughput (see Figure 8).

Even this late in the season, some respondents still preserved and stored fruits and vegetables. One respondent dried apples that she received from her parents' garden; another pickled cabbage bought from a farmer. Two gardeners stored the last of their harvest: pumpkins and Jerusalem artichokes. One of the respondents sold $9.5 \mathrm{~kg}$ of produce from his garden (pumpkins and garlic)

\footnotetext{
112 The share of preserves in the total consumption of fruit was 18 per cent in winter, 16 per cent in autumn, 5 per cent in spring and 3 per cent in summer.

113 In autumn, 17 per cent of vegetable consumption is covered by preserves, and this number rises to 25 per cent in winter, whereas in spring and summer it is negligible ( 8 and 2 per cent, respectively).

114 Direct sales covered 17 per cent of the total throughput.
} 
in autumn. This was the only case when sales were a significant use of produce; however, they still made up an insignificant part of the total throughput.

\subsection{Summary of seasonal patterns}

This chapter presented food log data, which indicate seasonal variations in respondents' food provisioning practices. Changes can be observed in respondents' diets (Figure 6) as well as in the sources they used to acquire food (Figure 7). Changes in usage (e.g. gifting, preserving) mostly follow similar patterns (Figure 8). Apart from these quantitative differences, the following paragraphs succinctly characterize each of the data collection periods.

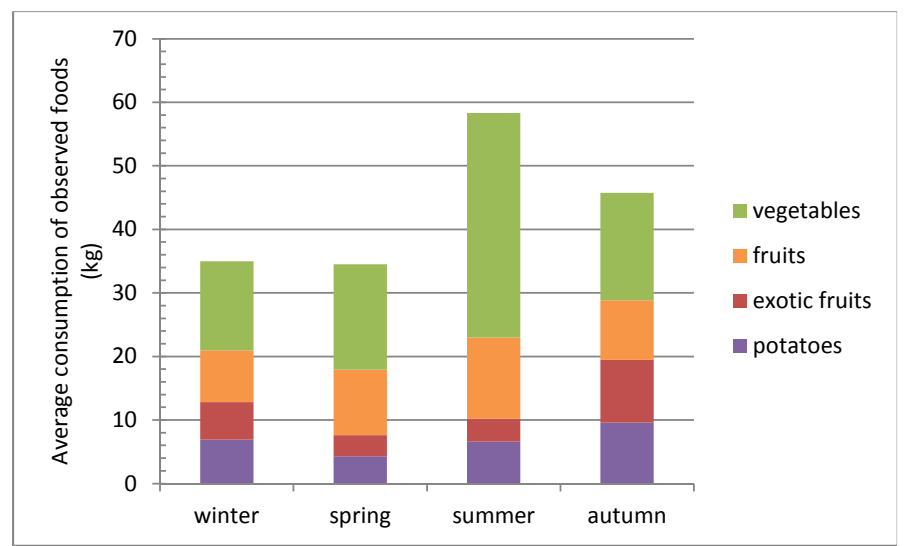

Figure 6: Seasonal changes in diets: average consumption per household $(\mathrm{kg})$ during the four rounds of data collection

Characteristic of my respondents' winter diets were low consumption of vegetables and fruits of temperate zone (the lowest of all seasons) and high consumption of preserves and exotic fruits. The most prominent sources were supermarkets, followed by bulk purchases from farmers. Some respondents still had stocks of home-grown food or homemade preserves from the previous year.

In spring, respondents' diets changed not only due to the first garden harvests, but also due to different shopping habits, explained by the higher quality and availability of spring vegetables in shops and the need to eat more fresh produce. Preserves were replaced by fresh foods, and respondents consumed fruits of the temperate zone instead of exotic fruits. Stocks from bulk purchases or the previous year's harvest were used up, which also resulted in lower consumption of potatoes and apples. Apart from gardens, farmers' markets appeared as a new source of food, while direct (on-farm) sales decreased.

The garden harvest shaped respondents' diets and food provisioning strategies in summer. The consumption of fruits and vegetables was the highest, as was respondents' self-sufficiency. In this season their diets were based on the garden harvest, resulting in less diversity of crops consumed. High yields also led to an increase in preserving and gifting. 
In autumn, potatoes, exotic fruits and preserves became more prominent again, while the consumption of fruits and vegetables decreased after the summer peak. Non-market sources, such as FSP but also gifts, remained relatively important, although commercial venues were the most prominent food source. Direct sales reappeared.

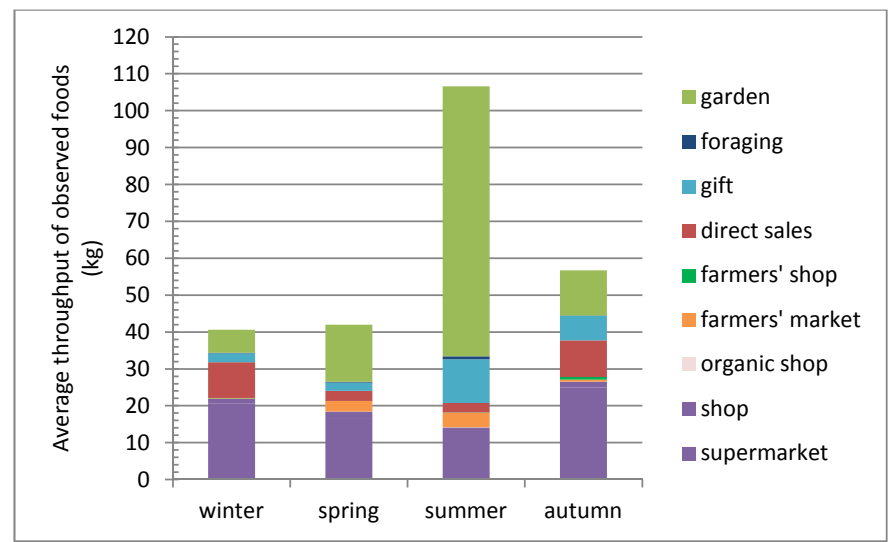

Figure 7: Seasonal changes in sources: total throughput average per household $(\mathrm{kg})$ in the four months of data collection.

Several general conclusions can be drawn from the seasonality of respondents' food provisioning practices observed over the course of one year. Firstly, respondents' diets and food sources are linked in various ways. Foods can be linked to specific sources, making respondents' diets susceptible to changes resulting from seasonal availability (as observed in the case of 'the potato mystery'). At the same time, dietary preferences are subject to seasonal changes which are not directly linked to the availability of foods (as observed in the case of 'the spring vegetable effect' or in the consumption of exotic fruits related to the celebration of St. Nicholas Day). These relationships are further explored and theorized in Chapters 5 and 6.

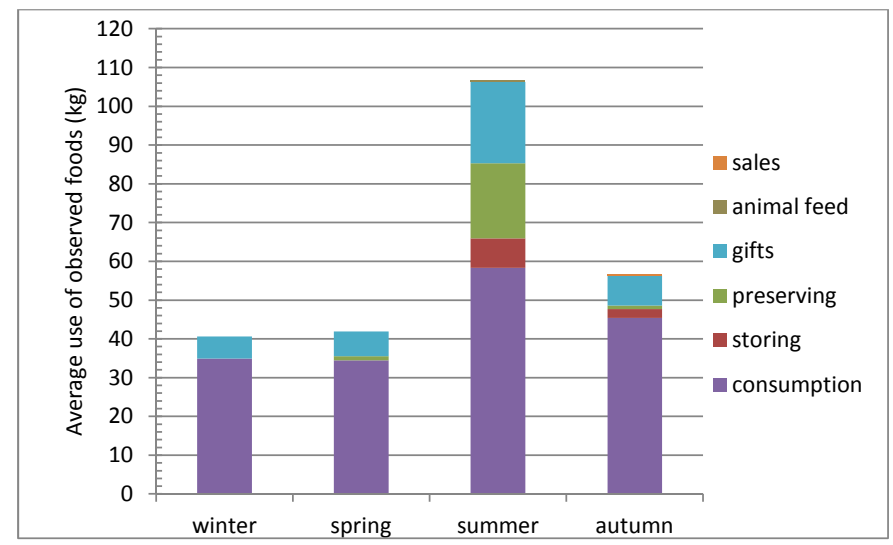

Figure 8: Use of food: average per household $(\mathrm{kg})$ during the four months of data collection 
Secondly, the food logs revealed that respondents participate in vibrant food sharing networks (see the gifts that gardeners received in Figure 7 and the food that they gave away in Figure 8). On average, respondents gave away more food than they received. This generosity can be linked to the meanings and values attached to FSP, which are discussed in Sections 5.2.3 and 5.2.4.

Thirdly, in relation to the role of FSP in broader food provisioning strategies, the food logs suggest that gardens can function as both seasonal and stable sources of food. Stocks and preserves are crucial in extending the use of garden produce beyond the summer. Preserving food is thus an important food provisioning strategy. Another particularity of FSP is that while gardens generally increase the diversity of foods that gardeners consume, ${ }^{115}$ they can lead to a more monotonous diet when abundant crops are harvested. Chapter 7 will further elaborate on the workings of gardens as a food source.

115 According to the food logs, gardeners produced over 100 different crops. This number would be even higher if different varieties were considered. Some of the crops grown in gardens, such as groundcherries, caigua or chokeberry, are not commonly available from commercial venues. Respondents also used wild plants growing in their gardens, such as orache and watercress. Even with more common crops, gardeners consumed less typical parts of the plants, e.g. garlic scopes. 


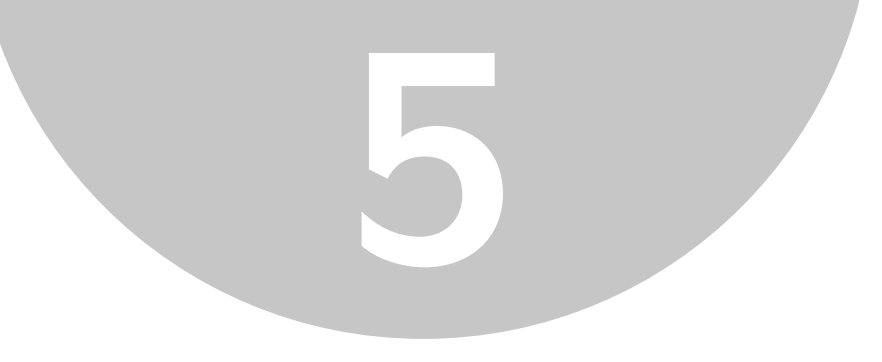

\section{Diverse food sources}

This chapter examines respondents' food acquisition practices - which sources of food they use, how and why. It aims to unravel the mechanisms which shape the role of the garden as a source of food in comparison to, and in interaction with, other sources of food. I start the chapter by presenting food log data to illustrate the diversity of food sources used by respondents. In doing so, I make the diverse food economies encountered in my research sample visible (GibsonGraham, 2008; Section 2.2).

Following Gibson-Graham (2008) and my own operationalization of diverse food economies (Section 3.1), I categorize the main sources identified in my respondent sample as constitutive of market, alternative market or non-market economies. To understand how diverse food economies operate (White and Williams, 2016; Section 2.3), I investigate food provisioning practices linked to these food sources.

In the second section of this chapter I build on Veen et al.'s (2014) use of practice theory to investigate the extent to which diverse sources entail diverse food provisioning practices (see Section 3.1). Belasco's (2008) triangle of consumer choice (Section 1.1.3) is used as an additional conceptual tool to compare diverse food provisioning practices: I explore how the three dimensions of convenience, identity and responsibility are performed and given meaning in relation to different types of food sources, and how they shape respondents' food provisioning strategies.

\subsection{An overview of diverse food economies}

The aggregate food log data reveal the variety of food sources that respondents used to acquire fruits, vegetables and potatoes during the four rounds of data collection. Figure 9 provides an overview of the sources of food consumed by respondents. ${ }^{116}$ The categories were developed during data processing and are explained in the subsections of this chapter.

116 Excluding food that respondents preserved and stored for future use and food they shared with other people. Respondents also recorded eggs, honey, mushrooms, meat, dairy and nuts which they obtained from non-market sources (see Section 3.3.1). These foods are also excluded from this figure. 


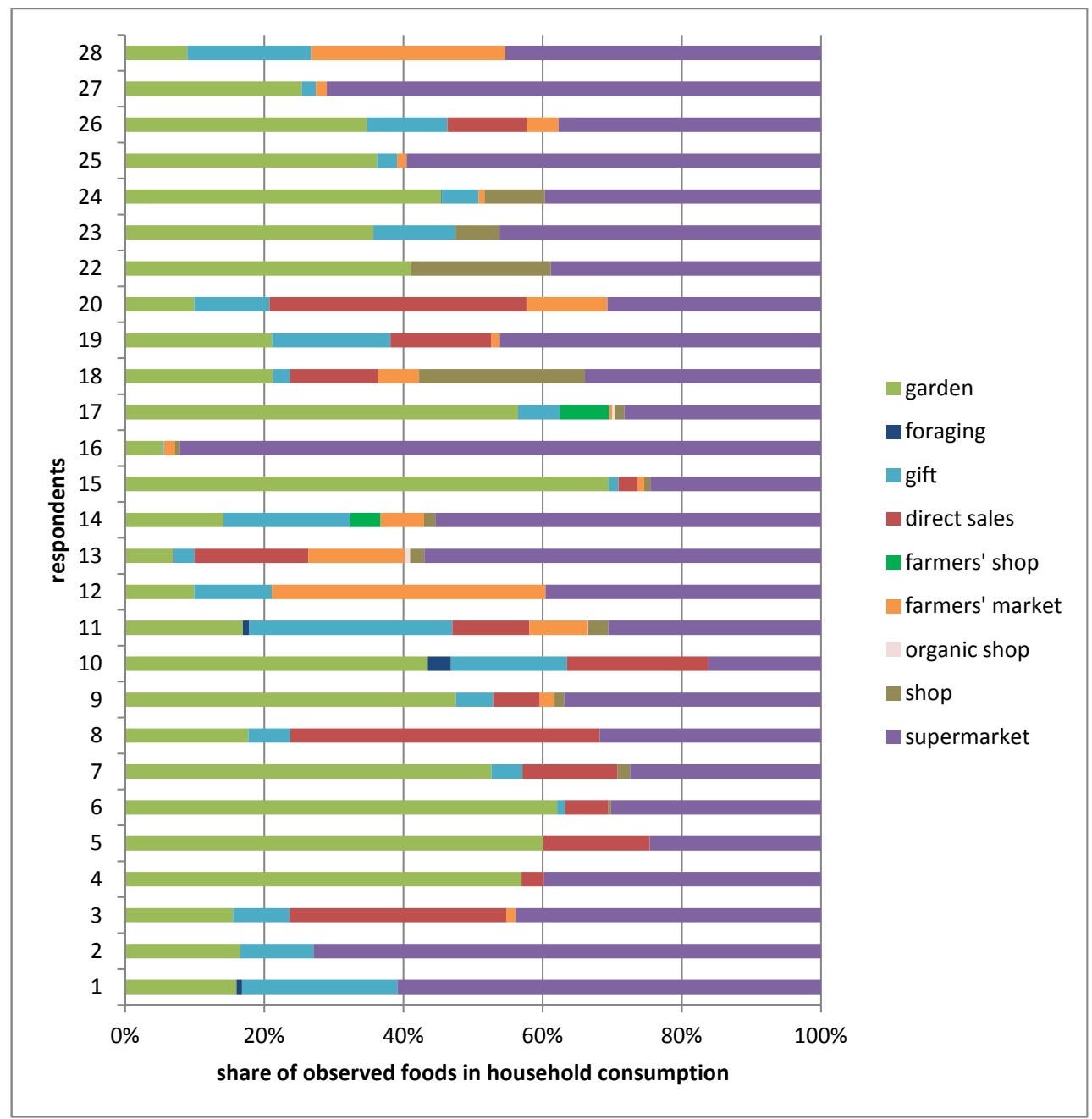

Figure 9: Sources of observed foods for household consumption

Before elaborating on the different types of sources and the ways they are used, I want to highlight several conclusions which can be derived from the quantitative data alone:

1. The main sources of the observed foods were supermarkets and respondents' own gardens.

2. Most respondents (24 out of 27) received some food as a gift or through a non-monetary exchange.

3. Direct sales were used by 15 respondents, often to purchase significant quantities of food.

4. Farmers' markets appeared commonly (in 17 cases), but they mostly accounted for a small share of respondents' food.

5. Buying food in smaller shops was rather rare. This source was used by 13 respondents, but mostly only for a very small amount of food. Organic food shops, farmers' shops and foraging were also marginal. 
From the diverse economies perspective it can be said that respondents' food provisioning practices involve a range of economic relationships, which can be categorized as market, alternative market and non-market. Gibson-Graham's (2006) categories of transaction, labour and market (Section 2.2) position diverse food sources on a spectrum ranging from a strictly economic seller-customer relationship guided by monetary exchange and market-based prices, through more personalized interactions where price might involve other criteria such as environmental sustainability or fair pay for producers, to mostly social relations detached from monetary transactions or even the logic of reciprocal exchange. In addition, I propose that in the case of food economies, this spectrum can also be read in parallel to different types of supply chains, from non-transparent long supply chains through more transparent ones to practices where the producer and the consumer roles merge.

Within my research sample, market sources included supermarkets and food shops. ${ }^{117}$ Organic food shops, farmers' markets, farmers' shops and direct sales are categorized as alternative market sources because they facilitate greater personal interaction between buyers and sellers and/or because the supply chains are shorter and/or more transparent. ${ }^{118} \mathrm{FSP}$, together with gifting, exchanging and foraging, is a non-market source. Figure 10, in which sources are categorized along this spectrum, shows a simplified picture of the diversity of food economies in the research sample. The following can be observed:

1. Non-market economies were a significant source of food for most respondents.

2. The majority of food was acquired either through non-market sources or through market sources, while alternative market sources were less prominent.

The first point confirms previous findings on the importance of informal economies in CEE, reasserting that non-market provisioning strategies have not disappeared despite the development of capitalist market economies in the region (Section 1.2). FSP and other informal economies are not only persistent, but they also contribute significantly to household food supplies. The participants in my research obtained on average 40 per cent of their consumed fruits, vegetables and potatoes from non-market sources (31 per cent from FSP alone). Respondents also recorded the use of non-market sources for eggs (13 respondents), mushrooms (8 respondents), nuts (7 respondents), meat (6 respondents), honey (6 respondents) and dairy

117 Food shops are smaller retail venues which sell groceries from conventional supply chains. In my sample, this category included neighbourhood food shops and kiosks as well as fruit and vegetable shops. This type of venue was typically used to make small purchases. Overall, purchases in small shops accounted for a marginal amount of food, and therefore this category is not treated separately in the following sections.

118 I am aware of several exceptions to this categorization. For instance, a regional chain of small shops called Brněnka, where seven respondents made occasional small purchases, also offers products from local producers. Most supermarkets sell some organic produce or even some produce from local (although not small) producers. Contrarily, some organic shops perpetuate conventional supply chains by placing strict standards on producers, relying on imported produce and so forth. The boundaries between the three categories are thus always blurry. While this topic is relevant within the debate on more sustainable food systems, in my sample all the aforementioned 'fuzzy' cases (buying food in regional small shops, buying food in organic shops and buying organic food in supermarkets) were relatively marginal. 
products (1 respondent). ${ }^{119} \mathrm{FSP}$, as well as other non-market food sources, thus comprises a significant part of respondents' food provisioning strategies.

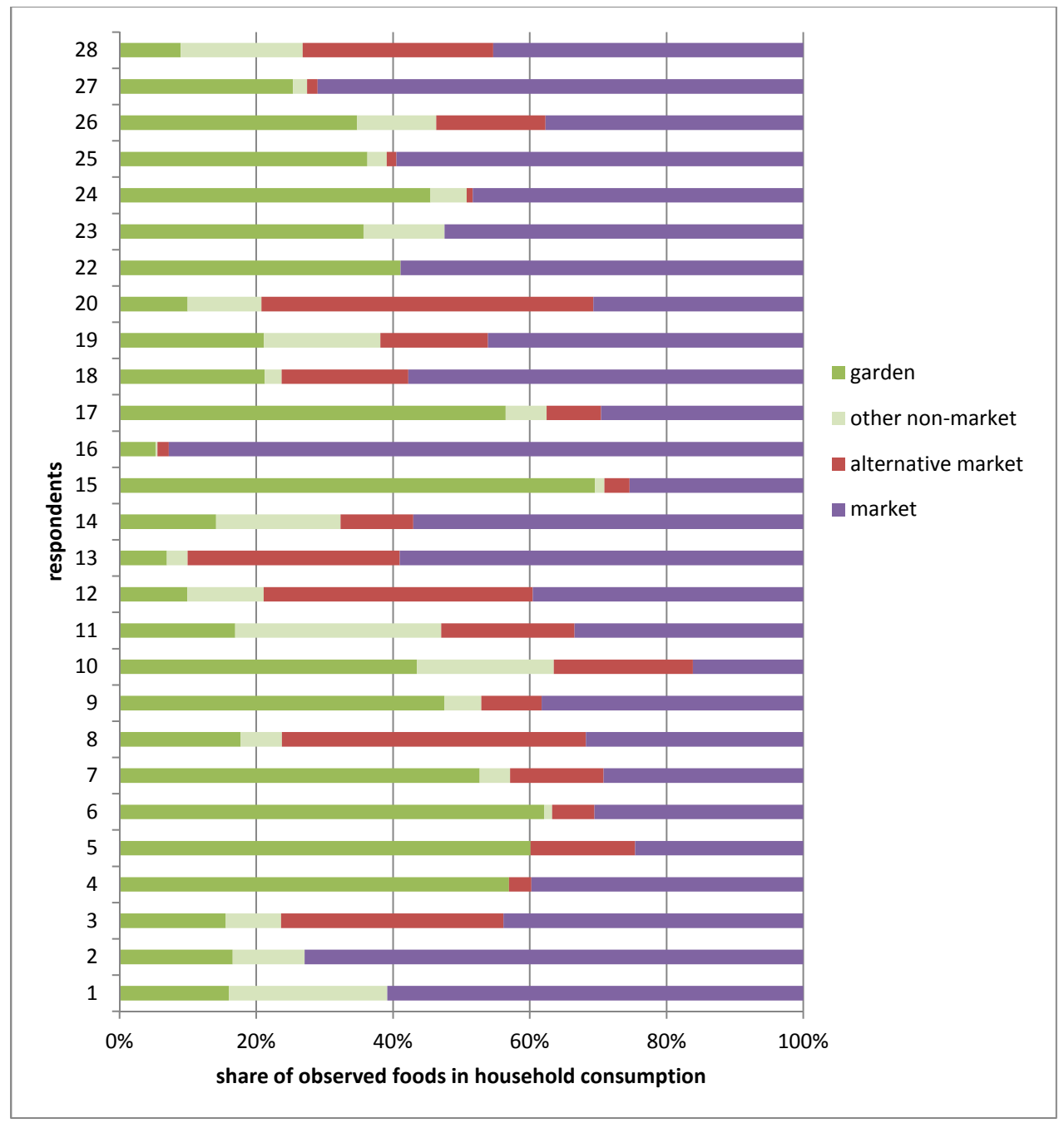

Figure 10: Types of sources of observed foods for household consumption

The overall importance of FSP and other informal food provisioning practices confirms previous research (Sovová, 2015). My findings are also remarkably consistent with data from Czech national surveys (Smith and Jehlička, 2013; Štiková et al., 2009). The most recent data (Vávra,

119 The data collection design does not allow for an assessment of the share of these foods from non-market sources in total consumption (see Section 3.3). However, the volumes seem significant in absolute terms. During the observed periods, all respondents together obtained nearly $28 \mathrm{~kg}$ of honey and 1,689 eggs from non-market sources. 
Daněk, et al., 2018) show that active gardeners ${ }^{120}$ in Czechia cover on average 32.5 per cent of their own consumption of fruits, vegetables and potatoes through FSP. Another 5 to 8 per cent of their consumption of fruits, vegetables and potatoes comes from gifts (Jehlička and Daněk, 2017). Therefore, in terms of the share of food obtained from non-market sources, my respondents do not differ from average Czech gardeners. ${ }^{121}$

Secondly, the lower prevalence of alternative market sources confirms the observations of Smith and Jehlička (2007) and Trenouth and Tisenkopfs (2015) mentioned in Section 1.2.5: in CEE, traditional (non-market) food practices prevail over (Western-style) AFNs. Indeed, non-market sources were more important than alternative market sources for all but five respondents. On average, respondents procured 14 per cent of the observed food from alternative market sources. Furthermore, and as detailed later, the vast majority of purchases made in the alternative market category comprised direct on-farm sales, which can be seen as traditional food networks (Tisenkopfs, 2017; see Section 1.2.5), rather than newly developed alternatives. The low representation of AFNs typically described in Western European literature (farmers' markets, CSAs, organic food shops) enhances the relevance of studying informal food economies domestic to the region. It also raises questions about respondents' motivations for using alternative market sources and whether these motivations can be seen as conscious consumerism (addressed in Section 6.2).

\subsection{Convenience, identity and responsibility}

In the following sections I unpack food provisioning practices related to different food sources. I first address market sources, represented by supermarkets, followed by diverse alternative market sources and the two most prevalent non-market sources, FSP and gifts, which are treated separately. Conceptually, I take inspiration from Belasco's (2008) triangle of consumer choice and an understanding of diverse food provisioning practices based on Veen et al.'s (2014) distinction between gardening and shopping. This lens allows me to investigate the underlying mechanisms of respondents' food provisioning practices. In other words, I try to illuminate how decisions between different food sources are made.

As mentioned in Section 1.1.3, Belasco's (2008) triangle of consumer choice proposes that three key factors shape consumers' decisions about food: convenience, identity and responsibility, in that order of importance. Convenience can be understood as the utility maximization assumed in mainstream economics: consumers aim to get the best possible goods in the easiest possible way. In practical terms, convenience involves criteria such as price, quality and the effort required to obtain the product in question. In Jackson et al.'s (2006) study, convenient food sources were venues that were easily accessible in terms of physical distance and travel time, where respondents could easily combine food provisioning with other errands, and which also had a pleasant atmosphere and convenient assortment in terms of quality and price.

120 People who reported producing some of their food, excluding professional farmers.

121 Note that the surveys mentioned here included FSP in both urban and rural settlements. See Section 7.1 for a more detailed quantitative comparison. 
Identity relates to what people consider to be food that fits their images of themselves. It involves understandings of taste, freshness and other characteristics of 'good food'. These criteria inform negotiations of convenience in a seemingly objective manner but are in fact based on personal values as well as social and cultural norms (Jackson et al., 2006; see also Mylan and Southerton, 2018). Lastly, responsibility comprises the moral dimension of food provisioning, that is, understanding the impact of one's consumer choices on the world.

In what follows, I will explore how convenience, identity and responsibility are understood and performed in gardeners' food provisioning practices. The rest of this chapter takes convenience as a starting point and explores its meanings in relation to diverse food sources. Identity and responsibility appear at several points in this chapter, and they are also discussed in more detail in Chapter 6.

The three factors formulated by Belasco (2008) help me to assess whether diverse food sources constitute different food provisioning practices and provide insight into the functioning of diverse food economies. This analytical step is inspired by Veen et al.'s (2014) study of the food provisioning practices of members of four community gardens in the Netherlands. They observed that while some people engaged in gardening for fun, others saw their gardens as sources of food. According to the authors, respondents' different motivations effectively constituted two different practices: gardening and shopping. This had implications for the perceived convenience of obtaining food from the garden. People involved in gardening found it convenient to harvest produce while practising their hobby. Conversely, people who engaged in shopping perceived gardens as less convenient compared to other venues. In sum, the two practices led to different considerations which shaped respondents' food provisioning strategies. Identifying food provisioning practices related to particular sources of food thus helps illuminate how diverse food economies are constituted.

\subsubsection{Convenient supermarkets}

Respondents mentioned convenience as the main factor in buying food. The majority did most of their grocery shopping in supermarkets, which were generally seen as more convenient than alternative market venues. Physical proximity was by far the most frequently mentioned factor influencing the decision where to buy food. In some cases, the choice of shop was related to the means of transportation available: some respondents would regularly make a trip to the supermarket by car to get larger amounts of supplies. Other respondents did not like the idea of travelling for shopping and preferred to get groceries near their homes or en route from work. Most respondents had no reason to question this logic, while others expressed conflicting priorities:

'The [supermarket chain] where I live is really terrible, but I still go there. There is another one two bus stops farther away; that's a perfect shop, but it's two stops farther away.' (r. 26)

Respondent 14, who was very conscious of her consumer choices, reflected on how convenience can overrule ideals based on responsibility and identity: 
'Even in summer I often preferred to get them [groceries] in the supermarket by car; for instance, when I was shopping for my work [in catering], I just got it in one go. These ideas that I will go with my net bag to the farmers' market just don't correspond to reality, because it's completely out of my way home.'

Nine respondents mentioned opening hours as a limiting factor for using alternative market venues. This was confirmed by people who were more flexible, for example, respondent 13, who was on parental leave, explained:

'When I worked, I didn't have much time to go to the farmers' market. When I got there at four o'clock, everybody was already gone. And four o'clock is still early; my husband comes from work at six or later, so he can never shop there. So, we used to shop more in supermarkets. Because when we went to a farmers' shop or an organic shop, it was overpriced.'

Price was a factor both when choosing which foods to buy and when choosing the venue, as Jackson et al. (2006) have similarly observed in the UK. Supermarkets were seen as cheaper in comparison to organic food shops and similar alternative market venues (see Section 5.2.2). In terms of choice of food, price actually contributed to seasonal eating patterns, since several respondents noted that particular fruits or vegetables were expensive (and not so tasty) outside their season (see Chapter 6)

Respondents mentioned quality in connection with particular supermarket chains and particular types of food (meat, bread, vegetables). In general, they had little positive to say about the quality of fruits, vegetables and potatoes purchased in supermarkets. Interviewees frequently compared home-grown foods to supermarket foods, raising the issues of transparent production methods, the use of agrochemicals, taste, health, nutrition and freshness, which I discuss in Chapter 6.

\subsubsection{Routinized and socially embedded alternative market sources}

Respondents used a broad range of alternative market sources - which generally involve shorter and more transparent supply chains that allow for more personal encounters between seller and buyer and where price is not necessarily (or not solely) guided by market logic. In practice, alternative market sources involved both monetary and non-monetary transactions, and relationship types ranged from strictly economic (seller-customer) to more personal, with a whole spectrum in between. That being said, less formal and more personal relationships prevailed over more formalized ones. Only a small minority of respondents purchased food in what I refer to as 'Western-style' AFNs (Section 1.2.5). In what follows, I present the alternative market sources encountered in my sample, ordered roughly from the most formalized to the most informal.

Organic food shops, that is, shops specialized in selling certified organic products, were very rare in my sample: three respondents used them to purchase exotic delicacies such as dates or raisins. ${ }^{122}$ Most respondents were either indifferent or sceptical about organic certification. ${ }^{123}$

122 Czech organic shops typically offer non-perishable foods. Fresh fruits and vegetables are only a minor part of their assortment

123 This is not surprising in the Czech context, where sales of certified organic goods are marginal, despite steady growth over the last decade. Organic certification is further discussed in Section 6.2.1. 
Even respondents who were more inclined to buy organic produce perceived price as a significant barrier.

Two respondents experimented with vegetable box schemes and online purchases from organic farms. In both cases, this was the result of an active search for quality food, driven partly also by environmental consciousness. However, both respondents perceived this source as inconvenient (in terms of price, assortment, quality and how deliveries are organized) and stopped using it during the observed period.

Farmers' markets and street sellers were one of the most common alternative market sources. They were used by 17 respondents in total, while for 5 of them these venues represented a relatively important source of food, especially in spring and summer. Inconvenient location and limited opening hours were perceived as a major disadvantage of farmers' markets and were explicitly mentioned by eight respondents. Another group of respondents identified with the idea of shopping at farmers' markets, and they mentioned this source during interviews. However, their food logs revealed that they rarely procured food from them. Arguably, convenience outweighed other considerations, as suggested by respondent 14 above (Section 5.2.1).

Four respondents stated that they did not buy food from farmers because the assortment was similar to what they could obtain from their own gardens:

'During the season I cover most of my vegetable consumption myself. What I buy extra in the supermarket is such a small amount, it doesn't pay off to travel to the other side of the city for it, to support a farmer. I feel like I'm a farmer myself... so I support myself.' (r. 27)

Several respondents doubted the origin of the food sold at farmers' markets, since these markets are open to both producers and retailers who re-sell foods obtained through conventional supply chains. Even respondents who shopped at markets regularly emphasized the importance of recognizing trustworthy stallholders. As respondent 28 put it:

'It's more that I find it pleasant that I can cycle there, and I don't have to go to the shop. But I wouldn't claim that when I buy things at the market, they are necessarily from some local farmers.'

The ambience of the farmers' markets mentioned here was often appreciated, together with the quality of the produce:

'It is fresh, and it is healthier. When you see it in the shop, they sprinkle the lettuce, you pick it and water comes out of it. But ifyou go to the farmers' market on Saturday morning, you see they have it freshly picked; there's still a bit of soil on it, or a caterpillar, that I don't mind.' (r. 20)

Respondent 13 further mentioned the ability to choose and the moderate prices found at famers' markets, which were more favourable than at other alternative market venues:

'I like that you can choose what you want, and at the same time it is cheap. The vegetable boxes are not terribly expensive, but they are more expensive.'

Respondents who used farmers' markets more often confirmed the importance of convenience in the sense that all of them managed to integrate farmers' markets into their routines and therefore perceived them as convenient. Respondent 13, who was on parental leave (see quote 
in Section 5.2.1), described how she would 'go to the farmers' market twice a week and load the stroller full'. Respondent 28 explained that cycling past the farmers' market and being able to make a fresh salad was a convenient lunch alternative in the summer, while in winter he would drive to a supermarket. Respondent 20 was able to shop at the farmers' market because of her flexible working hours, and respondent 12 lived across the street from a farmers' market.

I developed the category of farmers' shops during data analysis to distinguish shops which sell produce from local small-scale producers regardless of whether it is certified organic or not. Two shops which fell within this category shared a degree of informality and trust-based relationships with both producers and consumers. One of them is an informal shop ${ }^{124}$ in Brno which serves as a distribution point for locally farmed produce and homemade goods. Respondent 14, who used this venue, appreciated its informality:

'Sometimes you get a drink there, or you can taste something; it has a human touch. It's pleasant. [...] I trust him [the shop owner] that he really watches the farmers who sell their produce there. [...] You also have these brand-name organic food shops; that's really for business. [Compared to those,] this one is sort of agreeable.'

However, the strict seasonality of the assortment and limited opening hours made shopping inconvenient for her.

The second farmers' shop was located in a smaller town near the second home of respondent 17. It primarily focused on garden tools, supplies, seeds and seedlings. However, it also served as a hub for local growers, both professional and non-professional:

'The owner has a list, and when I come there, and I say I want this, she checks the list and tells me who might still have it and orders it for me. Plus, she has seasonal produce from the area.'

These two shops illustrate the diversity of respondents' food provisioning practices, as they are positioned in the grey zone between official retail and sharing based on social relationships. Their informality, the importance of personal relationships and even the somewhat loose attitude towards legal requirements contrast with the approach of organic shops (with certified produce).

Direct sales were the most common alternative market source, used by 15 respondents in total and accounting for 16 per cent of their consumption on average. ${ }^{125}$ They were mostly used for bulk purchases in autumn and winter but were also quite significant in other seasons. This category included a diversity of sources: for example, vegetable gardens, on-farm potato sales, orchards and pick-your-own strawberry fields.

Direct sales were often based on social contacts and in some cases were also embedded in place: direct purchases from 'the farmer in the next village over' or even 'the neighbour' were recorded by respondents who either lived in a rural-like neighbourhood at the edge of Brno or travelled to the countryside to their second home. Other respondents relied on social networks in places where they grew up, as respondent 12 explained about his source of potatoes:

124 Due to legislation related to food sales, the shop officially operates as a club: when entering, customers become 'members' and purchase food at their own risk.

125 But note that foods purchased directly from farmers were commonly shared with other households in large amounts. Their share in the total throughput of food was thus higher. 
'It is a small village, 34 houses, and I come from there. We know each other [the farmer and I]; we basically went to school together.'

Respondent 24's description portrays these networks as extended and vibrant:

'I pick up the phone, and I say I'm coming on Saturday, get four rabbits ready for me. Well, I still have to pay for it, but he makes it cheaper for me. [...] I have my sources there. I come from there, I have my family and acquaintances. I go by all my aunties and cousins; I leave in the morning and come back in the evening completely exhausted [...]. I bring back meat, honey. Now I also get more vegetables from there because my aunt is over 70, and she doesn't know what to do with it, so she calls me, come. I bring it here, and I distribute it further, to the kids, something to the neighbour, something I process myself.'

This quote also demonstrates a spectrum of monetary and non-monetary transactions which is rather fluid and in which direct sales sometimes overlap with sharing networks. In many cases, I needed additional explanations from respondents to properly categorize these types of sources. For instance, I only learned during my final interview with respondent 20 that food recorded as 'from a farmer' was not necessarily bought for money, since some of the farmers were acquaintances of her family.

Furthermore, social relationships that facilitated direct sales were in many cases indirect. It was not uncommon for respondents to ask their family members or acquaintances to purchase produce via their contacts in the countryside. In some cases, these food provisioning practices were also strongly embedded in respondents' identities:

'My mom buys poppy seeds at a farmers' market at her place in Vysočina. The producer is from the village where my family comes from. The poppies are grown in the place from which I remember my grandma, who has always been my role model. So, I see it as supporting the local markets there. My mom always buys it for me, she is happy that she can give me something; she always has the need to give me something, so I tell her just buy me poppy seeds for my birthday.' (r. 10)

In other cases, however, buying from a farmer was simply a convenient way of getting food. Respondents relied on their social networks as 'middle-men' without taking much interest in the original source:

'My husband's cousin brings us potatoes from Vysočina; he buys them from someone there.' (r. 6)

These 'less direct sales' also presented a methodological challenge, as respondents sometimes conflated their suppliers. To give an example, respondent 19 purchased potatoes in bulk together with her two brothers, since one of them knew a local potato farmer and also owned a cellar where the potatoes could be stored. The respondent would then collect a sack of potatoes every time she went to visit her brother (see quote in Section 7.3.1). When recording this in the food log, she mentioned her brother as a source, which did not quite capture the entirety of the supply chain. The food logs assumed singular, straightforward sources of food. Although they were designed as tools to capture the diversity of food sources, the reality I encountered was at times so varied that it almost did not fit my methods.

Respondents chose direct sales because they perceived food quality to be better compared to conventional market sources: 
'With the potatoes from Vysočina we never had a bad variety. They're really high-quality potatoes. Because what we sometimes buy [in the supermarket] when we run out of these and the new ones are not there yet, that is mostly without taste or smell; it just isn't a potato.' (r. 5)

Taste was linked to more natural ways of production:

'For the fruit to look beautiful, it needs to be sprayed against this, that and that. And that bothers me. I know; people want it. They come to the shop, and they don't buy an ugly apple or pear; everybody buys the nice one. But on the other hand, what's in it? That bothers me a bit. So, I prefer to buy an odd-shaped pear from a farmer, even with a worm in it. That I don't mind, but I think he doesn't have it sprayed as much as in the shops.' (r. 8)

The same respondent, however, also experienced quality issues with food from direct sales:

'One year we also bought potatoes. It was a farmer from Břeclav, but they were not so good; they got black. So, the next year I didn't buy them again. With potatoes it's a bit of a problem. I don't know if it's the manure or what, that the potatoes turn black inside. [...] I prefer to buy them from a farmer rather than in the shop, but if I have to throw them away, that sucks. I don't need it to look beautiful, but it shouldn't be black and rotten.'(r. 8)

It seems that respondents perceived direct sales as fairly convenient. This can be explained by their routinized and socially embedded nature. Purchases were often linked to specific crops and specific sources: respondents would always buy potatoes from a specific farmer, honey from a neighbour who keeps bees and so on. Because direct sales were typically used for bulk purchases of durable crops (potatoes, apples), making the trip to a farm was relatively convenient.

In some cases, getting food was part of a broader social encounter with relatives and acquaintances. Such socially embedded sources therefore did not 'compete' with conventional market sources. Analogically to the point made by Veen et al. (2014), respondents were not only involved in the practice of shopping, but rather in the practice of (for instance) visiting a neighbour. Collecting the produce on the same occasion thus seemed fairly convenient.

The importance of social relationships was confirmed by respondents who lacked such networks. When asked about direct sales, respondent 16 answered, 'We don't know any farmers.' Other respondents were motivated to buy food from short supply chains due to ethical or environmental concerns (which would qualify as responsibility in Belasco's scheme) but found them difficult to access due to convenience or price when relying on more commercialized venues. As expressed by respondent 17: 'I think that once you build a network of acquaintances who supply something, you get access to affordable and high-quality food.'

\subsubsection{Obtaining food as a gift}

All research participants were involved in gifting and sharing networks to some extent. Overall, gardeners gave away more food than they received, which confirms the understanding of gardening as a generous practice (Jehlička and Daněk, 2017; Smith and Jehlička, 2013). This practice is also related to dealing with harvest surpluses (see Section 7.3.3). Figure 11 shows that gifting and sharing networks had varying levels of importance for respondents, a finding that 
suggests that respondents played different roles in these networks: some of them are the 'central nodes' from which large volumes of fresh and processed food is (re)distributed, ${ }^{126}$ whereas others are mostly at the receiving end. In this section I focus on gifts as sources of food, that is, transactions where respondents acted as receivers.

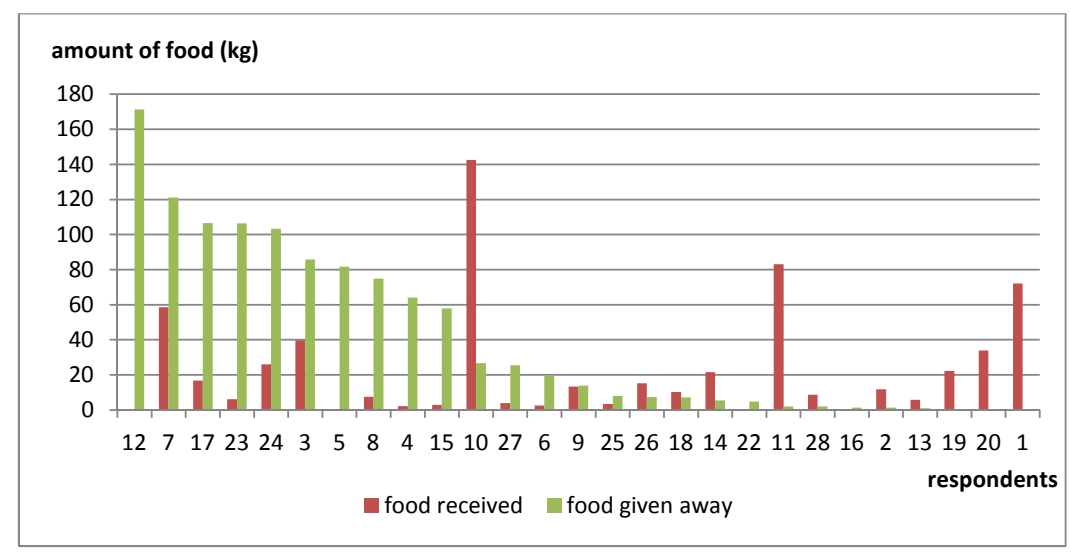

Figure 11: Gifting and sharing transactions recorded during the four months of data collection

Except for three respondents, all gardeners received food gifts from other people. On average gifts accounted for 9 per cent of the respondents' food consumption, but they were more significant for five respondents, who covered between 17 and 29 per cent of their consumption from gifts they received.

The quantitative data capture only a part of respondents' sharing practices. Firstly, sharing happens at various stages of food provisioning. In three cases, ${ }^{127}$ garden ownership was shared with family members in different ways, as was - to varying extents - labour and the harvest. For instance, respondent 9 regularly used the garden located at her parents' house. Whereas I initially understood the yield of this garden as a gift, the respondent later clarified that she was in fact involved in production, reconceptualizing this produce as her own: $:^{128}$

'My parents would not be able to manage the garden without us. My mom really enjoys it, but for instance she wouldn't be able to dig over the big potato field on her own. This way everybody benefits. We help them out, it makes them happy, and we get the food, which they also couldn't eat by themselves.'

Secondly, the social metabolism perspective presents households as clear-cut units with flows of food coming in and out. In some cases, however, extended family households engaged in joint

126 Apart from giving away their own produce, respondents also distributed foods acquired from other sources.

127 See respondent sample in Table 6.

128 The methodological choice to conceptualize the produce as the respondent's own production was based on the distinction between gifting and sharing laid out in Section 3.3.1. However, it was not unambiguous. While the respondent harvested the produce by herself (using the garden as her own without restriction), she left the decisionmaking about which crops to grow to her parents (still being partly in the role of a guest). Furthermore, she did not have to deal with all the garden produce, leaving the logistics of processing or distributing surplus to her parents. 
food provisioning, which complicated the distinction between 'sharing' and 'own consumption' (as discussed in Section 3.3.1). For instance, respondent 17 explained:

'Once the garden starts producing, I bring a part of it [the harvest] to grandma; she processes it [into meals or preserves], and she sends at least a part of it back to us. So, it's not really a gift; it's more of a cycle of things in the family.'

Some respondents mentioned significant amounts of food shared during family visits, particularly when relatives were involved in childcare on a regular basis. ${ }^{129}$ Sharing therefore also appeared in the form of eating together or sharing prepared meals and preserves, rather than fresh produce. These more subtle ways of sharing food were difficult to capture in the food logs. The actual extent of sharing was thus almost certainly higher than the quantitative data suggest. Thirdly, 'sharing' or 'gifting' defines the type of transaction but not the original source of food. The food that respondents received (and gave away themselves) was in most cases home grown or acquired from the alternative-market rural networks that I described in Section 5.2.2. However, in some cases gifts also included food from market sources, such as exotic fruits purchased in supermarkets for the celebration of St. Nicholas Day. ${ }^{130}$

Even non-monetary 'supply chains' sometimes involved more than two parties. Thus, people who do not have a direct relationship could share produce: ${ }^{131}$

'My sister lives with her boyfriend, and his family has a garden in North Bohemia. They are quite a substantial source of vegetables for our household. They have lots of apples; all our apples are from them. They also keep a big flock of chickens; every month we get around 30 eggs for us and my mother.' (r. 14)

'I get food from my daughter from the village [where she lives]. They have a functioning barter system. They have a big vineyard, and my son-in-law makes delicious wine. So, he gives wine to someone, that person brings him a rabbit. Now he is bringing me pheasants [that he obtained in exchange for wine].' (r. 20)

Lastly, the nature of the transaction was also ambiguous in some cases. As mentioned, obtaining food from acquaintances in the countryside included diverse types of transactions, from monetary payment to non-reciprocal sharing with a variety of non-monetary exchanges in between. Respondents received food in exchange for helping out in the food production process, they exchanged home-grown or homemade produce, and these goods were also used as compensation for unrelated products or services. For instance, respondent 12 regularly helped harvest potatoes at the field of his childhood friend in exchange for several sacks of potatoes, which supplied his and his children's households for the winter. Respondent 20 , who works as a tax advisor, mentioned often receiving honey as a thank you for her services.

The work of Belk (2010) was useful for placing non-market transactions on a spectrum ranging

129 When relatives looked after children in their households, they would also offer them food. The sample included households with children who would sometimes eat at the house of other relatives (thus lowering food consumption in the main household) as well as households where children would often visit and eat (thus increasing consumption).

130 Gifts of (store-bought) fruits or vegetables were mostly motivated by concerns about the recipient's healthy eating; see also Section 6.2.2

131 Similarly as I described in the case of direct sales in Section 5.2.2. 
from exchanges (where food is immediately reciprocated for with other goods or services, often based on an agreement) through gifts (which tend to occur in a more ritualized fashion on special occasions and are guided with a sense of general and less immediate reciprocity) to sharing (which is routine and without expectations of reciprocity). On this spectrum, sharing was more typical for (extended) families, whereas more reciprocal transactions (gifts and exchanges) appeared between neighbours and acquaintances. Gardens were spaces of ad hoc exchanges of surplus seedlings and produce, different varieties or specialities offered 'for degustation'. Respondents who kept animals received old bread or other leftovers to feed them, which they reciprocated for with an occasional gift of eggs or meat. Gardeners also mentioned the wide circulation of other materials related to food provisioning practices. For instance, respondent 23 explained that glass jars used for pickles were never purchased but instead collected amongst family and friends.

Some families developed a stable system for dividing crops and labour:

'Our family has a three-generational barter [system]. My grandpa makes all kinds of jams. Sometimes we get some mixed pickles, because I really like them, but I cannot make them the way my dad does. So, it's not that they would have too much, but they know that we like it, so we make an exchange. Our speciality is zucchinis; we supply them with those. Not so much preserves, that is their thing, but we give them fresh things, green peas, beetroot, onions.' (r. 3)

In these networks, reciprocity is not strictly weighed in terms of the value of the exchanged goods or the time passed between giving and getting something back. Instead, as the quote suggests, specialization is based on skill and identity. In other cases, family specialization resulted from convenience in terms of equipment and materiality; for example, relatives with a bigger garden would grow potatoes, whereas gardeners from a warmer region would specialize in fruit trees. Here, the intention to share yields is already included in gardeners' planning of what to grow, and respondents receive substantial amounts of food from their relatives:

'With potatoes, garlic and onions we have big fields at my parents' place. So, we usually have them for the whole year.' (r. 28)

Moreover, many specialties ${ }^{132}$ were also linked to specific informal sources: meat, fish, honey, homemade preserves, homemade cheese and nuts. These links developed over time as respondents received the same foods from the same sources:

'With our friends it [sharing] is really casual, although some things also already have a tradition. Last year we didn't make apple juice because there were no apples, but normally we got used to making apple juice at our friends' place, and then we mostly also get some juice. So that's the start of a tradition.' (r. 10)

Such connections could become very strong for particular crops and sources, ${ }^{133}$ as the same respondent shared:

'We ran out of dill, and my partner said, "Well, they must have it in the supermarket." And I said, "Are you crazy? Why would I buy dill?" Because I always had it from my mom, it wouldn't even cross my mind to buy it in a shop.'

132 Foods which were a highly appreciated addition to respondents' diets rather than staples.

133 Such links are further explored in Sections 5.2.4 and 6.1.1. 
Sharing transactions were often guided by a sense of mutual aid and solidarity, based on the givers' and receivers' shared understanding of home-grown food as better than food from conventional market sources (see Section 6.1). Home-grown food is thus seen as an asset, something of special value. Some accounts even suggest that people without access to home-grown or homemade food are disadvantaged or even unable to participate in sharing networks. For instance, when I asked respondent 26 whether she received something in return for the home-grown food she shared with her friends, she replied:

'When they don't have a garden, they have nothing to give.'

Similarly, when asked about receiving food as a gift, respondent 16 replied:

'We don't have acquaintances that would be able to give us something.'

Respondents were therefore mostly grateful to receive food. In some cases, however, receiving was almost perceived as 'helping out' with the surplus produce of others, driven by a shared responsibility not to waste food. Respondent 14 reflected on her position in informal sharing networks, combining both sentiments: ${ }^{134}$

'I would say that we receive more because we don't have anything to give in return. But it is also nice for the family that gives us the food because then they don't need to leave it to rot. I feel that we get it because otherwise it would go bad. We never felt guilty or awkward about not giving anything back. I don't really think about it, although it is a bit peculiar.'

Even more noticeably, respondent 24 produced and distributed large amounts of food, but she would still receive extra fruits and vegetables from an elderly relative who was not able to process them herself (see the quote on direct sales in Section 5.2.2). While home-grown food is seen as precious, respondents understand that it can also become a burden. Both attitudes are based on respondents' experiences as producers and their awareness of the ins and outs of growing food (see also Section 7.3.3).

The social aspect, which I already mentioned in relation to food provisioning from some alternative market sources (Section 5.2.2), is even more important for receiving food as a gift. The essential role of social relationships is strongly reflected in the negotiation of convenience in informal food networks. In most cases respondents received smaller amounts of food on numerous occasions, instead of large amounts all at once. Food was usually collected during family visits and the supply was dictated by their frequency:

'I go [to my parents' house] about once a month, sometimes more often. Sometimes there are more birthdays and celebrations. But I definitely don't go there every week, so it's always just for some time; it's not a constant supply.' (r. 28)

At the same time, however, the logistics of sharing food are considered in these interactions. For instance, respondent 28 further explained that 'a package' would be waiting for him every time he visited his parents, who would also dry tomatoes for him:

134 This quote also shows that reflection was induced only by my questioning and that respondents do not commonly think about these relationships. This is associated with respondents' general understanding of their food provisioning practices as ordinary, a point mentioned in Section 3.4 
'I feel really sorry when I receive a big package of vegetables from my parents and I'm completely unable to process it. So, I try to motivate my parents to dry them for me.'

Such organizational arrangements were required especially for networks which were more geographically spread out, while closer and more interlinked households were able to share even perishable food more casually. In the case of respondent 1 , sharing partners were hundreds of kilometres apart:

'My boyfriend has an aunt in eastern Slovakia. She gives us lots of homemade preserves, fruits, vegetables, meat. His parents usually pick it up there, and they bring it to Bratislava, so every time we see them there, we exchange some food. This happens, let's say, once every three months.'

The understanding of convenience in gifts and sharing is strongly shaped by the social nature of these food sources. Veen et al.'s (2014) point on different practices, which I mentioned in relation to alternative market sources (Section 5.2.2), applies even more strongly to non-market food provisioning. On the one hand, gifts do not seem convenient if they are viewed only as a means of food provisioning, since they can be irregular, and recipients cannot really control them or rely on them. On the other hand, if respondents understand these informal networks as mostly social, they can be seen as a convenient way of obtaining food without much effort, while being engaged in another practice (e.g. visiting relatives). The social nature of this source thus creates a fundamentally different understanding of convenience, one that cannot compare to convenience as it is understood for market sources. As a result, non-market sources do not 'compete' with market sources in terms of convenience, while in terms of quality, they are actually perceived as better (as I elaborate in Chapter 6).

\subsubsection{Pragmatic and personal food growing}

One of the starting questions I posed to understand how gardens work as sources of food was how people decide which crops to grow and how their decision-making process compares to choices they make about other ways of food provisioning. What distinguishes FSP from other sources of food is that gardeners act as both producers and consumers and that both these roles influence their decision-making. Acting as consumers, respondents based crop selection on their food preferences (i.e. growing what they want to eat), which were weighed against producer-side considerations, namely the suitability of crops for local conditions and their difficulty to cultivate. Local conditions included soil type and fertility. Climate was a crucial factor especially in relation to drought, which has become a major issue in the region. Plot size was also a consideration, especially in relation to space-demanding crops. The food log data confirmed that respondents from allotments (where the plot size is generally smaller) ${ }^{135}$ had the lowest harvest of home-grown potatoes (a common example of a space-demanding crop).

One of the candidate mechanisms related to convenience was the distance of the gardens from respondents' homes. Although this factor was discussed by respondents, it seemed less important than in relation to shopping venues, and it was mostly considered in combination with the

135 Most respondents from allotments had plots of 200-250 $\mathrm{m}^{2}$. 
aforementioned factors of how difficult certain crops are to grow and how suitable they are for local conditions. Respondent 13 explained how her attention shifted from her second-home garden to a newly acquired home garden:

'I want to garden mostly here, because I don't know how often we get to the second garden. Last year we only managed to go there once every two months, so the variety of vegetables got narrowed down to garlic. You just need to put it in the ground in November and harvest it in July. Even if it is overgrown with weeds, it doesn't matter. And then there are fruit trees and bushes, which basically do not require care. So, we just go there to mow the grass.'

While respondents with second-home gardens agreed that the location of the plot caused occasional challenges, the food log data do not show significant differences in terms of self-sufficiency, amount of produce or diversity of crops between different types of plots. This suggests that the disadvantage of having a garden in a more remote location is outweighed by other factors (for instance, secondhome gardens tend to be larger than plots located in the city) and that respondents manage to adapt their gardening practices (e.g. by harvesting all produce in one go rather than gradually, as was typical for gardeners who were able to visit their plots more often). Two respondents with secondhome plots even managed to keep bees, with assistance from people who lived permanently by these gardens. Apart from that, however, only respondents with home gardens kept livestock (six households had chickens for eggs, two of which also kept rabbits for meat).

While gardeners applied a number of strategies to improve growing conditions, they also weighed the 'costs' of production against the 'benefits' of the harvest. In these considerations, costs were only occasionally understood in financial terms. They mostly referred to the convenience of growing a particular crop in terms of necessary labour:

'I know that carrots and radishes are more work than good. You need to thin them and weed them a lot. With tomatoes you don't have to sweat so much.' (r. 1)

Beyond convenience, efforts and financial costs were sometimes intertwined with environmental responsibility, especially when it came to watering and the use of agrochemicals:

'One problem [...] is that it's terribly dry, sometimes to the extent that I divide it into two seasons, spring and autumn. In summer the plot parches. There is a water tap for watering, but you can't water it enough; it just wouldn't be profitable, economically or ecologically. You would have to go there every day and pour gallons of water on it.' (r. 27)

'I don't grow cabbage because the cabbage whites would eat it, and I don't want to spray it.' (r. 23) - 'So we prefer to buy it... and then it's chemical anyways.' (r. 24, in a joint interview)

Several respondents reported that they stopped growing crops susceptible to pests due to their negative attitude towards agrochemicals. As respondent 24 in the quote above remarked, though, these considerations do not extend to other food provisioning practices: being an environmentally conscious gardener does not necessarily make one a responsible consumer, as I elaborate in Section 6.2.1.

Whether growing particular crops is 'worth it' or whether it 'pays off' was mentioned by most respondents; some of them even used these expressions verbatim. This shows, on the one hand, that 
FSP is an economic activity guided by pragmatic 'cost-benefit' considerations. The understanding of costs is, however, specific to FSP. Instead of being guided by 'consumer convenience' (i.e. physical proximity, financial costs and other factors mentioned in relation to market sources), respondents weighed the 'costs' in terms of 'producer convenience' and in mostly non-monetary terms. They did not deliberate about whether it is convenient to use gardens to provision food, but whether it is convenient to grow specific crops. Furthermore, convenience often overlapped with responsibility and identity considerations; for example, growing crops that required treatment with agrochemicals was considered inconvenient.

In addition, gardeners' consumer considerations (related to the 'benefits' of the garden as a food source) were also complex. In this case, the key factor was the perceived quality of the food. While gardeners considered home-grown food to be generally better than food from other sources (see Section 6.1), this applied to some crops more than others. Gardeners were less likely to grow crops which were (perceived as) difficult to grow especially when they could easily obtain them from other sources in comparable quality. For instance, several respondents mentioned that they do not grow potatoes because they take up too much garden space and can be easily obtained through other sources - in some cases from relatives living in the countryside. Lettuce, radishes and carrots were repeatedly mentioned as crops which are both difficult to grow and cheap to buy.

The food log data confirm that some crops were strongly linked to a particular type of source: market (supermarkets and shops), alternative (organic food shops, farmers' shops, farmers' markets and direct sales) or non-market (FSP, gifts and exchanges, foraging). Figure 12 shows the most commonly consumed crops that tend to be provisioned from a particular type of source. ${ }^{136}$ At the bottom of the figure are crops which were relatively often purchased from alternative market sources (specifically direct sales), followed by mostly home-grown fruits and fruits that were most commonly purchased from conventional market sources. ${ }^{137}$ The top of the figure shows source patterns for vegetables. Most of the tomatoes originated from respondents' gardens, which confirms their statements about the large quality difference and hence a strong preference for home-grown. Contrarily, although lettuce was perceived as difficult to grow and easy to buy by some respondents, most of it still originated from gardens. ${ }^{138}$ Most convincingly, the top of the figure features crops which were often described as difficult to grow and affordable to buy from market sources.

Despite these common patterns, the balance between costs and benefits or producer and consumer roles is a matter of personal negotiation, as illustrated in the two following quotes on strawberries:

136 For some of the most commonly consumed crops a clear link to a source was impossible to establish. For fruits, these were grapes, pears and apricots. For vegetables, they were bell peppers, beetroots and kohlrabi. These crops are excluded from the figure.

137 Exotic fruits, which would also fall into this category, are excluded from the figure.

138 Despite the perceived difficulties, two-thirds of respondents produced lettuce. Furthermore, those who produced it generally had larger quantities than those who obtained it from other sources. This 'garden bias' might apply to other crops too: respondents who used market sources purchased the amount of food they needed, whereas quantity was more difficult to regulate in gardens, which sometimes yielded more than the respondents would have otherwise provisioned. 
'I don't grow strawberries at all. I consider that complete idiocy. You get strawberries for one or two weeks, right at the time when they have them on the [market] square for 40 crowns a kilo. But strawberries take so much work, to harvest, to replant every three years, to cut the shoots.' (r. 23)

'I probably wouldn't grow strawberries for myself; they are quite labour intensive, but my kids are so crazy about them that I would feel sorry not to put them [in the garden].' (r. 17)

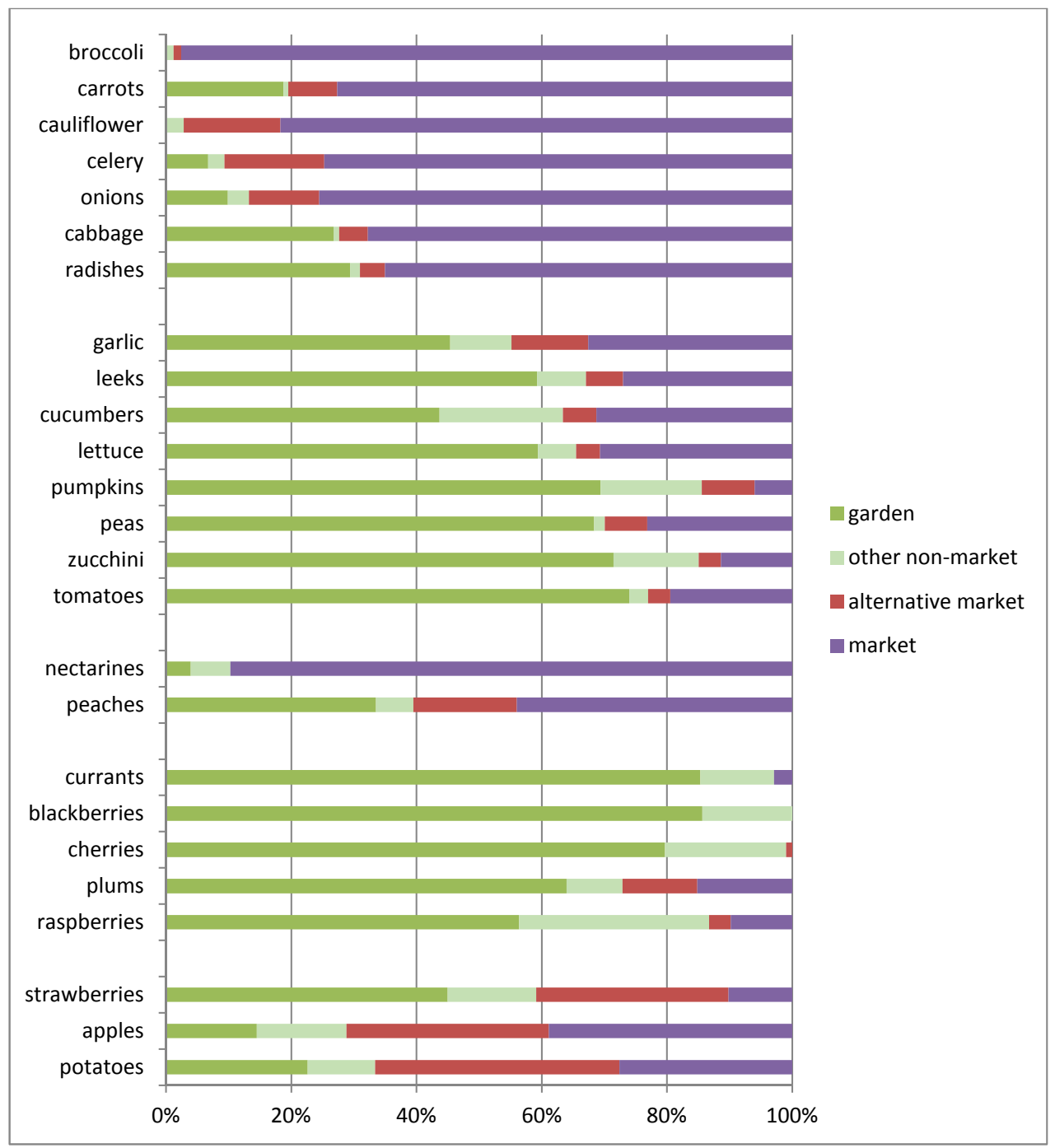

Figure 12: Crops linked to sources. The figure represents the most prevalent crops that tend to be provisioned from a particular type of source. The ratios are based on the total amount offoods recorded in all food logs during the observed periods. 
Here, the seemingly pragmatic criterion of food quality enters the fuzzy territory of emotions and identities. Respondents' understandings of good food (which I further discuss in Chapter 6) were shaped by their personal experiences with gardening. For instance, the image shared by respondent 22 links the better quality and freshness of home-grown herbs to the process of harvesting them:

'I grow herbs on the patio. [...] Lavender, sage, lovage, mint, lemon balm. In the morning I go, I cut some for myself and I make tea. It's better fresh than the dried hay.'

Words such as experience and lifestyle, which were used by some respondents in relation to gardening, suggest that growing food goes beyond a simple hobby and is in fact strongly embedded in gardeners' identities. When asked why he grows food, respondent 5 responded with the following words:

'First of all, having fresh vegetables is an unmatched, unbeatable experience. The second thing is to show our grandkids what can be done in the garden, or how you actually get fruit.'

The exchange between respondents 23 and 24 during a joint interview illustrates how economic considerations are intertwined with understandings of food quality and respondents' identities and self-fulfilment:

'- For me it is not important to grow [food] because of money.

- For me neither. You save money, but you don't have to.

- I could easily buy it. But for me it's important that it has a different taste.

- That's the main thing.

- And that it's mine. I mean that there's something behind it.

- It makes you happy. Look at the bell pepper I have. [showing a picture on her phone] It brings me joy.'

The heavy influence of identity shines through in the statement of respondent 14, in which her garden is positioned as a measure of what is natural and 'right':

'It is the most perfect experience, eating what we got from the garden or what someone gave us from their garden. It's a euphoric feeling that this is the way it's supposed to be, that this is right, some idea that we are still somehow connected to the land.'

These personal understandings are part of the negotiations around FSP just as much as the pragmatic considerations about what is worth growing discussed at the beginning of this section. The sensory, emotional, embodied and experiential aspects of FSP are an intrinsic part of the meaning of this practice. The respondents' experience as gardeners-producers shapes, at least in some cases, their identities, and with that their perspectives on food provisioning in general.

\subsection{Summary: Diverse economies, diverse considerations}

The provided overview of respondents' food sources demonstrates that Belasco's (2008) factors of convenience, identity and responsibility take on diverse meanings and varying degrees of importance for different types of sources. Convenience, in the commonly understood sense of 
physical proximity, sufficient opening hours and affordability, is only an important factor for conventional market sources, that is, supermarkets. For this type of food source, convenience is in fact the most important benefit, whereas the quality of supermarket foods is perceived as lower, and identity or responsibility considerations are rarely mentioned.

Alternative market sources (such as farmers' markets and direct sales) and non-market sources (FSP and gifts), on the other hand, are more strongly linked to respondents' identities. That is not to say that convenience does not play a role here, but rather that it is understood differently. The convenience of alternative market sources is relational rather than absolute: it is determined by the extent to which alternative market venues are integrated into respondents' routines. In terms of opening hours, for instance, farmers' markets are less convenient than supermarkets. However, they can become convenient if respondents manage to adjust their daily schedules. For city dwellers, buying from a farmer is less convenient in terms of geographical proximity than stopping by a supermarket, but once the trip to the farm becomes a tradition, it turns into a convenient way of supplying one's potatoes for the whole winter.

It could be argued that through this routinization, provisioning food from (some) alternative market sources becomes a separate practice, which has a different meaning and which is guided by a different logic than shopping at conventional market venues. This tentative conclusion is based on Reckwitz's (2002) understanding of practice as a 'routinized behaviour'. I do not aspire to precisely delineate the borders of food provisioning practices but merely to point out their distinctiveness. In other words, the conceptual question of whether shopping at a farmers' market is a different practice than shopping in a supermarket (and whether it is always so) cannot be answered with certainty. The important point is that different food sources are guided by different considerations.

Identity and personal relationships are crucial for less formal alternative market sources and non-market sources, for example, receiving food as a gift. In this case, specific understandings of convenience can be clearly linked to different practices people engage in. When going to the supermarket, respondents perform the practice of shopping, and therefore consider convenience in terms of the location of the shop, prices and so forth. Contrastingly, visiting relatives constitutes a separate practice with its own meanings and motivations - socializing, strengthening family relations, enjoying each other's company and the like - in which identity plays a key role. If regarded from the perspective of shopping, gifts from family members can hardly be seen as convenient, given the irregularity and unreliability of such food supplies. Nonetheless, if people obtain food 'on the side' while visiting relatives, food provisioning becomes effortless and is therefore seen as convenient.

The same mechanism applies to FSP, as was first described by Veen et al. (2014). If regarded from the perspective of shopping, gardens might be less convenient than other sources in terms of location, required effort and so forth. However, for people who enjoy the practice of gardening, obtaining food while performing this activity becomes very convenient. This nuance was illustrated in my respondents' accounts which acknowledged that home-grown food is not cheaper if the necessary inputs and labour are financially accounted for, but that it is worthwhile because of values related to the gardeners' identities - joy, self-fulfilment and so forth. 
It can be generalized that when obtaining food from less formalized and marketized sources (FSP, gifts and some alternative market sources) respondents perform a variety of practices and roles. While in this thesis these practices are seen as food provisioning, they also need to be understood as, for instance, social activities and hobbies. In this respect, they are more closely linked to respondents' identities: their lifestyle, social networks, relationships with particular places and the like. On the one hand, this multifaceted nature can make alternative market and non-market food provisioning practices more attractive and more strongly positioned in respondents' lives. On the other hand, it can also compromise their functioning as food sources, as the food provisioning function might be outweighed by the social function, and as they need to compete against other social activities and hobbies for respondents' time. Some of these considerations are further explored in relation to FSP in Chapter 7.

This chapter proposes two additions to Belasco's (2008) framework. Firstly, the diversity of meanings of convenience, identity and responsibility that I encountered suggests that when applying this analytical tool, one needs to be aware of the specifics of particular food provisioning practices and asses them in their complexity. That is to say, for instance, that while location and accessibility of a garden influences its use, these factors cannot be simply juxtaposed to the convenient location of a supermarket.

Secondly, and with the addition of a specific nuance to the previous point, investigations of food provisioning strategies need to account for different economic roles and identities. Belasco's framework does not challenge the mainstream economic perspective in which households are seen as places of consumption. Together with much of the food studies literature, it conceptualizes food provisioning strategies as consumer choices. In contrast, applying a wider understanding of the economy as an array of practices which satisfy people's needs (Section 2.1) unravels a spectrum of diverse food provisioning practices in which households take on diverse roles. These roles entail new perspectives from which convenience, identity and responsibility are negotiated. The most striking example presented in this chapter is that producer convenience includes a whole new set of considerations that are unrelated and inapplicable to consumer convenience.

In sum, food provisioning practices are guided by different sets of considerations, which can be largely related to their position on the market-non-market spectrum. Contrasting the underpinning logic of FSP and other non-market sources with considerations applied to market-based food sources reveals the specific nature of informal food economies. At the same time, two factors seem to be universally applicable to all types of food sources and in fact crucial in respondents' food provisioning strategies. These two factors, namely the respondents' understandings of food quality and the moral obligation to provide good food for their loved ones, are discussed in the following chapter. 


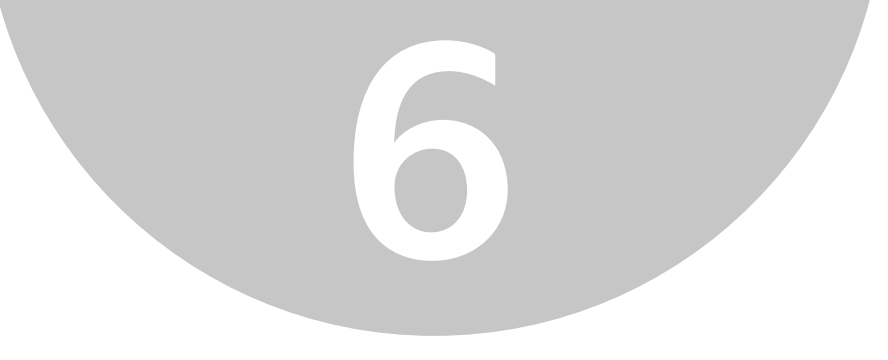

\section{Understanding good food}

Respondents' strategies regarding food sources (i.e. deciding about where to get food) are closely linked to their diets (i.e. deciding what to eat). This chapter therefore focuses on respondents' eating habits, examining how the notion of 'good food' is constructed within diverse food provisioning practices. Conceptually, I continue to explore Belasco's triangle, focusing specifically on identity in Section 6.1 and responsibility in Section 6.2. Diverse economies and practice theory are used to a lesser extent in this chapter.

As already mentioned in Chapter 5 , respondents perceive differences in the quality of food from different sources. Taste was typically highlighted in connection to home-grown food, while the quality of food from supermarkets was often criticized. In the first section of this chapter I explore the underlying logic of this hierarchy of sources, and I show how it is shaped by gardeners' identities. By juxtaposing these insights with the seasonal patterns identified in Chapter 4, I illuminate how perceptions of quality influence respondents' food provisioning choices.

Although respondents perceive fruits, vegetables and potatoes in supermarkets as being of low quality, supermarkets were significant sources of these foods. ${ }^{139}$ In the second section of this chapter, I explore this paradox, viewing it through the lens of responsibility - the third apex of Belasco's (2008) triangle. In my inquiry into respondents' responsibility considerations, I first explore to what extent the construction of 'good food' overlaps with values and concerns associated with the search for more sustainable food systems. Furthermore, I introduce other responsibility concerns which guided my respondents' food provisioning practices, namely negotiations of care and healthy eating. By again relating these insights to seasonal patterns, I illuminate the seemingly paradoxical practice of shopping in supermarkets.

\subsection{Hierarchy of sources}

During our conversations about FSP, respondents often stressed that home-grown food was tastier than products bought in supermarkets. Closer investigation revealed that what was often described as taste referred in fact to a complex notion of food quality. Respondents' understandings of good food comprised one of the key factors which shaped their food provisioning strategies. Respondents perceived quality differences in food from different (types of) sources, which resulted in a clear hierarchy. Home-grown food was generally perceived as

139 For 15 respondents, supermarkets were the most important source of food overall. Ten respondents got most of their food from their gardens. Two respondents used direct sales the most. 
the best, followed by (home-grown) gifts. Produce from alternative market sources was still comparable, whereas food from conventional supply chains was deemed to be of low quality. This hierarchy is more or less explicitly illustrated in some of the respondents' accounts. For example, respondent 10 stated the following:

'I don't necessarily need to grow everything; you can always exchange [food] with someone, or in the worst case you buy it.'

In what follows I will summarize respondents' understandings of food quality, ${ }^{140}$ upon which the hierarchy of sources is based. As the following quote demonstrates, food quality is a complex construct which includes and conflates several factors, namely transparent origins, chemical-free production methods, healthiness, freshness, taste and other sensory and experiential aspects: ${ }^{141}$

'I think that home-grown [food] is definitely higher quality. For instance, I don't use many chemicals. Other people may use chemicals in their gardens, and they have more beautiful, bigger vegetables. But is it better taste- or health-wise? I have seen how tomatoes are grown in Turkey, on those fields of polytunnels. Well, they're red, but they don't have any flavour. Or if I buy strawberries now [in winter], they taste like beetroot. A strawberry, when you pick it in the garden, the sun is shining on it and it's warm; you don't get that taste even if you buy it on the market from a farmer, but if you have it warm, freshly picked, that's something exquisite. And that's exactly why I do it.' (r. 15)

When talking about transparent food origins and chemical-free production methods, respondents often deemed food from market sources as untrustworthy, 'sprayed' and 'chemical'. This food was especially contrasted with home-grown produce where respondents 'knew exactly what they put into it'. The aversion to agrochemicals is thus based on respondents' experience with food growing, in other words, their identity as producers. Using agrochemicals in the garden had negative connotations for virtually all respondents (see also Section 6.2.1). Some, however, saw pesticides as a necessary evil which was unavoidable for particular crops or situations:

'We mostly don't use chemicals, only for some things, for instance, grapevine; you cannot treat it any other way than chemically.' (r. 5)

However, many respondents chose not to grow crops susceptible to pests, as mentioned in Section 5.2.4. Respondents also recognized that these attitudes were specific to their gardening practices and the values they attributed particularly to home-grown foods (as also already mentioned in the same section). Take the following examples:

'I was always against chemicals; I can buy that [chemically treated produce] in the shop, but in the garden I don't spray anything.' (r. 22)

'Sometimes it is necessary, but then we try to spray it for instance with tobacco, and we make sure to do it as early before the harvest as possible. Sometimes it's not feasible. Rather than losing all tomatoes to mould, we spray them, but we try to minimize it. That's why we grow it in the garden.' (r. 3)

140 Similar understandings of quality have been documented in the literature on FSP in CEE; see Section 1.2.4. Furthermore, many of these issues already appeared in Chapter 5 in relation to particular types of sources. However, they merit recapitulation here.

141 See also the end of Section 5.2.4 which introduces some of these factors in relation to home-grown food. 
The understanding of FSP as a way of providing chemical-free foods is thus performative, bringing together both the producer and consumer roles that gardeners take on during this practice. The appreciation of non-sprayed fruits and vegetables leads to respondents' reluctance to use agrochemicals for gardening. Vice versa, chemical-free growing methods inform respondents' appreciation of home-grown food. Furthermore, it seems that these considerations are enabled by the special status of FSP as both a food source and a hobby, as reflected by respondent 27:

'I didn't spray [my garden] even when the cabbage whites were eating my Savoy cabbage. Let them eat it. But that's really because I see it very much as a hobby; it's not like I'm a farmer who needs to sell it somewhere.'

Respondents used a number of sensory indicators to assess the quality of foods. As already mentioned in some of the quotes in Chapter 5, crops produced with the use of industrial pesticides or fertilizers might look more appealing, but they lack flavour or aroma. The following statement from respondent 25 provides another example of this opinion:

'Obviously most of the things can be bought in the shop. But we have a garden so we can buy [only] what is tasty. For instance, now in winter I picked an apple [in the shop], I wanted to smell it, and nothing. So, I put it back again because the apple did not have any smell.'

Hence, respondents' views on appropriate production methods are not only based on rational understandings of production processes but also on more intuitive and experiential perceptions. In the quote from respondent 15 at the start of this section, a strawberry warm from the sun is better than a tomato grown in a polytunnel also by virtue of the growing experience. ${ }^{142}$ In fact, the intuitive notion of 'right' and 'wrong' growing methods might be more important than the actual amount of agrochemicals that might have been applied in both situations. Ideas about the right ways of producing food are based on diverse ways of knowing, and intuitive and experiential understandings contribute to the perception of home-grown food as impossible to surpass by products from any other source.

Furthermore, and as already documented in the literature (e.g. de Hoop and Jehlička, 2017; Gabriel, 2005; see Section 1.2.4), food quality has a social component. This was particularly apparent for alternative market sources (Section 5.2.2), and even more so for informal networks operating in the grey zone between direct sales and gifts. In these trust-based transactions, simply knowing from whom food comes from can be more important than whether it was produced in compliance with any standards. For instance, respondent 10 explained why she preferred to get food from acquaintances over farmers' markets:

'One anyway doesn't know where it [food] comes from [at the farmers' market]. I don't really have trust in it. I prefer to get something from an acquaintance, although I know that they can also use something [agrochemicals], or I don't know exactly. I don't dig into it, but I know that there is a person behind it, so I have more trust in it.'

The social aspect of less formal food networks that I mentioned in Section 5.2.2 therefore does not only render them convenient (in their own way), but it also affirms the quality of the food

142 See also the end of Section 5.2.4 on experiences related to FSP and the accounts of experiences from farmers' markets in Section 5.2.2. 
they provide. The importance of personal relationships might also be one of the reasons why traditional food networks (Tisenkopfs, 2017; see Section 1.2.5) such as FSP, sharing and alternative market sources based on social networks are more prevalent in my sample than more formalized and professionalized ones, e.g. buying certified organic produce in specialized shops. Personal relationships are effectively seen as a guarantee of quality, whereas institutional guarantees seem less trustworthy.

To summarize, there is a hierarchy of food sources informed by a specific understanding of good food, which stems not only from rational knowledge but also from experiential, sensory and emotional perceptions and social relationships. Food quality thus extends beyond objective criteria for production methods, nutrient contents or food safety. In other words, understandings of good food are closely linked to identity (as also discussed by Jackson et al., 2006). Specifically, the fact that gardeners understand their own produce as a benchmark for quality suggests that their understandings of good food are informed, at least to some extent, by their identity as producers. Considering the prevalence and long tradition of FSP in CEE, these identity considerations could be seen as at least partly culturally informed. ${ }^{143}$ The embeddedness of notions of good food in identity probably also explains the central role that these understandings play in food provisioning strategies.

Notably, the resulting hierarchy is the very opposite of assumptions based on mainstream economic logic. The marketization and formalization theses (introduced in Section 1.2.2) assume that informal economies are inferior and will be gradually replaced by market-based sources (Acheson, 2007). My respondents' understandings of good food categorically contradict this assumption: non-market food sources are actually seen as the best, while market sources are framed - often explicitly - as a second option (see also White and Williams, 2016, discussed in Section 2.2). While this conclusion might seem counterintuitive from mainstream economic positions, it is in fact not new in the literature on FSP in CEE (see Section 1.2.4). In order to advance this scholarship, in the following subsection I use some of the seasonal patterns introduced in Chapter 4 to demonstrate how this hierarchy of sources shapes respondents' food provisioning strategies.

\subsubsection{Good food sources and seasonal eating}

The hierarchy of food sources based on understandings of good food is one of the main mechanisms underlying respondents' food provisioning strategies, which can also explain many of the seasonal changes introduced in Chapter 4. For example, respondents lower their consumption of particular crops once they stop being available from preferred sources. The perceived difference of quality leads respondents to prefer non-market and alternative market sources for some foods (see Figure 12 in Section 5.2.4). Since these sources tend to be more seasonal, the consumption of such foods fluctuates. In other words, the seasonality of sources shapes the seasonality of diets.

143 The notion of culturally appropriate foods is used in the food sovereignty discourse mostly in relation to particular crops. Stretching the concept allows the conceptualization of FSP and traditional food networks as culturally appropriate food practices (see also the notion of 'quiet food sovereignty' in Visser et al., 2015). 
This can be observed, for instance, in the decline of the consumption of potatoes in spring (the 'potato mystery' introduced in Section 4.2) and high summer peaks ${ }^{144}$ of vegetables strongly linked to the garden, depicted in Figure 13. The consumption of these crops follows the seasonal rhythm of their harvests; the respondents eat most tomatoes in summer, most lettuce in spring, most potatoes in autumn and so forth. Seasonality is thus shaped by the materiality of the crops; note also that there was a less steep decline in the consumption of foods with longer shelf lives such as potatoes and pumpkins compared to perishables such as lettuce, which is practically only consumed in season. ${ }^{145}$

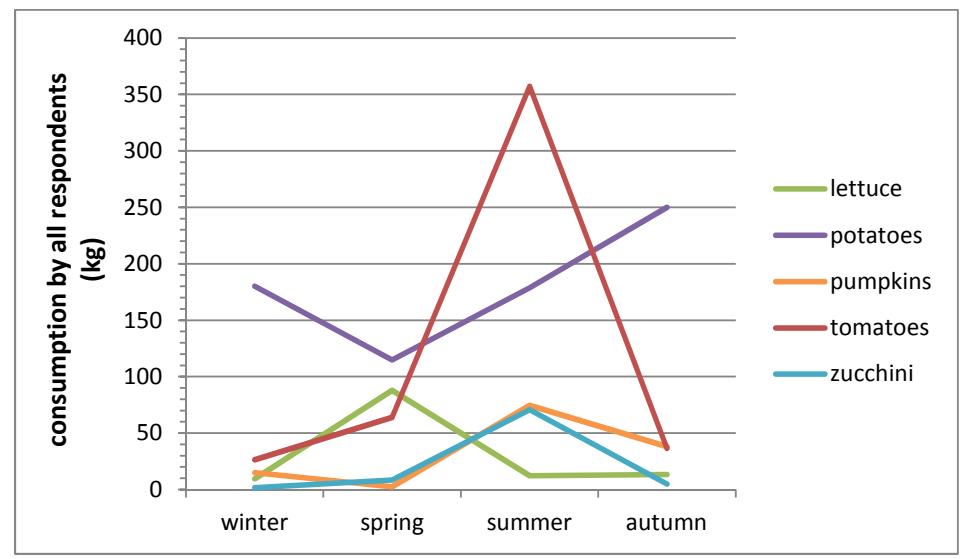

Figure 13: Seasonal consumption of vegetables linked to non-market sources

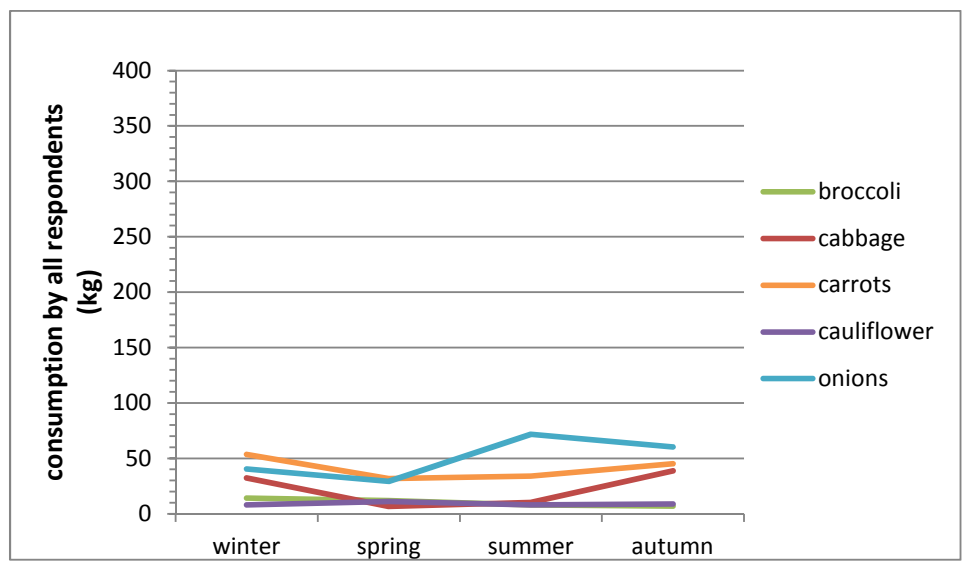

Figure 14: Seasonal consumption of vegetables linked to market sources

144 The summer peak itself results in some cases also from an abundant harvest (i.e. the garden yields are so high that respondents consume more of particular vegetables than they normally would - the 'garden bias' introduced in Section 5.2.4). However, the decline in other seasons also points to respondents' reluctance to provision these vegetables from lower quality sources, as was explicitly confirmed by multiple gardeners for tomatoes and potatoes.

145 For the sake of clarity, the amounts here only account for respondents' own consumption, excluding flows of food that were shared or preserved, which however follow the same patterns. 
In comparison, vegetables provisioned either from market sources or from a larger diversity of sources were consumed in comparable amounts throughout the year (Figure 14), or they displayed diverse seasonal patterns that were more difficult to interpret. These 'non-seasonal' foods typically included staples that could be obtained from diverse sources in comparable quality and/or foods that were seen as difficult to grow (as discussed in Section 5.2.4).

It could be argued that the seasonality of these crops is to some extent also shaped by the fluctuation of produce from seasonal sources. For instance, carrots - which were mostly purchased in supermarkets - were consumed slightly more in autumn and winter, possibly also because during these seasons respondents had fewer vegetables from their gardens. Thus, carrots obtained in supermarkets effectively replaced home-grown tomatoes (and other vegetables) in respondents' diets. Multiple respondents explained the summer peak in the consumption of (mostly shop-bought) onions by the need to use more onions for meals made with garden vegetables, as mentioned in Section 4.3 .

It thus appears that the seasonal availability of food from gardens and other less formal sources drives seasonal changes in respondents' diets, ${ }^{146}$ even beyond foods that are directly linked to these sources. To use the phrasing of social practice theory, the meanings (understandings of good food) and materialities (seasonality of produce) related to less formalized food sources (FSP, gifts, direct sales) play a crucial role in the negotiations of broader food provisioning practices.

Concerns about food quality and the hierarchy of sources were also one of the motivations for stocking and preserving food for winter, practices that enabled respondents to temporarily extend the availability of food from desired sources (and hence food of the best quality). ${ }^{147}$ The link between food quality, food sources and seasonal patterns is clear in the following quotes from respondents who made preserves from their own harvest or even food purchased from alternative market sources:

'Even in winter we didn't buy vegetables at all. We had some pickled beetroot of our own. I also pickled cabbage, some of my own and some I bought from a farmer. I have dried mushrooms, so [we eat] everything with mushrooms, the last pumpkins, lots of potatoes, rice, lentils.' (r. 10)

'One reason is that some things are more expensive in the winter, like tomatoes, and they are also gross. It's just not tasty if you buy a tomato now in January. Of course you can buy lecsó. ${ }^{148}$ But it [making it yourself] saves money, and I know what is in it, from which ingredients it is, and it is healthier than the one you can buy. Now [in winter] the farmers don't have certain vegetables anymore, so it's better to preserve the good ones from summer.' (r. 13)

When asked about seasonal changes in his household's diet, respondent 5 replied:

'It changes throughout the year. Tomatoes and bell peppers are there during summer, not so much in winter, because tomatoes from the shop are flavourless. [...] In winter we have what is frozen, preserved or stored in the cellar.' (r. 5)

146 At least in terms of vegetable consumption. Seasonal patterns for fruits were less clear, and the scope of this study does not allow me to consider the consumption of other types of foods, although some respondents mentioned, for instance, eating less meat during the peak garden harvest in the summer.

147 See section 7.3.1 on how stocks and preserves are used.

148 A dish with tomatoes and bell peppers also sold in cans. 
Once stocks run out, households can choose one of two options: either changing their diets (as indicated by respondents 5 and 10 above, and further explored in Section 7.3.3) or provisioning the desired foods from lower quality sources. The latter solution then leads to the paradox introduced at the start of this chapter: although respondents criticized the quality of food from supermarkets, they still used them as important sources. The next section seeks to further unpack this mechanism by exploring the diverse responsibility considerations underlying respondents' food provisioning practices.

\subsection{Responsibility: Towards the world and the household}

In Belasco's (2008) triangle of consumer choice, responsibility refers to understanding and considering the impact of individual consumer choices on others, the world and the environment. In this context, responsibility can be understood as conscious or ethical consumerism (see Section 1.1.3), and a part of the search for a more sustainable food system. This section starts from this perspective, providing an account of ethical and environmental considerations in respondents' food provisioning strategies.

In the second part of this section (6.2.2), I will expand on Belasco's understanding of responsibility using the concept of lay normativity developed by Sayer (2004). Sayer states that moralities are not only abstract, rational and external systems of regulations but also social norms translated into everyday decision-making through ideas of right and wrong with direct implications for people's well-being. Studying morality thus entails exploring what people care about and why (p. 18). On the household level, this relates to the needs and the collective well-being of the household's members (Mylan and Southerton, 2018; Niehof and Wahlen, 2017). Apart from externally oriented responsibility 'towards the world', that is, conscious consumerism, I therefore also explore the 'internal' responsibility that respondents have towards their households.

\subsubsection{Environmental ethics and conscious consumption}

Many of the determinants of 'good food' mentioned in Section 6.1 echo the debates on more sustainable food systems (Section 1.1.1). Most respondents were concerned with the transparent origins of their food and the use of agrochemicals; some also problematized long-distance transportation and the (non-)seasonality of the assortment of conventional market venues. However, the entanglement of these issues with other aspects of food quality often resulted in specific understandings and internal contradictions.

Only few respondents could be categorized as conscious consumers in that they deliberately tried to improve the impact of their consumer (i.e. shopping) choices on the world. In total, eight respondents mentioned some ethical or environmental considerations during introductory interviews. These concerns often merged with other considerations, such as a lifestyle fitting to the respondent's identity: 
'I have considered different ways of eating. A year ago, I was trying the paleo diet, where you eat quite a lot of animal protein only with vegetables and fruits and virtually no grains or legumes. I try to take some inspiration from everything and find some compromises. I want it to be healthy but at the same time environmentally responsible, ethical... All these conditions which I would like to fulfil, and it's not always possible, so I compromise. When I feel tired, I eat more meat, which I don't buy from conventional production. Then we have a month without meat because I don't feel good about eating dead animals.' (r. 13)

Animal products were a common object of the ethical concerns of my respondents, as the other quotes below illustrate. In regards to fruits and vegetables few respondents spoke directly about moral considerations (i.e. supporting small shops versus supermarket chains) or environmental concerns (i.e. the environmental impact of long-distance food transport). More often, these issues were rather implicit and blended with other considerations such as food quality or price:

'I don't want to be judgemental, but I think that it is not entirely right that all vegetables are so easily available thanks to imports. Firstly, it is terribly expensive in the supermarket outside the season, and exotic fruits ripen in trucks or under artificial conditions. It is not natural; now [in winter] is the time to eat root vegetables, potatoes, cabbage.' (r. 14)

As noted in Section 5.2.1, these other factors (especially convenience) could also easily outweigh respondents' moral intentions. Several respondents spoke about ethical and environmental concerns during introductory interviews, but these issues rarely reappeared in later stages of the research. Moreover, the food logs showed that respondents' food provisioning practices were sometimes at odds with their proclaimed attitudes. ${ }^{149}$ It appears that respondents were aware of the social desirability of conscious consumerism, but they did not always succeed at integrating it into their food provisioning practices. Similar tensions between attitudes and behaviours have been widely documented in the literature on conscious consumption (Section 1.1.3).

Despite their strong ideas about good food, most respondents were sceptical of labels, certifications or specialized shops which would be typically recognized as facilitating conscious consumption. The case of organic food illustrates this tension, reaffirming gardeners' affinity with traditional rather than alternative food networks. As mentioned in Section 5.2.2, buying certified organic goods was rare within my sample. While respondents explained not buying organic produce because of its higher price, some of their expressions also hinted at a lack of trust in certification, framing it as a suspicious novelty:

'I don't buy organic food because there is no such thing as organic food. I come from a village; I know how it goes. My parents used to grow vegetables a lot, so I'm aware that if you don't spray it, it simply won't grow. Organics, that is only a matter offashion. But I like what the farmers [at the market] have.' (r. 20)

This comparison between organic food and farmers' markets confirms the importance of social relationships for creating trust in food quality. As mentioned in Section 6.1, gardeners' identities as producers play an important role in their understandings of good food and appropriate sources. In this case, somewhat paradoxically, their own experience with growing food can lead

149 For instance, respondents criticized the long-distance transportation of food but still purchased fruits and vegetables which had to be imported (e.g. exotic crops). Other respondents talked about consciously trying to eat seasonally, but their food logs indicated otherwise. 
to scepticism in terms of what is possible without the use of chemicals, as demonstrated even more strongly in the following quote:

'These health food shops and such that have appeared, well, I know because I grow food myself-when you come to the shop and you buy beautiful apples, and they claim that they are free of chemicals, then I don't believe it because you cannot grow apples like that. It is all just fraud.' (r. 15)

On the other hand, and alongside these suspicions, most respondents saw a similarity between food from less formalized sources (the 'good food' introduced in Section 6.1) and organic food. Some of them even half-jokingly used the word organic (bio in Czech) to describe the qualities of food from these sources. For instance, an older respondent argued that what is nowadays labelled 'organic' used to be the standard in the past:

'That's how we lived. When our grandma sent us a chicken, it was actually yellow; it was well fed, not like the poor chickens that are crammed in there nowadays. So, we grew up on organic food. Even during the war, there was less food, but it was all organic; it was of higher quality than nowadays.' (r. 16)

Respondent 1 had friends who were hunters, and she purchased wild boar meat from them. She explained:

'...and it's organic. It runs around in the forest its entire life, and then it's just shot. I like that it doesn't suffer somewhere on a farm.'

In practice, ethical concerns paralleled respondents' understandings of good food and the hierarchy of food sources, as illustrated by the following quote from respondent 13 . Note again the importance of social relationships and the strategy of avoiding the food in question in case it is not available from the desired source or in the desired quality:

'I try to get home-grown eggs from one lady who lives in the same village as my mom. My mom comes here [to Brno] fairly regularly to babysit our son, so she brings them. [...] And if not, I order them from [a farmer with an online store]; they also have their own eggs. I don't know what it looks like, if it's exactly free range, I didn't ask. But they are their eggs, which is nice. And if I can't get those either, I buy free range or at least from barn-raised chickens. I try to avoid the ones from caged chickens, then I prefer not to eat them.'

The same ethical reasoning motivated respondent 1 to keep chickens. Her explanation also demonstrates how different considerations (in this case ethics, convenience and price) are interlinked:

'I don't want to support chicken factory farms; I find it insane. And I thought I have a garden, so why not: it's an easy solution, and we don't have to buy [the eggs]. Maybe it was also the price of organic eggs. You pay 6 to 10 crowns for an egg, so then I resorted to buying eggs from barn chickens but then I was doubting whether it made any sense, it's almost the same as the caged ones. So, I thought when we have the space, and I live here now permanently, it would be great to keep chickens. I think everyone who has a garden should have them.'

The connection between respondents' ethical and environmental concerns and their understandings of good food seems to be close and interdependent. On the one hand, ethical considerations inform what respondents understand as good food: meat from a wild boar is good also because it avoids animal suffering. On the other hand, ethical concerns are themselves 
shaped by broader understandings of good food: food embedded in social relationships is seen as more trustworthy than certified products. Due to this interdependence, ethical considerations apply to some food sources more than to others: they are part of good food from less formalized sources, but they have less bearing on shopping in more formalized venues.

This can be explained through the distinctions between different food provisioning practices or different economic roles and identities. Respondents' negative attitudes towards agrochemicals, which were already mentioned in Sections 6.1 and 5.2.4, provide the most striking example of different practices' diverging meanings. Aversion to agrochemicals forms a crucial part of the meanings attached to the practice of FSP. In their producer roles, gardeners adopt multiple strategies to act on these attitudes, including experimenting with different gardening methods, intensifying manual labour, avoiding growing pest-susceptible crops altogether and rationalizing the use of agrochemicals as a necessary evil. Aversion to agrochemicals also contributes to respondents' understandings of good food and the resulting hierarchy of sources. 'Non-chemical food' is thus part of the meanings associated with non-market and alternative market food provisioning practices. Contrastingly, when respondents assume the role of consumers and provision food from market sources, concerns about production methods are less prevalent, if present at all: they are not part of the meanings associated with the practice of shopping at conventional venues.

The responsibility lens thus confirms the conclusions about respondents' convenience and identity considerations that I presented in Chapter 5: obtaining food from diverse food sources entails, at least to some extent, different food provisioning practices, each of which is guided by its own logic. In relation to consumer ethics, these insights are relevant for the literature on AFNs and urban gardening. Some authors (Kim, 2017; Okvat and Zautra, 2011) see the value of urban gardens in education and awareness raising: they hope that the knowledge about food production that gardeners gain through their experience as producers will contribute to their sustainable consumer practices. My conclusions indicate, however, that such knowledge transfer is not straightforward: one can be an environmentally conscious gardener yet a mainstream consumer.

Furthermore, these findings affirm the need to understand conscious consumption more broadly, that is, beyond the implicit bounds of the market (see Section 1.1.3). The ethical and environmental considerations related to my respondents' FSP practices as well as their understandings of good food sources show that they are without a doubt engaged in ethical food provisioning, although most of them do not practise ethical shopping (see also Kosnik, 2018). In other words, gardeners' practices might not fit the scholarly understanding of ethical consumption, but they can still be relevant for a more sustainable food system. Furthermore, the next subsection shows that moral considerations about food provisioning are not limited to 'responsibility towards the world' but that they also involve negotiating responsibilities towards respondents' households. 


\subsubsection{Caring about healthy eating}

As noted in the previous section, respondents' ethical and environmental considerations are blended with and to some extent even overshadowed by broader understandings of good food. Few respondents were explicitly concerned with the impact of their food provisioning strategies on the world. For most, concerns about food production were related mostly to health, food quality and safety. Such motivations are rather common even for so-called conscious consumers who can be motivated by lifestyle and food quality rather than a higher morality and the desire to challenge the dominant food system (the reflexivity issue discussed in Section 1.1.2). An example from the Czech context is provided in Zagata's (2014) study of motivations for buying organic food. Consumers who bought certified organic produce mostly appreciated that it was 'chemical-free' and therefore healthy, while environmental concerns were secondary.

This is not to say that respondents' food provisioning strategies are not shaped by ethical considerations and responsibilities. As Sayer (2004) argues, the moral dimension is unavoidable in any social action, as long as it is understood not as an abstract, externally imposed set of rules and norms, but as the everyday consideration of right and wrong, that is, 'lay morality'. In a household context, these moral considerations are geared towards the well-being of household members and providing for their daily needs (Niehof and Wahlen, 2017). Food provisioning as a caring practice which reproduces and sustains life (see Section 2.1) is thus a moral pursuit. 'Feeding the household' is perceived and carried out as a moral obligation by food providers, and this responsibility is often gendered (McIntyre et al., 2009; Niehof and Wahlen, 2017).

My research confirms these understandings of food provisioning as a moral practice, and it shows how this type of responsibility towards the household shapes respondents' food provisioning strategies. Providing good and healthy food for the household was the main responsibility concern I encountered within my sample. The notion of healthy food was included in respondents' understandings of good food and appeared frequently in the discussions about their eating habits. While respondents ascribed different meanings and different levels of importance to food being healthy, some form of health concern was an intrinsic part of their food provisioning practices.

The notion of health appeared in several variants. Some respondents paid more attention to their diets because of their own health status. For others, caring about eating well was a part of their lifestyle, and they enjoyed experimenting with new food trends. However, most respondents did not identify as followers of a healthy lifestyle. Their opinions on what was healthy (fruits, vegetables, legumes) or unhealthy (fried foods, processed foods, sausages, sweets) were rather conservative and commonsensical. Fruits and vegetables were an important part of healthy eating in this group. Since these foods were the main focus of my research, discussions of healthy diets often centred on eating enough of them. . $^{50}$

Respondents' gardens contributed to healthy diets by virtue of providing fruits and vegetables of good (perceived) quality and in abundant quantity. Some respondents felt that their gardens helped increase their consumption of these foods:

150 I was surprised to discover that some respondents even regarded the food logs as a tool for tracking whether they had eaten enough fruits and vegetables. 
'I think we eat more vegetables than we used to. I personally always ate them, but I think for my husband it increased rapidly. I'd say that when the garden is producing, three-quarters of what we eat is vegetarian; it is significantly more.' (r. 3)

When asked whether the increase in vegetable consumption was caused by the garden, the respondent confirmed:

'I think so. There's a lot. It is at home; it's right here behind the door. But that's good, that was the purpose; it was meant to make us eat healthier.'

In this way, the practice of FSP can be seen as (partly) motivated by the responsibility to provide healthy food. This is also apparent in the following quote, which further documents the relation of gardening without agrochemicals to health (rather than to environmental concerns):

'[We grow so many carrots] because some of our children still have little children, so for them to have nonchemical carrots.' (r. 5)

Apart from chemical-free production, the notion of health was also connected to other aspects of understanding good food. Respondent 24's story about her grandson reveals once again the interconnectedness of food quality, embodied experience and identity, which overpowers concerns about hygiene:

'The little one walks around, picks something and eats it right away. I don't care about washing it. It's in the garden, eat it with the soil and with the worms, I don't mind, because I know it's healthy. So that's my approach. That's how I grew up, so I'm not concerned with whether it's washed or not.'

The previous three quotes demonstrate respondents' understanding of food provisioning as a matter of responsibility towards the household. They frame growing food as a way of caring for loved ones, and they also point to the most common recipients of this care - children and male partners. Within my sample, food provisioning was mostly the domain of women. ${ }^{151}$ For many of them, making food healthy was a conscious effort, which was apparent from common formulations such as 'I try to make sure that the food is healthy/nutritious/includes enough vegetables.' What is more, many respondents described male household members as almost innately resisting eating fruits and vegetables or eating healthy food in general: $:^{152}$

'Me and the kids eat plenty of fruits and vegetables. With my boyfriend it's worse. We try to motivate him, but he would at most have a radish or a kohlrabi; that's a bit worse.'(r. 27)

'I try to put in some vegetables ifpossible. That is mostly my thing. I like anything green; I don't have a problem with it. With my husband it's worse. [...] The only thing my husband eats is bell peppers and radishes.' (r. 4)

151 Several households shared food provisioning responsibilities in diverse ways (see Sections 5.2.3 and 7.1), and the sample also included two single male households. Nonetheless, women were the main food providers in most households (see the sample composition in Section 3.3.3). I believe that my sample is in this sense not exceptional in the Czech context, where food provisioning is traditionally seen as women's work (see also Section 2.1).

152 While this can be attributed to social norms about gender-appropriate food, some of my respondents offered an alternative interpretation which linked the consumption of fruits and vegetables to the need to prepare them. They explained that their partners would find it inconvenient to prepare a fruit or vegetable snack for themselves, but they would gladly eat fruit and vegetables offered in a ready-to-eat state (i.e. washed, peeled, sliced). 
When I asked whether bell peppers and radishes were vegetables that the respondent's husband liked, she replied:

'Well, likes. He eats it. Because he should eat some vegetables.'

Responsibility for the diets of loved ones extended beyond the practice of meal preparation and beyond the physical space of the household, focusing on eating habits in general:

'We're not vegetarians, but I try, because the kids get meat at [the] school [canteen] all the time. I think they get it four times a week, so I try to cook without meat at home because I feel that we all have enough of it already.' (r. 9)

It also extended beyond the main household ${ }^{153}$ to other family members:

'Lately, my son has appreciated it [homemade preserves] a lot. He just got divorced. He lives on his own, and he's learning how to cook. So, I gave him what I had in the pantry, the baked vegetables, and he doesn't stop singing their praises. He says, "Mom, that's so good." And I know at least that he eats healthily, so I'm happy.' (r. 24)

Healthy eating was negotiated to some extent at all stages of respondents' food provisioning practices: growing food, procuring food from diverse sources, and preserving and preparing meals. In each step, these practices were also affected by other factors, such as convenience, price and identity:

'I try to include legumes and minimize meat products, but it's also not always possible. Sometimes it is easier to make a sandwich.' (r. 3)

'Fruits and vegetables, that's sort of a long-term goal, to include them more. [Eat more] legumes. Less sugar. But at the same time don't avoid things like pig slaughter feasts. ${ }^{154}$ (r. 7)

These negotiations are often routinized and implicit:

'I always try for the food to be healthy. But I have to say that it's also somehow a given. I already have some foods [in my cooking repertoire], and I don't really think about whether they are actually healthy. For instance, I make fried cheese with potatoes. That's not entirely healthy, but I make it. I don't really contemplate it. I have some foods that I cook. I also want it to be cheap. I look in the wallet and in the fridge, and based on that I cook.' (r. 8)

Nonetheless, responsibility considerations - in the sense of providing healthy food for loved ones - heavily influence respondents' food provisioning strategies. In the next section, I show that some of the seasonal patterns identified in Chapter 4 can be in fact explained through this guiding principle.

153 See notes on nested and interconnected households in Sections 3.1.2 and 3.3.1.

154 Slaughtering a pig in the context of household or small-scale farming is traditionally performed not only as a way of obtaining food but also as a social gathering during which traditional dishes are prepared and consumed. In this quote, the respondent positions this practice as a tradition in which she wishes to participate-despite her understanding of healthy food, informed by a modern lifestyle. 


\subsubsection{Healthy eating throughout the seasons}

The responsibility to eat healthily lies at the intersection of food provisioning negotiations about diets (which foods to eat) and sources (where to acquire these foods). These two considerations result in two patterns. Firstly, as health was linked to quality, respondents preferred to provision food from what they perceived as the highest quality sources. Their food provisioning strategies were thus based on the hierarchy of sources introduced in Section 6.1, together with other considerations of convenience and identity (Section 5.2). This resulted, for instance, in the avoidance of some foods outside the season, as explained in Section 6.1.1.

Secondly, however, since fruits and vegetables were perceived as necessary for healthy diets, respondents felt responsible for procuring them in sufficient quantities in order to cover their households' needs and dietary preferences. It is for this reason that respondents resorted to lower quality sources, especially if the desired foods were not easily available from the preferred sources, which tend to be more seasonal. In other words, the responsibility to eat healthily (understood as consuming enough fruits and vegetables) would in some cases outweigh respondents' preference for good sources. These negotiations can be seen in accounts which explicitly describe market sources as supplementary and used typically in the winter months:

'I cook vegetables a lot. Now [in winter] I buy frozen mixes, for instance, green peas and carrots, and I buy lettuce and Chinese cabbage because I don't have that from the garden now, so I need to buy it.' (r. 22)

The increased use of market sources in winter and autumn, documented in Figure 7 (Section 4.5), confirms that these sources are mobilized as a second option when respondents cannot get their food from their preferred sources. ${ }^{155}$ In addition, respondents adopt diverse strategies to extend the availability of food from good sources. Bulk purchases from direct sales in autumn and winter (Figure 7) or higher reliance on preserves in these seasons (Section 4.1; quotes at the end of Section 6.1.1) can be seen as examples of this mechanism.

In addition, respondents adapt their diets seasonally in diverse ways. As already mentioned in Section 6.1.1, crops which are strongly linked to 'good sources' show more seasonal variation. If they cannot be obtained from the desired sources, respondents lower their consumption or resort to preserves. At the same time, some crops are purchased from market sources predominantly in autumn and winter. The increased consumption of exotic fruits in these seasons (Sections 4.1 and 4.4 ) is an example of this mechanism. Some respondents explicitly linked this pattern to health considerations:

'Last winter it was mostly citrus fruits; it's recommended for the flu. Vitamin C alleviates the symptoms and prevents the flu from developing. So, when I have a sore throat, I go to the shop and get citruses.' (r. 2)

'I ate oranges all the time in winter, and I also ate heaps of mandarins. Because the apples don't have so many vitamins anymore, so I thought the exotic fruits are good. Then in the spring there are other sources of vitamins again.' (r. 22)

155 On average, respondents acquired $25 \mathrm{~kg}$ of observed foods from market sources in autumn, $21 \mathrm{~kg}$ in winter, $17 \mathrm{~kg}$ in spring and $14 \mathrm{~kg}$ in summer. 
Seasonal eating and the underlying understanding of health and food quality thus also extend to shopping practices. ${ }^{156}$ The following quote further reveals how this pattern is enhanced by price considerations:

'I try to buy seasonal goods logically also because they tend to be better. And it is also reflected in the price. You don't buy the most expensive things in the winter, but you also try to get a spectrum of vitamins.' (r. 1)

The responsibility to provide healthy food thus illuminates the seeming contradiction mentioned at the start of this chapter: respondents are critical of market sources in terms of food quality, but they still use them to procure fruits and vegetables to meet the dietary needs of their households when the preferred, yet more seasonal sources are not available. More broadly, it also clarifies respondents' understandings of FSP as a food source. While FSP is seen as a good food source and thus a way of accomplishing the moral task of providing good food, the vast majority of respondents did not strive to become self-sufficient as a matter of moral principle or environmental consciousness - certainly not in a way that would limit the household food supply. In the end, having enough healthy food was the main priority. Needless to say, respondent households differed in their understandings of the types and the quantity of food required for a healthy diet: while some respondents perceived it as natural to obtain their winter vitamins from pickled cabbage and beetroot from 'good sources', others felt the need to consume exotic fruits, and yet others preferred to maintain a steady diet all year long, using supermarkets to purchase food that they grow in their gardens in summer.

As mentioned at the start of this section, conscious consumerism often blends what Zagata (2014) terms 'altruistic' motivations (i.e. environmental concerns) with more 'egocentric' ones (i.e. food quality). I interpret these motivations as two types of morality and responsibility: one focused outwards on the world and one focused inwards on the household. My results indicate that the two can work in synergy, for instance, when understandings of good food blend with ethical considerations (Section 6.2.1). However, they can also be at odds when the responsibility for healthy eating prevails. In my sample, respondents who ascribed more importance to eating fruits and vegetables relied more on market sources in autumn and winter, unless they managed to stock up enough fresh produce and make preserves. In comparison, respondents whose diets included less fruits and vegetables were overall more self-sufficient because they reduced their consumption once they ran out of their own harvest. These interactions between FSP and healthy eating are further explored in Chapter 7.

\subsection{Summary: Negotiating quality, responsibility and seasonality}

This chapter continued my investigation of respondents' food provisioning strategies based on Belasco's (2008) triangle of consumer choice and conceptual borrowings from practice theory. Having established the importance of food quality in Chapter 5, here I have unpacked how the understanding of quality is constructed. I have shown that notions of good food are strongly linked to identity: they are informed by respondents' experiences as producers; their

156 See also previous notes on the seasonal patterns of crops linked to market sources in Section 6.1.1 
sensory, intuitive and embodied perceptions; and their appreciation of social embeddedness. This combination of factors results in a hierarchy of sources which privileges non-market food provisioning practices over conventional market venues.

Subsequently, I used this notion of good food to explain some of the seasonal patterns observed in my respondents' food provisioning strategies. I concluded that FSP and other informal food sources are central to respondents' food provisioning strategies not only in terms of food acquired from these sources but also in terms of the broader seasonal patterns they create. The hierarchy of sources, based on understandings of good food, is one of the main mechanisms which guide food provisioning strategies.

The second section of the chapter zoomed in on the third apex of Belasco's triangle, responsibility. In his theory of consumer choice, Belasco states that responsibility is the least important consideration and that moral concerns about the impacts of one's consumer choices are only negotiated within the limits of identity and convenience. I claim that if we broaden the notion of responsibility to include not only conscious consumption concerned with 'the outside world' but also, and even more importantly, the moral imperative to care for loved ones, responsibility can in fact be seen as one of the main guiding forces of food provisioning.

To summarize, the food provisioning strategies of my respondents were guided by two main mechanisms: the responsibility to provide healthy food for their loved ones and a specific understanding of what good food is. Figure 15 provides a visual overview of the functioning of these mechanisms and their relation to seasonal patterns. Notions of good food are intrinsically linked to respondents' identities (Sections 5.3 and 6.1) and ethical considerations (Section 6.2.1). These factors shape how convenience is understood and considered for diverse sources (Section 5.3). Section 6.1 showed how understandings of good food inform a hierarchy of sources, but it encountered a paradox in respondents' use of market sources. Section 6.2 resolved this contradiction by unravelling the responsibility for healthy eating as an overarching mechanism. Since health is part of respondents' complex understandings of good food, this responsibility can sometimes work in synergy with providing food from good sources. However, when limited by the seasonality of good sources, respondents developed other strategies to fulfil the responsibility to provide healthy food. These strategies include changes in sources, changes in diets or diverse combinations of the two, depending also on identity, convenience and external responsibility considerations. ${ }^{157}$ Some of these practices, such as supplementing food from market sources, are at odds with respondents' ideas about good food.

157 I elaborate on the use of these strategies in Chapter 7, which explores how gardens are integrated into food provisioning practices. 


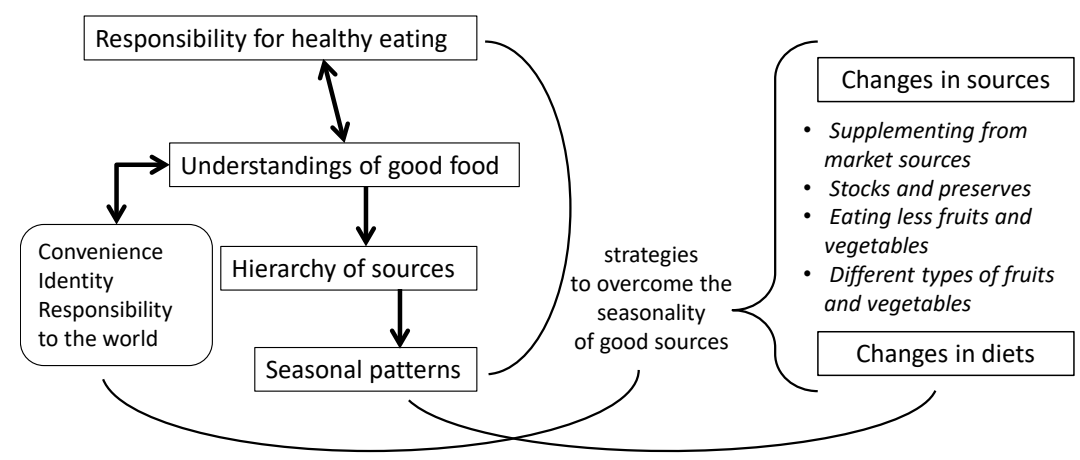

Figure 15: Mechanisms guiding respondents' food provisioning strategies

Returning to the three main factors in consumer choice identified by Belasco (2008), I contend that responsibility is in fact the most important factor, if understood in broader terms. Identity can be seen as the second most significant factor, since it informs understandings of good food. Convenience is only negotiated within the boundaries set by the dominant factors. My findings thus diverge significantly from Belasco's theory. As already mentioned in Section 5.3, this difference can be explained by the wider range of food provisioning practices and economic roles that this research considers. If I would only study my respondents' consumer behaviour and their shopping practices, Belasco's triangle would be correct: when shopping in supermarkets, respondents indeed value convenience the most, and (externally oriented) ethical considerations are only integrated within its boundaries.

Nonetheless, the food provisioning practices of my respondents extend beyond the realm of the market and beyond their consumer role. FSP as well as other less formalized sources are strongly embedded in gardeners' identities. The meanings associated with these practices foster a specific understanding of good food. Informal sources are thus a crucial influence on respondents' food provisioning practices. With this, I conclude my investigation of respondents' broader food provisioning practices. In the next chapter I will leave Belasco's triangle aside to focus on the role of the garden as a food source by exploring different ways of practising FSP and bringing together respondents' producer and consumer roles. 



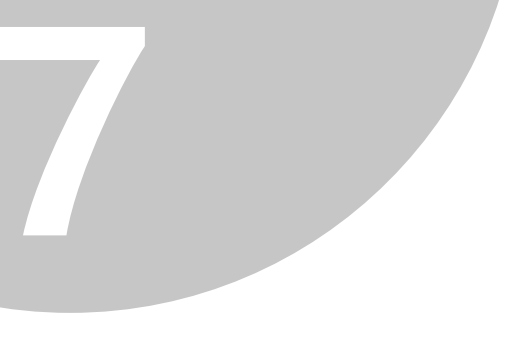

\section{The garden-kitchen interaction}

The previous chapters have explored gardeners' broader food provisioning practices in terms of which food sources they use and how they relate to their diets. I have identified seasonal patterns and unpacked their underlying mechanisms, showing diverse ways in which sources and diets are interlinked. This chapter offers deeper insight into FSP, that is, respondents' use of their gardens as food sources.

The starting point of this chapter is the multifunctionality of gardens. ${ }^{158}$ While the focus of my research is on FSP, gardens are not only food sources, as explained in Section 5.2.4. Furthermore, it can be argued that gardens are not food sources per se, but need to be constituted and used as such. Gardening does not always involve producing food. FSP, on the other hand, entails not only gardening, but also eating from the garden. It takes place in two spaces - the garden and the kitchen - in which gardeners take on the roles of both producers and consumers.

The interaction between these two roles is investigated in this chapter through the conceptual tools of practice theory. My inspiration is, once again, the work of Veen et al. (2014), introduced in Section 5.2. Following their conceptualization of gardening and shopping as different practices, I identify two main practices related to using the garden as a food source. On one hand, the practice of gardening involves activities such as obtaining seeds and seedlings, sowing, planting, weeding, tilling, watering, applying fertilizers and pesticides and harvesting. Learning about gardening methods, talking to other gardeners, participating in social activities in the garden, observing nature or relaxing in the garden can all be seen as part of gardening. On the other hand, the practice of food provisioning includes harvesting from the garden, shopping and obtaining food from other sources. It involves planning and preparing meals, enacting food preferences, making preserves, storing food, dealing with surpluses or leftovers, sharing food, eating at home and elsewhere, disposing of food and so forth.

Food self-provisioning, as mentioned, happens at the intersection of these two practices, integrating gardens and kitchens, production and consumption. This connection is the focus of this chapter. Investigating how gardening and food provisioning are integrated is, in fact, an iteration of the main research question: How is food self-provisioning involved in the broader food provisioning practices of urban gardeners? For analytical purposes, however, this chapter starts by presenting gardening and food provisioning as separate practices. In the first section of this chapter I discuss how respondents talked about these two practices and their relationships during interviews.

158 The understanding of gardens as places with multiple functions is well established in urban agriculture scholarship (see Section 1.1.4). 
In the second section, I explore the interactions between gardening and food provisioning through the data collected in food logs. The combination of qualitative accounts and quantitative data on food production and consumption allows me to identify four ideal types of gardenkitchen interaction. The third section draws on these ideal types to identify factors which influence the relationship between gardening and food provisioning and thus shape how FSP is practised. With that, I provide more general insights into how the interaction between gardening and food provisioning is established, paying special attention to the temporality of gardens as a source of food.

\subsection{Gardening and food provisioning: Integrated or separate?}

The distinction between gardening and food provisioning became apparent already during introductory interviews. My questions revolved around gardening (size of the plot, crop selection, gardening methods) as well as food provisioning (food sources, dietary preferences, meal organization within the household). During our conversations, I noticed that some respondents were more interested in discussing topics related to gardening - they would elaborate on different production methods and planting plans - whereas others were keener to share their food provisioning strategies, discussing, for example, the selection of food sources, meal planning, recipes and dietary considerations.

In several households the practices of gardening and food provisioning were in fact performed by different people: for example, respondent 7 was involved in food provisioning, while gardening was mostly the domain of her father, with other household members assisting; respondents 15 and 17 were enthusiastic gardeners but food provisioning (particularly meal planning and cooking) was mostly performed by their wives. On the one hand, this meant that sometimes respondents did not have complete knowledge about the practices in question. On the other hand, the division of tasks ${ }^{159}$ made me more aware of different parts of gardeners' food practices, and respondents' 'semi-outsider' perspectives often resulted in unconventional and valuable reflections. ${ }^{160}$

Some respondents explicitly expressed their preferences for gardening or food provisioning. More gardening-oriented participants were passionate about learning new growing methods, fine-tuning the design of their plots, or trying new plant varieties. The harvest was seen as a 'byproduct' of these efforts, or nearly as a burden. Respondent 27's reflection on her motivations for gardening is an example of this:

'I just enjoy working with soil; that is definitely the first and if I'm honest probably the only reason. But apart

159 While these three households divided tasks roughly along the line between gardening and food provisioning, diverse divisions were present in the rest of the sample as well, with different household members engaging e.g. in obtaining food from different sources, making preserves, or doing specific tasks in the garden.

160 For example, respondent 7 was surprised by the amount of food her household produced. Throughout the research project, she developed an inquisitive approach to her father's motivations for food growing, which was enabled by her position as a 'participant observer'. Similarly, the reflections of respondents 15 and 17 on the considerations which guided their wives' cooking were more nuanced than other participants' accounts of their own practices. 
from that, if I want to rationalize it somehow, I like the fact that I have some space where [...] I can put out a birdhouse [...]. I call it a refuge for all living creatures. [...] With respect to food growing I have to say that I like planting and growing, but when I'm supposed to harvest and preserve and process, then I prefer to give it away.'

Another group of respondents also enjoyed gardening as a hobby, but food production was an intrinsic part of this - see, for instance, the quotes from respondents 5 and 14 in Section 5.2.4, which describe obtaining home-grown food as a great experience and a reason to garden. The following statement made by respondent 13 provides another example:

'I have always been interested in gardens and gardening. At the moment I design natural gardens [as my job], I have an inclination to this. [...] Of course, being self-sufficient always appealed to me. I am interested in sustainable lifestyle, and I think that it is nice to shorten the cycles of goods and food. I've always tried to produce as much as possible by myself, so it doesn't have to be imported from somewhere in South America or Italy, for instance; that's already quite far.' ${ }^{161}$

Here, food provisioning and gardening are integrated and overlapping. In other cases, gardening could in fact be seen as part of food provisioning. Food, rather than gardening itself, was the focus of respondent $7:^{162}$

'My relationship to the garden is very utilitarian. I really like going there to pick raspberries, currants and everything. [...] And every now and then I have to hoe something there, but that is more of an obligation.'

Lastly, some respondents were more interested in food provisioning than (productive) gardening, while they understood the two practices as largely unrelated. For instance, the garden of respondent 20 was mostly recreational, with a swimming pool and a large lawn used by children and dogs. Although eating well was an important part of the respondent's identity and lifestyle, the garden was not seen as a relevant food source. As the respondent explained:

'Ifyou count it up, it doesn't pay off. It is just a bonus that you can pick something when you're here, a tomato, currants, raspberries. But the drought this year... We didn't have a single apricot or apple because it all froze. And if you don't water daily, it withers. [...] I think that nowadays growing food on this type of soil doesn't pay off.' 163

To summarize, the link between gardening and food provisioning can be established in different ways. Some respondents performed these practices as related and overlapping, while others engaged in them separately. Some respondents were more interested in gardening, others, in food provisioning. In some households these practices were carried out by different people who gave them different meanings. In the next section, I systematize these observations using the quantitative data from food logs.

161 Similar reflections on FSP as an environmentally sustainable practice were rare within my sample; hence, in this respect this quote should not be seen as representative.

162 But as I show later, gardening - and not food - was the main focus of her father, which shaped the results of the household as a whole, seemingly contradicting the quote shared here. A single plot can harbour multiple meanings for different users.

163 Note again that the factors due to which growing food did not 'pay off' were related to growing conditions and labour, as I discussed in the understanding of convenience in FSP in Section 5.2.4. 


\subsection{Four ideal types of garden-kitchen interaction}

Recent research on urban gardening points to the importance of going beyond motivations and meanings and investigating the materiality of practices (Tornaghi, 2014). My own experience (Sovová, 2015) as well as the accounts of others (Kortright and Wakefield, 2011; Veen et al., 2014) reveal that gardeners who are passionate about their hobby can produce substantial amounts of food without consciously trying to do so. At the same time, gardeners driven by an interest in sustainable food provisioning do not always succeed in eating from their plots. During the analysis, I therefore compared respondents' 'sayings' about gardening and food provisioning with the quantitative data which operationalized both of these practices in 'doings' through the food logs.

Figure 16 represents the relationship between food production and consumption in quantitative terms, using data from the four months during which respondents kept food logs. The horizontal axis represents the food that respondents produced, capturing total garden yields. The vertical axis maps respondents' eating habits by showing the amount of fruits, vegetables and potatoes from all sources consumed in their households per person. The axes intersect at the median values of each variable; therefore, respondents whose numbers are located above the $\mathrm{x}$ axis consumed (per person) more than the median, and respondents whose numbers are on the right side of the $y$ axis produced more than the median during the observed periods. ${ }^{164}$ The squares with respondent numbers are colour coded according to the three types of gardens represented in the sample: ${ }^{165}$ pink for allotments, brown for home gardens and purple for secondhome gardens. Thus, at first sight there are no obvious patterns related to garden location and ownership. The two axes create four segments corresponding to four ideal types of relationship between food provisioning and gardening. ${ }^{166}$

Since this segmentation is based on the median amounts of fruits, vegetables and potatoes produced and consumed in respondent households, it is worth comparing these values with national averages. In terms of household food production, two data sets provide relevant information, though neither of them allows for a directcomparison due to different methodologies. Firstly, a statistical survey from 2007 (Štiková et al., 2009) measured consumption in kind - that is, the consumption of products acquired outside the formal economy. On average, people ate $34.2 \mathrm{~kg}$ of potatoes, vegetables and fruits from non-market sources. This average includes both producing and non-producing households, and it is thus likely higher for households involved in FSP. At the same time, the category of consumption in kind does not differentiate home-grown food from food obtained via other informal sources (e.g. received as a gift).

164 I use median values instead of averages in order to avoid distortion by extremely low and high values. The median, or middle value, splits the data set in two: half of the values are higher and half lower than the median.

165 Respondents with multiple gardens are categorized based on the plot they used most; the 'allotments' category also includes other gardens located in the city but not next to respondents' homes (see Section 3.3.3 on the research sample).

166 The ideal types refer to the encountered iterations of the link between food provisioning and gardening rather than to respondents themselves. My approach is similar to Halkier and Jensen's (2011) focus on practices instead of individual practitioners. Each of the ideal types is performed by multiple respondents, while at the same time respondents can be affiliated with one or more of these ideal types. Gardeners can thus engage in different types of behaviours pertaining to different ideal types, as discussed further. 


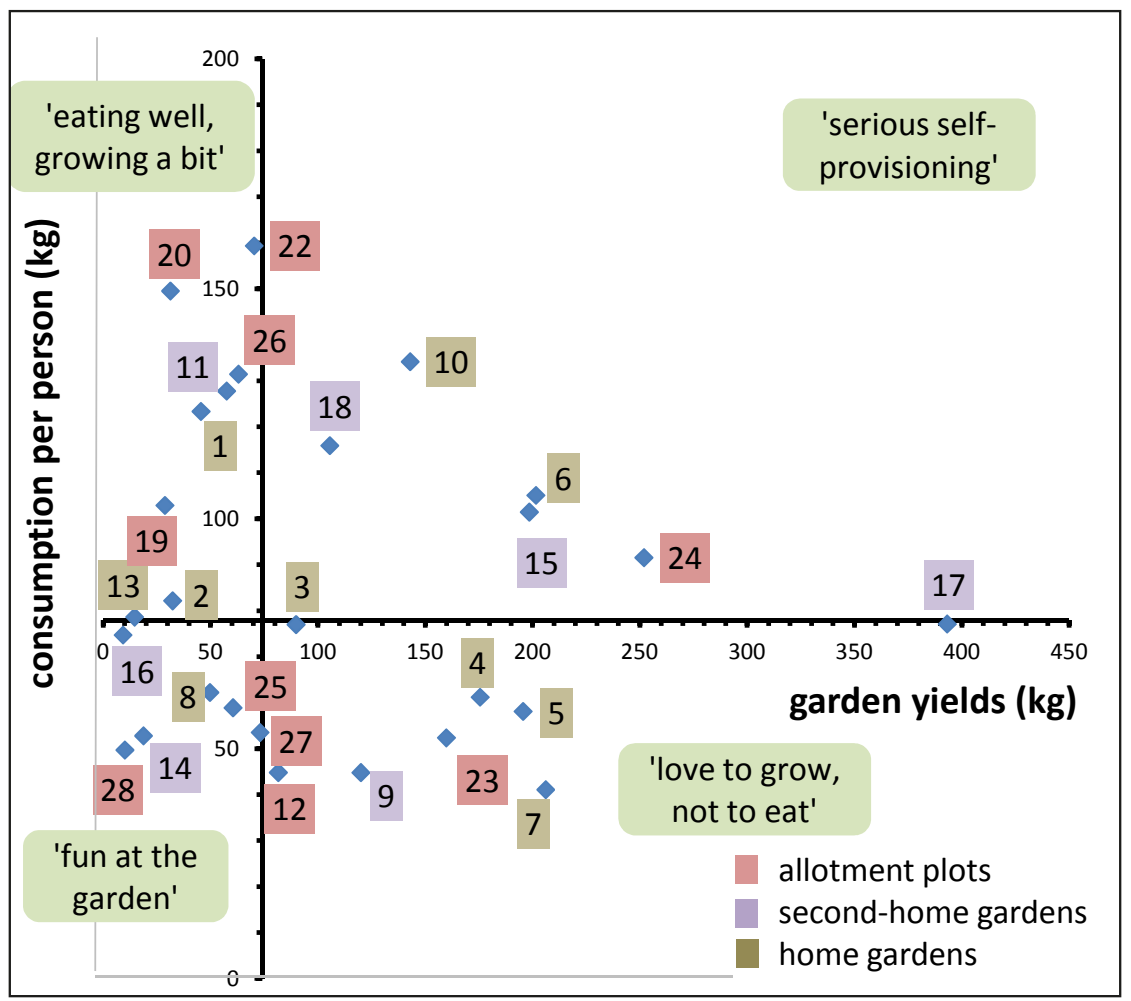

Figure 16: Four ideal types of the kitchen-garden interaction based on quantitative data collected in food logs during the four months of data collection

Secondly, Vávra, Daněk et al. (2018) estimate that Czech gardeners produce $43.6 \mathrm{~kg}$ of fruits, vegetables and potatoes per person per year. This number is based on the level of self-sufficiency reported by gardening households in a representative survey and the average consumption of fruits, vegetables and potatoes in Czech households. The value thus excludes produce which was not consumed by gardeners themselves. Furthermore, it assumes that gardening households consume 'average' amounts of the observed foods, whereas my data indicate some differences (see further).

Unlike these two sources, my research measured total garden production. During the four months of data collection, the median garden output was $73 \mathrm{~kg}$ per household, or $32 \mathrm{~kg}$ per person. Through simple extrapolation ${ }^{167}$ it can be estimated that per year, respondent households

167 This estimate is based on a monthly median value calculated from the four months of data collection. Note that with the current data collection design, the category of 'home-grown' included previously made stocks and preserves which gardeners consumed during the observed period, as well as the garden harvest which they stored or preserved for later use. Using these data to calculate median values might cause the 'doubling' of some entries, i.e. counting the same food items when they are harvested (and stored/preserved) and then again when they are consumed (after being retrieved from stocks/preserves). The yearly production rate thus might be slightly lower, particularly in households which actively relied on stocks and preserves. 
produced $219 \mathrm{~kg}$ of food in their gardens, or $97 \mathrm{~kg}$ per person. Note, however, that these numbers include not only produce used for households' own immediate consumption but also homegrown food which was stored, preserved or given away. During data collection, gardeners stored or preserved 18 per cent of their produce ${ }^{168}$ on average and gave away another 20 per cent. When subtracting this share of the produce (and calculating based only on the produce used for households' immediate consumption), the median production per year and person would be $64 \mathrm{~kg}$. This could mean that the aforementioned estimates of the average production of Czech gardeners are lower than reality or that the gardeners in my sample produced more than the national average.

In 2015 food consumed in Czech households included on average $43.1 \mathrm{~kg}$ of potatoes, $44.6 \mathrm{~kg}$ of fruits and $46.6 \mathrm{~kg}$ of vegetables per person (Czech Statistical Office, 2016). The consumption patterns recorded in the food logs of my respondents show a lower consumption of potatoes $29.8 \mathrm{~kg}$ per person and year - a comparable consumption of fruits - $44 \mathrm{~kg}$ - but a significantly higher consumption of vegetables - $108.4 \mathrm{~kg}$ per person and year. ${ }^{169}$ Combining the consumption of fruits, vegetables and potatoes into one figure reveals that my research participants' consumption of these foods exceeds the national average by nearly $48 \mathrm{~kg}$. Based on the four months of data collection, only five households in my research sample consumed less fruits, vegetables and potatoes than the Czech average.

The quantitative data which gave grounds to the segmentation of my sample into four ideal types should be seen in this context. More than absolute values, the data give relevant information about the relationship between the production and consumption of the observed foods within each household, with some respondents clearly positioned as producers, others more as consumers and yet others integrating both these roles. From there, the four ideal types - introduced in the following subsections - are identified as possible arrangements between the practices of gardening and food provisioning.

Apart from production and consumption volumes, respondents' positions in the figure are also determined by a number of factors which are not adequately reflected in the quantitative data. Based on the in-depth knowledge of each household's situation obtained through repeated qualitative interviews with the respondents, I therefore introduced four coloured clusters to the figure, which give more nuance to respondents' affiliation with the four ideal types (Figure 17). These 'corrections' will be explained in the remaining sections of this chapter, as they contribute to creating a general insight into factors which shape the relationship between food provisioning and gardening beyond gardeners' attitudes and motivations.

168 Presumably part of the preserves was later used for household consumption and part was given away.

169 Annual median values calculated from data collected during four months. 


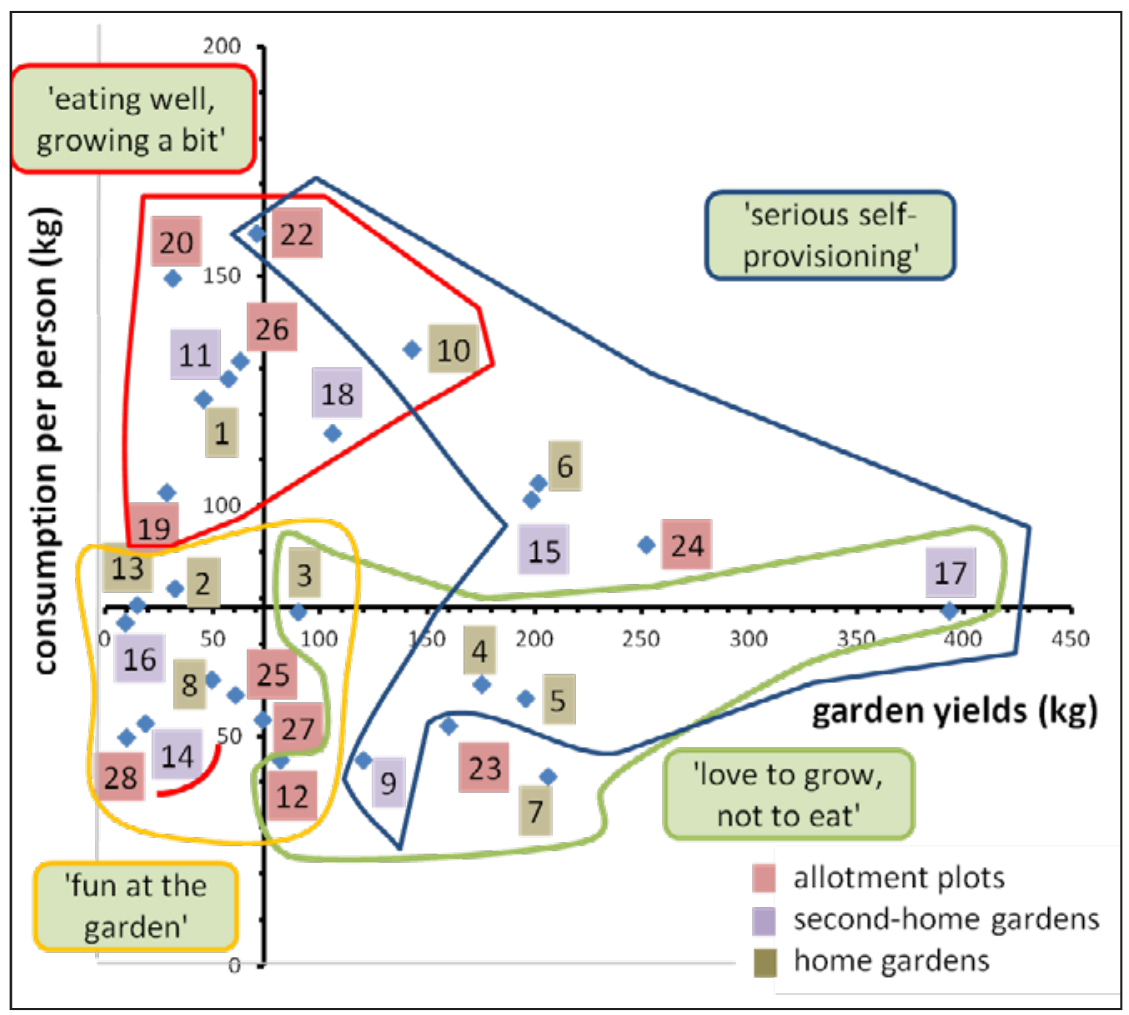

Figure 17: Four ideal types of the kitchen-garden interaction. Clusters corrected based on qualitative data.

\subsubsection{Love to grow, not to eat}

This group is characterized by high garden yields and relatively low consumption of fruits, vegetables and potatoes. ${ }^{170}$ Respondents affiliated with this category have significant expertise in gardening. Growing food is a hobby that they practise with serious dedication - it is part of their lifestyle and identity. They spend much time at their plots and have well-developed growing methods and planting plans, which sometimes involve sequential planting (i.e. a new crop is planted after the previous one was harvested) to cope with limited garden space. Preservation and distribution are crucial, since these households produce more of the observed foods than they consume. Respondents 7, 12, 17 and 23 were the most generous in the sample: they each distributed over $100 \mathrm{~kg}$ of food in the observed periods (see Figure 11 in Section 5.2.3 for an overview of gifts and sharing).

Why did these successful gardeners not eat more of their harvest? The answer requires an investigation of their diets and meal arrangements. In the households of respondents 7 and 23 , the consumption of fruits and vegetables is largely driven by the garden harvest: food is eaten

170 As mentioned, only five respondent households consumed less fruits, vegetables and potatoes than the national average. Four of them were affiliated with this ideal type. 
(or preserved or distributed) because it grew in the garden. When asked about the importance of fruits and vegetables in the household diet, respondent 7 explained:

'It isn't [important]. It's more of a very light garnish, marginal. [We mostly eat] meat and a side dish. We don't really do vegetables; we don't care much about it. Or now in the summer we do, but when it's not there [from the garden], we don't really consume it. It grows in the garden and then it has to be eaten.'

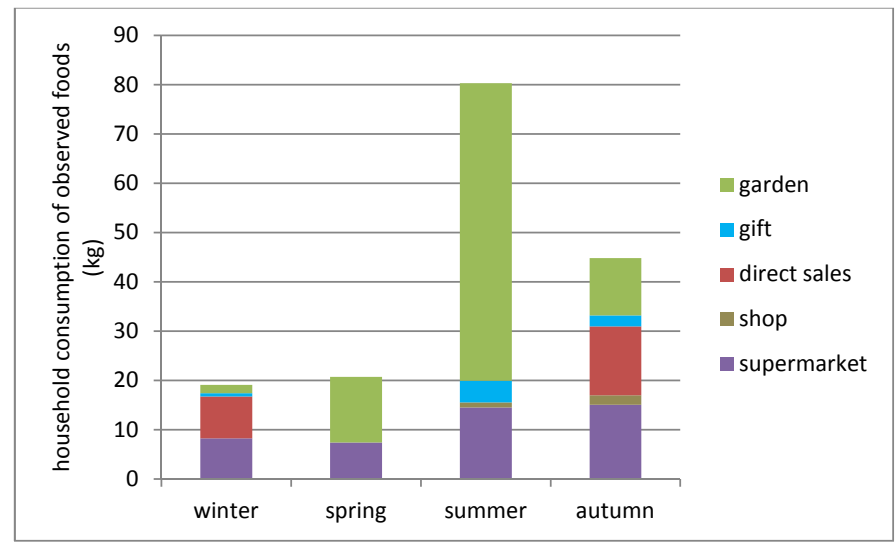

Figure 18: Household consumption of fruits, vegetables and potatoes throughout the year by source, respondent 7. The summer peak demonstrates that consumption was driven by the garden harvest.

The food log of this respondent's four-person household showed that this approach leads to high seasonal fluctuations: the amount of fruits and vegetables consumed in the growing season is significantly higher than during the rest of the year (Figure 18). In a later interview, the same respondent reflected on another dimension of seasonal consumption:

'I find it somehow logical, when it's not there in the winter, why would I buy it in the supermarket. For instance, tomatoes and cucumbers, why would I eat them and buy them when they are not tasty?'

High seasonal fluctuations were also recorded in the food log of respondent 23. In her single-person household, this consumption pattern was strengthened by seasonal differences in meal arrangements. The main growing season coincided with the time when the respondent, who works as a teacher, could not get lunches in the school canteen, and she therefore prepared more meals at home. From autumn to spring her consumption decreased not only because the garden produced less, but also because the respondent ate her main meal outside the household.

Dietary preferences and meal arrangements are thus crucial for the consumption of fruits, vegetables and potatoes recorded in the food logs, and they play a role in gardeners' levels of self-sufficiency. The importance of these factors is confirmed by other households which would fit well in the category of 'love to grow, not to eat' based on their food log data - but less well based on their attitudes and seasonal patterns. In the case of respondent 9, consumption of the observed foods was lowered overall because all household members ate lunches outside the house. However, the garden was used as a significant and stable source throughout the year, and there was less seasonal fluctuation in 
consumption. Food provisioning and gardening seem equally important and well integrated in this respondent's accounts. These characteristics correspond to the category of 'serious self-provisioning'

The same applies to the household of respondent 4, where most meals were home cooked, but the preference for traditional Czech cuisine based on meat and carbohydrates lowered the amount of fruits and vegetables included in the dishes. These examples show that respondents' positions on the vertical axis (i.e. the consumption of fruits, vegetables and potatoes per person in the observed periods) are shaped by their food preferences and meal arrangements.

\subsubsection{Fun at the garden}

This ideal type is characterized by low garden yields as well as low consumption of fruits, vegetables and potatoes per person. The majority of the gardeners affiliated with this category perceived gardening as a hobby, but they saw it as unrelated to food provisioning. An older couple (respondent 16) used their plot mostly for recreation. They only grew tomatoes and harvested fruit from trees and bushes. The rest of the gardeners were active in food growing but did not have the ambition to become self-sufficient.

A typical characteristic of this category is that respondents divide their time between multiple activities, of which gardening is only one. For respondents 2 and 28, both single men in their 30 , gardening was just one of the hobbies they engaged in. They used it to relieve the stress of their professional jobs, and they enjoyed experimenting with diverse crops and growing techniques. Both men also practised cooking as a hobby, preparing specialities such as kimchi or home-baked bread. At the same time, they often ate outside the household, which decreased the consumption recorded in the food logs.

Another group of gardeners in this category wished to produce more food for their households - therefore constituting the practices of gardening and food growing as overlapping - but they were unable to do so. Respondent 8 complained about her demanding job and care work responsibilities, which left too little time for gardening, preserving and even cooking. For respondent 13 it was her first season working in her new garden, and yields were low because of unfavourable growing conditions.

Respondent 14 considered good food very important, enjoyed discovering new trends and exotic ingredients and strived to be a conscious consumer. She clearly positioned gardening as part of food provisioning: a sustainable way of acquiring good food. ${ }^{171}$ But the same lifestyle which informed the respondent's interest in food did not easily accommodate FSP, which the respondent experienced as being time and labour intensive and difficult to combine with other parts of her life: $:^{172}$

171 The emphasis on food, rather than on gardening, could place the respondent in the category of 'eating well, growing a bit'. However, the consumption of her household was much lower than was typical for that group, as the food supply often relied on restaurant or take-away food which was not recorded in the food logs.

172 This confirms a point on different understandings of convenience made in Chapter 5: if understood as a food source, the garden can seem rather inconvenient. 
'The people who have all these stocks or preserves, do they also have jobs? Because I would love to do this, and I would love to be self-sufficient, but I can't imagine how I would combine it with my job during the season. So maybe it will come later. Because at the same time self-provisioning is kind of lonely. The idea of having a house somewhere and taking care of the garden, then you can't do many other activities.'

Being a beginning gardener, this respondent felt a lack of food-growing skills. Her case also illustrates the importance of coordinating food-growing and food-processing activities and spreading out the use of the harvest throughout the year. Her household consumed virtually all home-grown food during a short period in the summer and relied on other sources for the rest of the year.

'I am a little frustrated that we were not able to grow so much. For instance, the zucchinis were great, but there were too many, so we gave away most of them. [...] I hate to throw food away, and what would you give for a zucchini in winter? But in summer it is really frustrating that you don't want to eat it anymore and nobody wants it.'

The coordination of food production and food consumption was also absent in the cases of respondents 3 and 12. While the yields of both gardeners were slightly above the sample's median value, the crops they produced did not match the consumption patterns of their households (affiliating them also with the group 'love to grow, not to eat'). Respondent 3 used a significant portion of the harvest to make preserves (29 per cent of the total harvest) or to give away as a gift (18 per cent), while the garden only covered 12 per cent of household consumption. This was due to a mismatch between the household's diet during the observed periods (in which the most consumed crops were potatoes, apples, cucumbers and oranges) and the crops produced (mostly cucumbers, tomatoes and onions, which were preserved and stored in large amounts). Respondent 12 was among the most generous food givers: 60 per cent of all food recorded in his food logs was shared, mostly with his two sons and their families. With the garden harvest, this trend was even stronger: 66 per cent was given away and 11 per cent preserved. As a result, the garden only covered 10 per cent of the consumption of the respondent's own household. This also corresponds with the respondent's motivations, which emphasized producing food 'for the kids', driven by care and responsibility.

\subsubsection{Eating well, growing a bit}

The main characteristic of this ideal type is an interest in healthy eating, and the food provisioning of respondents affiliated with this category is strongly guided by this responsibility (see Section 6.2.2). Fruits and vegetables are an important part of these respondents' diets. A focus on food prevailed in interviews, while gardening was seen as a source of pleasure, but often unrelated to food provisioning. The case of respondent 20 demonstrates the separation between gardening and food provisioning. As already mentioned, this respondent paid attention to her diet and the quality of food. Her household sourced significant amounts of food from direct sales and farmers' markets, which were perceived as offering higher quality food. Apart from the respondent's above-average consumption of fruits and vegetables, her efforts to eat healthily were also apparent in her experimenting with meat and milk substitutes, replacing white bread with full grain and similar measures. Gardening, however, was largely unrelated to 
this lifestyle. As explained in Section 7.1, this respondent saw FSP as inefficient and prioritized the recreational use of her plot.

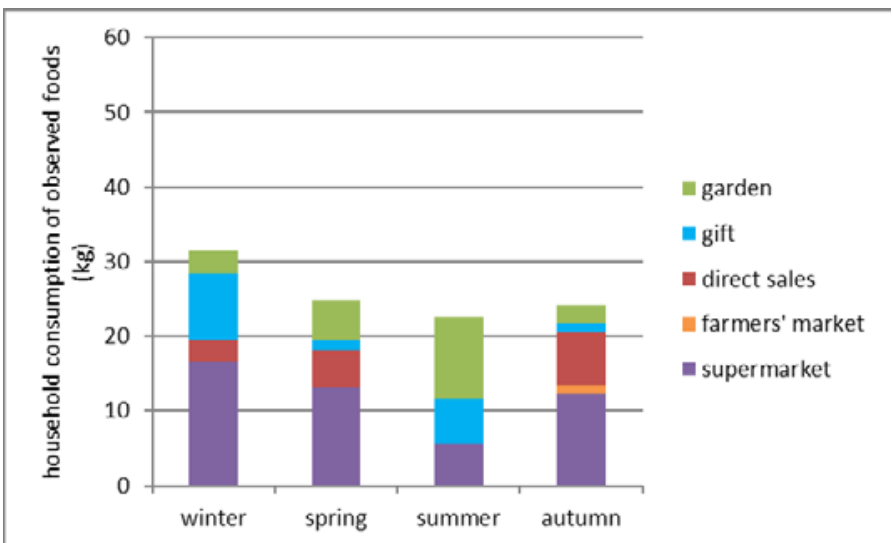

Figure 19: Household consumption of fruits, vegetables and potatoes throughout the year by source, respondent 19. During summer, the garden replaced other food sources, while the overall consumption of observed foods remained comparable.

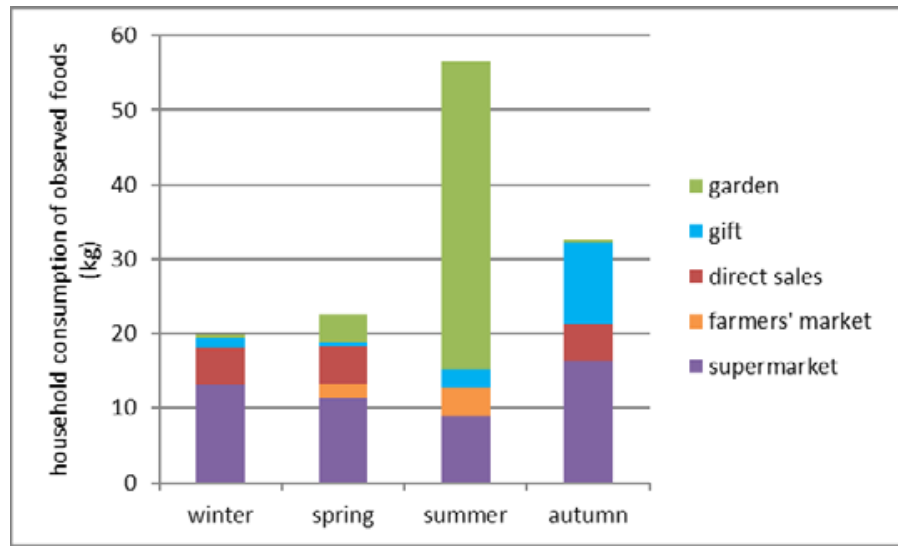

Figure 20: Household consumption of fruits, vegetables and potatoes throughout the year by source, respondent 26. During summer, the garden harvest increased the household consumption of observed foods, while a comparable amount offood remains purchased from other sources.

Respondents 19, 22 and 26 had the highest level of self-sufficiency within this category, covering 21, 41 and 35 per cent of their households' consumption from their gardens, respectively. While their main interest still lay in healthy eating, this was coordinated to some extent with growing food in the garden. All of them actively used homemade preserves, and their diets changed seasonally based on the availability of food from the garden. Respondents 19 and 22 maintained a relatively stable consumption of the observed foods throughout the seasons, similar to respondent 20 . The garden thus replaced other sources in the growing season, but the focus on healthy eating prompted 
the respondents to supply fruits and vegetables from other sources once their own harvests ran out (as explained in Section 6.2.3). In comparison, respondents 1 and 26 recorded higher seasonal fluctuations in consumption; their gardens supplemented their consumption during the growing season. ${ }^{173}$ Figure 19 and Figure 20 show these two different patterns. ${ }^{174}$

The food log of respondent 11 (Figure 21) documents the changes that she experienced during her pregnancy, which coincided with the year that the data were collected. During the introductory interview, she expressed high motivation to be self-sufficient as well as an interest in food origin and quality, which translated into the use of alternative market sources, a seasonal diet and conscious efforts to extend the season through the use of preserves and winter crops. Throughout the year, her focus on eating healthily began to outweigh concerns about conscious consumerism and self-sufficiency. Convenience became more important when acquiring food, and eventually food provisioning tasks were taken over by the respondent's partner, who introduced a new set of strategies and sources. According to the respondent, garden yields were significantly lower than in other years as she became gradually less able to travel to the garden and tend to the crops. Her practice of FSP, therefore, shifted from 'serious self-provisioning' to 'eating well, growing a bit' during the research period.

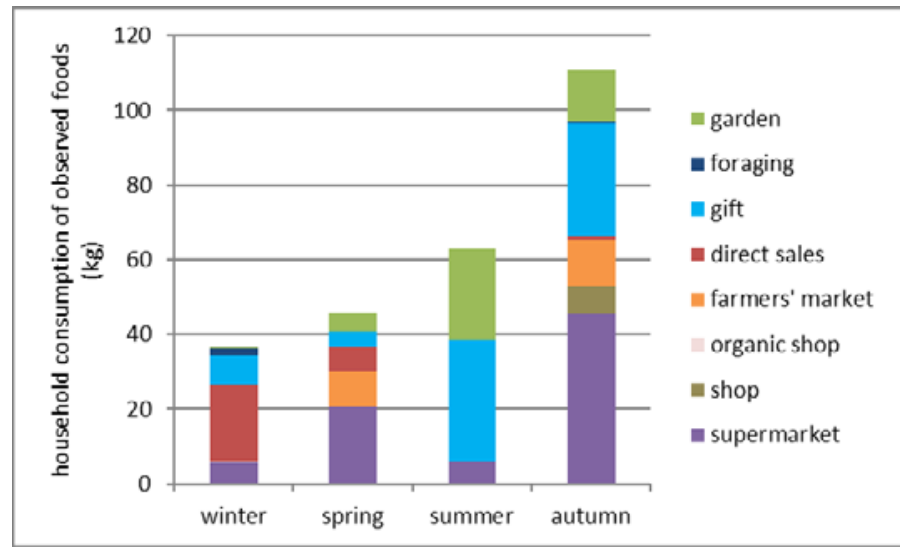

Figure 21: Household consumption of fruits, vegetables and potatoes throughout the year by source, respondent 11

Household food sources were further diversified with gifts from relatives, who decided to support the new family by providing them with home-grown food. Lastly, the overall growth in consumption in autumn, rare within the research sample, was caused by the start of maternity leave, which increased the number of meals the respondent ate at home. While this case does not easily fit in any of the patterns I generally observed in my sample, as an anecdote it provides unique insight into the evolution of both gardening and food provisioning practices in a new life situation, which involved not only the household but also the social networks of the household members.

173 The seasonal fluctuation in consumption is similar to the pattern of respondents 7 and 23 described in the ideal type 'love to grow, not to eat', but respondents 1 and 26 presented here consumed more fruits, vegetables and potatoes per person overall, which reflects their prioritization of healthy eating. 


\subsubsection{Serious self-provisioning}

In this ideal type, gardening and food provisioning are well integrated: gardening is seen as a way of obtaining food, and at the same time, the garden harvest shapes respondents' food provisioning practices and their diets. Respondents affiliated with this ideal type are indeed serious about gardening: while they still perceive it as an enjoyable hobby, it is an important part of their identity and significantly influences their life, as illustrated by this anecdote from respondent 17:

'I plan my holidays according to what ripens when. My family knows that I would be grumpy if they plan something in mid-June, when garlic is harvested. I might very well be by the sea for a week, but I would spend the entire time talking about how it's falling apart in the ground, and they don't want to risk that.'

What is more, respondents 11,15 and 17 expressed the wish to downscale their paid jobs to be able to spend more time growing food, while respondent 10 actually took this step. Her statement reveals an understanding of FSP as part of a non-monetary economy which contributes to higher quality of life:

'I have a part-time job now because I always felt so sorry that from spring to autumn it is nice outside, and I was stuck in the office, which was torture for me. So now I work part time to be able to tend to the garden and my hobbies, music and so on. I find it important to make life enjoyable, so it's not just drudgery. [...] What also motivates me is that I realized that I prefer to have a more modest lifestyle over making money and spending it on food which might be even cheaper to buy but I don't know how it was produced and what they put in it.'

Dedicating a great amount of time to gardening was characteristic of 'serious self-provisioners'. High yields and high time and labour inputs made respondents aware of the economic dimension of FSP, which was often related to caring for the family. Respondent 24 did not work due to a long-term illness, but the time she spent performing care work was easily the equivalent of a fulltime job. Growing, processing, preserving and preparing food for the wider family, together with caring for her grandchildren, occupied most of her time. These accounts were confirmed by my observations during home visits. A similar pattern was observed for respondent 5's household, which comprised a pensioned couple who dedicated significant time to gardening and taking care of their grandchildren. In both cases, the respondents' broader families benefited from this invisible work performed outside the paid economy.

Another characteristic of 'serious self-provisioning' is a passion for learning about gardening, which reveals the importance of this practice for respondents' identities. During an interview at her home, respondent 10 proudly showed me a collection of books on food growing, permaculture, tree pruning, chicken rearing and the like. Respondent 17 had a particular interest in growing garlic, and he followed specialized fora on the topic. It is worth noting that in their exploration of gardening techniques, respondents draw from a wide range of methods, both conventional (e.g. using artificial fertilizers or pesticides) and alternative (e.g. intercropping, using companion species or natural remedies). Their gardening practices are eclectic, driven by curiosity and personal trial-and-error experience, rather than dogmatic adherence to a single approach.

'Serious self-provisioners' have elaborated cropping schemes which help them maximize the use of their gardens, both in terms of space (i.e. sequential planting allowed for multiple harvests 
from the same bed) and time (i.e. garden yields were distributed from early spring till late autumn). Respondent 24 grew a significant amount of food in a small allotment plot, overcoming space limitations with an ambitious cropping scheme:

'Sometimes I'd need to stack the garden up. Especially in the spring, when seedlings are waiting in line, and you first need to harvest one thing to plant the next one. In the meantime, it sprouts, it grows big. For instance, zucchinis were standing here in the line until peas were harvested.'

Planting schedules were closely coordinated with preserving and distributing the harvest, as explained by respondent 17:

'There are a couple of crops which just grow; they get harvested in one go, and then I try to get rid of them. And I put a lot of them [in my garden], because they grow by themselves. One is spinach, which I regularly sow in autumn; in the spring it sprouts by itself. It is low maintenance, but it is for instance five big boxes at once. So I keep some and I quickly distribute the rest to relatives, who process it for themselves. [...] It's basically spinach for the whole year. I freeze a lot of it.'

In this way, most respondents in this category used their gardens as a significant source of food throughout the year. This contrasted with the more prevalent pattern in which garden harvests peaked in the summer but were negligible in other seasons; compare, for instance, the composition of food sources in the households of respondents 7 and 26 in Figure 20 and Figure 18 above with that of respondents 5 and 15 below (Figure 22 and Figure 23).

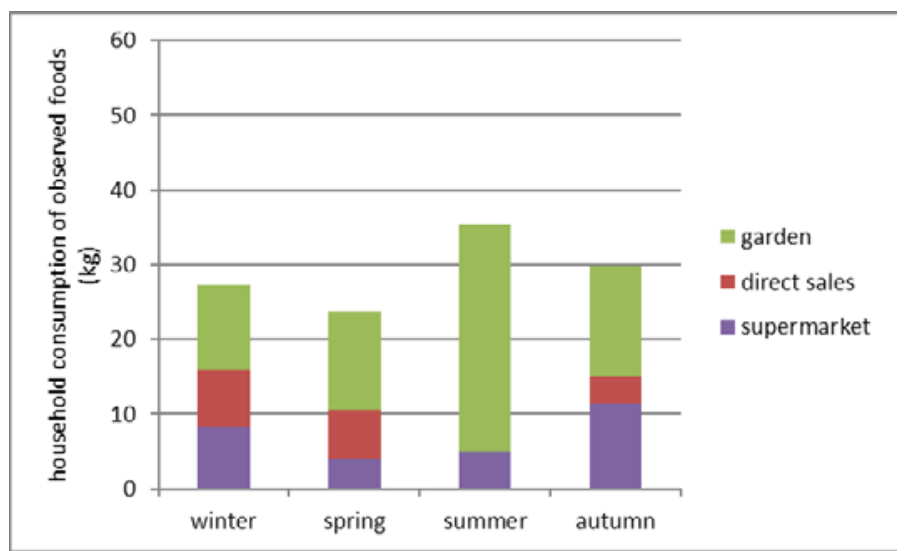

Figure 22: Household consumption of fruits, vegetables and potatoes throughout the year by source, respondent 5

In their gardening practice, 'serious self-provisioners' showed similarities with the category 'love to grow, not to eat'. However, they were more successful in integrating their gardening and food provisioning practices and using their garden yields in their kitchens. The ability to eat from the garden year-round partly depends on the crops that gardeners produce. For instance, respondent 15 grew potatoes, apples, carrots and cucumbers, which were stored and pickled and used in all seasons as a stable part of the household diet. In autumn and winter, these staples comprised most of the home-grown foods consumed by the household. 


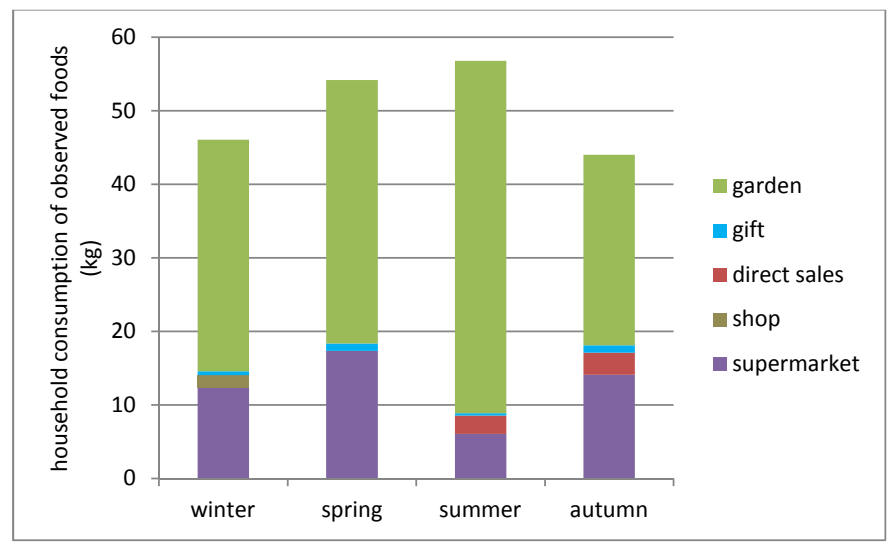

Figure 23: Household consumption of fruits, vegetables and potatoes throughout the year by source, respondent 15

The active, regular use of stocks and preserves as a way of extending the garden season is also illustrated in the food log of respondent 5. During the observed periods, the household used 28 $\mathrm{kg}$ of previously preserved or stored foods from the garden, and at the same time, nearly $44 \mathrm{~kg}$ of garden produce was processed into preserves or stored for later use. This way, the surplus harvest from more plentiful seasons was distributed over time. The amount of food needed for the winter was estimated based on experience, so that the harvest from one season would last until the first harvest of the next year - but not longer:

'I preserve as much as I consume during the year. Ifyou keep it [the preserves] longer, the quality decreases.' (r. 5)

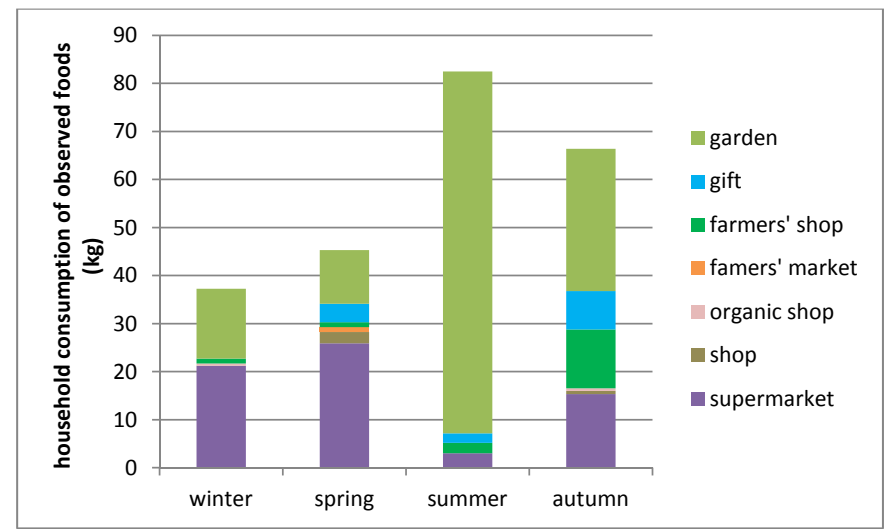

Figure 24: Household consumption of fruits, vegetables and potatoes throughout the year by source, respondent 17

Gardeners relied on proper storing facilities (e.g. cellars) as well as their knowledge and skills. Storing and preserving were already planned at the start of the season, when respondents decided how much food to grow:

'If it was only for seasonal consumption, we would plant half the amount.' (r. 5) 
Stocks and preserves, together with gardening techniques to extend and spread out the harvest period (sequential planting, selection of crops with diverse ripening times, growing of winter crops, use of greenhouses, hotbeds and local hot spots, growing seedlings indoors and so on), were means by which respondents shaped their food self-provisioning practices to meet their food consumption habits. But the link between food provisioning and gardening was also strengthened in the reverse direction, that is, when gardeners adapted their diets to seasonally available produce. While the garden remained a relatively significant source of fruits and vegetables throughout the winter, in absolute terms the consumption of these foods decreased, as demonstrated by the sources and consumption patterns of respondent 17 captured in Figure 24. Even in the least abundant months of winter and spring, the garden accounted for 39 and 25 per cent of the fruits, vegetables and potatoes consumed by the household, respectively. In absolute terms, however, the consumption of these crops was lower than in summer and autumn. Consumption patterns therefore follow the availability of home-grown food to some extent. ${ }^{175}$

Apart from seasonal changes in the amount of fruits, vegetables and potatoes consumed, respondents also adapted their diets as to which crops were consumed. Respondent 9 reflected on the seasonal eating habits that she developed as a child growing up in a highland area:

'It was traditionally a poor region; not much grew there and I notice that I am quite conservative when it comes to food. [...] I am simply used to making potatoes in 50 different ways, cabbage in 50 different ways, and that's enough for me. [...] Even though everything is available nowadays, for me it [diet and seasonal crop availability] is still linked. I am used to that when something is not available from the garden, then we just don't eat it and we eat something else that is there.' ${ }^{176}$

Another habit that the same respondent kept from her childhood was not eating preserved fruit when fresh fruit was still available; as she recalled, compotes were 'forbidden' during the summer. Indeed, many respondents used preserves in a conscious and planned way, guarding them for the winter, but at the same time trying to finish eating them before the new harvest. During the spring round of interviews, several respondents mentioned that they were trying to 'clear out the freezer' to make space for the new harvest. These are examples in which the garden strongly influences respondents' diets.

In some cases, gardening and food provisioning were interlinked so closely that it was difficult to ascertain which practice was influencing the other, that is, whether the garden informed the diet or vice versa. For instance, respondent 15 was proud to be self-sufficient in potatoes. He explained that his family liked eating potatoes and appreciated the quality of home-grown produce. During another interview, when asked about his diet, he stated:

'We have lots of potatoes from the garden, so we mostly cook something with potatoes.'

175 Several other mechanisms are also at play in this case, such as the 'spring vegetable effect' mentioned in Section 4.2: the desire to eat more fresh vegetables and the improving quality of store-bought crops in the spring prompted the household to shop more. Another seasonal effect can be seen in the crops purchased from farmers and gifts received at the end of the harvest season, which figure prominently among autumn food sources (see also Section 4.4).

176 This quote demonstrates how identity shapes the strategies applied to overcome the seasonality of desired food sources - a mechanism mentioned in Section 6.3. 
This illustrates the tight connection between gardening and food provisioning: gardeners understand both practices as overlapping and interrelated, and they perform them in a coordinated way. 'Serious self-provisioners' were the most successful at practising FSP - that is, producing a substantial amount of food to cover their dietary needs. Together with the three categories described above, they offer lessons about factors which can facilitate or hinder the use of gardens as food sources. These factors are the focus of Section 7.3.

\subsubsection{Summary}

This section showed that the practices of gardening and food provisioning have different importance for different gardeners and that they can be constituted and performed as more or less integrated or separate. Figure 25 offers a schematic summary of the four ideal types of the relationship between gardening and food provisioning which I introduced. In the 'eating well, growing a bit' category gardeners are focused on healthy diets, while their gardens serve as a food source only to a limited extent. 'Serious self-provisioners' produce and consume large quantities of potatoes, fruits and vegetables, and they see a close link between gardening and food provisioning. Respondents affiliated with the 'fun at the garden' category enjoy gardening as a hobby but produce few fruits, vegetables and potatoes, while these foods are also not very important in their diets. Lastly, some gardeners 'love to grow, not to eat' - they enjoy growing food, but their consumption of fruits, vegetables and potatoes is low and often driven by the garden harvest.

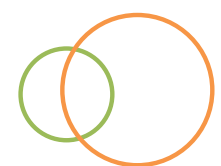

Eating well, growing a bit

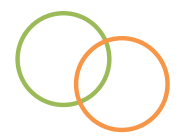

Fun at the garden

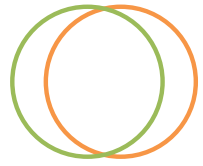

Serious self-provisioning

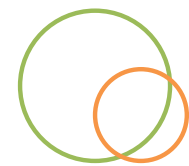

Love to grow, not to eat

Figure 25: Four ideal types of the garden-kitchen interaction. Green circles represent gardening; orange circles represent the consumption of fruits, vegetables and potatoes. The size of the circle illustrates the quantity of food produced and consumed. The extent to which the circles overlap represents the level of coordination between food growing and consumption. ${ }^{177}$

177 In theory, a fifth ideal type could represent cases in which both gardening and food provisioning are important, yet they do not overlap. This would mean that gardeners grow a great quantity of food and also consume large amounts of fruits, vegetables and potatoes, but they acquire these foods from different sources. This ideal type is omitted from the figure because it did not appear within my sample. Respondents who produced an above-average amount of food either consumed it (serious self-provisioning), or gave it away because they did not eat so many fruits, vegetables and potatoes (love to grow, not to eat). The hypothetical case of significant, yet separate food provisioning and gardening would point to a lack of coordination between growing and eating: such gardeners would consume different crops (or at different times) than they produce. Within my sample, however, food provisioning and gardening practices were always linked to some extent. 
The following section builds on the insights gained from these four ideal types to explore the factors which shape the relationship between gardening and food provisioning. As I discussed in Section 7.1, some respondents enacted food provisioning and gardening as separate practices through their choices and attitudes. From a practice theory perspective, it could be argued that the separation of gardening and food provisioning resulted from diverging meanings of these two practices. For these respondents, gardening meant relaxation, spending time in nature and so forth, but it was not understood (or only to a limited extent) as a way of obtaining food.

In other cases, however, respondents described gardening as overlapping with food provisioning during interviews, but their food logs showed only limited use of their gardens as food sources. The practices of gardening and food provisioning were constituted as related in respondents' 'sayings' but less so in their 'doings'. In particular the 'eating well, growing a bit' category but also to some extent the 'fun at the garden' category included respondents who wished to integrate gardening and food provisioning more and use their gardens as a source of food to a larger extent. For these respondents, the two practices had compatible meanings. Their disconnection thus needs to be explained by other factors.

\subsection{Practising food self-provisioning}

The previous sections explored different relationships between the practices of gardening and food provisioning. In this section, I focus on the practice of FSP, which I understand as the integration of gardening and food provisioning, in other words, as an alliance between the garden and the kitchen. I investigate how this alliance comes about. The 'how' in my main research question - How is food self-provisioning involved in the broader food provisioning practices of urban gardeners? - is thus approached in the sense of 'by which means'. Empirically, this section builds on the ways FSP was performed by my respondents. Insights from gardeners affiliated with the 'serious self-provisioning' category are particularly relevant, since these practitioners achieved the highest level of integration between their gardens and kitchens. Once again, however, my focus is on practices rather than individual practitioners, as I attempt to identify factors which facilitate or hinder FSP.

This investigation starts rather broadly, by examining the position of FSP in daily routines and the way this practice competes with other practices. Specifically, I explore how FSP - seen as an informal economic practice - interacts with gardeners' involvement in the formal economy. I proceed by discussing two strategies which facilitate FSP. First, I present preserving and storing as practices which enable FSP by extending the availability of home-grown produce beyond the gardening season. Second, I show that coordination and planning are key competences required for mediating the garden-kitchen interaction. The general topic central to this section is time - in the sense of the seasonal character of gardens, which puts natural limits on FSP, and in the more economic sense of time as a 'resource' invested into diverse practices. 


\subsubsection{Gardening, food provisioning, and competing practices}

In everyday life, people engage in different practices which compete for their time. In the literature on urban gardening, time constraints are mentioned as one of the barriers for participating in this practice, next to space for gardening and skills in food growing (Kortright and Wakefield, 2011; Schupp et al., 2015). From a practice theory perspective, the struggle to fit gardening into daily life can be conceptualized as a competition between this practice and other ones. From a diverse economies perspective, these competing practices can form different types of economies (Section 3.1). This section looks at how the practice of FSP - seen as pertaining to the realm of the informal economy - interacts with respondents' involvement in the formal economy, that is, their jobs.

The existing literature has examined this relationship on the macrolevel, using quantitative data on economic activity and involvement in FSP. Alber and Kohler (2008), for instance, established a positive correlation between national unemployment rates and the share of the population involved in FSP. Their conclusion, that FSP is a result of unemployment and economic need, was disproved by Jehlička et al. (2013), who demonstrated that in most European countries there is no difference between the percentage of food self-provisioners among the unemployed and the economically active population. On the other hand, the same study by Jehlička et al. (2013) found that in Czechia pensioners were involved in FSP more often than other groups. This could indicate a relationship between economic activity and involvement in FSP: the practice of FSP competes with working practices, and therefore people who are retired have a higher chance of integrating FSP into their lives.

While the aforementioned studies examined the relationships between economic activity and involvement in FSP, they did not consider the amount of food people produced. This is the perspective my research adds. My starting assumption was that people who are less involved in the formal economy (i.e. those without a job or who work fewer hours) might be able to dedicate more time to FSP and therefore obtain a larger harvest and/or be more self-sufficient.

The need to negotiate between the practice of FSP and working practices was confirmed by several respondents who perceived their jobs as a source of time constraints and a barrier to their greater involvement in FSP. Time dedicated to gardening heavily determines the amount of garden produce, as demonstrated by both ideal types that obtained above-average harvests from their gardens ('love to grow, not to eat' and 'serious self-provisioning'). Respondents affiliated with these ideal types often spent much time in their gardens, prioritizing gardening over other practices. These gardeners also recognized the time and labour required for processing the harvest, preparing meals and other food provisioning practices.

Among the few studies examining the extent of FSP (i.e. the amount of food produced), Jehlička and Daněk's (2017) paper suggests that pensioners generally produce and share more home-grown food because they can allocate more time to gardening. Veen et al. (2014) argue that people eat more from their gardens if they manage to integrate gardening into their daily routines. The observations from my small sample confirm both conclusions. Respondents ate more from their gardens if they were able to dedicate more time to FSP - either because they were, in Jehlička and Daněk's (2017) terms, more 'time-rich', or because they prioritized FSP in the time they had available. 
Retired gardeners obtained on average the highest amount of produce and achieved the highest levels of self-sufficiency. Apart from having more time in general, pensioners seemed to integrate gardening more strongly into their daily lives. Many of them worked in the garden every day and spent most of their time there, particularly during the summer. ${ }^{178}$ Gardeners who are retired but mentioned having many other activities reported less home-grown produce in their food logs than pensioners who described gardening as particularly important for their identity and life satisfaction.

A similar pattern was confirmed when I compared gardeners who held jobs. People with flexible or shorter work hours produced more food on average than full-time workers, but both of these groups display significant internal differentiation, which can be explained by respondents' motivations and the integration of gardening into their daily routines. Some of the highest levels of self-sufficiency were obtained by respondents who consciously strived to balance work with gardening and were aware of these practices' competing demands (see Section 7.2.4). Furthermore, respondents organized diverse arrangements which allowed them to share the tasks required for FSP within their social networks - from relatives and neighbours assisting with watering and harvesting, to collective preserve-making and specific divisions of food provisioning tasks within families (see also Section 5.2.3).

My results show that the practice of gardening competes with the practice of working in the formal economy, but also with other practices. Several respondents discussed the challenges of combining gardening with care practices. Two respondents who were on maternity leave explained that the time off from their paid jobs allowed for higher flexibility in food provisioning practices, such as cooking, making preserves or shopping at alternative market venues with shorter opening hours (e.g. farmers' markets, as mentioned in Section 5.2.2). However, childcare was not always compatible with gardening, as children had to be entertained and looked after in the gardens. A similar issue was described by gardeners who were involved in caring for their grandchildren (e.g. respondent 8, as mentioned in Section 7.2.2). In such cases, several practices performed in the informal economy compete for practitioners' time, and the resulting constraints are strongly gendered. McIntyre and Rondeau (2011) described a similar pattern in their study of Canadian farmwomen.

In the ideal type 'fun at the garden', several respondents struggled to balance gardening with other leisure practices, such as when respondent 14 described FSP as a 'lonely pursuit' (Section 7.2.2), or when respondents 2 and 28 engaged in gardening as one of their many hobbies. Coordinating gardening with these activities was crucial especially given the specific temporality of this practice: the timing of sowing, planting, watering and harvesting is dictated by the materiality of the garden and the crops, which does not always allow for much flexibility. ${ }^{179}$ The quote in which respondent 17 explains how the family holiday is planned around the garlic harvest (Section 7.2.4) is an example of such coordination.

178 Furthermore, older gardeners were also the most experienced and had developed a high level of competence not only in gardening and food provisioning but also in coordinating the two practices (see further).

179 See also Schoneboom (2013), who argues that while the understanding of work and time in relation to gardening differs fundamentally from experiences in the paid economy, work in the garden is not free of stress and time pressure. 
Apart from the practice of gardening, FSP is shaped by respondents' food provisioning practices, particularly their consumption patterns and meal arrangements. In some households, a significant portion of meals was eaten outside the household, for instance, at work or in school canteens. In effect, such households had fewer opportunities to use their own produce, as mentioned in the case of respondents 9 and 23, who fall into the 'love to grow, not to eat' category (Section 7.2.1). The respondents who shared the highest percentage of their harvest ${ }^{180}$ all had limited opportunities to prepare food at home because of the work arrangements of household members. ${ }^{181}$ Being able to prepare food is therefore just as important for the garden as a food source as is being able to grow food. In other words, FSP competes with other practices not only 'in the garden', but also 'in the kitchen', where food provisioning practices such as harvesting or cooking from home-grown produce compete with practices such as eating out and ordering take-away food. ${ }^{182}$ The next sections elaborate on the specific temporality of the garden as a food source and possible strategies for dealing with this issue.

\subsubsection{Storing and preserving}

This section discusses storing and preserving practices as ways of integrating gardening and food provisioning. One of the challenges of FSP lies in the different temporalities of gardening and food provisioning: while people need food all the time, the garden only yields produce in certain months - about half of the year in the Czech climate. Indeed, most research participants used their gardens as a seasonal source. A peak in garden harvests is apparent in the summer data (see e.g. Figure 20 in Section 7.2.3). During the rest of the year, respondents relied on other food sources. Six respondents (out of 27), however, managed to eat from their gardens all year round (see Figure 23 in Section 7.2.4). For these gardeners, storing and preserving were key strategies for overcoming the seasonality of home-grown food. In what follows, I will present storing and preserving as stand-alone practices with their own constitutive elements. At the same time, storing and preserving can facilitate the practice of FSP by enabling the integration of food provisioning and gardening.

Materiality is central to storing and preserving, as both practices address the ephemeral nature of gardens and crops. An important material aspect mentioned particularly in relation to storing was access to suitable infrastructure, that is, a cellar with an appropriate temperature and air humidity. Such cellars were typically located in old, freestanding houses where respondents lived and/or gardened. Gardeners who lived in flats generally had more limited access to food-storage

180 Respondents 7, 8, 12 and 23 who gave away between 48 and 66 per cent of what they produced.

181 Although other factors, such as dietary preferences in the case of respondent 7 , or the motivation to give food away in the case of respondent 12 , also played a role.

182 These food provisioning practices are also indirectly linked to gardeners' involvement in the paid economy: respondents often ate outside the household while they were at work. Furthermore, working restricts the time available to cook from scratch. In Daniels and Clorieux's (2015) study from Belgium, working households were more likely to purchase ready-made foods or to eat out because of time constraints. That was also the case for people described as 'urban professionals' in Trenouth and Tisenkopfs's (2015) Latvian study. 
facilities. ${ }^{183}$ If they had access to a cellar, it was either too dry or too warm for the long-term storage of crops. These gardeners therefore adopted diverse strategies for storing their crops.

One of them was sharing storage spaces with other households in the extended family. For instance, respondent 9 used the garden adjacent to her parents' house in the countryside and also stored crops in their cellar: ${ }^{184}$

'My parents have a really good cellar, where potatoes, beetroots and carrots and everything last easily until April. They store whatever they can. At our place it wouldn't be possible. We have this city-type cellar. It's not cold, and the humidity is also not good. So, they store it there, and then we bring it by five kilos.'

Sharing food-storage spaces with extended family was often embedded in broader social interactions, similar to sharing food (see Section 5.2.3 and notes on direct sales in Section 5.2.2). Respondent 19 described how she combined visiting her hometown with picking up produce stored in her brother's cellar:

'I go there about every fortnight. I pass by the cemetery, I pick up some potatoes, we drink a coffee and I go home. It's actually a way of visiting him; I go to see him and pick it up on the way.'

As I have already discussed, food provisioning practices can become more convenient and more strongly embedded in gardeners' routines if they are interconnected with other social practices, such as spending time with family (Section 5.3). At the same time, similar logistical arrangements can sometimes cause inconveniences - such as when respondent 9 was not able to bring enough stocks from her parents' place because of a broken car.

Other strategies for overcoming limited access to appropriate storage spaces involved creative ways of storing food with the available equipment, developed through trial and error over the years. These storing competences involved tailor-made solutions for specific crops, the needs of the households and the spaces at their disposal, as well as the microclimatic conditions of a given season:

'Hokkaido [pumpkins] can be stored for a long time; I know how to pack them in paper boxes. In [the flat in] Brno, I tried some things in the cellar, some things on the balcony, if possible, in a thermo box.' (r. 18)

The relationship between gardening and storing and preserving can take on different forms, in which materialities, competences and meanings pertaining to one practice can facilitate or hinder the other. To begin with, the materiality of garden crops determines storing and preserving options: apart from having enough produce, storing and preserving requires suitable types of fruits and vegetables. For instance, respondent 16 stated:

'The crops we grow cannot be stored, apart from apples.'

Materialities linked to the practice of gardening thus enable the practices of storing and preserving, and subsequently also food self-provisioning options outside the gardening season. Some crops cannot be kept for a long time or have only limited processing options. Some preserves

183 The food log data show that respondents with home gardens or second-home gardens were more self-sufficient in the winter round of data collection than allotment holders who lived in flats.

184 In this case, food was stored near the garden in which it was grown. Other respondents even brought their produce to a separate location to store it. 
(e.g. canned or frozen soups and vegetable mixes) can make up entire meals, whereas others (e.g. jams or compotes) serve as supplements or garnish rather than staples. Growing suitable crops enhances the potential to use the garden as a stable food source, as illustrated by the example of respondent 15, who covered most of his household consumption of potatoes, apples, carrots and pickled cucumbers (see Section 7.2.4).

Gardeners' competences play a key role in these interactions. As already mentioned in relation to respondent 18 above, knowledge of the material characteristics of crops is crucial for the practice of storing. The same can be said about preserving: the competence to process particular crops in a suitable way is gained throughout the years, often by trial and error:

'It was an experiment, at first I tried freezing [the tomatoes], which I found was very unfortunate. It wasn't what I expected; frankly, it was disgusting. So, I was looking for a better way, which seems to be drying and preserving in oil.' (r. 29)

While the materiality of crops determines storing and preserving options, some gardeners actively adjusted their gardening practices to fit storing facilities:

'I try to grow things that can be stored. What cannot be stored I only try to produce in quantities I can give away. For instance, when I plant new trees, I look at the durability of the fruits.' (r. 17)

'I don't grow carrots. Firstly, they are quite difficult to grow; they need watering and loosening the soil. A kilo of carrots costs five crowns even in December, and I don't have space to store them anyway, even if I grew a tonne, I cannot fit more than a kilo in the fridge.' (r. 27)

The practice of gardening is thus shaped by the materiality of storing. In the latter case, the lack of storing infrastructures acts in synergy with the difficulty of cultivating carrots, the growing conditions, and the availability of other food provisioning practices. ${ }^{185}$

In order to facilitate the integration of the garden and the kitchen, storing and preserving practices need to be linked not only to gardening but also to food provisioning. In other words, crops grown in the garden need to be stored or preserved properly, and they need to be used in the kitchen. While this seems straightforward, the last point - using stocks and preserves in the kitchen - should not be taken for granted. In particular, the practice of preserving was sometimes driven by the garden harvest, without regard for the future use of the preserves. Respondent I's jam-making is an example of such 'reactive' preserving:

'I feel sorry to just let it [the fruits] fall on the ground and rot. It's always a lot at once, and it's always the time of year when there's nobody around, at the start of the summer holidays. [...] But I don't know what to make from it. I don't make compotes; I only make jams. We do eat jams, but not so much. So, I make it, and then I give it away. [...] I try to get rid of it, especially when I know that another season is coming. [...] Or when we have visitors, I make pancakes to use it up.'

This way of preserving is thus connected to gardening but less so to food provisioning: it deals with what gardeners produce but not with what they eat. As a result, 'garden-driven' preserving

185 The statements of respondents 17 and 27 show how the materialities of crops and storing facilities shape what I call 'producer convenience' (see Section 5.2.4), i.e. they establish which crops are convenient to grow. 
does not necessarily enhance FSP, that is, the ability to use the garden as a food source throughout the year. In comparison, practising a 'kitchen-driven' variant of preserving entails making preserves which are later used in household diets, thus facilitating FSP. Kitchen- and garden-driven preserving are variations of the same practice which entail specific materialities but also different meanings. Whereas kitchen-driven preserving means extending the season and providing homemade food in winter, garden-driven preserving is understood mostly as a way to prevent food waste. ${ }^{186}$

To summarize, storing and preserving practices can mediate the garden-kitchen interaction and thus facilitate FSP. On the garden side, these practices constitute a way of handling surplus produce and distributing it temporarily. On the kitchen side, stocks and preserves increase the diversity of food (sources) available outside the growing season. Thus, storing and preserving reconcile the different temporalities of gardens and kitchens. However, the extent to which these practices effectively enhance FSP depends on how they are coordinated with both gardening and food provisioning. This coordination requires specific competences, as I will explain in the next section.

\subsubsection{Coordinating the garden-kitchen interaction}

One of the most important factors in using the garden as a food source is the gardener's portfolio of skills and knowledge. Current literature on urban gardening has identified two main skill sets: knowing how to grow food (e.g. Schupp et al., 2015) and knowing how to prepare it (Dobernig et al., 2016). My research highlights the less obvious but crucial ability to manage, plan and coordinate the link between the garden and the kitchen. In practice this competence translates into the integral planning of both production and consumption, in which eating is coordinated with growing on a daily as well as a seasonal basis. ${ }^{187}$

Food provisioning influences gardening in the sense that dietary preferences are one of the most important factors in deciding which crops to grow. Put simply, gardeners grow the crops they like to eat. Since most respondents have had their gardens for some time, this decision had been partly made already:

'I grow more or less the same things all the time.' (r. 15)

The well-established link between the kitchen and the garden was clear when respondents referred to their crop selection as 'kitchen basics', 'what is needed for cooking and so forth. Furthermore, some gardeners already planned the specific uses of produce when selecting crops. This was particularly striking in the case of preserves. For instance, respondent 3 stated the following:

186 In a similar vein, the practice of gifting food can also be guided by different logics. In some cases, sharing or gifting was an aim to which gardening contributed, for instance, when respondents deliberately produced more food to share it with family members, or when home-grown or homemade food was used as a gift for a special occasion. In other cases, however, gifting and sharing were 'garden-driven' - they served as a way of dealing with surplus harvest.

187 Planning competences are also required for the practices discussed here: gardening, preparing meals, obtaining food and making preserves all involve planning. The focus of this section, however, is on the planning that covers all these practices and brings them together. 
'We were thinking about growing cucumbers this year to make pickles.'

For respondent 23 , the garden and the kitchen were so interlinked that when I asked about the crops she grew, she basically answered by sharing a recipe:

'Every year I add some crops and stop growing others. Last year I made mixed pickles and Vegeta' ${ }^{188}$ for the first time. The pickles turned out well, but I need to put them in smaller jars. The Vegeta turned out really well, so I will do that and leave something else out.'

These two quotes illustrate respondents' preserving competences, i.e. their knowledge of the material properties of particular crops and their suitability for specific preserves. However, the ability to make preserves is only integrated into FSP through the added step of planning and coordination, in which gardeners combine knowledge about growing (how to grow cucumbers), preserving (pickles need to be put in smaller jars) and cooking (how to use Vegeta in meals). These considerations are driven by the desire to extend the availability of home-grown produce, as is apparent in the following quote:

'I try to make it last a bit. So it isn't just that we eat it now [in the summer] and then we won't have anything. That's why we pickle and dry. With some things, like cucumbers or cabbage, we also ate some, but the first thing is to preserve them. On the other hand, the tomatoes we mostly tried to eat; I find that more practical.' (r. 10)

The temporality of garden produce plays a key role in planning both production and consumption. Gardeners determine the amounts of particular crops they wish to produce by considering their future use. The planting of each crop needs to be planned according to its ripening time. Timing is crucial, as harvesting needs to be coordinated with processing the produce. Respondents recognized the combination of these tasks as time and labour intensive: ${ }^{189}$

'You bring it home, and you're standing at the stove till midnight. I come from the garden, and I start a second shift at home.' (r. 23)

'I would like to have more time for processing - that is probably the most demanding part of the entire process. Planting, caring for it, harvesting, that's fine. But then I come to Brno [from my second-home garden] on Sunday evening, and the flat is full of it, and I know that I can't store it and I would need two more days just to put the tomatoes in the freezer. One year we were really bringing them 20 kilos at a time. We made a huge amount oflecsó, and we were so happy in the winter. It was really great.' (r. 11)

Indeed, while the seasonal work associated with harvesting, processing and preserving was sometimes strenuous, gardeners understood its value because it enabled them to enjoy homegrown produce in months when the garden was not producing. Respondent 17 expressed this in a straightforward way:

'Vegetables grow all at once. There is a moment at the end of the summer when you need to harvest the tomatoes right now, or else they get hit by the frost and it's over. I tell myself that if I now invest the time in it and make preserves, I can retrieve them during the rest of the year. So, I am basically conserving time.'

188 A condiment made of salt and dried vegetables. Vegeta is the brand name of a commercial product.

189 This adds another dimension to the competition between FSP and other practices discussed in the first section: not only does FSP require time, but the moment when work needs to be done is dictated by the temporality of the garden. 
The importance of planning competences for dealing with produce was confirmed by the fact that not all respondents were satisfied with how they managed this coordination task, as I discussed in relation to respondent 14, who falls into the 'fun at the garden' category (Section 7.2.2). Several respondents were overwhelmed by the abundant summer harvest and struggled to process or distribute the produce, and hence their level of self-sufficiency dropped quickly once the garden season ended.

Coordinating gardening with food provisioning also requires significant skills and knowledge on the 'kitchen' side, that is, in meal planning, cooking and eating (see also Section 7.2.4). Particularly in the summer months, garden produce had a strong influence on respondents' diets, and it often replaced other food sources (see Section 4.3 for details). Knowing enough recipes with particular vegetables was just as important as being able to adjust one's diet during harvest:

'One day I had tomatoes with zucchini and bell pepper, the next day I had some bell peppers with zucchini and tomato, and the third day I had the same. Just a bit of onion, dice everything, stew it a moment and it's done. Once I threw rice in it, the second time I threw in some pasta, and that's what I ate the whole summer.' (r. 23)

Outside the main growing season, eating from the garden was not guided by the immediate harvest but by the availability of stocks and preserves. Therefore, when respondents planned storing and preserving in their gardening practice, they also considered how these foods would be used in their diets, de facto planning their meals several months ahead. Preserves had their place in particular dishes, such as when respondent 22 used zucchinis, tomatoes and bell peppers for chutney 'to go with meat'. Sometimes preserves were even linked to special occasions: red currant jam was made for Christmas sweets or desserts (respondent 25), and spinach was kept in the freezer until the next season for Easter stuffing (respondent 24) ${ }^{190}$ Even outside the growing season, some respondents adjusted their diets to the garden produce they had stored or preserved (see also Section 7.2.4). During our encounter in November, respondent 10 explained:

'We are now starting to eat cabbage, beets and pumpkins. For instance, now we had baked potatoes with butternut squash. It's nothing special. I make different types of pumpkins, but it's quite similar. When I make risotto, it's with pumpkin. We cut down on mushrooms for a while because we had had too many. That will come back again. Now we make cabbage, cabbage with dill; we ferment beetroot with cabbage and cabbage alone. And my partner tried pickling green tomatoes. That might not work out; it's an experiment, but we would have to throw it away otherwise.'

This quote illustrates a rather elaborate strategy resulting from the respondent's garden plan (what to grow and in what quantity), her knowledge of the material characteristics of the crops (ripening times, durability, suitability for different uses), her skills in turning produce into preserves and meals (knowledge of recipes, cooking skills, creative experiments), and her ability to constantly balance dietary preferences with available ingredients. Although these can be seen as separate competences related to individual practices (gardening, preserving, cooking), the

190 These 'kitchen-driven' preserves differ from the 'garden-driven' preserves presented in the previous section in that the latter were not produced in a coordinated manner and were not used in respondents' diets. 
added layer of coordination mobilizes and integrates them. ${ }^{191}$

Thus, coordinating the garden-kitchen interaction by integrating food production, processing and consumption entails an additional competence. This competence can be seen as specific to the practice of FSP - that is, using the garden as a food source - and an addition to competences pertaining to gardening and food provisioning. Coordination competences seem particularly relevant in relation to the seasonal nature of gardening and the ability to practise FSP yearround.

\subsection{Summary: Gardens as food sources}

This chapter unpacked how gardens are understood and used as sources of food. Inspired by practice theory, I have positioned FSP, that is, using the garden as a source of food, as the intersection of two sets of practices: those relating to the garden ('gardening) and those relating to the kitchen ('food provisioning'). This intersection, shown in Figure 26, was the focus of this chapter.

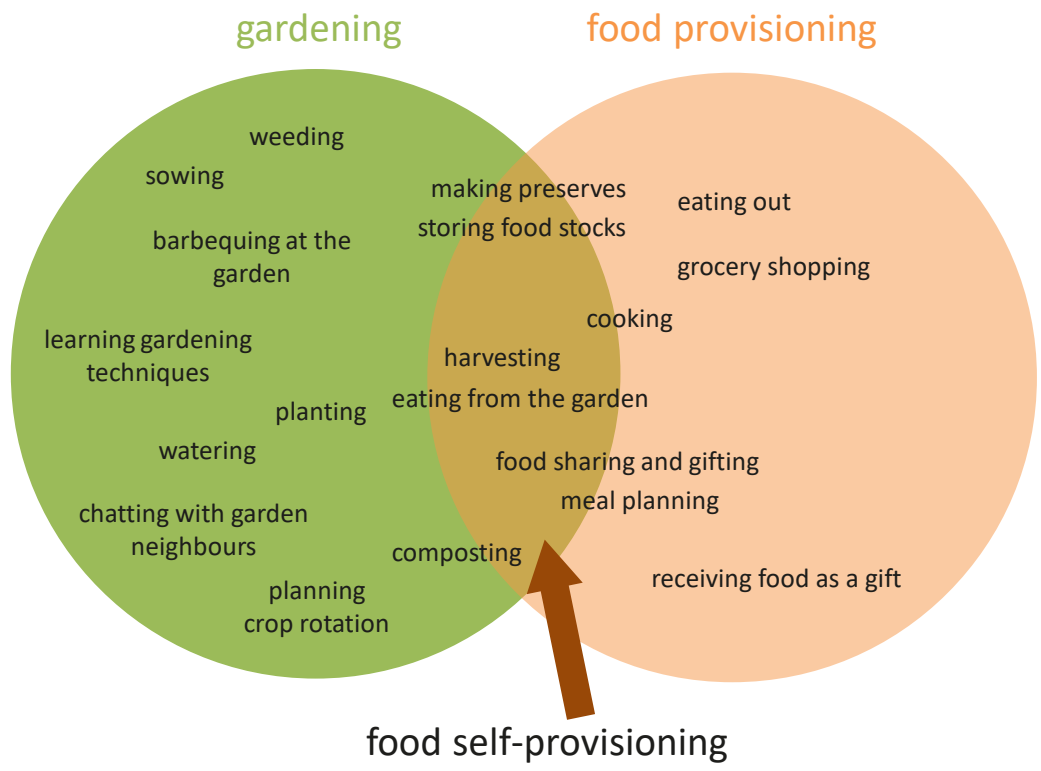

Figure 26: Food self-provisioning as an intersection of gardening and food provisioning practices

A Czech national survey from 2015 (Jehlička and Daněk, 2017) showed that 96 per cent of households with access to agricultural land used it for food production. The remaining 4 per cent

191 Similarly, Trubek et al. (2017: 300) describe cooking competences as 'the ability to draw upon a "stock of knowledge" that is stored in [the cooks'] heads, hearts, hands, noses and mouths'. Improvisation and flexibility are important parts of this ability. Indeed, although this section highlights the long-term planning of the garden-kitchen interaction, the reality of food growing and food provisioning is often dynamic and unpredictable. The ability to improvise is as necessary a skill for FSP as is the ability to plan. 
might include people who garden but do not produce food (e.g. they have ornamental gardens), alongside those who have access to land but use it in a different way or do not use it at all. In general, though, gardening almost always overlaps with food provisioning in the Czech context. Producing food in the garden was the main criterion for selecting research participants. All respondents thus used their gardens as food sources to some extent. Nonetheless, the ways in which they linked their gardening and food provisioning practices differed.

I first mapped out the diversity of approaches to the garden-kitchen interaction within my research sample. Drawing on respondents' sayings about food provisioning and gardening, and the amount of food they produced and consumed, I have identified four ideal types of gardenkitchen interaction, which were presented in the second section of this chapter.

Respondents' 'doings' (i.e. the quantity of food consumed and produced) were not always in line with their 'sayings', that is, the meanings they attributed to FSP. In other words, gardeners' intentions were not always translated into actions. Such discrepancies concerned several topics mentioned in previous chapters; they mostly related to gardeners' understandings of food provisioning norms and responsibilities. For instance, some respondents wanted to consume more fruits and vegetables (Section 6.2.2), and others wished to use alternative market sources more often (Section 6.2.1). As far as FSP is concerned, several respondents desired to eat more from their gardens but were unable to do so. The circumstances that prevented the fulfilling of this ambition, together with factors which made other gardeners more successful at FSP, were used to identify the general mechanisms of practising FSP. The three main factors I encountered were presented in the third section of this chapter, and they included finding time for FSP among other competing practices, effectively using stocks and preserves to extend the garden season, and being able to coordinate production and consumption.

Section 7.3.1 investigated the relationship between gardeners' involvement in the paid economy and their engagement in the informal economic practice of FSP. I have identified several practices which compete with FSP in gardeners' everyday lives. Working in the paid economy as well as performing care work or engaging in diverse leisure practices compete with the practice of gardening. Furthermore, practices such as eating out, ordering take-away food or using convenience products for cooking compete with the practice of eating from the garden. Therefore, while gardeners' involvement in the paid economy has a strong influence, their ability to practise FSP is also shaped by other competing practices. Furthermore, prioritizing activities related to FSP and planning them accordingly in relation to other practices, possibly with the involvement of other people, was just as important as - if not more important than - 'objective' time availability. This confirms Veen et al.'s (2014) point about the importance of integrating gardening into daily routines, and it hints at the significance of planning and coordination, which I discuss separately.

Planning and coordination also appeared in my investigation of the role of stocks and preserves in Section 7.3.2. Storing and preserving are presented as practices with their own constitutive meanings, materialities and competences. Crops, storage facilities and gardeners' competences to deal with these materialities determine the meaning of storing and preserving in the garden- 
kitchen interaction. Stocks and preserves are key for using the garden as a food source outside the productive season, but they can only fulfil this function when they are integrated with both gardening and food provisioning - in other words, a sufficient amount of suitable crops must be produced, processed appropriately, and later integrated into the household diet.

The coordination and planning competences which I discuss in Section 7.3.3 are thus effectively found within and around diverse practices related to FSP. Practitioners need to coordinate their gardening and food provisioning activities with other competing practices. Furthermore, both of these practices also require planning at different stages. Gardening plans cover, among other things, the timing of sowing, planting and harvesting, including 'advanced' practices such as preparing seedlings on the windowsill or sequential planting in the same bed. Food provisioning practices involve, for example, the planning of grocery shopping and cooking, which includes negotiations about time, convenience, food preferences, responsibilities for good eating and dealing with leftovers.

Depending on the point of view and the focus of inquiry, planning can thus be seen as a competence needed to perform certain practices or even as its own (dispersed) practice. To give an example, planning crop rotation can be seen as one of the competences required for gardening, alongside, for instance, the technical skill of planting seedlings in the right way and knowledge of local growing conditions. But it can also be seen as a practice in itself, consisting of specific materialities (the available garden area, seeds and seedlings), competences (knowing the planting and harvesting times of crops) and meanings (looking forward to the next garden season).

This dispersed nature of coordination and planning is recognized in the literature. For instance, McIntyre and Rondeau (2011: 118) define food provisioning as

a breadth of complex activities, including the acquisition, preparation, production, consumption, and disposal of food, where technical skills (e.g. growing, shopping, meal planning, food preparation, cooking) and resources are tacitly coordinated by a primary food provider within the social context and demands of household members, as well as the broader environment in which they live.

In this understanding, meal planning appears as a straightforward 'technical skill'. On the other hand, another type of competence is required to coordinate different food provisioning activities and to integrate them into the broader context. This type of coordination was addressed in Section 7.3.3.

In their investigation of related practices, Shove et al. (2012:36) identify 'diverse elements [which] circulate within and between many different practices, constituting a form of connective tissue that holds complex social arrangements in place, and potentially pulls them apart'. Planning and coordinating competences comprise such a connective element: as I showed, they enable (or hinder) the integration of gardening and food provisioning practices. Unlike Shove et al., however, I do not see coordination as a single competence shared by both food provisioning and gardening. Instead, I argue that this competence is specific to the practice of FSP, as it transcends the competences required for gardening and food provisioning. 
What sets this type of coordination apart is its temporality, as it often extends over the several months between planting crops and eating them, while typically drawing from knowledge acquired over years of experience. Coordinating the garden-kitchen interaction is informed by the materialities of these two practices, and it also has immediate and tangible implications for which crops are planted, harvested, preserved and consumed at a given moment. At the same time, however, this competence is separate from the instantaneous act of planting or eating, since it deals with longer time spans and in a way a more abstract manner of thinking. ${ }^{192}$

This realization is relevant, since current literature on urban gardening - while acknowledging the importance of 'garden' and 'kitchen' skills (Dobernig et al., 2016; Kortright and Wakefield, 2011; Schupp et al., 2015) - takes for granted the integration of the two. Again, the literature on food provisioning and cooking competences provides a useful parallel. Trubek et al. (2017: 299) argue that while the practice of cooking has been traditionally regarded as a matter of following a series of steps (planning, provisioning, preparing, plating and packing up leftovers), researchers need to pay more attention to how these stages are integrated by cooks, as this requires complex competences extending beyond the home kitchen. Using the garden as a food source further increases this complexity. 


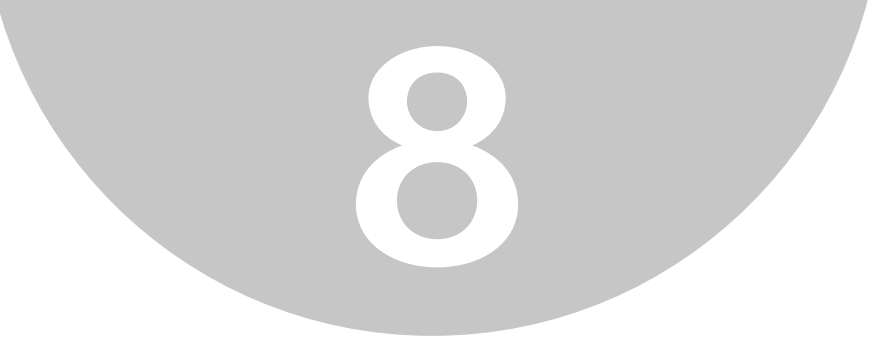

\section{Discussion of research results}

This thesis explored food provisioning practices in 27 gardening households in Brno, Czechia, to answer the research question 'How is food self-provisioning involved in the food provisioning practices of urban households?' I approached this question both quantitatively and qualitatively, as captured in the two sub-questions:

1. How much food do gardeners acquire through food self-provisioning in absolute terms (kg) and in relation to the total food throughput (\%)?

2. How is the position of food self-provisioning within broader food provisioning practices constituted?

In this chapter I discuss my answers to these questions. The first section deals with the role of FSP within broader food provisioning practices in both quantitative and qualitative terms. Sections 2 and 3 discuss my research results in relation to literature on (alternative) food provisioning, addressing the topics of economic and geopolitical diversity, and the issue of ethics and reflexivity. Section 4 zooms in on the ways in which FSP is integrated into gardeners' food provisioning, followed by Section 5 dedicated to the issue of seasonality. Finally, I conclude the discussion by reflecting on the theoretical frameworks used in this research in Sections 6 and 7 .

\subsection{The role of FSP within broader food provisioning practices}

This research explored the role of gardens as sources of food, both in terms of the amount of produce and in terms of their meanings and interactions with other food sources. On a quantitative level, food log data show that FSP is a significant source of food. During the four months of data collection, respondents produced on average $107 \mathrm{~kg}$ of fruits, vegetables and potatoes in their gardens, covering 31 per cent of their household consumption. ${ }^{193}$ These figures hide significant differences among respondents. The harvest from the least productive garden was $9 \mathrm{~kg}$ of produce, whereas the most productive garden yielded nearly $400 \mathrm{~kg}$ of food during the four months of data collection. The most self-sufficient household covered nearly 70 per cent of its consumption of fruits, vegetables and potatoes from its garden during the observed periods, and the rate of self-sufficiency was over 50 per cent for another five households. Contrarily, three respondents covered less than 10 per cent of their consumption from their gardens, with the lowest self-sufficiency rate being slightly above 5 per cent.

193 The median values were $73 \mathrm{~kg}$ of garden produce and 25 per cent self-sufficiency. 
Furthermore, respondents also experienced significant seasonal differences. Predictably, the largest garden harvest was recorded in the summer round of data collection, when the average rate of self-sufficiency rose to 56 per cent. Fifteen respondent households supplied more than half of their consumption from their own sources during this round of data collection, with the two most self-sufficient households covering over 90 per cent of their consumption of fruits, vegetables and potatoes. During the winter round of data collection, contrarily, four households reported no home-grown food, and another nine respondents ate only symbolic amounts (below $2 \mathrm{~kg}$ ) of food from their own resources. The average self-sufficiency rate was 13 per cent.

These quantitative results enrich the current literature on urban agriculture, in which data on food production is scarce. As Tornaghi (2014) critically remarks, urban agriculture is assumed to have a number of benefits, including improved access to fresh foods, but there is little empirical evidence on whether these goals are achieved. Taylor and Lovell (2014) further remark that most research in the Global North is focused on community gardens and that particularly little is known about the contribution of other types of gardens to food production. My research fills these knowledge gaps, while it is also consistent with self-sufficiency rates reported by Czech gardeners in representative national surveys. According to the latest data from 2015 (Vávra, Daněk, et al., 2018), Czech gardeners cover 32.5 per cent of their consumption of fruits, vegetables and potatoes from their own sources. My study complements these results methodologically: the food logs provide detailed and accurate insights into the practices of a small research sample, while the national survey works with a representative sample but also with the potentially imprecise self-reports of respondents.

While the significance of FSP is apparent from the quantitative data alone, the qualitative layer of this research further illuminates the role of FSP. The position of FSP among other food provisioning practices is privileged because of the specific meanings attributed to gardens as food sources. All respondents enjoyed gardening as a hobby and a meaningful, fulfilling activity. At the same time, home-grown food was perceived as having the best possible quality in terms of taste, freshness and transparent origin. 'Fun' and 'good food', to summarize these two factors, are recurring themes in research on urban gardening and often figure among the most important motivations and meanings of this practice across different contexts (e.g. Kortright and Wakefield, 2011; Smith and Jehlička, 2013). This research contributes to the literature by showing how these meanings associated with FSP shape gardeners' broader food provisioning practices.

Expanding on the work of Veen et al. (2014), and using Belasco's (2008) framework to trace the factors influencing food provisioning practices, I have argued that FSP is guided by a fundamentally different logic than other (and namely market-based) ways of obtaining food. Issues such as convenience and cost-effectiveness take on different meanings due to the dual nature of FSP as both a provisioning and leisure practice. In the hierarchy of food sources, FSP and other informal food provisioning practices are placed highest: they provide what gardeners perceive as good food, not only in terms of nutrition and taste but also in terms of environmental impact, social relationships, symbolic meanings and identity.

This privileged position of FSP among other food sources has strong implications for gardeners' food provisioning. My data indicate that gardeners consume overall more vegetables than the 
average Czech population. ${ }^{194}$ During the growing season, the garden is an important food source, and it shapes respondents' diets. Moreover, the influence of FSP extends beyond the growing season and affects other food provisioning practices. Since home-grown food is deemed the best possible, gardeners' experiences as producers provide a benchmark for their preferences as consumers. For instance, some respondents excluded certain foods from their diets when they were not available from the garden because the quality from other sources was below their standards. Although not all respondents resorted to such radical actions, similar behaviours were strong enough to create discernible patterns of seasonal consumption.

Similar interactions between FSP and other food sources have not been, to my knowledge, sufficiently researched. The existing literature (e.g. Kim, 2017; Okvat and Zautra, 2011) investigates the relationship between FSP and other food provisioning practices from the perspective of environmental education. It explores the potential of FSP as a means of raising awareness about food production and, consequently, encouraging more conscious consumption. My research confirms these hopes to some extent. Eating seasonally available produce or sourcing food from local informal sources can be seen as examples of more sustainable food provisioning, and the underlying logic of these practices can be traced back to respondents' involvement in FSP and their understandings of good food. However, my results also demonstrate that the translation of meanings from one practice (gardening) to another (shopping) is not straightforward and can in fact take unexpected turns. For instance, gardeners' aversion to agrochemicals did not prevent them from shopping at conventional venues. For several respondents, their experience with food growing in fact contributed to a lack of trust in certified organic produce.

My research adds to previous works on CEE (e.g. Jehlička et al., 2013; Pungas, 2019; Smith, 2003) which show that FSP cannot be interpreted as a 'fall-back' option used in difficult circumstances (Acheson, 2007; Alber and Kohler, 2008). Contrarily, for my respondents, FSP was a preferred way of obtaining food. With that said, my findings also echo White and Williams's (2016) problematization of framing non-capitalist economies as 'alternatives'. As they contend, the word alternative connotes either niche practices or less desirable options. In this sense, FSP is thus certainly not an alternative in the context of CEE. Firstly, a significant portion of the population (38 per cent in the case of Czechia) is engaged in FSP, and those who do not grow food themselves are still often connected to broader sharing networks, which facilitate indirect contact with this practice (Jehlička and Daněk, 2017). Secondly, and perhaps more importantly, my results show that FSP is seen as the source of the best possible food, and other venues are in fact framed as an alternative or 'backup' option for cases when garden produce is not available.

\subsection{Diverse food economies in CEE and beyond}

Beyond answering my research question and unpacking the functioning of FSP in people's everyday lives, this thesis attempted to challenge existing assumptions about FSP in CEE and to bring knowledge from this region into the debates on more sustainable food provisioning. For

194 Based on values extrapolated from the four months of data collection and data from the Czech Statistical Office (2016). 
this purpose I used the diverse economies framework, which allowed me to legitimize FSP as an informal economic practice. Staying open to diverse economic arrangements further enabled me to explore the food provisioning practices of my respondents in an inclusive fashion.

This open-minded approach proved very useful. The inventory of food provisioning practices of my respondents confirms the accounts of CEE foodscapes provided by Smith and Jehlička (2007) and Trenouth and Tisenkopfs (2015). More sustainable ways of food provisioning described under the heading of AFNs in Western Europe were rarely used by my respondents. An investigation of formalized and market-based food provisioning practices results in a disappointing picture. Only when expanding the conceptual lens to include the local foodscape in its entire economic diversity does the vibrant sphere of less marketized and often informal food provisioning practices appear.

Apart from FSP, which was the central theme of my research, I have also observed a plethora of food provisioning practices located in between formalized and market-based AFNs and informal sharing. These 'traditional food networks' (Tisenkopfs, 2017) involve practices such as obtaining produce in exchange for labour, buying food for a non-market price from social networks, or informally exchanging goods and services. While these practices seem widespread (see e.g. Aistara, 2015; Goszczyński et al., 2019; Mincyte, 2012), they remain invisible due to their informality. Their functioning merits further research, which is likely to yield interesting insights into the role of social networks and trust, as well as into different forms of exchange and reciprocity.

CEE foodscapes are shaped by interactions between traditional practices, neoliberalization tendencies and AFNs modelled after initiatives from different cultural and social contexts (Smith and Jehlička, 2007; Trenouth and Tisenkopfs, 2015). The very delineation of AFNs in the context of CEE is challenging, since the scholarly understandings developed in Western Europe do not always fit the realities on the ground (Goszczyński et al., 2019; Trenouth, 2013). Research carried out in CEE - including my own work - has often grappled with the concept of AFNs (Pungas, 2019; Sovová, 2015; Spilková, 2016). Some scholars have proposed more nuanced variations, such as the imitated, embedded and mixed AFNs of Goszczyński et al. (2019), or Tisenkopfs's (2017) traditional food networks. Others have developed new concepts more suited for local realities, for example, Smith and Jehlička's (2013) quiet sustainability, followed by Visser et al.'s (2015) quiet food sovereignty.

At the same time it has become apparent that the concept of AFNs is not necessarily useful for the Western context either, since it obscures, rather than clarifies, the functioning of existing food practices (Tregear, 2011). Instead of using simplified labels and making assumptions about different ways of food provisioning, researchers should approach food provisioning practices in a critical, yet open-minded fashion. Economic arrangements and the social relations underpinning food networks should be a part of this critical inquiry (Wilson, 2013).

Keeping an open mind to diverse economic arrangements facilitates a context-sensitive account of existing ways of food provisioning. It opens new possibilities for the search for more sustainable food systems, possibly overcoming some of the issues critiqued in relation to market-based AFNs, 
such as elitism or the inequality between producers and consumers (Tregear, 2011; Wilson, 2013). I therefore argue that AFN scholarship can benefit from a conversation with diverse economies research, which moves beyond capitalocentrism and encourages the exploration of alternative market and non-market economic practices (Gibson-Graham, 2008; Rosol, 2020; Wilson, 2013). Making these practices visible and investigating their functioning enable them to contribute to more sustainable futures (White and Williams, 2016). The inclusion of informal food economies in the debate thus does not only create a space in which CEE can become a relevant source of knowledge, but it is highly useful beyond the regional context.

Research on Western Europe and North America has already accounted for emerging nonmarket food provisioning practices such as food sharing (Morrow, 2019; Veen, 2019) and initiatives with an explicit commitment to disengaging from capitalism (Clark, 2004; Wilson, 2013). However, it might have yet to discover practices which are less formalized, older and more 'ordinary'. Activities such as FSP, gleaning, foraging and preserving food, while more commonly associated with CEE, probably also survive, unseen, in the West. ${ }^{195}$ These 'quiet' yet 'actually existing alternatives' (Veen, 2015) might complement more political projects in the search for non-capitalist ways of food provisioning (Wilson, 2013).

The goal is thus not to determine what is 'alternative' but to make sure that the conversation about food provisioning is more comprehensive (see also Fickey and Hanrahan, 2014). Taking economics into account is crucial in this process, firstly - as I have discussed - because making diverse types of food provisioning visible opens up more ample possibilities for exploring sustainable food systems, and secondly, as my research shows, because different economic roles enacted by practitioners shape their food provisioning choices. Acknowledging that people are not only consumers, but that they can also become producers and distributers - not to mention their non-economic roles such as citizens or carers - thus advances the understanding of their practices.

\subsection{Ethical food provisioning: Rethinking reflexivity}

One of the much discussed issues in the literature on more sustainable food provisioning revolves around reflexivity and consumer ethics. The notion of ethical consumption stems from the assumption that people adapt their (provisioning) behaviour based on knowledge of its impacts on the world and a sense of moral obligation. In Section 1.2.3 I reviewed some of the criticisms of this approach, particularly those focused on its normativity, which puts unrealistic expectations on higher moralities (Tregear, 2011).

Instead, I chose to work with a more open-ended understanding of ethics, which is based on Sayer's (2004) concept of lay morality and which broadens Belasco's (2008) notion of responsibility. In line with this approach, I argue that food provisioning - much like other subsistence or reproductive practices - is driven by an ethic of care. This repositions the discussion on reflexivity and ethics.

195 McLain et al.'s (2014) study of urban foraging in the USA is an example of research which unravels some of these hidden practices. 
Contrarily to research which frames ethical considerations as an optional layer added on top of other considerations (e.g. Belasco, 2008; Connors et al., 2001), I argue that all provisioning practices have a moral dimension (Jackson et al., 2006). What needs to be investigated is which moral considerations practitioners negotiate and how. Furthermore, my perspective differs from the notion of ethical or conscious consumption in that I see moral considerations as often routinized, implicit and unconscious (Jackson et al., 2006; Sayer, 2004).

The main moral concern of my respondents was to provide good, healthy food for their loved ones. On the one hand, this translated into a preference for 'good sources' based on a hierarchy which considered FSP and other informal sources as better than commercial venues. On the other hand, the preference for these sources was never allowed to threaten the dietary needs and wishes of household members. If food was not available from the preferred sources, gardeners would resort to what they saw as lower quality sources to satisfy their households' demands.

Previous works (e.g. McIntyre et al., 2009; Tregear, 2011; Veen et al., 2012) have noted that food system actors are driven by a range of motivations and that the more virtuous ones (e.g. social justice, environmental sustainability) interact with more mundane concerns (e.g. spending time with family, eating healthy food). My research adds to this literature by pointing out some of the interdependencies of these two types of considerations. In respondents' understandings of good food, considerations of taste, food safety, health, and environmentally sound production methods, to name just a few, mingled and overlapped. As Jackson et al. (2006) note, the construction of 'good food' is based not only on 'objective' criteria such as freshness or production methods, but also on often implicit considerations of identity and care for others, as well as acquired social norms.

Distinguishing between 'egoistic' and 'altruistic' motivations (Zagata, 2014) might be useful in that this distinction facilitates a better understanding of practitioners' considerations. However, such conceptualizations should not obscure the intertwined nature of ethical negotiations, nor should they produce the artificial categories of 'better' or 'worse' motivations. Not least because motivations are not necessarily informative about actions, as documented by the ample literature on the attitude-behaviour gap (e.g. Terlau and Hirsch, 2015), or, on the other hand, by accounts of quiet sustainability (Smith and Jehlička, 2013) practices which can be socially and environmentally beneficial while driven by non-reflexive motivations.

Another critique of the conscious consumerism perspective is that it reduces ethical considerations to the moment of food acquisition (Pottinger, 2015). In reality, diverse food provisioning practices can have a moral dimension at all their different stages. My research unravelled gardeners' strong ethical positions in relation to producing food. Caring for the garden and the family led to a preference for non-chemical and natural ways of production. As discussed, gardeners developed several strategies to comply with this moral stance, which however was not fully transferred to their consumer behaviour.

Apart from FSP, ethical considerations underlie the related practices of gifting, sharing and exchanging, in which generosity seems to be a norm common among gardeners (Jehlička and Daněk, 2017; Pottinger, 2018). Home-grown food facilitates diverse types of relationships with 
varying degrees of reciprocity. ${ }^{196}$ Some are closer to the pre-calculated and utilitarian exchanges described by Acheson (2007), for instance, when members of social networks 'specialize' in different foods based on their skills or available infrastructures and these foods are later exchanged in a barter-like fashion. Other relationships appear in the form of unconditional sharing, in which home-grown food is treated as commons, typically by members of an (extended) household (Belk, 2010). Home-grown or homemade food can also be given as a present on special occasions. In this case, gifting is embedded in a shared appreciation of the exceptional value of home-grown food. In other cases, gifting is a means of distributing surplus to prevent food waste. The underlying moral imperative is then focused on the materiality of the gift itself, instead of on generosity towards the recipient.

Through this variety of practices, gardeners create a practical understanding of economic diversity, guided by the ethics of care (Holmes, 2018; Pottinger, 2018). Individual gardeners take on different roles in these economies: some of them distribute large amounts of food, whereas others rely on gifts as food sources. These inequalities can be conceptualized as generalized reciprocity (Belk, 2010) or generous exchange (Pottinger, 2018): giving and receiving are not seen as economic transactions but rather as moral and social practices built on shared values. These practices are both based on and constitutive of social relationships. Food sharing networks, apart from extending the food provisioning options of their members, can thus be seen as contributing to social resilience (Jehlička et al., 2019).

The appreciation of home-grown food is central to the moral understandings of FSP and food sharing. Through the practices of growing, sharing and gifting, food is decommodified (Gabriel, 2005; Pottinger, 2018). Its value is not constructed in monetary terms but in terms of the care and labour invested in production, the wealth of gardeners' skills and the material affordances of gardens and crops grown (McClintock, 2010). The particularities of the value of garden produce are best captured in seemingly contradictory statements: on the one hand, gardeners generally agree that FSP is not economically profitable, while on the other hand they argue that homegrown food is better than anything money can buy (as also documented by Pungas, 2019). The non-market nature of FSP makes home-grown food 'better' - not only in terms of taste but also ethically (Gabriel, 2005; Sosna et al., 2019; cf. Clark, 2004).

The aforementioned moral obligation not to waste food is a result of this appreciation: discarding food which was grown with such care and effort is perceived as wrong (Pottinger, 2018; Sosna et al., 2019). 'Garden-driven' preserving (i.e. making preserves to use up garden produce without integrating them into the household diet), while not effective in terms of FSP, can thus be seen as an ethical practice guided by an intrinsic understanding of right and wrong (Sayer, 2004). However, more experienced and skilful gardeners take pride in coordinating growing food with eating, preserving and distributing it so that everything is used, as was also described by Kortright and Wakefield (2011).

Frugality drives broader gardening practices, which often entail the recycling and up-cycling of different materials, such as plastic cups reused for growing seedlings, diverse materials

196 See also Davies et al. (2017) for a typology of urban food sharing. 
repurposed for the construction of sheds, or the relatively common sight of discarded bathtubs used for harvesting rainwater. Arguably, the ethical norms of thrift also influence gardeners' broader food provisioning practices, for instance, when kitchen leftovers are composted in the garden. However, wasting food is problematized more if this food is home-grown. As Sosna et el. (2019: 325) put it, 'food from the stores does not mobilize the same moral commitment'. This confirms that thriftiness, the stigmatization of food waste, and FSP share the same ethical underpinning based on an appreciation of the (care) work of gardeners as well as of gardens as natural resources (Pungas, 2019; Sosna et al., 2019).

This thesis advances the discussion on reflexivity and quiet sustainability by showing that many of the values implicit in respondents' food provisioning practices are compatible with the search for a better food system. Several mostly younger respondents described FSP as a more sustainable way of food provisioning, which suggests a gradual approximation of the meanings associated with FSP and AFNs (cf. de Hoop and Jehlička, 2017). For others, this connection was not apparent. All respondents, however, understood FSP as a fundamentally different way of obtaining food. It can thus be argued that while FSP is not conceptualized as an alternative, it is practiced as such that is, as an essentially different and inherently better way of food provisioning.

To summarize, the urban gardeners participating in my research were not 'ethical consumers' in the narrow sense as they did not factor social and environmental considerations into their shopping choices. Nonetheless, a strong moral dimension was found particularly in their nonmarket food provisioning practices. FSP facilitates informal sharing networks based on an ethics of generosity and care, together with an appreciation of both human and non-human labour.

\subsection{Turning the garden into a food source: How does FSP work?}

The ambition of this research was not only to describe the role of gardens in people's food provisioning practices but also to explain how this role comes about - in other words, how FSP 'works'. In order to do that, I examined the relationship between two practices which are commonly conflated: gardening and food self-provisioning. ${ }^{197}$ This conflation - made implicitly by my linking to literatures on both urban gardening and FSP - is justifiable: in the Czech context, nearly all people with access to a garden or other type of land use it to produce some food (Jehlička and Daněk, 2017). However, a closer look reveals the diverse ways in which gardening and FSP are understood, practiced and combined.

My results indicate that some gardeners are in fact not too interested in FSP. While they still grow food in their gardens, they see the harvest mostly as a 'by-product' of their hobby or a pleasant addition to spending time at the garden. The garden is thus not seen as a food source, and FSP is largely unrelated to other food provisioning practices. While this might seem counterintuitive,

197 As introduced in my literature review, food self-provisioning (FSP) is a term encountered in the literature on CEE. Similarly to terms such as subsistence or household food production, FSP emphasizes the productive function of food growing. In comparison, the word gardening points to a multiplicity of functions, one of which can be food production. Gardening, more than FSP, implies leisure, but the term is also used in research concerned specifically with food production (e.g. Taylor and Lovell, 2014). 
such an attitude reflects the multifunctionality of gardens. The fact that these spaces can hold different meanings for different people has been documented by existing research. For instance, Zavisca (2003) shows how Russian dachas ${ }^{198}$ can be used for subsistence production, for leisure or as symbols of social status. While these nearly contradictory functions concern different people, it is not uncommon for gardeners to draw on multiple discourses to give meaning to their practice.

More recently, Kortright and Wakefield (2011) identified five types of garden use in Toronto. Cooks' gardens serve mostly to access fresh organic food. Teaching gardens are used to teach children about food production and nature. Some respondents established environmental gardens to lower their ecological footprint, while others enjoy tending their hobby gardens as a leisure activity. Lastly, aesthetic gardens are designed as pleasant spaces with less focus on food production. This typology provides a relevant comparison to my results particularly because it shows that meanings and motivations can translate into outcomes in surprising ways. The case of hobby gardeners is the most remarkable. As the authors state:

Though their [hobby gardeners'] focus was more on the process of growing food and the plants themselves rather than the production of large quantities of food, these gardeners were among the largest producers of food, particularly of vegetables, encountered in the study. They also tended to share food with others, since unlike many other respondents they did not consciously limit what they grew to what the household could consume. (Kortright and Wakefield, 2011: 45)

This description is close to the ideal type 'love to grow, not to eat' identified in my research. Gardeners affiliated with this category also produce significant amounts of food without consciously trying to do so - their focus is mostly on enjoying gardening and improving their skills in this hobby. Similarly, Veen et al.'s (2014) research has shown that people with an intrinsic motivation for gardening can in fact eat more food from their gardens than gardeners interested in sustainable food provisioning. This again confirms that virtuous motivations should not be overrated, and contrarily, that mundane impulses such as 'having fun' can lead to the successful integration of provisioning practices into people's lives. Given the multifunctionality of gardens, researchers need to pay attention to the meanings that practitioners attribute to gardening, bearing in mind that several meanings will play a role for most gardeners. At the same time, both meanings and material outcomes need to be considered to truly understand the practice.

The different meanings attributed to gardening stem from the dual nature of this practice as both a hobby and a provisioning activity. Research on CEE in particular has often viewed 'leisure' and 'subsistence' as two opposing poles (Acheson, 2007; Alber and Kohler, 2008). ${ }^{199}$ More recent research suggests that these two aspects of FSP are not exclusive and that they in fact complement

198 Zavisca (2003: 786) defines a dacha as 'a plot of land used for gardening or leisure'.

199 For the clarity of argument, I do not expand on the diversity of meanings hidden behind the simplifying categories of subsistence and leisure. I am aware that the productive function of gardens can be motivated by a range of factors: economic need, accessing food unavailable on the market, obtaining food of good quality and known origin, and so forth. Similarly, calling gardening a 'hobby' does not fully convey the meanings of this practice for people's identities, for their sense of purposeful work or for interacting with nature. 
each other (Jehlička et al., 2013; Pungas, 2019). My research shows that although FSP is practiced as a hobby and not as a response to economic need, it has an intrinsic economic dimension. This facet of the practice is recognized in gardeners' pragmatic considerations concerning which crops to grow, how to distribute their harvest or how to extend the availability of home-grown food beyond the garden season.

An important point to mention is that in these negotiations, gardeners act as both producers and consumers or, as Kosnik (2018) puts it, prosumers. My research inquired into how these two roles are consolidated, revealing a web of multidirectional interactions between gardens and kitchens. To summarize some of the main trends, I have shown that respondents grow what they like to eat, but at the same time, they eat what has grown in their gardens. Apart from influencing respondents' diets in terms of both amounts and types of produce, gardens also determined which foods were (not) acquired from other sources. Vice versa, the availability of desired goods from other sources shaped the selection of garden crops. As mentioned, gardeners' experiences as producers informed their understandings of good food, thus influencing their food provisioning beyond the practice of FSP.

Another contribution of my research to existing knowledge on FSP is the finding that the integration of production and consumption is not self-evident, but that it requires specific competences and efforts, in addition to time and basic material equipment. Once gardeners understand their plots as food sources, they still need to actualize their potential to serve as such by coordinating their gardening and food provisioning practices. In other words, FSP does not only require gardening competences (such as knowing how to grow food) and food provisioning competences (such as knowing how to prepare meals), but it also needs additional coordination competences which bring gardening and food provisioning together. These skills include, for instance, the ability to process the harvest or to determine which crops need to be produced in what quantity to satisfy household food preferences. The integration of production and consumption is particularly challenging due to the asynchronicity of the two practices: while food consumption is linked to day-to-day routine, food production follows seasonal rhythms, as I elaborate in the next section.

My findings on the importance of coordinating the garden and the kitchen might create the impression that FSP is a carefully planned, pre-calculated practice. In reality, improvisation is an important part of the ability to integrate gardening and food provisioning, as both of these practices are inherently unpredictable and dynamic. Furthermore, while FSP is guided by pragmatic considerations, it also entails experiential and emotional aspects, the affective and the visceral (Carolan, 2015), which are just as important for the meanings and functioning of this practice, although more difficult to grasp.

A number of works have discussed the 'enchanting' (Bhatti et al., 2009) potential of gardens as 'tactile spaces' (Carolan, 2007) in greater depth than this thesis has done. FSP is, by definition, a sensuous, embodied experience. It is through the interaction between the body and the natural environment that affective engagement is established. As Hayden and Buck (2012:334) put it, it is in doing that the spaces of pre-cognitive becoming are opened up to elicit responses in bodies first and only (perhaps) in thought afterwards' (emphasis in original). While such affective responses 
are difficult to capture in words (Carolan, 2015), they shined through in my respondents' descriptions of their experiences with gardening and eating from their gardens.

The focus of this study on the economies related to FSP runs the risk of 'economizing' and rationalizing a practice which has a strong affective dimension. Nonetheless, this affective dimension is in fact an intrinsic part of the 'garden economy' because it constitutes the understanding of the value of home-grown food. The embodied and embedded interactions facilitated by the practice of FSP have a strong moral dimension. Carolan (2007) as well as Hayden and Buck (2012) argue that such 'hands-on' experiences contribute to an environmental ethics of care. In my research, the perceived quality of home-grown food was clearly connected to gardeners' bodily engagement with the materialities of the garden, and, as mentioned in the previous section, it was also framed in ethical terms (see also Pottinger, 2018). In this sense, everyday encounters with the garden indeed transform gardeners' connections with the world (Bhatti et al., 2009).

\subsection{Seasonality}

A novel contribution of this research to the literature on urban agriculture concerns the seasonality of gardeners' food provisioning practices. The fact that gardening is a seasonal practice is obvious, yet seldom discussed in the literature on this topic. ${ }^{200}$ In this study, I decided to follow gardeners' food provisioning practices throughout the seasons to investigate any possible changes. The results exceeded my expectations. Together with the responsibility to provide healthy food and the hierarchy of food sources based on understandings of what constitutes good food, seasonality was one of the key mechanisms shaping gardeners' food provisioning practices. Unlike the other two, however, seasonal patterns are not cultural but mainly a natural influence. ${ }^{201}$ The changing of the seasons shaped gardeners' food provisioning in two ways: firstly in terms of the availability of garden produce and secondly in the organization of food provisioning practices.

Obviously, gardens only produce food for a part of the year, the length of which depends on climate, gardening techniques and additional equipment used (greenhouses and the like). The materiality and temporality of gardens thus determine which crops are available at what time of the year. Apart from ripening and harvesting times, material properties also involve the shelf life of crops or the options available for preserving them, both of which are mobilized through gardeners' skills and the (preserving and storing) equipment and infrastructures at their disposition.

For most respondents, the contribution of the garden to their food supply peaked during the summer. However, six gardeners who participated in my study were able to use their gardens as a stable source of food throughout the year. This was facilitated by storing and preserving food as

200 This claim is based on a search in the Web of Science using the terms 'season" AND "urban agriculture", 'season* AND "food provisioning", 'season" AND "urban garden"' and 'season* AND food AND garden'. The relevant articles identified in these searches usually referred to data collected during an unspecified 'growing season'. Another group of studies revolved around diverse farming practices applied in rainy and dry seasons.

201 Although some seasonal patterns are also socially constructed, such as foods eaten for specific festivities. 
well as by adjusting their diets both in terms of the quantity of fruits and vegetables consumed and in terms of the types of foods consumed in different seasons. Gardens thus generated seasonal patterns in respondents' diets.

In addition, the seasonality of FSP also shaped the use of other sources, which were typically mobilized to complement or substitute the garden outside the growing season. More often than not, changes in food sources and diets correlated: crops such as tomatoes, zucchinis, currants and berries were mostly consumed in season, when they were harvested from gardens. The switch to market-based sources in autumn and winter thus also entailed a change of diet, with the consumption of exotic fruits being typical for this part of the year. In sum, FSP creates seasonal patterns which extend beyond the use of the gardens.

The second influence of the temporality of FSP concerns the organization of food provisioning practices. The timing of FSP tasks such as harvesting and processing produce is dictated by the seasonality of the garden. The time demands of competing practices are an important and underexplored topic in the discussion on more sustainable food provisioning. Shopping in alternative venues, participating in a CSA or growing food in the garden compete for practitioners' time with the convenient options facilitated by conventional food sources (Szabo, 2011). More tasks are involved in processing the acquired foods - cooking from scratch or preserving (Tregear, 2011). These time demands are often gendered (McIntyre et al., 2009; Szabo, 2011). My addition to this literature is the finding that this work is - much like other reproductive tasks - inflexible in terms of time. This adds another challenge to the need to negotiate competing practices under time constraints.

The two dimensions of the seasonality of FSP can be conceptualized using Southerton's (2013) framework on the temporality of practices. Firstly, the seasonality of the garden itself can be viewed as a collective temporal rhythm. Collective temporal rhythms condition how practices are understood and performed. For instance, the opening hours of shopping venues or social norms associated with habitual mealtimes shape the performance of various food provisioning practices. Similarly, changing seasons can be conceptualized as a collective temporal rhythm which conditions the practice of FSP. What sets FSP apart from other practices is that this rhythm is not socially constructed but is produced by non-human nature.

Secondly, FSP can be considered a practice which configures the temporalities of daily life. Southerton argues that practices produce their own temporal demands, and some practices can only be performed under specific temporal conditions. Indeed, the actions required to perform FSP need to happen at a given time, and they need to be coordinated and synchronized. Crops must be planted within a particular time range. Once ripe, they typically have to be harvested within days. There is only a brief window of time for processing the most perishable ones. These demands shape the position of FSP among the other practices of gardening households. The seasonality of the garden thus orders the temporal rhythms of everyday life, as demonstrated in Wahlen's (2011) longitudinal study of a household involved in FSP.

The neglect of seasonality in the literature on AFNs and FSP points to an alarming disconnect between research and practice. Moreover, the atemporality of food provisioning research 
decreases the validity of its conclusions. In this study, some patterns only became apparent due to a multi-staged investigation which accounted for seasonal variations. Research limited to the growing season (such as the otherwise insightful studies of Duchemin et al., 2008; Gittleman et al., 2012; Kortright and Wakefield, 2011; or Vitiello and Nairn, 2009) implicitly assumes that once the garden stops producing there is not much to observe. My research proved the contrary: FSP shapes respondents' food provisioning at all times. It could be argued that the summer season provides insight into the somewhat 'ideal' functioning of FSP. Produce is abundant, the garden becomes a significant food source and the only possible trouble revolves around processing and distributing the harvest. However, only the observation of respondents' practices in the lessthan-ideal seasons reveals the actual importance of the garden and the extended influence of FSP on other food provisioning practices.

\subsection{Reflections on practice theory}

This section, which presents more theoretical reflection, elaborates on several conceptual tools offered by practice theory which advanced my analysis and on the contributions of my research to this theory. I have engaged with practice theory in an eclectic and pragmatic manner. The main conceptual borrowings used in this thesis were (1) focusing on practices instead of practitioners (following Halkier and Jensen, 2011); (2) understanding practices as intertwined doings and sayings (following Schatzki, 1996); and (3) operationalizing practices as alignments of materials, meanings and competences (following Shove et al., 2012). My theory building benefited from distinguishing between different (food provisioning) practices inspired by Veen et al. (2014) and Halkier (2009), as well as from exploring how diverse practices interact (Shove et al., 2012; Warde, 2005). In what follows I reflect on these conceptual steps, as well as several new topics which arose from my engagement with practice theory: the importance of routines and routinization (Wahlen, 2011) and the question of change and continuity (Shove et al., 2012).

Practices can be understood as patterns of behaviour which can be 'filled out' in different ways by different practitioners (Shove et al., 2012). While I studied the food provisioning practices of 27 households, my intention was not to describe the practitioners but to identify general patterns in the practices that they engage in, and thus to build a theory applicable beyond the case in question. The validity of the results is further strengthened by the combination of quantitative and qualitative data. Mindful of the attitude-behaviour gap and the risk of imprecision in selfreporting, I collected data through food logs and interviews. I was interested not only in hearing about respondents' food provisioning practices, but also in seeing how they materialize (Holmes, 2018). This resonates with Warde's (2005: 134) reminder that practices consist of both doings and sayings and 'analysis must be concerned with both practical activity and its representations'. The notions of 'doings' and 'sayings' as two layers of a practice were useful for integrating the two different types of data.

During data analysis, I applied elements of practice theory in two ways: firstly, to explore practices related to diverse sources of food (Chapters 5 and 6) and secondly to understand the functioning of FSP (Chapter 7). My exploration of respondents' broader food provisioning 
practices was inspired by the work of Veen et al. (2014). Following their conceptualization of 'shopping' and 'growing' as two different practices, I explored to what extent different food sources constitute separate practices. I conclude that FSP is indeed a specific practice which is not easily commeasurable with other food provisioning practices. Furthermore, my findings indicate that (at least some) alternative market sources also constitute practices of their own.

The different considerations which guide shopping in the supermarket, buying produce from a farmer and growing it in the garden can be explained by the relation of these practices to other social practices. In the case of FSP, the practice of obtaining food was connected to the practice of gardening and thus guided by its logic. The aforementioned study by Veen et al. (2014: 292) summarizes this mechanism:

[Gardeners] perform a practice that is meaningful in itself-gardening. The vegetables acquired are a direct result of this, especially as harvesting is an essential part of the gardening practice. People visit the allotments to do their gardening work, so bringing home vegetables involves no extra effort. [...] As long as working the garden is a routine, getting vegetables from it is as well. Moreover, by physically and emotionally engaging in the practice of growing food, gardeners perceive their food as 'good food' [...].

Indeed, interest in gardening as a hobby results in the privileged position of FSP in comparison to other food provisioning practices. Furthermore, the practice of gardening creates a distinct economic subjectivity (Drake, 2019): respondents turn from food consumers into food producers. This changes the understandings and the importance of convenience, responsibility and identity in relation to FSP.

A combination of multiple practices can also explain the position of some alternative market and non-market sources, which are often based on social relationships or connection to place. In this case, the practice of obtaining food is, for instance, linked to the practice of visiting relatives. This link again shapes the meaning of the practice in terms of convenience or food quality. For my research participants, the best food was obtained from non-market and less formalized food sources which were embedded either in gardeners' own experience with food production or in their identity and social relationships.

Existing research has established that in order to use their time well, people prefer provisioning practices which align well with other daily tasks (Jackson et al., 2006); in other words, people coordinate multiple practices (see also Mylan and Southerton, 2018). My findings on alternative market and non-market food provisioning highlight the role of social relationships, identity and emotional engagements in these synergies. A general hypothesis which can be drawn is that practitioners are more likely to engage in a food provisioning practice if it is linked to other social practices which they enjoy and value. On a theoretical level, I suggest that practice-centred research can benefit from seeing practices in interactions and synergies, which might shape and reinforce their meanings (see also Shove et al., 2012).

After exploring respondents' broader food provisioning practices, I inquired into the practice of FSP. Here, practice theory provides another way of grasping the multifunctionality of urban gardens. Food provisioning in gardens is closely linked to other practices, and the combination 
of these practices influences how gardens serve as food sources. I conceptualized FSP as the intersection of gardening and food provisioning practices. Considering that both gardening and food provisioning are relatively generic patterns which can be filled out in different ways (Shove et al., 2012), it is not surprising that approaches to FSP differ.

In order to investigate what shapes the practice of FSP beyond gardeners' motivations and meanings of this practice, I draw on Shove et al.'s (2012) conceptualization of practices as alignments of materialities, meanings and competences. The authors argue that these elements can interact within as well as across practices. This conceptual borrowing was particularly useful to grasp how elements of different gardening and food provisioning practices can facilitate or hinder FSP. Firstly, the elements of a practice mutually shape each other. In the practice of preserving, for instance, the materialities of crops, freezers, fruit dryers and so forth mobilize specific competences, or, put differently, these materials are integrated into the practice through gardeners' skills and know-how.

Secondly, even more complex interactions happen across different practices. For instance, available storage facilities shaped gardeners' growing as well as eating practices. Another example was that meanings attributed to home-grown food 'spilled over' to influence broader food provisioning practices. At the same time, other meanings, such as the much discussed notion of 'non-chemical' food, remained limited to a particular practice (gardening) and did not penetrate others (grocery shopping). On a theoretical level, thus, the question could be why some elements are more likely to 'circulate between many different practices' (Shove et al., 2012: 36) than others and how exactly this circulation happens.

This relates to the broader question of stability and change. Practice theory offers a middle ground between structuralist approaches and methodological individualism (Jones and Murphy, 2010). This allows me to acknowledge the context and history of FSP in CEE without assuming a clear development path. Understanding different ways of food provisioning as social practices means that they can persist and evolve. It is in this light that I interpret Smollet's (1989: 132) argument quoted in Section 1.3.5:

If we imagine that social life at a particular stage is composed of sets of traits or traditions, we will assume that these evaporate somehow at a later stage, and are replaced by others. But society is not made of traits and traditions. Society is a process, involving the action, interaction, and thought of conscious human beings - people, who actively transform the patterns of social behavior they inherit from the past, including kinship relationships. So that they will serve their needs in a new type of society. (emphasis in original)

To paraphrase this idea, seeing society as an aggregation of evolving social practices can explain why FSP and other traditional food provisioning practices persist despite major societal changes and despite possible changes to these practices' constitutive elements. The ways in which FSP is practiced have changed in recent decades as new materials, competences and meanings have emerged. At the same time, however, the constitutive elements have remained sufficiently stable: for instance, gardeners have maintained access to land, gardening skills and knowledge have not been lost, and the appreciation of home-grown food has remained an important value. 
More importantly, these constitutive elements are still brought together in a pattern which is recognizable to practitioners.

Wahlen (2011) argues that domestic practices are routinized and thus rather persistent. While these practices are constantly developing, reproducing and reconfiguring, practitioners are not always aware of these micro-changes as they perform such practices without much reflection. His longitudinal study (1970-1990) from Germany illustrates that routinized domestic practices including FSP persist despite major socio-economic changes.

Wahlen's (2011) understanding of routinized practices as subject to micro-changes but overall stable provides a complementary perspective to Shove et al.'s (2012) theorization of evolving practices. According to these authors, practices are always in the process of formation, whereas their elements are comparatively stable. As such, these elements can circulate between places and endure over time. In Wahlen's (2011) study, however, the elements of practices changed, for example, when the household acquired a washing machine. But this did not change laundering practice as a pattern of behaviour: clothes continued to be washed on one day every two or three weeks.

Looking at the case of FSP, I argue that the pattern of the practice is relatively stable and thus transferable, whereas its constitutive elements vary according to context. Practices can be performed in a number of different ways while still remaining recognizable as patterns of behaviours (Shove et al., 2012: 38). Even my small sample shows that there are different ways of practicing FSP. Despite this diversity, however, conclusions can be made about the pattern itself. For instance, the fact that FSP consists of practices related to the garden and the kitchen is a given. The integration of the two will thus likely always require some effort and competence from practitioners, although the specific challenges and ways of addressing them will depend on the contextual variation of the elements, for example, the climate, cooking traditions or storage facilities. In this sense, practices as patterns of behaviour are transferable to other contexts as long as they can be re-established through a connection of localized elements. To this extent my conclusions can be relevant beyond the case I studied.

\subsection{Reflections on the diverse economies framework}

The diverse economies framework was crucial for the way in which I approached my research topic. It provided the explanatory basis for two knowledge gaps identified in the literature review. On the one hand, market-based AFNs are criticized for being elitist and perpetuating the power inequality between producers and consumers (Tregear, 2011). On the other hand, nonmarket provisioning practices, which might overcome these issues, are under-represented in the literature on AFNs. Informal food practices from CEE are not included in the debate, and they are instead theorized as remnants of the past. Both these knowledge gaps can be interpreted as the results of capitalocentric thinking in social science (Gibson-Graham, 2008).

The diverse economies framework overcomes this bias. As already mentioned, it allows me to reconceptualize FSP as an economic practice while avoiding the negative connotations 
of the shortage economy. Furthermore, it opens up the opportunity to explore diverse food provisioning practices without assumptions about their guiding logics and interactions. These two conceptual moves are facilitated by two 'thinking techniques' proposed by Gibson-Graham (2008), namely weak theory and reading for difference.

Weak theory is a way of generating knowledge which refuses to be guided by 'strong theories' about the order of the world and its dominant forces (Gibson-Graham, 2014). Strong theories of transition and neoliberalization gave grounds to theorizations of informal economies as gradually disappearing from CEE (Acheson, 2007; Alber and Kohler, 2008). The weak theory approach refuses such predictions, focusing instead on describing the existing and its possibilities. From this position, FSP appears as a vibrant and multidimensional practice with a strong moral dimension and potential openings for environmental ethics and sustainable modes of provisioning. The technique of reading for difference takes this commitment even further, as it focuses on making visible the existing economic diversity, thus disrupting the supposed dominance of capitalism and making other economies credible (Gibson-Graham, 2008; Santos, 2004).

The commitment of the diverse economies framework to identify and produce spaces of economic difference makes this conceptual lens suitable for research on more sustainable food systems, particularly as scholars increasingly recognize the need to engage with the economic side of AFNs (see e.g. Rosol, 2020). Indeed, the body of scholarly literature bringing together diverse economies and food studies has increased since I first began this research project (e.g. Davies et al., 2017; Drake, 2019; Kosnik, 2018). However, CEE continues to be a blind spot on the map of diverse food economies. Economic diversity in post-socialist CEE remains theorized to a large extent in terms of coping strategies and overcoming difficulties (Cassidy, 2011; Chakars and Sweet, 2014; Pavlovskaya, 2004). My research complements this literature by using a case from CEE to reframe the existing economic diversity in terms of an ethic of care and the appreciation of the good life (see also Jehlička et al., 2019).

The risk of this approach is that trying to challenge dominant narratives can create biases similar to those of the dominant narratives themselves (Fickey and Hanrahan, 2014; Mauthner and Doucet, 2003). While embracing the performativity of research, diverse economies studies need to balance the goal of empowering difference with a critical perspective. Without a critical lens, this study might be liable to depicting FSP in CEE as a practice which is not at all economically motivated, free of internal struggles and invariably environmentally friendly. To overcome this risk, I focused my attention on understanding how respondents' diverse provisioning practices 'work' (White and Williams, 2016), instead of evaluating their results.

I have shown that FSP is, to some extent, guided by economic considerations in the broader sense of the word, but that gardeners' considerations of 'what pays off' in fact stretch far beyond utilitarian logic. Furthermore, I unpacked the understanding of FSP as a 'hobby' by showing its relevance for gardeners' identities and their sense of self-fulfilment. My findings illustrate the tensions inherent in the practice of gardening as a leisure activity as well as the time and labour demands of FSP, which are dictated by seasonal rhythms and linked to often gendered food provisioning responsibilities. Lastly, I elaborate on gardeners' ethical commitments towards the natural environment while also exposing some inconsistencies in their positions. That being 
said, I leave the evaluation of the impacts of FSP on nature to others (e.g. Vávra, Daněk, et al., 2018). ${ }^{202}$

While the diverse economies scholarship aims to expand the notion of the economy beyond the market, it also runs the risk of overly 'economizing' the practices in question. As I was often reminded, my respondents did not engage in FSP as an economic practice per se: while FSP contributed to satisfying the economic needs of their households (i.e. food), the purpose and meaning of this practice extended far beyond that. As Lee (2006) points out, economies cannot be separated from the multiple values, social relations and ethical considerations which emerge in everyday practices. My operationalization of diverse economies aimed to reflect this multiplicity. The analytical categories used in diverse economies scholarship - enterprise, labour, property, transactions and finance (Gibson-Graham et al., 2013) - inspired my search for potentially relevant factors shaping food provisioning practices. Furthermore, I took inspiration from the social metabolism framework in order to investigate how diverse economies are made material (Holmes, 2018). However, this approach did not sufficiently cover the qualitative aspects of food provisioning practices: how they are understood, which values they carry and how they are put into practice. I thus introduced several borrowings from practice theory to embed material flows of food in patterns of behaviours with their respective meanings and competences.

The combination of diverse economies and practice theory might be inspiring for future research. It allows scholars to grasp the rather abstract notion of 'economies' and understand how they, to use Lee's (2006) phrasing, 'take place' - in other words, how they are practiced. Furthermore, the notion of social practice as an alignment of multiple elements resolves the 'entanglement' of the economy in everyday life and multiple values (Lee, 2006). All these elements, including materiality, can be conceptualized as components of social practices. In turn, diverse economies can be seen as amalgamations of diverse social practices.

This conceptual step opens up several questions relevant for understanding diverse economies. For instance, if economies consist of practices, who are the practitioners involved in their performance? And if we see economies as (bundles of) practices - that is, patterns of behaviour - how do these patterns emerge and evolve? The contribution of this thesis to the existing works bringing together diverse economies and social practice theory (e.g. Holmes, 2018; Schmid, 2018; Smith, 2019) lies in the investigation of the relationship between practices and economies. If practices constitute economies, how exactly does this happen?

Specifically, my investigation of diverse food sources examined whether certain practices - such as 'shopping' - invariably result in a single type of economy, in this case, market capitalism. Alternative market venues in particular seem to be located in an uncertain grey zone. For instance, some practitioners can use farmers' markets to practice 'shopping' in the same fashion they would do in supermarkets. For others, 'going to the farmers' market' becomes its own practice with a distinctive set of meanings, competences and materialities. The implications

202 The role of non-human others in the facilitation of diverse economies related to FSP could be explored in future research, in line with the growing interest of diverse economies scholars in human-nature interactions (GibsonGraham et al., 2016). 
of these nuances for the (re)production of diverse economic relations merit further research. ${ }^{203}$ My results suggest that alternative market and non-market sources gain a more robust position within respondents' food provisioning if they become part of their own specific practices. For instance, and confirming the conclusion of Veen et al. (2014), gardens become more relevant as food sources if they are part of a distinctive practice, in this case, gardening. Similarly, if 'buying from the farmer' becomes an established practice, possibly strengthened by its social meanings, it no longer competes with the practice of 'shopping'.

As already mentioned, synergies with other practices embedded in practitioners' identities and social relationships play an important role. 'Non-economic' practices and values, such as enjoying a hobby or a social encounter, thus seem crucial for fostering non-capitalist economic relations. 'Surviving well', the central concern of 'taking back the economy', indeed means more than fulfilling economic needs (Gibson-Graham et al., 2013). Paying attention to the affective engagements, moral understandings and social relationships which underlie these more-thaneconomic relations can advance the understanding of how diverse economies are (re)produced. 

market-based AFNs are liable to reproduce the divide between producers and consumers and the inequalities this entails, practicing FSP brings people as close as possible to their food. It would be naïve to claim that FSP exists 'outside' the capitalist economy, as many of the materials required for this practice are subject to market relations, with access to cultivable land being the most prominent vulnerability. Despite that, FSP facilitates a diverse economy in which the practices of provisioning, sharing, giving and exchanging prevail over selling and buying. ${ }^{206}$

While the academic literature ascribes a number of benefits and functions to urban gardens, their contribution to food production is under-researched. This thesis thus set out to investigate the role of urban gardens in food provisioning and the mechanisms through which this role is established. Working with gardening households in Brno, Czechia, I have sought to introduce insights from CEE into broader debates, while challenging the dominant narrative of widespread FSP as a sign of an underdeveloped 'transition economy'.

The main research question 'How is food self-provisioning involved in the food provisioning practices of urban households?' can be answered on two levels. In respect to the extent and importance of the practice, I conclude that FSP is central to the food provisioning of gardening households. Apart from the amount of produce, FSP also creates dietary patterns which in turn shape the ways other food sources are used throughout the seasons. Furthermore, referring to the means and mechanisms which make FSP part of broader food provisioning practices, I highlight two factors, both related to the multifaceted nature of FSP. Firstly, the position of FSP among other food provisioning strategies is strengthened by the link of this food source to leisure, fulfilment, and, broadly speaking, gardeners' identities. Put simply, FSP is an important part of gardeners' food provisioning because they find it fun to do. Secondly, FSP is mobilized as a food provisioning practice through a number of specific competences pertaining not only to food growing and food preparation but also to the integration of the two.

Engaging with the debates on alterity, this research contends that FSP in Czechia (and by extension, CEE) is not an 'alternative' in the sense of a lesser second choice or a coping strategy, as indicated by previous scholarly accounts (e.g. Alber and Kohler, 2008). Nor is it an 'alternative' in the sense of a conscious effort to oppose or circumvent the conventional food system. However, FSP is practiced as an alternative in the sense of a fundamentally different and inherently better way of food provisioning. Furthermore, considering the economic subjectivities and relations facilitated by FSP, this practice can be seen as an economic alternative, a way of 'performing the economy otherwise', as Leyshon and Lee (2003) put it (quoted in Wilson, 2013: 728). Although informal food economies in CEE are typically not guided by reflexive and political motivations (Aistara, 2015; Pungas, 2019; Visser et al., 2015), the construction of the meaning and value of home-grown food provides a practical alternative to seemingly omnipresent neoliberalism. In Holmes's (2008) words, it is an ordinary practice which facilitates an extraordinary economy.

Expanding on this idea, I conclude that when thinking about sustainable food provisioning, scholars and practitioners need to look beyond market venues and beyond people's roles as

206 Other practices which were not explored in this study but are related to the practice of FSP include caring and guarding (Pottinger, 2018); commoning (Morrow, 2019); and creating, repairing and upcycling (Smith, 2019). 
consumers. I have shown that there is a plethora of under-researched informal food practices whose potential for sustainable provisioning, diverse economic arrangements and mutually beneficial human-nature relations need further investigation. Furthermore, my findings show that diverse ways of food provisioning foster distinctive economic roles. In these roles, people relate to, and make choices about, food in significantly different ways. Theorizations on reflexivity, convenience, food quality and other presumed drivers of social action need to take this diversity into account. 



\section{References}

Acheson J (2007) Household Exchange Networks in Post-Socialist Slovakia. Human Organization 66(4): 405-413. DOI: $10.17730 /$ humo.66.4.9853464486q3530v.

Aistara GA (2015) Good, Clean, Fair ... and Illegal: Paradoxes of Food Ethics in Post-Socialist Latvia. Journal of Baltic Studies 46(3): 283-298. DOI: 10.1080/01629778.2015.1073915.

Alber J and Kohler U (2008) Informal Food Production in the Enlarged European Union. Social Indicators Research 89(1): 113-127. DOI: $10.1007 /$ s11205-007-9224-1.

Belasco W (2008) Food: The Key Concepts. Oxford and New York: Berg.

Belk R (2010) Sharing. Journal of Consumer Research 36(5): 715-734. DOI: 10.1086/612649.

Bennholdt-Thomsen V (2012) Subsistence: Perspective for a Society based on Commons. In: Bollier D and Helfrich S (eds) The Wealth of the Commons: A World beyond Market and State. Amherst: Levellers Press, pp. 219-224.

Bhatti M and Church A (2001) Cultivating Natures: Homes and Gardens in Late Modernity. Sociology 35(2): 365-383. DOI: 10.1177/S0038038501000177.

Bhatti M, Church A, Claremont A and Stenner $P$ (2009) 'I love being in the garden': enchanting encounters in everyday life. Social \& Cultural Geography 10(1): 61-76. DOI: 10.1080/14649360802553202.

Blom B and Morén S (2011) Analysis of Generative Mechanisms. Journal of Critical Realism 10(1): 60-79. DOI: $10.1558 /$ jcr.v10i1.60.

Bourdieu P (1998) Practical Reason: On the Theory of Action. Stanford: Stanford University Press.

Bruinsma J (2003) World Agriculture: Towards 2015/2030 An FAO Perspective. London: Earthscan.

Burger Chakraborty L, Sahakian M, Rani U, Shenoy M and Erkman S (2016) Urban Food Consumption in Metro Manila: Interdisciplinary Approaches Towards Apprehending Practices, Patterns, and Impacts. Journal of Industrial Ecology 20(3): 559-570. DOI: 10.1111/jiec.12402.

Cameron J and Wright S (2014) Researching diverse food initiatives: from backyard and community gardens to international markets. Local Environment 19(1): 1-9.
Carolan M (2007) Introducing the concept of tactile space: creating lasting social and environmental commitments. Geoforum 38(6): 1264-1275.

Carolan M (2015) Affective sustainable landscapes and care ecologies: getting a real feel for alternative food communities. Sustainability Science 10(2): 317-329. DOI: 10.1007/s11625-014-0280-6.

Carolan M (2016) The Sociology of Food and Agriculture. Second Edition. Abingdon and New York: Routledge.

Cassidy K (2011) Performing the cross-border economies of post-socialism. International Journal of Sociology and Social Policy 31(11/12): 632-647.

Chakars M and Sweet EL (2014) Professional women and the economic practices of success and survival before and after regime change: diverse economies and restructuring in the Russian Republic of Buryatia. GeoJournal 79(5): 649-663.

Church A, Mitchell R, Ravenscroft N and Stapleton LM (2015) 'Growing your own': A multi-level modelling approach to understanding personal food growing trends and motivations in Europe. Ecological Economics 110: 71-80. DOI: 10.1016/j. ecolecon.2014.12.002.

Clark D (2004) The Raw and the Rotten: Punk Cuisine. Ethnology 43(1): 19. DOI: 10.2307/3773853.

Clarke N, Cloke P, Barnett C and Malpass A (2008) The spaces and ethics of organic food. Journal of Rural Studies 24(3): 219-230.

Collins R (2015) Keeping it in the family? Re-focusing household sustainability. Geoforum 60: 22-32. DOI: 10.1016/j.geoforum.2015.01.006.

Comaroff J and Comaroff JL (2012) Theory from the South: Or, how Euro-America is Evolving Toward Africa. Anthropological Forum 22(2): 113131. DOI: 10.1080/00664677.2012.694169.

Connors M, Bisogni CA, Sobal J and Devine CM (2001) Managing values in personal food systems. Appetite 36(3): 189-200. DOI: 10.1006/ appe. 2001.0400.

Czech Statistical Office (2011) Educational attainment of population based on Census - 2011. Available at: https://www.czso.cz/ documents/10180/20536250/17023214a04. pdf/e4feoc99-oc5a-49ee-8d54- 
cbda60892fie?version=1.1 (accessed 30 January 2020).

Czech Statistical Office (2016) Household Budget Survey 2015. Consumption in Kind and Total Consumption, Expenditures in Kind. Available at: https://www.czso.cz/ documents/10180/32579067/1600181614. pdf/6e4e7507-f8da-4ca5-b92f$62 b_{38231 c d f}$ ?version=1.1 (accessed 5 February 2020).

Daniels S and Glorieux I (2015) Convenience, food and family lives. A socio-typological study of household food expenditures in 21st-century Belgium. Appetite 94:54-61. DOI: 10.1016/j. appet.2015.04.074.

Dansero E and Puttilli M (2014) Multiple territorialities of alternative food networks: six cases from Piedmont, Italy. Local Environment 19(6): 626643. DOI: $10.1080 / 13549839.2013 .836163$.

Dash A (2014) Toward an epistemological foundation for social and solidarity economy. UNRISD Occasional Paper: Potential and Limits of Social and Solidarity Economy. Geneva: United Nations Research Institute for Social Development.

Davies AR, Edwards F, Marovelli B, Morrow O, Rut M and Weymes M (2017) Making visible: Interrogating the performance of food sharing across 100 urban areas. Geoforum 86: 136-149. DOI: 10.1016/j.geoforum.2017.09.007.

de Hoop E and Jehlička P (2017) Reluctant pioneers in the European periphery? Environmental activism, food consumption and "growing your own". Local Environment 22(7): 809-824. DOI: 10.1080/13549839.2017.1289160.

de Zeeuw H and Dubbeling M (2009) Citites, Food and Agriculture: Challenges and the Way Forward. Leusden: RUAF Foundation.

Delgado C (2017) Mapping urban agriculture in Portugal: Lessons from practice and their relevance for European post-crisis contexts. Moravian Geographical Reports 25(3): 139-153.

Djokić V, Ristić Trajković J, Furundžić D, Krstić V and Stojiljković D (2018) Urban garden as lived space: Informal gardening practices and dwelling culture in socialist and post-socialist Belgrade. Urban Forestry \& Urban Greening 30: 247-259. DOI: 10.1016/j.ufug.2017.05.014.

Dobernig K, Veen EJ and Oosterveer P (2016) Growing urban food as an emerging social practice. In: Spaargaren G, Weenink D, and Lamers M (eds) Practice Theory and Research: Exploring the Dynamics of Social Life. Abingdon and New York: Routledge, pp. 153-178.

Domazet M and Marinović Jerolimov D (eds) (2014) Sustainability Perspectives from the European SemiPeriphery. Zagreb: Institute for Social Research in Zagreb and Heinrich Böll Stiftung Hrvatska.

Donath S (2000) The Other Economy: A Suggestion for a Distinctively Feminist Economics. Feminist Economics 6(1): 115-123. DOI: 10.1080/135457000337723.

Drake L (2019) Surplus Labor and Subjectivity in Urban Agriculture: Embodied Work, Contested Work. Economic Geography 95(2): 179-200. DOI: 10.1080/00130095.2018.1492875.

Duchemin E, Wegmuller F and Legault AM (2008) Urban agriculture: multi-dimensional tools for social development in poor neighbourhoods. Field Actions Science Reports 1: 11.

Duffková J (2002) První a druhý domov: Vývoj české záliby v chataření a chalupaření z pohledu sociologie. Př́tomnost.

Dutko P, Ploeg MV and Farrigan T (2012) Characteristics and Influential Factors of Food Deserts. United States Department of Agriculture.

Duží B, Tóth A, Bihuňová M and Stojanov R (2014) Challenges of Urban Agriculture: Highlights on the Czech and Slovak Republic Specifics. In: Vávra J, Lapka M, and Cudlínová E (eds) Current Challenges of Central Europe: Society and Environment. Prague: Charles University, pp. 82-107.

Dwyer SC and Buckle JL (2009) The Space Between: On Being an Insider-Outsider in Qualitative Research. International Journal of Qualitative Methods 8(1): 54-63. DOI: $10.1177 / 160940690900800105$.

Eizenberg E (2012) Actually Existing Commons: Three Moments of Space of Community Gardens in New York City. Antipode 44(3): 764-782. DOI: 10.1111/j.1467-8330.2011.00892.x.

ETC Group (2009) Who will feed us? Questions for the Food and Climate Crises. Available at: https:// www.etcgroup.org/whowillfeedus (accessed 30 January 2020).

Exner A and Schützenberger I (2018) Creative Natures. Community gardening, social class and city development in Vienna. Geoforum 92: 181-195. DOI: 10.1016/j.geoforum.2018.04.011. 
Farges G (2015) Convergence on Sustainable Lifestyles? Mechanisms of Change and Resistance in a French Allotment: Convergence on sustainability in an allotment. Sociologia Ruralis 55(1): 1-21. DOI: $10.1111 /$ soru.12052.

Feagan R (2007) The place of food: mapping out the 'local' in local food systems. Progress in Human Geography 31(1): 23-42. DOI: $10.1177 / 0309132507073527$.

Fendrychová L (2015) „Jiná“ geografie alternativnich potravinových sití: farmářské trhy jako cestujicí koncept. PhD Thesis. Charles University, Prague.

Fendrychová L and Jehlička P (2018) Revealing the hidden geography of alternative food networks: The travelling concept of farmers' markets. Geoforum 95: 1-10. DOI: 10.1016/j. geoforum.2018.06.012.

Fickey A and Hanrahan KB (2014) Moving Beyond Neverland: Reflecting Upon the State of the Diverse Economies Research Program and the Study of Alternative Economic Spaces. ACME: An International E-Journal for Critical Geographies 13(2): 394-403.

Fraňková E, Haas W and Singh SJ (eds) (2018) SocioMetabolic Perspectives on the Sustainability of Local Food Systems: Insights for Science, Policy and Practice. Cham: Springer.

Frélichová V (2013) Potenciál komunitou podporovaného zemědělství $v$ ČR. Master Thesis. Masaryk University, Faculty of Social Studies, Brno. Available at: https://is.muni.cz/th/h8guz/ (accessed 29 January 2020).

Gabriel C (2005) Healthy Russian Food is Not-forProfit. Michigan Discussions in Anthropology 15: 183-222.

Gibas P, Matějovská L, Novák A, Rolfová E, Tvardková V, Valešová I and Veselý M (2013) Zahrádkové osady: Stíny minulosti, nebo záblesky budoucnosti? Prague: Charles University.

Gibson-Graham JK (2006) The End of Capitalism (as We Knew It): A Feminist Critique of Political Economy; with a New Introduction. Minneapolis and London: University of Minnesota Press.

Gibson-Graham JK (2008) Diverse economies: performative practices for 'other worlds'. Progress in Human Geography 32(5): 613-632. DOI: 10.1177/0309132508090821.

Gibson-Graham JK (2014) Rethinking the Economy with Thick Description and Weak Theory. Current Anthropology 55(S9): 147-153. DOI:
$10.1086 / 676646$.

Gibson-Graham JK, Cameron J and Healy S (2013) Take Back the Economy: An Ethical Guide for Transforming Our Communities. Minneapolis: University of Minnesota Press.

Gibson-Graham JK, Hill A and Law L (2016) Reembedding economies in ecologies: resilience building in more than human communities. Building Research \& Information 44(7): 703-716. DOI: 10.1080/09613218.2016.1213059.

Gittleman M, Jordan K and Brelsford E (2012) Using Citizen Science to Quantify Community Garden Crop Yields. Cities and the Environment 5(1): 1-14. DOI: $10.15365 /$ cate.5142012.

González de Molina M and Toledo VM (2014) The Social Metabolism. Environmental History. Cham: Springer. DOI: 10.1007/978-3-319-06358-4.

Goszczyński W, Śpiewak R, Bilewicz A and Wróblewski M (2019) Between Imitation and Embeddedness: Three Types of Polish Alternative Food Networks. Sustainability 11(24): 7059. DOI: $10.3390 /$ su11247059.

Gritzas G and Kavoulakos KI (2016) Diverse economies and alternative spaces: An overview of approaches and practices. European Urban and Regional Studies 23(4): 917-934. DOI: 10.1177/0969776415573778.

Halkier B (2009) A practice theoretical perspective on everyday dealings with environmental challenges of food consumption. Anthropology of Food (S5). Available at: https://doi.org/10.4000/ aof.6405.

Halkier B and Jensen I (2011) Methodological challenges in using practice theory in consumption research. Examples from a study on handling nutritional contestations of food consumption. Journal of Consumer Culture 11(1): 101-123. DOI: $10.1177 / 1469540510391365$.

Hayden J and Buck D (2012) Doing community supported agriculture: Tactile space, affect and effects of membership. Geoforum 43(2): 332-341. DOI: 10.1016/j.geoforum.2011.08.003.

Holloway L, Cox R, Kneafsey M, Dowler E, Venn L and Tuomainen H (2010) Are you alternative?'Alternative'food networks and consumers' definitions of alterity. In: Fuller D, Jonas AEG, and Lee R (eds) Interrogating Alterity: Alternative Economic and Political Spaces. Farnham: Ashgate, pp. 161-173. 
Holmes H (2018) New spaces, ordinary practices: Circulating and sharing within diverse economies of provisioning. Geoforum 88: 138147. DOI: 10.1016/j.geoforum.2017.11.022.

Hošková K (2011) Analýza sporu o zrušení zahrádkářských kolonii v centru Brna. Master Thesis. Masaryk University, Faculty of Social Studies, Brno. Available at: https://is.muni.cz/th/tiafh/ (accessed 30 January 2020).

Hrazdírová E (2010) Zahrádkář - producent čistých potravin či milovník chemie? Master Thesis. Masaryk University, Faculty of Social Studies, Brno. Available at: https://is.muni.cz/th/uxuje/ (accessed 30 January 2020).

Humphery K (2011) The simple and the good: ethical consumption as anti-consumerism. In: Lewis T and Potter E (eds) Ethical Consumption: A Critical Introduction. Abingdon: Routledge, pp. 40-53.

IFAD and UNEP (2013) Smallholders, Food Security, and the Environment. Rome: International Fund for Agricultural Development.

Jackson P, Perez del Aguila R, Clarke I, Hallsworth A, de Kervenoael R and Kirkup M (2006) Retail Restructuring and Consumer Choice 2. Understanding Consumer Choice at the Household Level. Environment and Planning A: Economy and Space 38(1): 47-67. DOI: 10.1068/ a37208.

Jechová K (2015) Komunitní zahrady. Public lecture. Společnost pro trvale udržitelný život. Available at: http://www.czp.cuni.cz/stuz/besedy/b_1502/ Jechova.pdf (accessed 20 February 2020).

Jehlička P and Daněk P (2017) Rendering the Actually Existing Sharing Economy Visible: HomeGrown Food and the Pleasure of Sharing. Sociologia Ruralis 57(3): 274-296. DOI: 10.1111/ soru.12160.

Jehlička P and Smith J (2011) An unsustainable state: Contrasting food practices and state policies in the Czech Republic. Geoforum 42(3): 362-372. DOI: 10.1016/j.geoforum.2011.01.005.

Jehlička P, Kostelecký T and Smith J (2013) Food Self-Provisioning in Czechia: Beyond Coping Strategy of the Poor: A Response to Alber and Kohler's 'Informal Food Production in the Enlarged European Union' (2008). Social Indicators Research 111(1): 219-234. DOI: 10.1007/ s11205-012-0001-4.

Jehlička P, Daněk P and Vávra J (2019) Rethinking resilience: home gardening, food sharing and everyday resistance. Canadian Journal of Development Studies / Revue canadienne d'études du développement 40(4): 511-527. DOI: 10.1080/02255189.2018.1498325.

Johanisová N (2012) Družstevnictví nepatři jen do historie. Prague: Glopolis. Available at: http:// glopolis.org/wp-content/uploads/soubory/ druzstevnictvi-nepatri-do-historie.pdf (accessed 31 January 2020).

Jones A and Murphy JT (2010) Practice and Economic Geography. Geography Compass 4(4): 303-319. DOI: $10.1111 / j .1749-8198.2009 .00315 . x$.

Kamiyama C, Hashimoto S, Kohsaka R and Saito O (2016) Non-market food provisioning services via homegardens and communal sharing in satoyama socio-ecological production landscapes on Japan's Noto peninsula. Ecosystem Services 17: 185-196. DOI: 10.1016/j. ecoser.2016.01.002.

Keyzlarová S (2012) Zahrádkaření a chataření environmentální, sociální a ekonomické aspekty na př́kladu města Brna. PhD Thesis. Masaryk University, Faculty of Science, Brno. Available at: https://is.muni.cz/th/xqadl/ (accessed 31 January 2020).

Kim JE (2017) Fostering behaviour change to encourage low-carbon food consumption through community gardens. International Journal of Urban Sciences 21(3): 364-384. DOI: 10.1080/12265934.2017.1314191.

Koopmans ME, Keech D, Sovová L and Reed M (2017) Urban agriculture and place-making: Narratives about place and space in Ghent, Brno and Bristol. Moravian Geographical Reports 25(3): 154-165. DOI: 10.1515/mgr-2017-0014.

Kornai J (1992) The Socialist System: The Political Economy ofCommunism. Oxford: Clarendon Press.

Kortright R and Wakefield S (2011) Edible backyards: a qualitative study of household food growing and its contributions to food security. Agriculture and Human Values 28(1): 39-53. DOI: 10.1007/s10460009-9254-1.

Kosnik E (2018) Production for consumption: Prosumer, citizen-consumer, and ethical consumption in a postgrowth context. Economic Anthropology 5(1): 123-134. DOI: 10.1002/sea2.12107.

Kuus M (2004) Europe's eastern expansion and the reinscription of otherness in East-Central Europe. Progress in Human Geography 28(4): 472489. DOI: 10.1191/0309132504ph4980a. 
Lee R (2006) The Ordinary Economy: Tangled up in Values and Geography. Transactions of the Institute of British Geographers 31(4): 413-432.

Malá S (2015) Komunitní zahrada jako cesta k samozásobitelství ve městě. Master Thesis. Masaryk University, Faculty of Social Studies. Available at: https://is.muni.cz/th/s2rei/ (accessed 30 January 2020).

Mauthner NS and Doucet A (2003) Reflexive Accounts and Accounts of Reflexivity in Qualitative Data Analysis. Sociology 37(3): 413-431. DOI: $10.1177 / 00380385030373002$.

Maye D and Kirwan J (2010) Alternative food networks. Sociopedia.isa.

McClintock N (2010) Why farm the city? Theorizing urban agriculture through a lens of metabolic rift. Cambridge Journal of Regions, Economy and Society 3(2): 191-207. DOI: 10.1093/cjres/rsq005.

McClintock N (2014) Radical, reformist, and garden-variety neoliberal: coming to terms with urban agriculture's contradictions. Local Environment 19(2): 147-171. DOI: 10.1080/13549839.2012.752797.

McIntyre L and Rondeau K (2011) Individual consumer food localism: A review anchored in Canadian farmwomen's reflections. Journal of Rural Studies 27(2): 116-124. DOI: 10.1016/j. jrurstud.2011.01.002.

McIntyre L, Thille P and Rondeau K (2009) Farmwomen's Discourses on Family Food Provisioning: Gender, Healthism, and Risk Avoidance. Food and Foodways 17(2): 80-103. DOI: 10.1080/07409710902925896.

McLain RJ, Hurley PT, Emery MR and Poe MR (2014) Gathering "wild" food in the city: rethinking the role of foraging in urban ecosystem planning and management. Local Environment 19(2): 220-240.

Mehić Z, Knierim A, Gerster-Bentaya M, Pintar $M$, Černič Istenič M and Glavan M (2015) The Contribution of Home Food Gardens to Alternative Food Systems - The Case of Slovenia. In: The XXVI European Society for Rural Sociology Congress, Aberdeen, Scotland, 18 August 2015, pp. 109-110.

Mellor M (2006) Ecofeminist political economy. International Journal of Green Economics 1(1/2): 139-150.

Micheletti M (2002) Individualized collective action. In: Nordic Political Science Association's Meeting,
Aalborg, Denmark, 14 August 2002.

Mies M and Bennholdt-Thomsen V (1999) The Subsistence Perspective: Beyond the Globalised Economy. London and New York: Zed Books and Spinifex Press.

Mincyte D (2012) How milk does the world good: vernacular sustainability and alternative food systems in post-socialist Europe. Agriculture and Human Values 29(1): 41-52. DOI: 10.1007/s10460011-9328-8.

Morrow O (2019) Community Self-Organizing and the Urban Food Commons in Berlin and New York. Sustainability 11(13): 3641. DOI: 10.3390/ su11133641.

Mougeot LJA (2000) Urban Agriculture: Definition, Presence, Potentials and Risks, and Policy Challenges. Cities Feeding People Series 31. Ottawa: International Development Research Centre.

Müller M (2018) In Search of the Global East: Thinking between North and South. Geopolitics: 1-22. DOI: $10.1080 / 14650045.2018 .1477757$.

Murton JE, Bavington D and Dokis CA (eds) (2016) Subsistence under Capitalism: Historical and Contemporary Perspectives. Montreal and Kingston: McGill-Queen's University Press.

Mylan J and Southerton D (2018) The Social Ordering of an Everyday Practice: The Case of Laundry. Sociology 52(6): 1134-1151. DOI: 10.1177/0038038517722932.

Niehof A and Wahlen S (2017) Moralities of sharing and caring: Gender and food in the moral household economy. Jaarboek voor Vrouwengeschiedenis 36: 147-163.

Norberg-Hodge H, Merrifield T and Gorelick S (2002) Bringing the Food Economy Home: Local Alternatives to Global Agribusiness. London: Zed Books.

Okvat HA and Zautra AJ (2011) Community Gardening: A Parsimonious Path to Individual, Community, and Environmental Resilience. American Journal of Community Psychology 47(3-4): 374-387. DOI: 10.1007/s10464-010-9404-z.

Pavlovskaya M (2004) Other Transitions: Multiple Economies of Moscow Households in the 1990s. Annals of the Association of American Geographers 94(2): 329-351. DOI: 10.1111/j.14678306.2004.09402011.x.

Pawson R (2008) Causality for beginners. In: ESRC/ NCRM Research Methods Festival, June 2008. Available at: http://eprints.ncrm.ac.uk/245/ (accessed 30 January 2020). 
Pérez Orozco A (2014) Subversión Feminista de La Economía. Aportes Para Un Debate Sobre El Conflicto Capital-Vida. Madrid: Traficantes de Sueños.

Plošková A (2015) Význam zahrady v životě starých žen. Master Thesis. Masaryk University, Faculty of Social Studies. Available at: https://is.muni.cz/ th/zkxga/ (accessed 30 January 2020).

Pole A and Gray M (2013) Farming alone? What's up with the " $C$ " in community supported agriculture. Agriculture and Human Values 30(1): 85-100. DOI: 10.1007/s10460-012-9391-9.

Pottinger L (2015) Cultivating alternatives: crafting, sharing and propagating seed-saving practice in the UK. PhD Thesis. University of Manchester, Faculty of Humanities, Manchester.

Pottinger L (2018) Growing, guarding and generous exchange in an analogue sharing economy. Geoforum 96: 108-118. DOI: 10.1016/j. geoforum.2018.07.007.

Pungas L (2019) Food self-provisioning as an answer to the metabolic rift: The case of 'Dacha Resilience' in Estonia. Journal of Rural Studies 68: 75-86. DOI: 10.1016/j.jrurstud.2019.02.010.

Rasper M (2014) Urban gardering: zahrady ve městě : 0 touze po návratu $k$ prírodě prorůstajicí asfaltem $i$ betonem. Prague: Dauphin.

Reckwitz A (2002) Toward a Theory of Social Practices: A Development in Culturalist Theorizing. European Journal of Social Theory 5(2): 243-263. DOI: $10.1177 / 13684310222225432$.

Reid L, Sutton P and Hunter C (2010) Theorizing the meso level: the household as a crucible of pro-environmental behaviour. Progress in Human Geography 34(3): 309-327. DOI: 10.1177/0309132509346994.

Renting H, Schermer M and Rossi A (2012) Building Food Democracy: Exploring Civic Food Networks and Newly Emerging Forms of Food Citizenship. International Journal of Sociology of Agriculture \& Food 19(3): 289-307.

Richtr J (2013) Produkce potravin ve městě - nové trendy v Praze. Pražské komunitní zahrady. In: PhD conference FACTU, Prague, 2013.

Římanová R (2014) Záhon mezi paneláky? V pytlích komunitních zahrad raší okurky i jahody. Idnes. $c z, 15$ March. Available at: https://www.idnes. cz/praha/zpravy/komunitni-zahrady-v-praze. A140311_2043947_praha-zpravy_bur (accessed 20 February 2020).
Rose R and Tikhomirov Y (1993) Who grows food in Russia and Eastern Europe? Post-Soviet Geography 34(2): 111-126.

Rosol M (2020) On the Significance of Alternative Economic Practices: Reconceptualizing Alterity in Alternative Food Networks. Economic Geography 96(1): 52-76. DOI: 10.1080/00130095.2019.1701430.

Santos B de S (2004) The World Social Forum: Toward a Counter-Hegemonic Globalisation (Part I). In: Sen J, Anand A, Escobar A, and Waterman P (eds) The World Social Forum: Challenging Empires. New Dehli: The Viveka Foundation, pp. 235-45.

Sayer A (2004) Restoring the Moral Dimension: Acknowledging Lay Normativity. Department of Sociology, Lancaster University. Available at: http://www.comp.lancs.ac.uk/sociology/papers/ sayer-restoring-moral-dimension.pdf (accessed 20 February 2020).

Schatzki TR (1996) Social Practices: A Wittgensteinian Approach to Human Activity and the Social. Cambridge: Cambridge University Press.

Schmid B (2018) Structured Diversity: A Practice Theory Approach to Post-Growth Organisations. Management Revue 29(3): 281-310. DOI: 10.5771/0935-9915-2018-3-281.

Schoneboom A (2013) Working through the allotment. Ephemera: Theory and Politics in Organization 13(I): 137-150.

Schupp JL, Som Castellano RL, Sharp JS and Bean M (2015) Exploring barriers to home gardening in Ohio households. Local Environment 21(6): 752767. DOI: $10.1080 / 13549839.2015 .1017807$.

Shaw D (2007) Consumer voters in imagined communities. International Journal of Sociology and Social Policy 27(3/4): 135-150.

Shimizu $\mathrm{H}$ and Desrochers $\mathrm{P}$ (2008) Yes We Have No Bananas: A Critique of the 'Food Miles' Perspective. SSRN Electronic Journal. DOI: 10.2139/ssrn.1315986.

Shove E, Pantzar M and Watson M (2012) The Dynamics of Social Practice: Everyday Life and How It Changes. London: Sage.

Simms A (2008) Nine Meals From Anarchy. London: New Economics Foundation.

Smith A and Stenning A (2006) Beyond household economies: articulations and spaces of economic practice in postsocialism. Progress in Human Geography 30(2): 190-213. DOI: 10.1191/0309132506ph6010a. 
Smith J (2003) From Házi to Hypermarket: Discourses on Time, Money and Food in Hungary. Anthropology of East Europe Review 21(1): 179-188.

Smith J and Jehlička P (2007) Stories around food, politics and change in Poland and the Czech Republic. Transactions of the Institute of British Geographers 32(3): 395-410.

Smith J and Jehlička P (2013) Quiet sustainability: Fertile lessons from Europe's productive gardeners. Journal of Rural Studies 32: 148-157. DOI: 10.1016/j.jrurstud.2013.05.002.

Smith TSJ (2019) 'Stand back and watch us': Postcapitalist practices in the maker movement. Environment and Planning A: Economy and Space. DOI: $10.1177 / 0308518 X 19882731$.

Smollett EW (1989) Kindred Relationships in Bulgaria - An Exploration. Ethnologia Europaea (XIX): 125-140.

Sonnino R and Marsden T (2006) Beyond the divide: rethinking relationships between alternative and conventional food networks in Europe. Journal of Economic Geography 6(2): 181-199.

Sosna D, Brunclíková L and Galeta P (2019) Rescuing things: Food waste in the rural environment in the Czech Republic. Journal of Cleaner Production 214: 319-330. DOI: 10.1016/j.jclepro.2018.12.214.

Southerton D (2013) Habits, routines and temporalities of consumption: From individual behaviours to the reproduction of everyday practices. Time \& Society 22(3): 335-355. DOI: 10.1177/0961463X12464228.

Sovová L (2015) Self-provisioning, Sustainability and Environmental Consciousness in Brno Allotment Gardens. Sociální studia / Social Studies 12(3): 11. DOI: 10.5817/SOC2015-3-11.

Sovová L and Krylová R (2019) The countryside in the city? Rural-urban dynamics in allotment gardens in Brno, Czech Republic. Moravian Geographical Reports 27(2): 108-121.

Spilková J (2016) Alternativní potravinové sítě: Česká cesta. Prague: Charles University, Karolinum Press.

Spilková J and Vágner J (2016) The loss of land devoted to allotment gardening: The context of the contrasting pressures of urban planning, public and private interests in Prague, Czechia. Land Use Policy 52: 232-239. DOI: 10.1016/j. landusepol.2015.12.031.

Štiková O, Sekavová H and Mrhálková I (2009) Vliv socio-ekonomických faktorů na spotřebu potravin. Prague: Institute of Agricultural Economics and
Information.

Szabo M (2011) The Challenges of "Re-engaging with Food“: Connecting Employment, Household Patterns and Gender Relations to Convenience Food Consumption in North America. Food, Culture \& Society 14(4): 547-566.

Taylor JR and Lovell ST (2014) Urban home food gardens in the Global North: research traditions and future directions. Agriculture and Human Values 31(2): 285-305. DOI: 10.1007/s10460-0139475-1.

Teislerová H (2006) Konec zahrádkářů v Čechách a na Moravě. Ta naše povaha česká. Czech TV. Available at: https://www.ceskatelevize. cz/porady/1100627928-ta-nase-povahaceska/406235100011020-konec-zahradkaru-vcechach-a-na-morave/ (accessed 20 February 2020).

Terlau W and Hirsch D (2015) Sustainable Consumption and the Attitude-Behaviour-Gap Phenomenon - Causes and Measurements towards a Sustainable Development. International Journal on Food System Dynamics 6(3): 159-174. DOI: 10.18461/ijfsd.v6i3.634.

Thelen T (2011) Shortage, fuzzy property and other dead ends in the anthropological analysis of (post)socialism. Critique of Anthropology 31(1): 43-61. DOI: 10.1177/0308275X10393436.

Tisenkopfs T (2017) Precious potato. Alterity from the farmer and consumer perspective. In: Alternative Food Supply Networks in Central and Eastern Europe: Towards new grounds for interpretation and collaboration, Riga, 13 October 2017.

Tisenkopfs T, Kovách I, Lošták M and Šūmane S (2011) Rebuilding and Failing Collectivity: Specific Challenges for Collective Farmers Marketing Initiatives in Post-Socialist Countries. International Journal of Sociology of Agriculture $\mathcal{E}$ Food 18(1).

Tornaghi C (2014) Critical geography of urban agriculture. Progress in Human Geography 38(4): 551-567. DOI: 10.1177/0309132513512542.

Tregear A (2011) Progressing knowledge in alternative and local food networks: Critical reflections and a research agenda. Journal of Rural Studies 27(4): 419-430. DOI: 10.1016/j.jrurstud.2011.06.003.

Trenouth L (2013) Tracing the Contours of Alternative Food Consumption in Post-Socialist Central and Eastern European Countries. Unpublished manuscript. 
Trenouth L and Tisenkopfs T (2015) The Evolution of Household Foodscapes over Two Decades of Transition in Latvia. Journal of Baltic Studies 46(3): 355-375. DOI: 10.1080/01629778.2015.1073927.

Trubek AB, Carabello M, Morgan C and Lahne J (2017) Empowered to cook: The crucial role of 'food agency' in making meals. Appetite 116: 297-305. DOI: 10.1016/j.appet.2017.05.017.

Tuvikene T (2016) Strategies for Comparative Urbanism: Post-socialism as a De-territorialized Concept. International Journal of Urban and Regional Research 4O(1): 132-146. DOI: 10.1111/1468-2427.12333.

UNFPA (2007) State of World Population 2007: Unleashing the Potential of Urban Growth. New York: United Nations Population Fund. Available at: http:// www.unfpa.org/sites/default/files/pubpdf/695_filename_sowp2007_eng.pdf (accessed 20 February 2020).

van den Berg LM and van Veenhuizen R (2005) Multiple functions of urban agriculture. Urban agriculture magazine.

van Veenhuizen R (ed.) (2006) Cities Farming for the Future - Urban Agriculture for Green and Productive Cities. Manila: RUAF Foundation, IDRC and IIRR Publishing.

Vávra J, Megyesi B, Duží B, Craig T, Klufová R, Lapka M and Cudlínová E (2018) Food Selfprovisioning in Europe: An Exploration of Sociodemographic Factors in Five Regions. Rural Sociology 83(2): 431-461. DOI: 10.1111/ruso.12180.

Vávra J, Daněk P and Jehlička P (2018) What is the contribution of food self-provisioning towards environmental sustainability? A case study of active gardeners. Journal of Cleaner Production 185: 1015-1023. DOI: 10.1016/j.jclepro.2018.02.261.

Veen EJ (2015) Community gardens in urban areas: A critical reflection on the extent to which they strengthen social cohesion and provide alternative food. PhD Thesis. Wageningen University, Wageningen.

Veen EJ (2019) Fostering Community Values through Meal Sharing with Strangers. Sustainability 11(7): 2121. DOI: $10.3390 /$ su11072121.

Veen EJ, Derkzen P and Wiskerke JSC (2012) Motivations, Reflexivity and Food Provisioning in Alternative Food Networks: Case Studies in Two Medium-sized Towns in the Netherlands. International Journal of Sociology of Agriculture $\&$ Food 19(3): 365-382.
Veen EJ, Derkzen P and Visser AJ (2014) Shopping Versus Growing: Food Acquisition Habits of Dutch Urban Gardeners. Food and Foodways 22(4): 268-299. DOI: 10.1080/07409710.2014.964604.

Veen EJ, Bock BB, van den Berg W, Visser AJ and Wiskerke JSC (2016) Community gardening and social cohesion: different designs, different motivations. Local Environment 21(10): 1271-1287. DOI: $10.1080 / 13549839.2015 .1101433$.

Visser O, Mamonova N, Spoor M and Nikulin A (2015) 'Quiet food sovereignty'as food sovereignty without a movement? Insights from postsocialist Russia. Globalizations 12(4): 513-528.

Vitiello D and Nairn M (2009) Community Gardening in Philadelphia: 2008 Harvest Report. Penn Planning and Urban Studies, University of Pennsylvania.

Vítková Z (2012) Založte komunitní zahradu a pěstujte zeleninu i sousedské vztahy. Ekolist, 11. Available at: http://ekolist.cz/cz/zelena-domacnost/ rady-a-navody/zalozte-komunitni-zahradua-pestujte-zeleninu-i-sousedske-vztahy\#disc (accessed 20 February 2020).

Wahlen $S$ (2011) The routinely forgotten routine character of domestic practices. International Journal of Consumer Studies 35(5): 507-513. DOI: 10.1111/j.1470-6431.2011.01022.x.

Warde A (2005) Consumption and Theories of Practice. Journal of Consumer Culture 5(2): 131-153. DOI: $10.1177 / 1469540505053090$.

Wegerif M (2014) Exploring Sustainable Urban Food Provisioning: The Case of Eggs in Dar es Salaam. Sustainability 6(6): 3747-3779. DOI: 10.3390/su6063747.

Wegren SK (2014) The Russian food embargo and food security: can household production fill the void? Eurasian Geography and Economics 55(5): 491-513. DOI: $10.1080 / 15387216.2014 .992449$.

White RJ and Williams CC (2016) Beyond capitalocentricism: are non-capitalist work practices 'alternatives'? Area 48(3): 325-331. DOI: 10.1111/area.12264.

Williams CC, Round J and Rodgers P (2013) The Role of Informal Economies in the Post-Soviet World: The End of Transition? London and New York: Routledge.

Wilson AD (2013) Beyond Alternative: Exploring the Potential for Autonomous Food Spaces. Antipode 45(3): 719-737. DOI: 10.1111/j.14678330.2012.01020.x. 
Zagata L (2014) Towards conscientious food consumption: exploring the values of Czech organic food consumers. International Journal of Consumer Studies 38(3): 243-250. DOI: 10.1111/ ijcs.12098.

Zavisca J (2003) Contesting Capitalism at the PostSoviet Dacha: The Meaning of Food Cultivation for Urban Russians. Slavic Review 62(4): 786-810. DOI: $10.2307 / 3185655$.

Zvončeková L (2019) Lokálne siete výmeny a spolupráce vo vybranom regióne na Slovensku. Master Thesis. Masaryk University, Faculty of Social Studies, Brno. Available at: https://is.muni.cz/th/xogr4/ (accessed 28 January 2020). 



\section{Summary}

This thesis provides insight into the role of urban gardens in people's food provisioning practices and the mechanisms through which this role is established. It does so through an in-depth study of the food provisioning practices of 27 gardening households in Brno, Czechia.

The topic is framed by the broader discussion on more sustainable ways of food production and consumption, alternative food networks (AFNs) and urban agriculture. While AFNs seek to create a more environmentally sustainable and socially equitable food system, they are often criticized for relying on market mechanisms and perpetuating the disconnect between producers and consumers. This may lead to an unequal distribution of power and issues of elitism and exclusivity (Tregear, 2011).

Food self-provisioning (FSP) can be seen as an alternative to the dominant food system in that it involves a short, localized supply chain. Furthermore, it overcomes some of the pitfalls of market-based AFNs, as it merges the producer and consumer roles, and it operates to a large extent outside market mechanisms. However, there is little knowledge on FSP in urban areas of the Global North. In this context, the literature mostly focuses on a specific type of FSP community gardening - and it offers limited information on the contribution of urban gardens to food production (Taylor and Lovell, 2014).

Furthermore, some geographical areas seem to be excluded from the debate. FSP is widespread in the post-socialist countries of Central and Eastern Europe (CEE): 50 per cent of the region's inhabitants grow some of their food, compared to 10 per cent in Western European countries (Alber and Kohler, 2008). It is therefore surprising that CEE is under-represented in the literatures on urban gardening and AFNs.

Instead, FSP in CEE attracts the attention of economists and anthropologists, who often see it as a coping strategy and remnant of 'pre-capitalist' times which will eventually be replaced by the market economy (Acheson, 2007; Alber and Kohler, 2008). This modernization discourse is often adopted even inside the countries in question. The desire to follow Western examples leads to the marginalization of traditional practices which are potentially relevant for sustainable food provisioning.

This dissertation addresses these issues by studying urban gardens in Czechia as spaces which can contribute to the current debates on AFNs and urban FSP in the Global North. The goal of the study is to explore how urban gardens function as sources of food and how they interact with other food sources. The main research question is, How is food self-provisioning involved in the food provisioning practices of urban households?

The theoretical approach is grounded in the diverse economies framework (Gibson-Graham, 2008), which broadens the notion of 'the economy' beyond capitalist markets and monetized transactions, and which calls for attention to alternative, non-market and informal economies. Using conceptual borrowings from practice theory, I operationalize diverse food economies as arrays of food provisioning practices. Different ways of dealing with food, such as growing, 
buying, cooking, eating and sharing food, are understood as patterns of behaviour which entail specific materialities, competences and meanings (Reckwitz, 2002; Shove et al., 2012). Special attention is devoted to the material aspect of these practices, that is, the food itself. I use the method of food logs to monitor the amount of food which enters and leaves respondent households. This quantitative account is inspired by the perspective of social metabolism (Burger Chakraborty et al., 2016; González de Molina and Toledo, 2014).

The fieldwork consisted of four rounds of data collection of one month in duration, spread over the course of one year. During each round, respondents used food logs to record the fruits, vegetables and potatoes which they produced in their gardens or obtained from other sources. The purpose of the multi-staged research design was to observe seasonal variations and to gradually build theory with the respondents' participation. Apart from an introductory semi-structured interview, I held shorter interviews during each round of data collection, in which I discussed the observed food provisioning patterns with respondents and asked follow-up questions. This allowed me to verify my interpretations and develop new theories.

The results are presented in four chapters of the monograph, which provide an in-depth account of the interactions between gardens, other food sources, respondents' eating habits and dietary preferences. The main topics include the seasonal patterns in respondents' food provisioning practices (Chapter 4), respondents' use of diverse food sources (Chapter 5), the considerations which guide their food provisioning practices (Chapter 6), and the ways their gardens are used as food sources (Chapter 7).

My comparison of gardens and other food sources suggests that different ways of obtaining food entail different food provisioning practices and are thus guided by their own logics. These can be explained as a result of multiple economic roles: while practicing FSP, gardeners act not only as consumers but also as producers. The producer identity creates distinctive understandings of factors such as convenience or cost-effectiveness. Gardening is therefore incommensurable with other food provisioning practices in which respondents act as consumers. Furthermore, non-market food provisioning practices are often embedded in broader social interactions, such as visiting relatives in the countryside. This strengthens the position of non-market food sources within respondents' food provisioning practices.

FSP plays a key role in gardeners' food provisioning practices. Gardens provide a significant amount of food, and they create seasonal patterns in respondents' food provisioning. In addition, respondents' experiences as producers shape their food provisioning practices beyond FSP. Home-grown food is seen as the best in terms of taste, freshness and transparent origin. This creates a hierarchy of food sources, in which FSP and other informal food provisioning practices are preferred over shopping for food in conventional market venues.

Respondents' understandings of good food have a moral dimension which includes environmental and social considerations. For most gardeners, however, FSP is not a practice driven by 'activist' motivations such as trying to lower their ecological footprint or to create an alternative to the conventional food system. The main moral concern guiding respondents' food provisioning practices is the responsibility to provide good, healthy food for their loved ones. 
This responsibility shapes respondents' practices in different ways. On the one hand, it leads to a preference for FSP and other non-market food provisioning practices, which are seen as sources of high quality food. On the other hand, if these preferred sources are not (seasonally) available, respondents resort to other sources to make sure household dietary needs are covered.

To understand the functioning of gardens as food sources, this research positions FSP at the intersection of two sets of practices, those related to the garden ('gardening') and those related to the kitchen ('food provisioning'). Using insights from both quantitative and qualitative data, I identified four ideal types of relations between these two sets of practices. Gardens as multifunctional spaces can hold different meanings for different users, and people can thus have a preference for gardening or food provisioning practices. Furthermore, gardening and food provisioning can be performed as more or less integrated: while some practitioners understand their garden as a food source, for others gardening is largely disconnected from food provisioning.

Apart from personal preferences and meanings attributed to these practices, three factors influence the integration of gardening and food provisioning. First, both gardening and food provisioning compete with other practices in gardeners' lives. Paid and unpaid work as well as engagement in different leisure practices limit the time available for gardening. Eating out, ordering take-away and using convenience foods limit the ability to eat from the garden. A second challenge lies in the diverging temporalities of gardening and food provisioning: while people need food all the time, the garden only yields produce during several months. Storing and preserving practices are crucial for extending the availability of garden produce beyond the growing season. However, they only contribute to FSP if they are integrated with both gardening and food provisioning - in other words, if a sufficient amount of suitable crops is produced, processed appropriately, and later integrated into the household diet. Lastly, I argue that using the garden as a food source requires specific coordination competences. In addition to knowing how to grow and prepare food, practitioners need to be able to coordinate production and consumption on a daily as well as a seasonal basis.

In sum, this research contributes to existing literature with findings on the productive function of urban gardens. It enriches AFN scholarship with insights into non-market food provisioning practices and points to the relevance of the diverse economies framework in the search for more sustainable food systems. My perspectives on alterity, reflexivity and ethical provisioning add to ongoing debates on these issues, highlighting the need to approach them in an openminded and context-sensitive fashion. I contribute to urban agriculture research by providing a detailed account of the functioning of FSP, emphasizing, among other things, the importance of seasonality and the coordination of food production and consumption in gardening households. By choosing Czechia as my study case, I expand the geographical range of existing research and challenge the stereotypical depictions of informal economies in CEE.

This thesis makes theoretical contributions to Belasco's (2008) triangle of consumer choice by suggesting that people's identity, convenience and responsibility considerations change based on the diverse economic roles they take on. My use of food logs is relevant for future studies inspired by the social metabolism framework, as my study provides an example of an empirical application of this concept, and it offers ideas for addressing some of this framework's 
methodological challenges, such as delineating system boundaries or categorizing different types of material flows.

Furthermore, the combination of the diverse economies framework and practice theory contributes to the theoretical development of both approaches. In respect to practice theory, my research particularly advances thinking about interactions between multiple practices and their constitutive elements, and it also touches upon questions of routinization, persistence and change, and the temporal orderings of practices. Concerning the diverse economies literature, my research provides ideas for the operationalization of diverse economies, and it highlights the importance of identity, affective engagements and social relationships for the (re)production of non-capitalist economic relations. By touching upon multiple biases in knowledge production, this thesis affirms the performativity of research asserted by diverse economies scholars, and it advocates for greater economic and geopolitical diversity in how we imagine the world. 


\section{Shrnutí}

Tato práce nabízí vhled do role městských zahrad pro získávání potravin a odkrývá mechanismy, které tuto roli ustavují. Činí tak prostřednictvím hloubkové studie získávání potravin ve 27 zahrádkářských domácnostech v Brně.

Téma je rámované diskusí o udržitelnějších způsobech produkce a spotřeby potravin, alternativních potravinových sítích (APS) a městském zemědělství. APS usilují o vytvoření environmentálně udržitelnějšího a sociálně spravedlivějšího potravinového systému. Tyto sítě jsou nicméně často kritizovány za to, že spoléhají na tržní mechanismy a podporují tak přetrvávající rozdělení mezi výrobci a spotřebiteli. To může vést $\mathrm{k}$ nerovné distribuci moci a problémy s elitismem a exkluzivitou (Tregear, 2011).

Samozásobitelství lze chápat jako alternativu k převládajícímu potravinovému systému v tom smyslu, že představuje krátký a místně ukotvený spotřebitelský řetězec. Zároveň překonává některé nedostatky tržních APS, protože sjednocuje role výrobce a spotřebitele, a funguje do značné míry mimo tržní mechanismy. Samozásobitelství v kontextu Globálního Severu je nicméně nedostatečně prozkoumané. Literatura se v tomto kontextu nejčastěji věnuje specifickému typu samozásobitelství - komunitním zahradám - a poskytuje jen omezené informace o přispění městských zahrad k produkci potravin (Taylor and Lovell, 2014).

Některé geografické oblasti navíc $v$ debatě téměř chybí. Samozásobitelství je rozššřřné v postsocialistických státech střední a východní Evropy (SVE): 50 procent obyvatel tohoto regionu pěstuje potraviny pro vlastní spotřebu, ve srovnání $\mathrm{s} 10$ procenty v západoevropských zemích (Alber and Kohler, 2008). Nízké zastoupení SVE v literatuře o městském zahrádkaření a APS je tak překvapující.

Namísto toho přitahuje středo- a východoevropské samozásobitelství pozornost ekonomů a antropologů, kteří ho často vnímají jako subsistenční strategii a pozůstatek „předkapitalistického“ období, jenž bude postupně nahrazený tržní ekonomikou (Acheson, 2007; Alber and Kohler, 2008). Tento modernizační diskurs přejímají často i autoři ze zemí SVE. Touha následovat Západní př́lklady vede $\mathrm{k}$ marginalizaci tradičních praktik, jež jsou potenciálně relevantní pro udržitelné získávání potravin.

Předkládaná dizertační práce reaguje na tyto problémy studiem českých městských zahrad coby míst, která mohou přispět do aktuálních debat o APS a městském samozásobitelství v zemích Globálního Severu. Cílem práce je prozkoumat, jak městské zahrady fungují coby zdroje potravin, a jak interagují s dalšími zdroji. Hlavní výzkumná otázka je: Jak se samozásobitelství podílí na získávání potravin v městských domácnostech?

Teoreticky je práce ukotvená v konceptu rozmanitých ekonomik („diverse economies“, GibsonGraham, 2008), jež rozšiřuje představu ekonomiky za hranice kapitalistických trhů a peněžních transakcí, a jež volá po větší pozornosti k alternativním, netržním a neformálním ekonomikám. Práce se dále konceptuálně inspiruje teorií sociální praxe. Rozmanité potravinové ekonomiky jsou tak operacionalizované jako množiny praktik používaných $\mathrm{k}$ získávání potravin. Různé zpưsoby zacházení s jídlem - pěstování, nakupování, vaření, jedení a sdílení potravin atp. - jsou chápané jako vzorce chování, jež zahrnují specifické materiality, kompetence a významy (Reckwitz, 2002; Shove et al., 2012). Zvláštní pozornost je věnovaná materiálnu, tedy jídlu samotnému. Metoda 
potravinových deníků sloužila ke sledování množství potravin, které vstupují do domácností respondentů, případně je opouštějí. Tento kvantitativní náhled je inspirovaný perspektivou sociálního metabolismu (Burger Chakraborty et al., 2016; González de Molina and Toledo, 2014).

Sběr dat proběhl ve čtyřech kolech trvajících jeden měsíc, která byla rozložená po dobu jednoho roku. V každém kole účastnící výzkumu zaznamenávali do potravinových deníků ovoce, zeleninu a brambory, které vypěstovali v zahradách nebo získali z jiných zdrojů. Cílem tohoto vícekolového výzkumného designu bylo pozorovat sezónní změny a postupně spolu s respondenty formulovat teorii. Kromě úvodního polostrukturovaného rozhovoru jsem vedla kratší rozhovory v každém kole sběru dat. Během nich jsem s respondenty diskutovala pozorované vzorce a ptala se jich na doplňující otázky. To mi umožnilo ověřit mé interpretace a rozvíjet nové teorie.

Výsledky výzkumu jsou představené ve čtyřech kapitolách monografie, které poskytují hloubkovou sondu do interakcí mezi zahradami, dalšími zdroji potravin, stravovacími zvyklostmi a jídelníčky účastníků. Hlavní témata zahrnují sezónní vzorce v získávání potravin (kapitola 4), různé zdroje potravin využívané respondenty (kapitola 5), faktory ovlivňující jejich potravinové praktiky (kapitola 6), a způsoby užívání zahrad jako zdrojů potravin (kapitola 7).

Srovnání zahrad a ostatních zdrojů potravin ukazuje, že různé způsoby získávání potravin představují specifické potravinové praktiky, jež se řídí odlišnými logikami. Ty lze vysvětlit jako důsledek různých ekonomických rolí. V rámci samozásobitelství zahrádkáři nejednají pouze jako spotřebitelé, ale také jako výrobci - pěstitelé. Tato identita pak vytváří specifické chápání faktorů jako je pohodlnost (konvenience) nebo výnosnost. Zahrádkaření je tak nesrovnatelné s dalšími způsoby získávání potravin, v nichž se respondenti chovají jako spotřebitelé. Netržní způsoby získávání potravin jsou navíc často zasazené v dalších sociálních interakcích, jako je navštěvování př́buzných na venkově. To posiluje roli netržních zdrojů v potravinových praktikách respondentů.

Samozásobitelství hraje $\mathrm{v}$ potravinových praktikách zahrádkářu klíčovou roli. Zahrady jsou zdrojem významného množství potravin a vytváří sezónní vzorce v potravinových praktikách respondentů. Pěstitelské zkušenosti respondentů navíc ovlivňují jejich potravinové praktiky nad rámec samozásobitelství. Domácí potraviny jsou vnímané jako nejlepší z hlediska chuti, čerstvosti a známého původu. Vzniká tak hierarchie zdrojů potravin, v níž je samozásobitelství a další neformální zdroje preferované oproti nakupování v konvenčních tržních zdrojích.

Představy respondentů o „dobrém jídle“ mají morální dimenzi, jež zahrnuje environmentální a sociální ohledy. Pro většinu zahrádkářò nicméně samozásobitelství není motivované „aktivistickými“ snahami o snížení vlastní ekologické stopy či vytvoření alternativy ke konvenčnímu potravinovému systému. Hlavním morálním impulsem, jenž řídil potravinové praktiky respondenti̊, byla zodpovědnost získat dobré a zdravé jídlo pro jejich blízké. Tato zodpovědnost ovlivňuje praktiky respondentů různými způsoby. $\mathrm{Na}$ jednu stranu vede $\mathrm{k}$ preferenci samozásobitelství a dalších netržních praktik, jež jsou chápané jako zdroje vysoce kvalitních potravin. Pokud ale tyto preferované zdroje nejsou (sezónně) dostupné, respondenti neváhají využít jiných zdrojů, aby zabezpečili potravinové potřeby svých domácností.

Ve snaze porozumět fungování zahrad coby zdrojů potravin tento výzkum konceptualizuje samozásobitelství jako průnik dvou typů praktik, souvisejících zaprvé se zahradou („zahrádkaření“) a zadruhé s kuchyní („zacházení s jídlem“, viz výše). Na základě kvalitativních i kvantitativních dat jsem identifikovala čtyři ideální typy vztahu mezi těmito dvěma druhy praktik. Zahrady coby multifunkční prostory mohou mít různé významy pro různé uživatele, a 
lidé tak mohou být více orientovaní na zahrádkaření nebo více na jídlo. Zahrádkaření a získávání jídla navíc mohou být vykonávané více či méně koordinovaně: zatímco někteří zahrádkáři chápou svou zahradu jako zdroj potravin, pro jiné spolu zahrádkaření a zacházení s jídlem nesouvisí.

Kromě osobních preferencí a významů přikládaných těmto praktikám ovlivňují míru integrace zahrad a kuchyní tři faktory. Zaprvé, zahrádkaření a zacházení s jídlem soutěží o čas s dalšími aktivitami v životech zahrádkářů. Placená i neplacená práce, stejně jako další volnočasové aktivity, omezují čas dostupný pro zahrádkaření. Stravování mimo domov, konzumace hotových jídel či polotovarů omezují možnost jíst z vlastní úrody. Druhá výzva spočivá v rozdílných temporalitách zahrad a kuchyní: zatímco lidé potřebují jíst pořád, zahrada poskytuje úrodu pouze po několik měsíců. Skladování a konzervace jsou kličové pro prodloužení dostupnosti úrody mimo pěstitelskou sezónu. Tyto praktiky ale přispívají k samozásobitelství jen tehdy, pokud jsou navázané na zahrádkaření i na stravování - jinými slovy, pokud zahrádkáři vypěstují dostatečné množství vhodných potravin, vhodně je zpracují a následně je zahrnou do svých jídelníčků. Zatřetí, využivání zahrady coby zdroje potravin vyžaduje specifické koordinační dovednosti. Kromě schopnosti vypěstovat a připravit jídlo musí zahrádkáři být schopní koordinovat pěstování a spotřebu jak každodenně, tak sezónně.

Shrnuto, tento výzkum přispívá do existující literatury poznatky o produktivní funkci městských zahrad. Obohacuje stávající vědění o APS o vhled do netržních způsobů získávání potravin a dokládá relevanci teorie rozmanitých ekonomik pro hledání udržitelnějších potravinových systémů. Moje poznatky o alteritě, relfexivitěa etickém získávání potravin přispívají do aktuálních debat o těchto tématech, a zdůrazňují potřebu k nim přistupovat s otevřenou myslí a citlivostí ke kontextu. Tato práce přispívá do výzkumu o městském zemědělství podrobným rozborem fungování samozásobitelství, jež mimo jiné zdůrazňuje důležitost sezónnosti a koordinace pěstování a spotřeby v domácnostech zahrádkářů. Volba Česka coby zkoumaného př́padu pak rozšiřuje geografický záběr existujícího výzkumu a zpochybňuje stereotypy o neformálních ekonomikách ve SVE.

$\mathrm{V}$ teoretické rovině tato práce přispívá $\mathrm{k}$ trojúhelníku spotřebitelské volby dle Belasca (2008) dodatkem, že faktory identity, konvenience a zodpovědnosti nabývají různých významů a důležitosti $\mathrm{v}$ závislosti na různých ekonomických rolích. Metoda potravinových deníků je relevantní pro další studie inspirované perspektivou sociálního metabolismu. Můj výzkum navrhuje možné empirické využití tohoto konceptu, a nabízí možná řešení některých jeho metodologických výzev, jako je stanovení hranic systému či kategorizace různých typů materiálních toků.

Kombinace konceptu rozmanitých ekonomik a teorie sociální praxe dále přispívá k teoretickému rozvoji obou př́stupů. $V$ souvislosti s teorií sociální praxe můj výzkum zejména přispívá k úvahám o interakcích různých praktik a jejich částí, a dotýká se také otázek rutinizace, setrvačnosti a změny, a časových rytmů praktik. Do literatury o rozmanitých ekonomikách tento výzkum přispívá možným způsobem operacionalizace rozmanitých ekonomik, a důrazem na roli identity, afektivních vazeb a sociálních vztahů pro (re)produkci nekapitalistických ekonomických vztahů. Tato práce se dotýká několika předsudků v produkci vědění, a potvrzuje tak performativitu výzkumu, na níž výzkumníci rozmanitých ekonomik poukazují. Spolu s nimi pak vyzývá k větší ekonomické a geopolitické diverzitě v našich představách o světě. 



\section{Samenvatting}

Dit proefschrift geeft inzicht in de rol van stadstuinen in stedelijke voedselvoorziening, en de mechanismen die daaraan ten grondslag liggen. Hiervoor heb ik 27 tuinierende huishoudens in Brno, Tsjechië onderzocht. Dit onderwerp past binnen een bredere discussie over duurzamere manieren van voedselproductie en -consumptie, Alternatieve Voedsel Netwerken ('Alternative Food Networks', AFNs), en stadslandbouw. Hoewel AFNs als doel hebben om een meer milieuvriendelijk en sociaal rechtvaardig voedselsysteem te creëren, worden ze bekritiseerd omdat ze afhankelijk zijn van marktmechanismen en zodoende een blijvende ontkoppeling tussen producent en consument in stand lijken te houden. Dit kan leiden tot een ongelijke machtsverdeling, elitarisme en exclusiviteit (Tregear, 2011).

Ik zie voedselzelfvoorziening ('Food self-provisioning', FSP) als een directe en lokale productieketen, en daarmee als mogelijk alternatief voor het huidige dominante voedselsysteem. Daarnaast biedt FSP een oplossing voor de problemen met marktgeoriënteerde AFNs: de rollen van producent en consument komen samen, en FSP vindt grotendeels buiten de markt plaats. Er bestaat nog weinig wetenschappelijke kennis over FSP in de stedelijke gebieden van West-Europa en Noord-Amerika. Literatuur dat zich op dit gebied richt focust tot op heden voornamelijk op een specifiek type FSP - de buurtmoestuin - en slechts in mindere mate op de bijdrage van stadstuinen aan voedselproductie (Taylor and Lovell, 2014).

Het is opmerkelijk dat sommige geografische gebieden nauwelijks in dit debat vóórkomen. FSP is wijdverbreid in het postsocialistische Centraal en Oost Europa (Central and EasternEurope, CEE), aangezien 50 procent van de bewoners in deze regio voedsel verbouwt. In WestEuropese landen is dit slechts 10 procent (Alber and Kohler, 2008). Toch zijn CEE-landen ondergerepresenteerd in de literatuur over stadslandbouw en AFNs.

FSP in CEE krijgt wel aandacht van economen en antropologen: zij zien het als een copingstrategie en een overblijfsel van pre-kapitalistische tijden. Ze verwachten dat FSP in deze landen uiteindelijk wordt vervangen door de markteconomie (Acheson, 2007; Alber and Kohler, 2008). Dit moderniseringsdiscours wordt vaak zelfs in de betrokken landen zelf gebruikt. Het navolgen van westerse voorbeelden leidt echter tot een marginalisering van traditionele praktijken die mogelijk relevant zijn voor duurzame vormen van voedselproductie.

De stadstuinen in Tsjechië die ik in dit proefschrift onderzoek kunnen bijdragen aan bovenstaande debatten over AFNs en stedelijke FSP in de westerse wereld. Mijn doel is om te begrijpen welke rol stadstuinen hebben in de voedselvoorziening en hoe ze interacteren met andere vormen van voedselvoorziening. De hoofdvraag luidt: Op welke manier vormt voedselzelfvoorziening onderdeel van de voedselvoorzieningspraktijken van stedelijke huishoudens?

Ik gebruik de theorie rondom 'diverse economies' (Gibson-Graham, 2008). Deze ziet 'de economie' als breder dan alleen het kapitalistische systeem en monetaire transacties. Ze richt zich juist op alternatieve, niet-marktgeoriënteerde, en informele economieën. Door gebruik te maken van concepten uit 'practice theory' operationaliseer ik diverse voedsel economieën als 
een verscheidenheid van voedselvoorzieningspraktijken. Ik zie activiteiten als het verbouwen, kopen, koken, eten en delen van voedsel als gedragspatronen die elk specifieke objecten, kennis en betekenissen met zich meebrengen (Reckwitz, 2002; Shove et al., 2012). Ik heb daarbij specifieke aandacht voor het materiële aspect: het voedsel zelf. Ik gebruik voedseldagboeken om te monitoren hoeveel voedsel het huishouden van de respondenten in- en uitgaat. Deze kwantitatieve methode is geïnspireerd op de theorie van 'social metabolism' (Burger Chakraborty et al., 2016; González de Molina and Toledo, 2014).

Verspreid over een jaar heb ik gedurende de vier seizoenen telkens één maand data verzameld. In iedere ronde gebruikten respondenten voedseldagboeken om vast te leggen hoeveel fruit, groente en aardappelen zij produceerden in hun tuinen en hoeveel ze uit andere bronnen kregen. Het doel van deze rondes van een maand was om mogelijke seizoens-variatie mee te kunnen nemen, en om samen met de respondenten een theorie te kunnen ontwikkelen. Ik hield inleidende semigestructureerde interviews met alle respondenten, en kortere interviews tijdens iedere ronde. Hierin besprak ik de voedselvoorzieningspatronen uit de dagboeken. Dit onderzoeksontwerp hielp me om mijn interpretaties te verifiëren en nieuwe theorieën te vormen.

In vier hoofdstukken van dit proefschrift presenteer ik de resultaten van mijn onderzoek. Samen geven deze hoofdstukken inzicht in de interacties tussen tuinen, andere voedselbronnen, eetgewoonten en dieetvoorkeuren van de respondenten. De belangrijkste onderwerpen zijn de seizoens-afhankelijke patronen in de voedselvoorziening van de respondenten (hoofdstuk 4), het gebruik van diverse voedselbronnen (hoofdstuk 5), de overwegingen die bepalen hoe de voedselvoorziening eruit ziet (hoofdstuk 6) en de manier waarop de respondenten hun tuinen als voedselbron gebruiken (hoofdstuk 7).

De vergelijking die ik maak tussen tuinen en andere voedselbronnen suggereert dat al deze manieren om voedsel te verkrijgen hun eigen praktijken kennen, met hun eigen logica. Dit kan worden verklaard door de verschillende economische rollen die respondenten bij die verschillende praktijken aannemen. Bij het uitoefenen van FSP treden tuinders niet alleen op als consument, maar ook als producent.Deze verandering van rol leid ook tot een verandering van begrip op het gebied van bijvoorbeeld gebruiksgemak of kosteneffectiviteit. Dit een belangrijke reden dat FSP slecht te vergelijken is met andere voedselvoorzieningspraktijken waarin de tuinders zich voornamelijk als consumenten gedragen. Bovendien zijn niet-marktgeoriënteerde voedselvoorzieningspraktijken zoals FSP vaak verbonden aan bredere sociale interacties, zoals het bezoeken van familie die op het platteland woont. Dit versterkt de positie van die praktijken in de voedselvoorziening van de respondenten.

FSP speelt een sleutelrol in de voedselvoorziening van tuinders. Tuinen produceren een aanzienlijke hoeveelheid voedsel, en creëren seizoens-patronen in de voedselvoorziening. Ervaringen als producent vormen daarnaast ook de andere voedselvoorzieningspraktijken. Zelfgeproduceerd voedsel wordt gezien als het smaakvolst, het meest vers, en met een duidelijke herkomst. Hierdoor ontstaat een rangorde van verschillende voedselbronnen, waarin FSP en andere niet-marktgeoriënteerde voedselvoorzieningspraktijken de voorkeur hebben boven voedsel uit meer conventionele en marktgeoriënteerde kanalen. 
Er zit een morele dimensie aan de manier waarop de respondenten naar voedsel kijken, waarin het milieu en sociale overwegingen een rol spelen. De meeste tuinders worden echter niet gedreven vanuit een 'activistische' motivatie om bijvoorbeeld hun ecologische voetafdruk te verminderen of een alternatief voor het huidige voedselsysteem te creëren. Respondenten willen vooral zorgen voor goed en gezond voedsel voor hun naasten. Deze verantwoordelijkheid vormt de respondenten en hun praktijken op verschillende manieren. Het leidt het tot een voorkeur voor FSP en andere niet-marktgeoriënteerde voedselvoorzieningsmogelijkheden, omdat men die van hoge kwaliteit acht. Wanneer deze niet beschikbaar zijn in het seizoen, maken de respondenten gebruik van andere voedselbronnen om in hun voedselvoorziening te voorzien.

Om te begrijpen hoe tuinen als voedselbron worden gebruikt, positioneer ik FSP op de intersectie tussen twee verschillende sets van praktijken, de één gerelateerd aan de tuin ('tuinieren') en de ander gerelateerd aan de keuken ('voedselbereiding'). Door gebruik te maken van zowel kwantitatieve als kwalitatieve data, heb ik vier ideaaltypen van relaties tussen deze twee sets praktijken kunnen onderscheiden. Tuinen zijn multifunctionele plekken:verschillende gebruikers geven er verschillende betekenissen aan, en waar sommige tuinders vooral geïnteresseerd zijn in tuinieren, zijn anderen juist vooral geïnteresseerd in voedselbereiding. Bovendien kunnen tuinieren en voedselbereiding op verschillende manieren worden geïntegreerd. Sommige tuinders zien hun tuin als een voedselbron, terwijl anderen tuinieren grotendeels los zien van de voedselvoorziening.

Naast de persoonlijke voorkeuren en betekenissen van respondenten zijn er drie factoren die de integratie tussen tuinieren en voedselbereiding beïnvloeden. Ten eerste, zowel tuinieren als voedselbereiding concurreren met andere dagelijkse praktijken. Betaald werk, het huishouden en hobbies beperken de tijd om te tuineren. Ook uit eten gaan, eten bestellen en het gebruik van gemaksvoedsel reduceert het bereiden van zelf-verbouwd voedsel. Een tweede factor die FSP beïnvloedt is het verschil in 'tijdelijkheid' tussen tuinieren en voedselbereiding: mensen hebben constant eten nodig, terwijl tuinen slechts enkele maanden per jaar voedsel geven. Het bewaren en conserveren van de oogst is daarom essentieel om tuinen ook buiten het groeiseizoen als voedselbron te gebruiken. Maar bewaren en conserveren kan alleen een vorm van voedselvoorziening zijn, als het geïntegreerd wordt in zowel tuinieren als voedselbereiding - met andere woorden, wanneer er voldoende geschikte gewassen worden geproduceerd, die op de juiste manier verwerkt worden, en deze vervolgens ook worden gebruikt in de maaltijd. Een derde factor is dat het gebruik van de tuin als voedselbron specifieke competenties op het gebied van coördinatie vereist. Naast kennis over hoe voedsel kan worden verbouwd en klaargemaakt, moeten tuinders ook in staat zijn om de productie en consumptie te coördineren, zowel met betrekking tot de seizoenen als met betrekking tot de dagelijkse maaltijd.

Mijn bevindingen over de productieve functies van stadstuinen dragen bij aan de bestaande literatuur. Ze verrijken de kennis over Alternative Food Networks met inzichten in nietmarktgeoriënteerde voedselvoorzieningspraktijken en laten zien dat het diverse economies raamwerk relevant is voor de zoektocht naar meer duurzame voedselsystemen. Mijn perspectief op 'alteriteit', reflexiviteit en ethiek is een toevoeging aan het huidige debat, en benadrukt dat het belangrijk is om die met een open mind en met aandacht voor de context te benaderen. 
Mijn gedetailleerde omschrijving van FSP levert een bijdrage aan het onderzoek rondom stadslandbouw, en maakt duidelijk dat onder andere seizoens-gebondenheid belangrijk is, evenals de coördinatie van productie en consumptie. Door te kiezen voor Tsjechië als casus vergroot ik de geografische schaal van bestaand onderzoek en stel ik stereotyperingen van informele economieën in CEE ter discussie.

Dit proefschrift voegt theoretische inzichten toe aan Belasco's (2008) 'triangle of consumer choice' door te suggereren dat afwegingen rondom identiteit, gebruiksgemak en verantwoordelijkheid veranderen naargelang iemands economische rol. Mijn gebruik van voedseldagboeken is relevant voor toekomstig onderzoek dat geïnspireerd is op het sociaal metabolisme raamwerk, omdat mijn studie een voorbeeld is van een empirische toepassing van dit concept. Het doet ook suggesties voor hoe om te gaan met bepaalde methodologische moeilijkheden van dit raamwerk, zoals het afbakenen van systeemgrenzen of het categoriseren van verschillende soorten materiaalstromen.

Tenslotte draagt de combinatie van het diverse economies raamwerk en practice theory bij aan het verder ontwikkelen van beide benaderingen. Met betrekking tot practice theory bevordert mijn onderzoek voornamelijk het denken over de interacties tussen verschillende praktijken en hun constitutieve elementen. Het richt zich op vragen rondom routine, continuiteit en verandering, en de tijdelijkheid van het ordenen van praktijken. Met betrekking tot het diverse economies raamwerk geeft mijn onderzoek inzicht in een mogelijke operationalisatie van diverse economies en het benadrukt het belang van identiteit, emotionele betrokkenheid en sociale relaties voor de (re)productie van niet-kapitalistische economische relaties. Door verschillende vormen van bias in kennisproductie aan te kaarten bevestigt dit proefschrift dat onderzoek performatief is, en ik pleit dan ook voor een grotere economische en geopolitieke diversiteit in hoe we ons de wereld voorstellen. 


\title{
Appendix 1 \\ Interview guide used for the first round of interviews
}

\author{
GARDEN
}

- Location (how far from home), ownership

- How long have you had the garden? What was your motivation to start gardening? What was your motivation to grow food?

- How often do you go to the garden? How much time do you spend there? Who uses the garden and in which way?

- Garden size, how much space is used for production. Conditions for growing (water, soil, sun, other factors)

- Do you have a greenhouse or other structures? Do you use (or would you like to use) some machines?

- Cultivation methods and sources of information (seeds, fertilizers, agrochemicals, compost)

- What do you usually grow? What will you grow this season? How do you make this decision? How do you plan what to grow?

- Is it important for you to grow some food?

HOUSEHOLD - EATING

- How many people live in your household?

- What are your eating habits? How often do you eat at home? How often do you eat together? Who usually cooks or prepares the food?

- Can you describe your diet? How do you decide what to prepare? What do you consider when planning your meals? Do you try to eat healthy/cheap/...? Do you eat a lot of fruits and vegetables? How often do you eat meat?

- Does the garden produce have an influence on your diet? Does your diet change seasonally?

- Do you store or preserve some of the garden produce? Why? How long do these stocks usually last?

\section{HOUSEHOLD - ACQUIRING FOOD}

- How is shopping for groceries organized? Who usually does the groceries? How often do you buy food?

- How do you decide where to do your groceries? (convenience, price, quality)

- Can you name all sources from which you get food? Do you also have other sources than the usual stores? (markets, buying directly from farmers)

- Do you have other ways of getting food than buying it? (foraging, gifts, exchange)

- Estimate the share of different food sources (including the garden) 


\section{SHARING AND GIFTING}

- Do you receive food from someone? How much? How often? How important is it? Is it something you count on? From whom do you receive food? What kind of relation do you have with them? How far from you do they live from you? How does sharing usually take place?

- Do you sell, or have you ever considered selling some of your produce?

- Do you give your garden produce to someone? To whom? Why? How much? How often? What kind of relation do you have with them? How far from you do they live from you? How does sharing usually take place? How do you decide with whom to share the produce? 


\section{Acknowledgements}

Describing a PhD project as a 'journey' is a cliché which implies a linear, straightforward trajectory with a beginning, a clear direction and a final destination. The real stories tend to be messier, complex mosaics of work and life, intertwined, iterative, with sidetracks, describing circles and spirals and not necessarily going anywhere in particular.

But if I was to pinpoint a particular starting point, it would be my internship in RUAF in 2013 which planted some ideas that later grew into this thesis. My first words of thanks thus go out to Henk Renting who welcomed me in RUAF and helped me open my horizons. Ever since, this journey evolved on two parallel tracks, one in the Netherlands and one in Czechia. I am grateful to everyone who supported me in these two worlds, and to all people who put up with my doubletrack life and made it possible.

First and foremost, I want to express my gratitude to the people who were involved directly in my PhD research - most importantly the 27 households of gardeners from Brno. Děkuju za pečlivost a snahu, kterou jste vložili do zapisování potravinových deníčků; za to, že jste vydrželi rok mnohočetného dotazování a otevřeli mi svoje zahrady a kuchyně. I když jsem se snažila vám váš čas a úsilí všemožně vynahradit, zůstávám vám stále mnoho dlužná. Díky také všem, kdo doporučili možné účastníky výzkumu a pomohli mi otevřít jejich dveře.

Every PhD candidate needs to thank their supervisors, but to me this does not feel as an obligation but as a privilege: I have been extremely lucky with my supervision team. I could not ask anything better and I can only wish such luck to other PhDs. I am grateful to Petr Jehlička for embarking on this project with me, for providing gentle structure and guidance during its initial stages and precise, insightful and supportive feedback later on. I had my doubts about long-distance supervision at the start of the project - to be honest I had very little idea what a $\mathrm{PhD}$ really entails - but it worked out wonderfully, thanks to your diligence and dedication, and our impromptu consults at conferences and on trains.

That being said, it is important to have a door to knock on for a quick question, a brainstorm or a reassuring conversation. For this I am thankful to Esther Veen who became my second supervisor after such knock on the door. Thank you for taking me on board and for always being available for a coffee or chat, sharing experiences, thinking along and boosting my motivation. To both Esther and Petr, thank you for reading my endless writings and commenting on them tirelessly. Your support made this project possible and you have been role-models for what kind of supervisor I would like to be. Finally, I am grateful to my promotor Han Wiskerke for making my double life between Brno and Wageningen legit by welcoming me to the Rural Sociology Group. Thank you for helping me navigate the administrative maze and finding gentle bends in what is possible.

Indeed, my work in both Brno and Wageningen was only feasible thanks to the good will of many people. On the Brno side, I want to thank Zbyněk Ulčák in his role of international mobilities coordinator for the encouraging recommendation that 'if you want to go there, you should just go and not make a big fuss out of it'. I am thankful to the administrators of the Faculty of Social 
Studies - Dagmar Hábová, Eva Dopplerová, Hana Hoblová and others - for facilitating this arrangement, offering flexible solutions and making me realize that the MU administration holds up more than well in international comparison. I also want to thank the secretaries and support staff of the Department of Environmental Studies and the Rural Sociology Group in this respect. I am grateful for the Erasmus, Freemover and other faculty funds that made my initial journeys possible, and I encourage other Czech students and scholars to make use of them.

The Department of Environmental Studies has felt like home, a true Alma Mater, for the last decade. While this is a collective achievement, several people deserve a special mention. I want to thank Nadia Johanisova, who was never my formal supervisor but has become an invaluable mentor, colleague and a friend. I appreciate that you supported my steps even if they led me far away. My thoughts also go out to Eva Fraňková who, as my MSc supervisor, encouraged the first seeds of this project, and who knew that I would pursue a PhD before I even thought of it myself. Both of you have inspired me with your scholarship, integrity and kindness. The opportunities to work with you have meant a lot - not only in gaining experience but also in lightening the precarity of a PhD livelihood.

I am grateful for the cooperative and collegial spirit within the 'ecological economics cell', which has, among other things, opened teaching opportunities which I deeply value. To my colleagues from the office 3.14 - thanks for the long conversations that made the little time I spent there always enjoyable, though not necessarily productive. My appreciation also goes to the $\mathrm{PhD}$ group at the Department of Environmental Studies for sharing passions, struggles and negotiations. On that note, I want to thank the Czech PhD Association for their work on improving the situation of aspiring researchers.

My stay at the Rural Sociology Group of Wageningen University brought my work to a whole new level. I am thankful to the colleagues here for accepting me in the group and for being an inspiration with your openness, your work ethics and your sharp thinking. I am particularly grateful for the nourishing and supportive spacetime created by the Foodscapes cluster. I value the conversations I was able to have with Anke de Vrieze, Oona Morrow, Chizu Sato, Jessica Duncan and other colleagues. I will cherish the memories of CSPS events, RSO outings and silly songs. A shout-out also to the organizers of the CSPS PhD writing retreat in 2019 and the emerging $\mathrm{PhD}$ community. To all my office mates, and with apologies to the cleaning personnel, thank you for tolerating my constant munching on rice crackers, it really helps me think.

Besides these nested networks, I was inspired by countless scholars during conferences, summer schools, field trips and courses. I cannot possibly name everyone who has been part of this intellectual mycelium, but I am deeply grateful to all of you. I also want to thank the people who were crucial in the final stages of preparing this publication. Nicholas Orsillo for the long days we spent searching the depths of the English language and unravelling what it was exactly that I wanted to say. Iliana Boshoven-Gkini for making a visual crystallisation of my ideas and turning all the writing into an actual book. And Inez, Esther and Coen for their joint efforts in translating bits and pieces for the Dutch audience. My sincere thanks to the examining committee for engaging with my work - I am looking forward to our conversation. Thank you for finding time for my defence, not once but twice. 
Living in two countries has both multiplied and divided friendships and personal ties. I would have probably never come back to Wageningen if it was not for the first people I met here Ramona, Evka and other Droevendaalers, and later my amazing housemates at H14. I am grateful to the communities around Boerengroep and OtherWise for the sense of belonging and purpose, and the courage to achieve great things together. Thank you for the open and care-full space, for your energy and critical thinking, and for all the potlucks! My deep appreciation also goes to the Creative Community Garden, a place which has certainly saved my sanity more than once. To the multiple generations of members and friends I met there - thank you for all the pizza parties, the shared projects and dirty hands, the space to be myself, and of course for all the kale. My thoughts also go out to María, Joost, Christina, Matthijs, Frank and other friends who make Wageningen feel like home, and to those creating instant little homes around the world. Coennie, we met in a special time indeed. Thank you for being the lighthouse when I am the sailor.

To my friends and family in Czechia, it is always more difficult for the ones who stay, and I am deeply grateful that you have understood my leaving and that you have been there for me every time I came back. To the Brno crew - Žaneta, Martina, Oleg, Lucina and others - I am happy that we can still be friends ten years later. Thank you for the birthdays, weddings and New Year's celebrations, and also for hosting me on your couches so many times. Tere, thanks for still being my person, bridging the gaps in geography and lifestyle. Mami a tati, díky za to, že jste mě nikdy do ničeho netlačili, ale vždycky ve všem podporovali. Taky se mi někdy stýská, ale o to víc si vážím času, kdy jsme spolu. 


\section{About the author}

Lucie Sovová was born on $24^{\text {th }}$ of December 1988 in Prague, Czechia, to a gardening family. She studied a bilingual Czech-Spanish gymnasium and wanted to become a translator, but changed her mind after an ecological awakening. She obtained her Bachelor degrees in Environmental Studies and Art Theory at Masaryk University in Brno. She worked in the international section of Mediafax press agency before continuing with her Master's in Environmental Studies. During her studies, she volunteered in environmental NGOs and joined the editorial board of Sedmá generace, a socioecological magazine whose name reminds us that we should think of the impact of our actions on the seven generations to come.

Lucie took the opportunities to study abroad and spent six months as an Erasmus student at the department of Environmental Sciences of the University of Granada, Spain. She first came to the Netherlands in 2013 to do an Erasmus internship at RUAF and nourish her interest in alternative food networks. During this stay, she ended up living in Wageningen by chance and lack of other options. This experience was so enchanting that she came back two years later, this time coorganizing the Farm Experience Internship as an intern at Boerengroep. In 2015, Lucie started her $\mathrm{PhD}$ at her 'home' Department of Environmental Studies in Brno. Before long, she brought this project to Wageningen too, becoming an external $\mathrm{PhD}$ candidate at the Rural Sociology Group.

Next to her PhD, Lucie has worked on three research projects on alternative economic practices in Czechia; assessment of urban food production areas; and food self-provisioning and sharing. Her academic interests broadly revolve around economic alternatives and food provisioning. She is a member of the Community Economies Research Network and she has also been involved in the degrowth movement.

Lucie discovered her passion for teaching as a course assistant and guest lecturer in ecological economics, and later got an opportunity to co-create and co-teach an ecological economics seminar for Bachelor Environmental studies. As a coordinator of the Research Mediation Program at OtherWise, she created the first edition of the Alternative Research Methods Training, an extracurricular course which offers hands-on experience with diverse research methodologies. Lucie also enjoys supervising students and she was one of the facilitators of the Field Research Practical, guiding a group of Bachelors of International Development through their first research experience in rural Ireland.

Lucie lives with her partner in Wageningen and often takes a long train ride to Czechia. Her dream is to be a part-time academic, part-time activist and part-time gardener between the two countries. e-mail:es_lucie@centrum.cz 


\section{Academic publications}

Sovová, L., Veen, E. J., 2020: Neither Poor nor Cool: Practising Food Self-Provisioning in Allotment Gardens in the Netherlands and Czechia. Sustainability, vol. 12, n. 12. DOI: $10.3390 /$ su12125134.

Johanisova, N., Sovová, L., Fraňková, E., 2020: Eco-social enterprises: ethical business in a postsocialist context. In: Gibson-Graham, J.K., Dombroski, K. (eds.): The Handbook of Diverse Economies. pp. 65-73. Edward Elgar Publishing, Cheltenham and Northampton.

Sovová, L., Krylová, R., 2019: The countryside in the city? Rural-urban dynamics in allotment gardens in Brno, Czech Republic. Moravian Geographical Reports, vol. 27, n. 2, pp. 108-121.

Dostalík, J., Sovová, L., Miovská, L., Ulčák, Z., Krylová, R., Kala, L., Pelikán, V., Fraňková, E., 2018: Metodika hodnocení městských produkčních a zahradních ploch. [Methodology of evaluation of urban productive and garden spaces]

Koopmans, M., Keech, D., Sovová, L., Reed, M., 2017: Urban agriculture and place-making: Narratives about place and space in Ghent, Brno and Bristol. Moravian Geographical Reports, vol. 25, n. 3, pp. 154-165.

Sovová, L., Dostalík, J., Kala, L., Ulčák, Z., Krylová, R., 2017: Zahrádkářské osady v Brně: př́ležitost pro zkoumání lidí a př́rody. [Allotments in Brno: an opportunity to research people and nature]. Geografické rozhledy, vol. 27, n. 2, pp. 28-31.

Sovová, L., 2015: Self-provisioning, sustainability and environmental consciousness in Brno allotment gardens. Social studies, vol. 12, n. 3, pp. 11-26. 


\section{Lucie Sovová}

\section{Wageningen School of Social Sciences (WASS) \\ Completed Training and Supervision Plan}

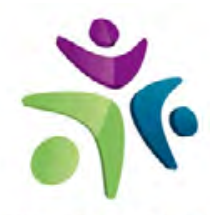

Wageningen School

of Social Sciences

\begin{tabular}{|c|c|c|c|}
\hline Name of the learning activity & Department/Institute & Year & ECTS $^{*}$ \\
\hline \multicolumn{4}{|l|}{ A) Project related competences } \\
\hline WASS introduction course & WASS & 2017 & 1 \\
\hline Writing project proposal & RSO, WUR & 2017 & 6 \\
\hline Sociology of Food and Place, RSO-31806 & WUR & 2018 & 6 \\
\hline $\begin{array}{l}\text { 'Leisure gardening or subsistence agriculture? The } \\
\text { social and the economic of growing your own' }\end{array}$ & $\begin{array}{l}\text { The value of life: measurements, } \\
\text { stakes, implications Conference, } \\
\text { Centre for Space Place and Society, } \\
\text { Wageningen }\end{array}$ & 2017 & 1 \\
\hline $\begin{array}{l}\text { 'Grow, exchange or buy? Eastern European food } \\
\text { alternatives through the lens of diverse economies' }\end{array}$ & $\begin{array}{l}\text { Alternative food supply networks } \\
\text { in Central and Eastern Europe } \\
\text { Conference, Baltic Studies Centre and } \\
\text { Latvian Academy of Culture, Riga }\end{array}$ & 2017 & 1 \\
\hline $\begin{array}{l}\text { 'Crowing, cooking and eating your own: a joyful } \\
\text { resilience of the everyday' }\end{array}$ & $\begin{array}{l}\text { SASA and CASA Joint conference, } \\
\text { Czech and Slovak Associations for } \\
\text { Social Anthropology, Bratislava }\end{array}$ & 2018 & 1 \\
\hline \multicolumn{4}{|l|}{ B) General research related competences } \\
\hline Research methodology: From topic to proposal & WASS & 2016 & 4 \\
\hline Introduction to Atlas.ti & MU & 2017 & 2 \\
\hline Popularization article & Sedmá generace & 2017 & 1 \\
\hline $\begin{array}{l}\text { Seminar to share preliminary results with } \\
\text { respondents }\end{array}$ & MU & 2017 & 1 \\
\hline Katherine Gibson masterclass & CSPS, WUR & 2017 & 0.1 \\
\hline Wageningen dialogue: cutting across the silos & Stichting Boerengroep & 2018 & 0.1 \\
\hline $\begin{array}{l}\text { Community economies research network } \\
\text { meeting }\end{array}$ & $\begin{array}{l}\text { Community economies research } \\
\text { network and Alice Salomon University }\end{array}$ & 2019 & 1 \\
\hline Popularization article & Gymnasion & 2019 & 1 \\
\hline
\end{tabular}




\begin{tabular}{lllc}
\hline Name of the learning activity & Department/Institute & Year & ECTS* \\
\hline C) Career related competences/personal development & & \\
Editing the proceedings from a seminar & Economy and Society Trust & 2017 & 2 \\
Teaching Seminar to Ecological Economics & MU & 2017 & 2 \\
Co-supervising a Master student & RSO, WUR & 2017 & 2 \\
Research Seminar & MU & 2018 & 6 \\
Supervising BSc and MSc thesis students & Educational staff development & 2018 & 0.5 \\
Adobe InDesign Essential Training & WUR & 2019 & 0.6 \\
Interdependence workshop & Community economies research & 2019 & 0.5 \\
& network & & 39.7 \\
\hline
\end{tabular}

*One credit according to ECTS is on average equivalent to 28 hours of study load 
The research described in this thesis was co-supervised and financially supported by the Department of Environmental Studies, Faculty of Social Studies, Masaryk University in Brno, Czechia.

Financial support from the Rural Sociology Group for research costs and the printing of this thesis is gratefully acknowledged.

Proofreading by Nicholas Orsillo, Dutch summary translated by Inez Dekker and Esther Veen. Cover design and layout by Iliana Boshoven-Gkini | AgileColor.com Printed by GVO drukkers \& vormgevers B. V. | gvo.nl 


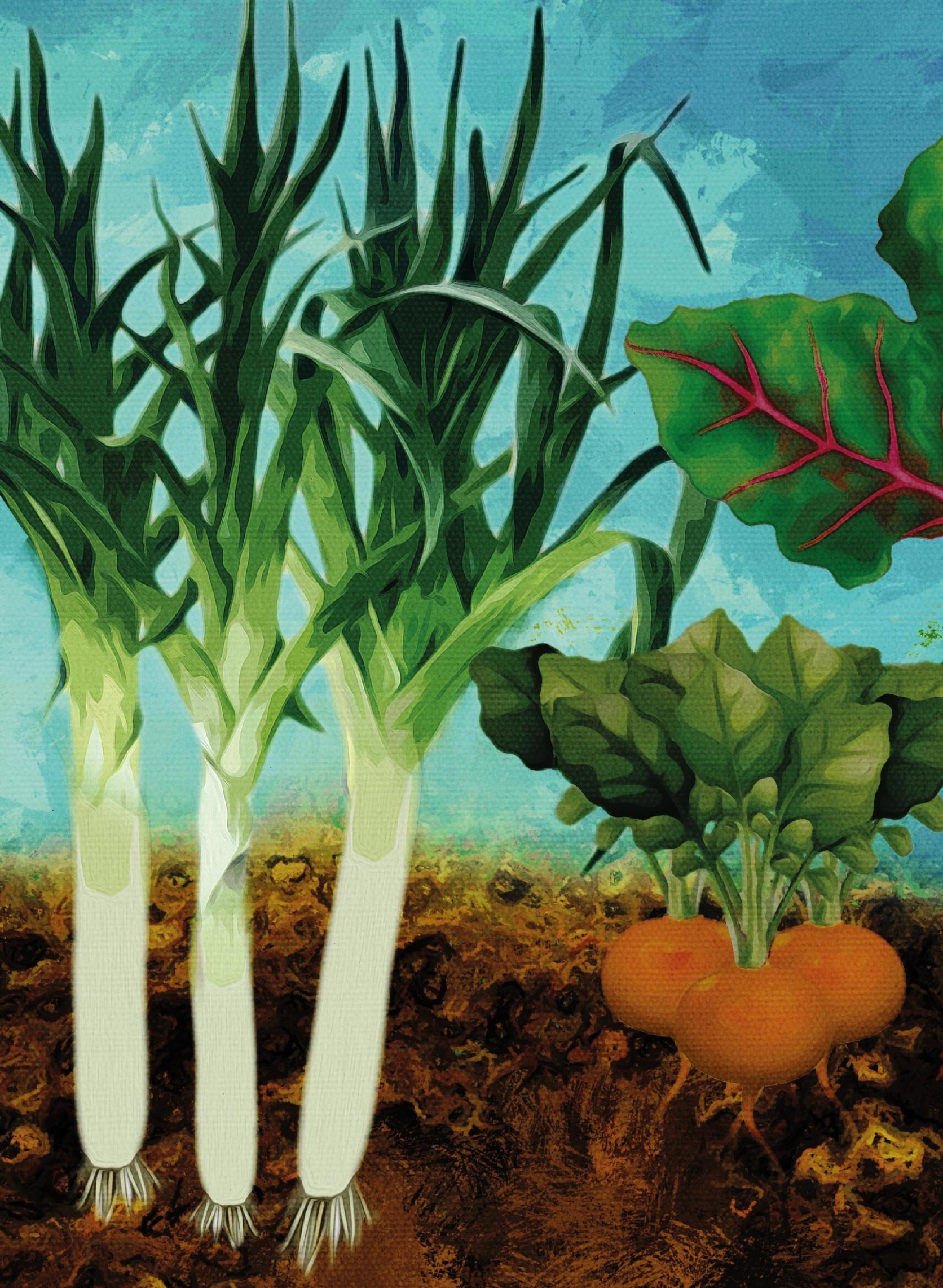

